\title{
BETWEEN CITY AND
}

\section{NATION OF SANCTUARY}

Examining the Political Geographies of Asylum and Hospitality in Wales

Submitted to Swansea University in fulfilment of the requirements for the Degree of Doctor of Philosophy

Year of Submission: 2020 


\section{Summary (Abstract)}

In response to what has been called the European 'refugee crisis' in 2015, the Welsh Government committed that Wales should become the world's first Nation of Sanctuary through building a culture of welcome and hospitality. This was an interesting moment given that Wales does not have direct responsibility for British borders. Considering the urban origins of the sanctuary movement, this was also the first-time a (devolved) state administration adopted this vocabulary to frame their relation to refugees and asylum seekers. What might it mean, in practice and in theory, for Wales to declare itself a 'Nation of Sanctuary'? What are the theoretical and political imaginaries of sanctuary, national identity and hospitality at work in this context? What are their historical precedents? And how do they relate to political responses to the crisis across the UK and Europe? This thesis examines what the idea of a Welsh Nation of Sanctuary means, what it does, and how the discourses and narratives of a 'Nation of Sanctuary' provide new ways of revisiting the metaphor of hospitality, and its role in sovereign framings of migration. While the critical literature on migration and the sanctuary movement explored the limits of hospitality as a framing response to the exclusionary politics of asylum, this thesis argues that this national sanctuary discourse is also used to challenge a sovereign nation-state on the expectations of what it entails to 'be a host' to refugees and asylum seekers. Drawing on semi-structured interviews, archival material and documents from the Welsh and British government, this thesis argues that this new national sanctuary framing creates a second othering. Here, a subnational or devolved territorial unit creates national self-imaginaries through a politics of differentiation against the sovereign nation-state, with regards to the exclusionary politics of asylum. 


\section{Declarations and Statements}

This work has not previously been accepted in substance for any degree and is not being concurrently submitted in candidature for any degree.

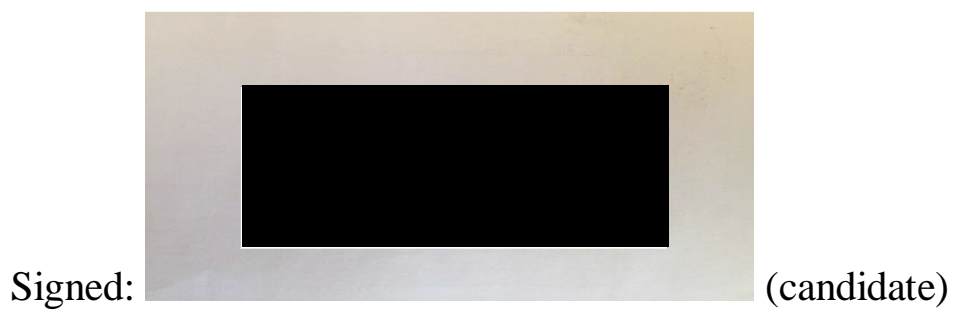

Date: $31 / 07 / 2020$

This thesis is the result of my own investigations, except where otherwise stated. Where correction services have been used, the extent and nature of the correction is clearly marked. Other sources are acknowledged by giving explicit references. A bibliography is appended.

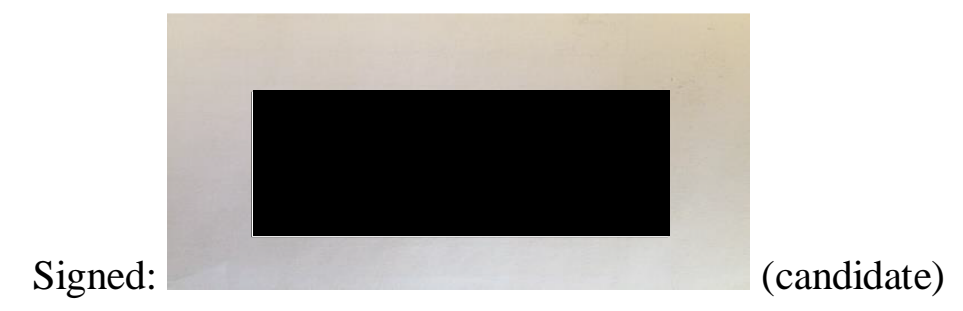

Date: $31 / 07 / 2020$

I hereby give consent for my thesis, if accepted, to be available for photocopying and for inter-library loan, and for the title and summary to be made available to outside organisations. 
Signed:

(candidate)

Date: $31 / 07 / 2020$ 


\section{TABLE OF CONTENTS}

\section{PART I: SANCTUARY CITIES, THE POLITICS OF HOSPITALITY AND NATIONAL IMAGINARIES OF ASYLUM.....................................................13}

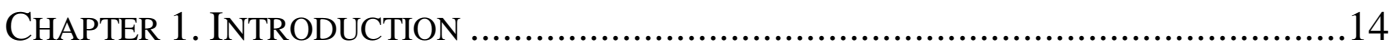

1.1. September 2015 - The European 'refugee crisis' and its discursive aftermath 15

1.2. A life lost and a live saved: Different sanctuary outcomes in Swansea, Wales

1.3. Outline of the main research question: Sanctuary and National Imaginaries 18

1.4. The structure of the research project, and outline of the chapters .... 21 CHAPTER 2. LITERATURE REVIEW: FROM URBAN SANCTUARY TOWARDS RE-SCALING CITIZENSHIP 28

2.1. Critical approaches to borders and migration 30

2.2. The City of Sanctuary movement in the UK. 33

2.3. Cities and re-scaling citizenship in an age of migration. 39

CHAPTER 3. THEORETICAL FRAMEWORK: HOSPITALITY, DOMOPOLITICS, AND NATIONALISM

3.1. The emergence of sanctuary: Humanitarian reason and government.... 49

3.2. The Derridean notion of hospitality: Between the conditional and the unconditional 53

3.3. The governmental deployment of hospitality: Domopolitics .57

3.4. Who is the 'host'? ... Debates on nations and nationalism .61

3.5. The Welsh "Nation of Sanctuary" as an empirical and theoretical puzzle. 65 CHAPTER 4. THE RESEARCH DESIGN: EXAMINING WALES AS A 'NATION OF SANCTUARY' 70

4.1. Defining a research focus, constructing a research design 71

4.2. Selecting a research methodology. 72

4.3. Data collection and qualitative research methods. .74

4.3.1. Semi-structured Interviews (Individual and joined interviews) .75

4.3.2. Archival research and document collection (Newspaper and policy documents) 
4.3.3 Participant observation and ethnographic fieldnotes..... .80

4.4. Exploring positionality in the analytical process. .83

\section{PART II: WALES AS A NATION OF SANCTUARY- THE EMERGENCE OF A CONCEPT BETWEEN THE SCALES .88}

CHAPTER 5. “A WARM WELSH WELCOME”? - THE EMERGENCE OF THE UK NATIONAL DISPERSAL PROGRAMME FOR ASYLUM SEEKERS, AND OF NATIONAL (SELF-) IMAGINARIES IN WELSH NEWSPAPERS.

5.1. The political background: New Labour, the Immigration and Asylum Act (1999) and the emergence of the new Welsh National Assembly .92

5.2. Newspaper narratives of the dispersal programme in Swansea and Wales 95

5.3. The British National Party in Swansea and Wales.... 102

5.4. The Cardiff Prison hunger strike and emerging (Welsh) national selfimaginaries 105

Chapter 6. The 'ReVOlution of Generosity'?: THE EMERGENCE AND DEVELOPMENT OF SWANSEA CITY OF SANCTUARY UNTIL THE LONG SUMMER OF MIGRATION.....

6.1. “A meeting was called..." - SBASSG and campaigning vs. practicalities 114

6.2. The second city: The emergence of the City of Sanctuary movement in Swansea. 116

6.3. "Two huge changes": Professionalization and neoliberalism in the City of Sanctuary. 123

6.3.1. The 'Welcome to Swansea' Scheme: Professionalising informal support groups 125

6.3.2. Responsibility and informal support: Moral justifications for neoliberal change.....

6.4. From the "revolution of generosity" towards a new moral nationalism .. 131 6.4.1 "The revolution of generosity": The summer of migration for Swansea City of Sanctuary..... 132

6.4.2. From moral urbanism to moral nationalism? The Sanctuary movement between the scales 135 
CHAPTER 7. Othering THE 'Host'- THE Welsh NATiOn OF SANCTUARY AND the BRITISH POLITICS OF REFUGEE RESETTLEMENT AFTER THE LONG SUMMER OF MIGRATION 140

7.1. The emergence of the Nation of Sanctuary phenomenon ........................ 142

7.2. The UK government's justification for refugee resettlement ....................147

7.2.1. To identify those most at risk...: The construction of 'deserving' and 'undeserving' subjects 148

7.2.2. Rigorous criteria to identify those most in need: Moralising domopolitical distinctions 150

7.2.3. "The whole country has been deeply moved": The construction of "Britishness" 152

7.3. Framings by the devolved government: "The Welsh approach”..............154

7.3.1. A "two-tier" system...in Wales? ....................................................158

7.3.2. The impact of the UK Immigration Act 2016 ..................................161

7.3.3. The response of the Welsh Government to the Committee report .....164

7.4. A Second Othering: The politics of differentiation ................................ 167

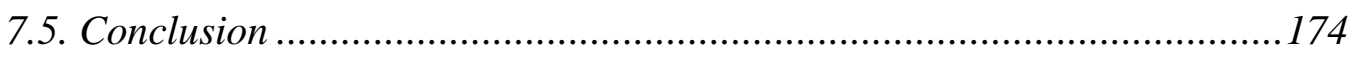

CHAPTER 8. AT THE LiMit OF THE HOSPITABLE NATION: Hosting SCHEMES AND ASYLUM SEEKER'S PERSPECTIVES ON DESTITUTION AND ‘HOME'-LESSNESS..........176

8.1. Asylum accommodation, destitution and the 'nation as home' ...............178

8.2. Hosting schemes and hospitable practice. 181

8.3. Statist versus private hospitality? Disrupting imaginaries of the hospitable nation. 188

CHAPTER 9. CONCLUSION: ASYLUM, NATIONALISM, AND INDEPENDENCE 194

9.1. Theoretical and political imaginaries of asylum in the 'Nation of Sanctuary' 196

9.2. Sanctuary imaginaries between the sovereign and the devolved nation-state 203

9.3. Hospitality, rightful presence and the question of national circumstances

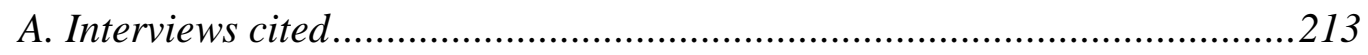

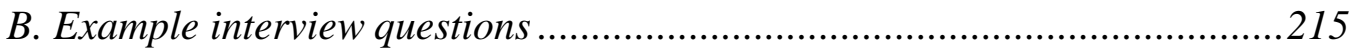


Interview: Alan Thomas, Co-founder of Swansea City of Sanctuary, former chair of trustees of National City of Sanctuary charity (2011-2016) 215 Interview: Daniella*, Swansea City of Sanctuary coordinator and Head of the Nation of Sanctuary Steering Group 216 Interview: Aled Edwards, Chair of DPIA, Wales Committee of the Equalities and Human Rights Commission 216 Interview: Clara* Welsh National Assembly Researcher, $9^{\text {th }}$ February 2018

C. Example interview transcripts

Interview transcript: Alan Thomas, Co-Founder of Swansea City of Sanctuary 219

Interview transcript: Aled Edwards, Former Chair Welsh Refugee Council, Chair DPIA 222

Interview transcript: Clara* Researcher for the Equality, Local Government and Communities committee at the Welsh Assembly .224

Interview transcript: Daniella* Development Worker Swansea City of Sanctuary, Head of the Nation of Sanctuary Steering Group .....................226

D. Examples of ethnographic fieldnotes....................................................229

1. Fieldnotes 'Wales as a Nation of Sanctuary' conference (27/04/2017) ...229

2. Fieldnotes Sanctuary in the Senedd Event, $24^{\text {th }}$ January 2018 ...............230

E. Example of research inquiry briefings.................................................2232

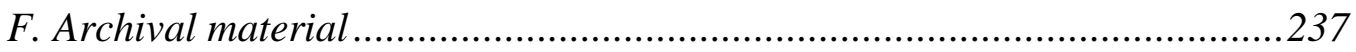

Document 1: Swansea Council document (2000) ..................................237

Document 2: South Wales Evening Post article (2000) ............................238

Document 3: South Wales Evening Post article (2001) ...........................239

Document 4: Western Mail article (2001) .............................................240

G. NVivo coding scheme (Preliminary) ..................................................2236

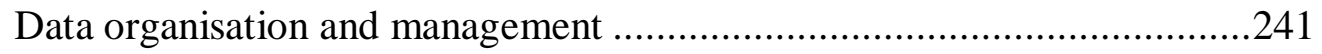

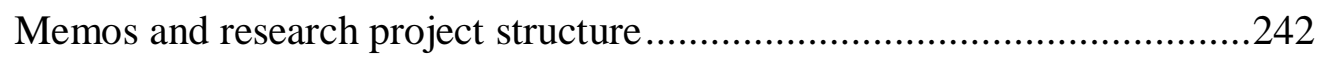

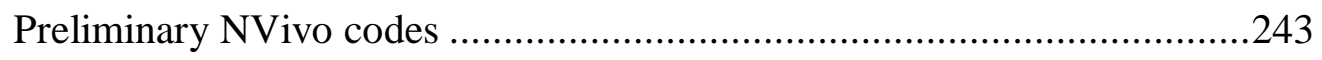

Emerging coding categories (example 1) .............................................244

Emerging coding categories (example 2) .............................................245

Coding with sensitivity to time and periodisation .................................246

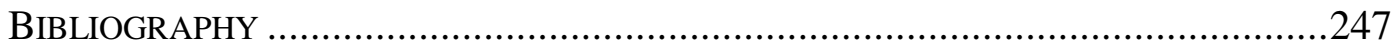


A. Books and academic journal articles..................................................24

B. Newspaper articles and online media material .......................................258

C. Parliamentary documents and administrative material (Government and Third Sector) 


\author{
Abbreviations \\ AM: Assembly Member \\ BBC: British Broadcasting Corporation \\ BNP: British National Party \\ CMS: Critical Migration Studies \\ COS: City of Sanctuary \\ DADT Policy: Don’t Ask, Don’t Tell Policy \\ DPIA: Displaced People in Action \\ DRC: Democratic Republic of Congo \\ ELCC: Equalities, Local Government and Communities Committee \\ EU: European Union \\ EYST: Ethnic Youth Support Team \\ MP: Member of Parliament \\ NASS: National Asylum Support Service \\ NHS: National Health Service \\ NOS: Nation of Sanctuary \\ SBASSG: Swansea Bay Asylum Seeker Support Group \\ SCOS: Swansea City of Sanctuary \\ SHARP: Swansea Humanitarian Aid Response Project \\ SVPRP: Syrian Vulnerable Persons Resettlement Programme \\ SNP: Scottish National Party \\ SWEP: South Wales Evening Post \\ SWP: Socialist Worker's Party
}


UNHCR: United Nations High Commissioner for Refugees

UK: United Kingdom of Great Britain and Northern Ireland

US: United States of America

WG: Welsh Government

WM: Western Mail

WRC: Welsh Refugee Council 


\section{Acknowledgements}

I began working on this doctoral thesis in October 2016 and, because neither research nor writing is a process that can usually be realised purely by oneself, there a lot of people who have my gratitude: without you, this research project would not have come to fruition. First, I want to express my gratitude to Swansea City of Sanctuary and their staff members for all their help and support, and for inviting me to great events and conversations during my time volunteering. While this research might at times raise some broader questions on sanctuary or hospitality itself, this does not diminish my admiration for your incredible hard work and commitment to a just cause, nor of you or of other volunteers from the Swansea City of Sanctuary and the Swansea Asylum Seeker Support Group. Your constant commitment and engagement is an example to be followed. In this context, thanks must in fact go out to all the different people who were so kind to sacrifice their own time to be interviewed for this research project. Moreover, I was also very fortunate to have an incredible amount of help and guidance from people in the academic community. I would like to warmly thank my doctoral supervisor of the last four years, Angharad Closs Stephens. Her tireless and generous academic and professional support was invaluable, and I could not have wished for a better and more supportive supervisor and mentor. In addition, I would also like to thank Jonathan Darling, whose comments and feedback during the process has proved important and influential for the further development of this research. There are also many more colleagues and friends who I would like to thank for their support. Thanks to my colleagues in the Department of Geography at Swansea University as well as the $\mathrm{PhD}$ student community, including Claire Foerster, Lucy Jackman and Eleanor Cotterill. I was also very fortunate to receive funding from the Economic and Social Research Council (ESRC), which enabled me to undertake this research project, and I am grateful for this grant. I am also deeply appreciative of the people who shared their personal stories of sanctuary, in their own and very challenging time. I hope that in a small manner this research can perhaps assist in imagining futures were, beyond the constant work that is already done by many in civil society, these acts of welcome also affect the states in which you find yourselves. Most of all, I am grateful to my family, 
who always provided me with support and guidance when I most needed it. I would like to dedicate this work to my daughter Clara Sophie, whose development each day since her arrival has been the most joyous event and process of my life. 


\section{Part I: Sanctuary cities, the}

\section{politics of hospitality and national imaginaries of asylum}




\section{Chapter 1. Introduction}

\section{“...it takes a death, really, to cause any major discussion...” (Interview, 2 November 2017)}

This research project starts with the stories and trajectories of three different lives two lives lost, and one life saved. What unites them is that these are all lives that have been marked by the exclusionary politics of asylum (Squire 2009). Two of them had been cast as 'illegal' and were othered by the European Union (EU) and its constituent member states, one of them specifically by the United Kingdom of Great Britain and Northern Ireland (UK). In the first stages of this research, I talked to an activist in Swansea, who had long been involved in supporting asylum seekers and refugees in their struggles with the 'hostile environment' that the British government creates for them. He observed that even in the context of this one Welsh city it was the death of a person that first triggered a wider public discussion about the plight of migrants once they reach Britain. I asked him about moments he remembered about his time supporting refugees since Swansea had become a dispersal area for asylum seekers who had reached the UK, and the murder of Kalan was one that sprung first to mind. This is the story of the first life lost.

Kalan Kawa Karim, a 29-year old activist for Kurdish rights in Iraq who had been tortured in jail under Saddam Hussein's regime, and who had been granted asylum in the UK, was killed in an unprovoked, racially motivated attack in the centre of Swansea, in the early morning hours of 6 September 2004 (Charles, Cheesman, Hoffmann et. al 2005). Of these three lives whose story I will retell in this introduction, he was perhaps the exception, in that he had not been illegalised by the British state, as so many other migrants had been. In this thesis, I am following Harald Bauder (2014) in using the term 'illegalised' (rather than legal or illegal) to draw attention to how national laws, policies and practices deny migrants full status or legal residency to frame them as the other. While Kalan had 'legal' status, his murderer still perceived him as a racialized, dangerous 'other' - in a manner that fits in with an outright hostile discourse of the so-called 'bogus' asylum seeker. However, this racist murder shattered this discourse, albeit momentarily. A large demonstration was organised in 
the city centre, with over 1,000 marchers making their way from Guildhall along St. Helen's Road, a multi-ethnic neighbourhood street in Swansea, to send a message of anti-racism and support for ethnic minorities in the city (Davies 2004). In addition to this demonstration of solidarity, there seemed to also be a concern with the (self-) image of Swansea, with the then Welsh Assembly member (AM) Andrew Davies stating that this march showed that: "the majority of the people in Swansea abhor racism. The city has a tradition of supporting repressed people" (ibid: 1).

Quickly, though, the case was forgotten by most people beyond the immediate activists and supporters for migrant's rights, and the mostly hostile narratives returned. The activist seemed to have been right - it took another death to start a major discussion. The next time more than 1,000 people assembled again at a demonstration in Swansea in support for refugees and asylum seekers was almost to the day eleven years later (BBC:2015b) when the picture of Alan Kurdi anchored the European 'refugee crisis' in the public imagination. What follows is the story of the second life lost.

\subsection{September 2015 - The European 'refugee crisis' and its discursive aftermath}

Aylan Kurdi was a three-year-old Kurdish-Syrian boy who drowned of the Turkish coast during his family's attempt to reach safety in Europe at the beginning of September 2015. The image of his body lying on the beach had been captured by Nilüfer Demir, a photojournalist. While the previous month had seen a terrible new record for migrant deaths in the region (see Missing Migrants 2020), this instance seemed to be more than the death of another anonymous migrant in the Mediterranean. For a brief period, at least, the discursive framing of refugees and asylum seekers shifted from fear and hostility to moral support. The picture triggered strong emotional responses in public opinion across Europe, even resulting in calls for more hospitable immigration policies. In Germany, the word Wilkommenskultur, which can be translated as 'culture of welcome', was recurrently used in public discourse to describe various forms of welcoming arriving refugees. This word was, as Doris Akrap wrote in The Guardian: "not born out of custom but established to create one" (2015). Shortly after the publication of the picture, the then UK Prime Minister David Cameron also vowed that Britain would "fulfil its moral responsibilities" by taking in 20,000 of the "most vulnerable" Syrian refugees over a period of five years until 2020 
(BBC: 2015a). The resolution was welcomed, but criticised for only taking in such a small number. Some days later, at the 17 September 2015, the devolved Welsh government then held an emergency summit in response to these crisis events, and committed that Wales should play a leading role in supporting refugees through becoming a 'Nation of Sanctuary'.

These intensified migratory movements during the summer of 2015 led to a momentary but renewed use of the language of welcome by various political actors. Indeed, the Welsh government adapted this vocabulary from the Swansea City of Sanctuary network, which was set up with the overarching aim to "build a culture of hospitality for people seeking sanctuary in the UK" (Squire 2011: 296). However, the convergence of events which was required to produce a more humanitarian approach towards refugees, culminating in the public spectacle of disseminating the picture of a drowned toddler, led critical migration scholars to caution that this would be a rather limited and short-lived response (see Haynes et.al 2016: 227). Nonetheless, the fact that discourses of humanitarianism temporarily replaced discourses of border security did not necessarily lead to an improved political response. In fact, it raises more interesting question about what has been termed 'humanitarian government' - the simultaneous deployment of logics of securitization and humanitarianism in the governance of disenfranchised subjects (Vaughan-Williams 2015). These questions from the ambivalent space between securitisation and humanitarianism become even more apparent when we turn to the story of a third life - one that was saved in Swansea.

\subsection{A life lost and a live saved: Different sanctuary outcomes in Swansea, Wales}

Otis Bolamu's story unfolded over Christmas in 2018 - or at least it seemed to for his supporters, and people like me in my role as a researcher, from the outside. For him, it had of course started earlier, in fact immediately when he had arrived in the UK in October the previous year, and had claimed asylum. This story is thus also one of a small victory over the 'hostile environment' that has been a central part of British asylum policy. Otis Bolamu had been imprisoned and tortured in the Democratic Republic of Congo (DRC) because of his opposition to the government of Joseph Kabila (Taylor 2018b). After fleeing, the 38-year-old had been dispersed to Home Office accommodation in Swansea, where he was well known in the asylum seeker 
community and with their supporters through volunteering in the Oxfam Bookshop at Castle Square in the city. He was forced out of his accommodation in a dawn raid by the police and border control agents, and taken to Brook House detention centre near Gatwick, where his deportation to the DR Congo was planned for Christmas Day (ibid). Hay, Brecon and Talgarth Town of Sanctuary, a support organisation which had been set up in response to the long summer of migration in 2015 (Interview, 28 March 2018) immediately started a petition to release Otis before Christmas, and to reconsider his case on the basis that he was in danger of being killed if deported. For a third time, it was death, or the threat of it, that (re)ignited the discussion of the plights of asylum seekers and refugees back to Swansea, here more than three years after the long summer of migration. The petition was shared through other organisations in Swansea, and was signed by more than 3,000 people in days the followed. In January, following this widespread attention and grassroots pressure, he was released and returned to Swansea (BBC: 2019). In the meantime, the grassroots campaign for Otis to stay in the UK had begun to attract the attention of local and national politicians in Wales.

After his return, Swansea council leader Rob Stewart told the BBC that the manner of his arrest and detention was 'alarming', and that: "As a city of sanctuary, we want to see people supported and feeling safe and we hope now this case can be brought to a resolution so that Otis can have a secure future where ever he intends to reside" (ibid). The Swansea West MP Geraint Davies also intervened with the Home Office on his behalf. The campaign continued, ultimately more than 60,000 people signed the petition, and more members of the community, alongside more Welsh assembly members and MPs, protested about his detention and called for his right to stay (Taylor 2020). But these calls now extended beyond the city of Swansea. The Welsh First Minister Mark Drakeford stated on Twitter that he had been in contact with the Home Office concerning Oti's case. Plaid Cymru's official account tweeted on 15 October 2019 that Otis and another asylum seeker: "are both based in Wales and are both at risk of deportation from a hostile UK government". It also referenced the South Wales West AM Bethan Sayed in saying that: "We have a duty to support people who need out support and ensure Wales is the nation of sanctuary that we purport to be" (2019). Exactly one year after this first release, The Guardian (Taylor 2020) reported that the 
Home Office had reversed their decision concerning his case and that Otis Bolamu had been granted asylum in the UK.

\subsection{Outline of the main research question: Sanctuary and National Imaginaries}

These three stories reflect my own point of entry into in the ambivalent space between asylum, sanctuary, humanitarianism and securitisation. They are moments which affected and anchored the research. The story of Kalan Kawa Karim emerged in one of the first interviews I conducted in the early stages of this project, when I was not sure exactly where the research would lead. Researching the case further in the local archives in Swansea, I was surprised with extent to which newspaper coverage of the case was concerned with reiterating how Swansea was "not a racist city" (in Lisle 2004b), that "racists are in the minority" (in Davies 2004) or that racism in the city "was not an everyday problem" (in Lisle 2004a) - framing the (self-) image of Swansea. The publication of the picture Aylan Kurdi in September 2015 was for me personally an entry point into the work that culminates here with this thesis. The picture that different publics in Europe saw that summer, myself included, made me want to learn about migration, to become involved in understanding and challenging the systemic inequalities that produced that situation in the first place. The third and final account, the story surrounding the successful grassroots campaign in support of Otis Bolamu, was unfolding when I was already in the process of writing this thesis. It has stayed with me because it confirmed some initial observations that I had made about the ambivalent politics of sanctuary.

Indeed, beyond the personal, there was an important shared element between the three stories which caught my attention, and which would lead me to the research topic of this thesis. The shared element was the importance these three stories had for the politics of 'place-making' (Guma et al 2019). With Kalan, it was about how Swansea saw and represented itself in response to the murder. In the case of, Aylan Kurdi and the effects of that photograph across Europe, it was about what this picture would mean for the self-imaginaries of European nation-states - they see and represent themselves as both sites of security and of humanitarianism. I wanted to read the case of Wales and the intention to become a 'Nation of Sanctuary' within this context. 
The first section of this chapter has described how, in response to the 'crisis' of refugees (De Genova and Tazzioli 2016) arriving in Europe over the summer of 2015, the Welsh Government held an emergency summit and committed that Wales should play a leading role as the world's first 'Nation of Sanctuary'. This was an interesting moment, given that Wales doesn't have responsibility for British borders. Therefore, the central research question of this project is:

What might it mean, in theory and practice, for a territory such as devolved Wales, to declare itself as the first Nation of Sanctuary?

In other words, what does the idea of a Nation of Sanctuary mean, and what does it $d o$ (discursively speaking)? From this main question, three more detailed sub-questions emerge: What are the theoretical and political imaginaries of sanctuary, national identity and hospitality at work in this context? What are their historical precedents? How do they relate to political responses to the 'crisis' across the UK and Europe? This thesis will answer the research question (and the associated sub-questions) by demonstrating how the idea of Wales as the first Nation of Sanctuary also forms a way of performing identity, and that urban, regional or national imaginaries of community have different discursive effects on the commitment of hospitality towards asylum seekers and refugees. The second element of the examination, concerning the differences that spatial imaginaries of community make for the commitment to hospitality towards migrants, emerged from the fact that the Welsh government had adapted this framing from the City of Sanctuary $(\mathrm{CoS})$ network. This had been set up with the declared aim to "build a culture of hospitality for people seeking sanctuary in the UK" (Squire 2011: 296). The response of the Welsh government to the long summer of migration, announcing their intention to become the world's first Nation of Sanctuary by building a culture of hospitality for refugees and asylum seekers, is a new empirical case. This is if we consider the urban origins of the sanctuary movement, and that this was the first-time a (devolved) state administration adopted this slogan to frame their responses to migration.

Before proceeding, it is therefore necessary to briefly define and specify how the terms 'state', 'nation' and 'national identity' are used in this thesis. The understanding of the state draws on Ernesto Laclau's and Chantal Mouffe's (2014: 163-164) definition that: "The State is not a homogenous medium, separated from civil society by a ditch, but 
an uneven set of branches and functions, only relatively integrated by the hegemonic practices that take within it". While building on some elements of a Foucauldian notion of the state as a 'envelope' (Bidet 2016: 126) in which multiple relations of power come to be regulated, this thesis follows their argument that the state can also be the seat of different democratic antagonisms. This is to the extent that a set of functions within it can "enter into relations of antagonism with centres of power, within the state itself, which seek to restrict and deform them" (Laclau and Mouffe 2014: 164). In opposition to such homogenising tendencies, this thesis proceeds from Angharad Closs Stephen's (2013: 25) caution that the question What is a nation? is also problematic, because it suggests an essentialising, national substance. Instead, this thesis follows Katherine Verdery's (1996: 226-227) definition of nation as a symbol and basis of social classification: "It names the relation between states and their subjects and between states and other states; it is an ideological construct essential to assigning subject positions in the modern state, as well as in the international order". Treating the nation as a symbol, rather than a thing, makes it possible to ask about the societal and institutional contexts in which competing definitions of the nation operate, what those different definitions accomplish, and for whom (Verdery 1996). This is also important for the definition of national identity as both the individual's sense of self as national, and the identity of the 'national' collective in relation to others of the kind, because one cannot assume that there is only one form of such 'national' selfexperience (ibid).

The literature on sanctuary movements has, to date, mainly focused on urban imaginaries, largely because there have been few attempts to date by the social movement itself to conceptualise sanctuary imaginaries at other geographical scales. This research project contributes to this literature by examining both how we might read and study this declaration critically, and asks what effects the subnational and devolved constitutional background can have for the politics of sanctuary cities. Jennifer Bagelman in Sanctuary City: A Suspended State (2016), grounds her ethnographic account in Glasgow in Scotland, and mentions that while immigration in the form of entry and legal status are reserved matters, there is "less certainty about the degree to which immigration policies after arrival are devolved, and which remain under the jurisdiction of Westminster" (Glasgow Refugee and Asylum Network 2014 in Bagelman 2016: 3). Harald Bauder (2016) also concluded his discussion on 
sanctuary cities by arguing that "national socio-demographic factors [...] as well as historical circumstances and political traditions, are likely to shape the possibility of implementing" them, and that thus further research "could explore which particular national circumstances enable or constrain various aspects of urban sanctuary" (ibid: 182). This research project directly addresses this call to explore those potentially enabling national circumstances.

Considering that the declared aim of building a culture of hospitality and welcome for refugees and asylum seekers is the considered yardstick for sanctuary cities (and nations) by the $\mathrm{CoS}$ grassroots movement, this thesis also examines the first subquestion on the role of the metaphor of hospitality in discourses around the topics of migration and the nation-state. It does so through exploring the ways in which policies and public reactions to the long summer of migration where expressed, justified and responded to. Here, it will also explore how the administrations of the nation-states nested in the devolved context of Britain used different moral imaginaries around hospitality to frame their political responses to the European refugee 'crisis', and what those contextual responses can tell us about subsequent national self-imaginaries with regards to the phenomenon of migration. My argument is that, while the critical literature on migration has successfully explored the limits of hospitality as a frame of response towards the exclusionary politics of asylum, this analysis might miss how the framing of hospitality is also at times used to challenge the sovereign nation-state on the grounds of what it means to be a 'host' to refugees and asylum seekers. In doing so, this doctoral thesis answers the main research question on what the idea of a Nation of Sanctuary means and does, through showing that the framing exercises what has been called a second othering. To show how this research project arrived at this answer, the next section will now set out an overview of the structure of the thesis.

\subsection{The structure of the research project, and outline of the chapters}

This thesis is structured into the following subsections: the introduction, Part I consisting of three theoretical chapters, Part II consisting of four empirical chapters, and a conclusion. The rationale behind this separation is to first contextualise the existing literature on sanctuary and migration, and to show where and how this research fits into this scholarly landscape, and where it contributes. This first part, after 
reviewing the literature, will examine which theoretical discussions have emerged from it, and identify which potential shortcomings exist in those discussions. Then, Part I will finish by explaining the research design, and the choice of methods employed in examining the central research question of this project, and how this might address those underexplored aspects of the critical migration literature.

Chapter 2 consist of a literature review of the critical migration and border studies literature in general, and of the literature on sanctuary movements and of sanctuary cities in particular. The starting point of the research was what has been described as the "long summer of migration" (Hess et al 2016) and how the call for Wales to become a Nation of Sanctuary emerged from it. Therefore, this literature review begins with a snapshot of the debates that were emerging within the Critical Border and Migration Literature at that point in time. In Europe's Border Crisis-Biopolitical Security and Beyond (2015) Nick Vaughan-Williams examined how the figure of the "irregular" migrant is often caught between discourses of securitisation and humanitarianism. It is in the context of those conceptual debates, and what he calls a crisis of humanitarian critique (ibid: 4), that this literature review is situated. Within this context, the chapter will examine the literature on the City of Sanctuary movement in the UK (see Darling 2010, Darling and Squire 2013, Squire 2011, Squire and Bagelman 2012, Squire and Darling 2013, Bagelman 2016, Bauder 2016), outlining their focus on the politics of identity, hospitality, and its governmental deployment. The third section examines the literature on the geographical background of this project: the relationship between cities and citizenship in the context of the politics of asylum. This is important, considering the empirical background is situated between the imaginaries of Swansea as a City of Sanctuary, Wales as a Nation of Sanctuary, and the sovereign British state.

Chapter 3 constitutes the theoretical framework. It introduces the theoretical concepts that will underpin the further analysis: humanitarian government, hospitality, and domopolitics. The preceding chapter investigated the critical literature on migration that was engaging with the broader Sanctuary Cities movement, from which two recurrent arguments emerged. First, that manifestations of sanctuary often "represent a means of governing through the assertion of humanitarian intentsions" (Darling 2013). And second, that the official framing of 'building a culture of hospitality' is "a limiting approach that is bound to the rationalities of power that produce uneven 
relations between guest and host" (Darling 2013). The first concept examined is therefore the notion of humanitarian government (Fassin 2012) between care and control. The second concept introduced is hospitality, or the metaphor of hospitality as it is used to describe the relation between states and the phenomenon of migration. This second section will introduce Jacques Derrida's conceptualisation of hospitality as ethics (2000) between the conditional and unconditional. This is followed by an account that conceptualises hospitality with regards to spatiality and home as a matter of "ethics, power and space" (Bulley 2017). The third concept is domopolitics, which has been conceptualised by William Walters (2004) as the governance of the nation as a home. It has been used by Jonathan Darling (2013) to show how the language of hospitality often enables the governmental ordering of responses to asylum. Domopolitics is important because it shows how the discourses of hospitality become a means of governing.

The last section of Chapter 3 will summarise where the literatures with regards to these three concepts stands, and suggest that a focus on the 'Nation of Sanctuary' phenomenon not only constitutes a new empirical case, but also provides new theoretical ways of revisiting the metaphor of hospitality and its role in sovereign framings of migration. The argument is that while the critical literature on migration has explored the limits of hospitality as a framing and response to the exclusionary politics of asylum, this analysis might miss how the framing of hospitality is also used to (additionally) 'other' the sovereign state on the ground of the expectations of what it means to be a host. While this process of is entangled with unequal power relations, it opens the space new theoretical considerations regarding the ambivalent politics of hospitality.

With regards to this theoretical focus, it is apparent that there are three ontological aspects to this research: the meaning of a specific phenomenon (hospitality), the process of its discursive construction (Nation of Sanctuary), and the effects and consequences of producing this meaning for relationships between people and place (national identity). Therefore, this research project is underpinned by philosophical assumptions central to hermeneutics and discourse analysis. Chapter 4 introduces these underpinning assumptions to contextualise and explain the research design, the methodological approach and the choice of research methods that directed the data collection. This included semi-structured interviews (individual and joined), archival 
research (newspaper and official documents), ethnographic fieldnotes and participant observation. It also describes how the fieldwork process started in Swansea. Before the project aim was refined, there were two issues that I wanted to explore: the emergence of the new concept of the Welsh 'Nation of Sanctuary', and the relations between community imaginaries and commitments of hospitality towards asylum seekers and refugees. Because Swansea had become the second official 'City of Sanctuary' after Sheffield, and the local City of Sanctuary organisation was the first within the national network that advocated for Wales to become a "Nation of Sanctuary', this grounding in Swansea was the natural point of departure to examine those questions. Part II consists of four empirical chapters, which uses the data collected to examine, analyse and evaluate the main research question on the effects of different national imaginaries for the commitment of hospitality towards migrants. Each chapter examines the accounts of different subjects, which are to an unequal degree involved in the construction of (national) hospitable imaginaries. Moreover, to provide a broader critical examination and problematisation of the 'nationalised' metaphor of hospitality, each chapter also engages with a different discursive element of dominant hospitable imaginaries.

The first empirical chapter, Chapter 5, is titled "A warm Welsh welcome?"- The emergence of the UK national dispersal programme for asylum seekers, and of national (self-) imaginaries in Welsh newspapers. The first step is to trace the implementation of the national dispersal policy for asylum seekers and refugees from the time it was announced in December 1999, until the first people arrived in Swansea in January 2002. It will also examine how the debates around the new policy affected emerging national self-imaginaries in Wales. This context is important, because the dispersal programme is argued to have "marked a sea change in British asylum policy, but it also marked a turning point for Wales" (Robinson 2003: 189). The chapter has two further objectives. First, it introduces the political and constitutional background for the implementation of the national dispersal policy in Wales: the creation of an increasingly hostile asylum regime under the Blair administration with the 1999 Immigration and Asylum Act, and the parallel emergence of a Welsh National Assembly and devolved public services, which were intended to become part of that new asylum regime. The second part of this section will investigate how the announcement of the new dispersal policy was narrated and discussed in Swansea and 
Wales. It will draw on the news coverage of the dispersal policy from the South Wales Evening Post and the Western Mail between 2000 and 2002. This chapter thus offers an historical context to earlier precedents of scalar sanctuary imaginaries. With this background, it is then possible to examine further what it means to declared oneself as a 'Nation of Sanctuary'.

Chapter 6, which is titled: From 'Multiculture' to the 'revolution of generosity': The emergence and development of Swansea City of Sanctuary until the long summer of migration, will investigate the moral dimension of the urban self-imaginaries of the sanctuary movement. This context is essential, because it is from this network that the idea of a 'Nation of Sanctuary' was adapted by the devolved Welsh Government. The chapter traces the emergence of the Swansea City of Sanctuary movement committed to building a culture of welcome and hospitality. The first section will investigate the emergence of the City of Sanctuary movement in Swansea in 2008, and the announcement that made Swansea the second official City of Sanctuary in the UK. The chapter will draw on interview data from local activists, as the focus is a grassroots movement that emerged from civil society. The theme is the internal debate over the focus of the movement, and what specific acts and activities were imagined by the movement to make the "good city" (Amin 2006). The second section will also look at the further developments of the City of Sanctuary network after Swansea had become the second City of Sanctuary in the U.K. It will investigate how this process was also affected by austerity and neoliberal processes of responsibilization (Rose 1999) that emerged in Wales, with cuts imposed on support services for refugees and asylum seekers. This chapter, in examining the emerging practical work of the Swansea City of Sanctuary network, establishes the conceptual groundwork to analyse what it would perhaps mean in practice for a nation to declare a 'Nation of Sanctuary'.

The third empirical chapter describes how the summer of 2015 constituted a rupture for some of these discursive-governmental techniques on migrants. As we have seen, in response to the European 'refugee crisis', the Welsh Government held an emergency summit and committed that Wales should become a 'Nation of Sanctuary'. With this context in mind, the aim of Chapter 7, titled Othering the Host-Welsh responses to the British politics of refugee resettlement after the long summer of migration is to compare the different discursive responses of the British and Welsh governments and administrations to the 'crisis'. It does so by examining the example of the Syrian 
Vulnerable Persons Resettlement Programme (SVPRP), drawing on a document analysis of policy papers and official statements. It examines how the contrasting discourses and narratives provide new theoretical ways of revisiting the metaphor of hospitality, and its role in sovereign framings of the politics of asylum. While the literature has explored the limits of hospitality as a response to the exclusionary politics of asylum, this chapter argues that it is also used to challenge $a$ given sovereign nation-state (Hill 2016) on the moral expectations of what it means to be a good (Amin 2006) and responsible 'host' to refugees and asylum seekers. The argument developed is that the hospitality discourse of the Welsh government at times uses a politics of differentiation from the British state that relies on will be referred to as a second othering. In drawing on the insights from the previous empirical chapters and from this section itself, Chapter 7 therefore provides a first answer to the research question. The 'Nation of Sanctuary' is meant to form a way of performing identity, and it does this through an othering of the sovereign state.

But what other potential ambiguities emerge within this new language of 'national' sanctuary? One problem is that the empirical focus on different scalar imaginaries of hospitality might still end up offering a platform for people who, in dominant framings, are constructed as the 'hosts': civil society actors, activists, and state intuitions. This not only forces those who are framed as the 'guests' - asylum seekers and refugees into a passive role, silencing their voices. It might reinforce and entrench unequal relations of power and domination associated with those terms. Therefore, Chapter 8 , titled The Limit of the Homely Nation: Hosting schemes and asylum seeker's perspectives on destitution and 'home'-lessness will focus on practices of hospitality in examining two private hosting schemes for destitute asylum seekers in Wales, called Share Tawe and ShareDydd. Drawing on joint interviews and ethnographic fieldnotes, the last empirical chapter will focus on how destitute asylum seekers experienced hospitality in the context of the two hosting schemes. It will study to what extent the encounters and interactions between those framed as hosts and guests might resist or transform the framing of hospitality altogether. The benefit of focusing on such practices is to assist in unearthing the ambivalences and power discrepancies inherent to hospitality. This chapter shows how the private offering of hospitality can entrench the unequal distinctions between established and less established residents, but also challenges the hostile environment for refugees and asylum seekers in the UK. 
Finally, the conclusion first summarises the key findings and arguments made throughout Part I and II, and offers an answer as to what the Nation of Sanctuary means and does, and what difference urban, regional or national imaginaries of community might make to the commitment to hospitality to asylum seekers. Ultimately, this research finds that some national imaginaries of community used hospitable sanctuary imaginaries of migration for an 'othering' of the sovereign (host-) state. The chapter therefore finishes by evaluating the extent to which this discursive second othering could move beyond the construction of national self-imaginaries to also challenge sovereign asylum regimes. The second part of the conclusion evaluates what the insights from answering this strategic question means for researching the relationalities between the sovereign nation-state, national independence and the exclusionary politics of asylum. 


\section{Chapter 2. Literature Review: From urban sanctuary towards re-scaling citizenship}

The starting point of this project was the "long summer of migration" (Hess et al. 2016), and how the subsequent call for Wales to become a 'Nation of Sanctuary' emerged from it. Therefore, this literature review begins with a snapshot of the debates and discussions that were emerging within the Critical Border and Migration Literature at that point in time. In his book, Europe's Border Crisis: Biopolitical Security and Beyond (2015), Nick Vaughan-Williams examined how the figure of the "irregular" migrant is often caught between the discourses of securitisation and humanitarianism. It is in the context of these conceptual debates, or what he calls a "crisis of humanitarian critique" (ibid: 4), that this literature review is situated. Furthermore, the literature review will explain how examining Swansea as the second official City of Sanctuary in the UK, and Wales as the first 'Nation of Sanctuary', contributes new insights to this literature.

The aim of this chapter is twofold. First, it outlines the importance of the 'Nation of Sanctuary' (NOS) as a unique and new empirical phenomenon. Considering that the sanctuary movement in the UK and North America has so far been entirely imagined and conceptualised in the critical literature as an urban phenomenon, emerging in response to the exclusionary politics of asylum associated with the sovereign nationstate, this new phenomenon and scalar imaginary in and of itself calls for a (re-) visiting of the scholarship on migration, sanctuary movements and cities. From this first objective to clarify an empirical puzzle follows the second objective to address the critical literature. There are two related issues that will be highlighted as underexplored, or narrowly conceptualised. They are argued to require further development to address the implications of sub-national rescaling of what has, to date, been primarily a local, and specifically urban, phenomenon. First: the critical literature on sanctuary movements has mainly focused on urban imaginaries, while less attempts have been made to conceptualise imaginaries by the movement on other geographical scales. Bagelman (2019: 155) pointed out that in sanctuary scholarship there are framings of sanctuary through urban (Ridgely 2008), national (Darling 2010), 
international (Bauder 2016) and planetary (Carney et al 2017) scales. But the movement itself has framed sanctuary as mainly an urban phenomenon. Second, the focus on those sanctuary cities in Britain, for example Sheffield in England (Darling 2010) and Glasgow in Scotland (Bagelman 2016), has often been on their relations with the politics of the British government. This has led to a narrow conceptual binary between the sovereign nation-state, on the one hand, and the city on the other, which falls short on exploring other scalar frames and imaginaries. This research project is the first within the literature on the City of Sanctuary movement in Britain that explicitly addresses devolved and sub-national imaginaries.

The first section of the chapter will provide an overview over the broader conceptual debates within the Critical Migration Studies (CMS) literature. The section will start with work that has examined the framing of migration as closely linked with processes of securitization and criminalisation (Bigo 2002, Huysmans 2006), often accompanied by or related to humanitarian discourses of victimhood (Walters 2011). The section will then introduce literatures that have cautioned against a prevalent focus on sovereign power and control over political struggle and contestation, for example, the acts of citizenship literature (Isin 2002, 2009). The first section will end with introducing theoretical work that has focused on ambivalence (McNevin 2013) within migration management and activism. With this conceptual background, the second section will then examine the scholarly literature on the City of Sanctuary (COS) movement in the UK (Darling 2010, Squire 2011, Darling and Squire 2013, Bagelman 2016, Bauder 2016 Squire and Bagelman 2012, Squire and Darling 2013), outlining their focus on the politics of identity, hospitality, and its governmental deployment. This section will also elaborate on the empirical contribution this research project makes in its focus on Swansea as the second City of Sanctuary in the UK, as little examination has been carried out on the potential influence of a devolved administration for the politics of sanctuary cities.

The third section will examine the literature on the relation between cities and citizenship in the context of asylum. First, it will provide an overview of the literature on the relation between the city and citizenship, followed by an examination of what the current COS literature (Darling 2016) emphasises when discussing the urban context of the movement. It will also discuss the challenges and potentialities of rescaling citizenship (Varsanyi 2006), including a detailed examination of Engin Isin's 
critique of the concept of 'scalar thought' (2007). It will outline which conceptual shortcomings emerge when considering such rescaling through a binary between the urban and the nation-state. This is important when considering the empirical background as being uniquely situated between the different imaginaries of Swansea as a City of Sanctuary, Wales as a Nation of Sanctuary, and their relations to the sovereign British state. The conclusion will reiterate how this research project with its focus on the emerging imaginaries around the Welsh Nation of Sanctuary will contribute to the literature on sanctuary movements. It does so in following Harald Bauder's suggestion in Sanctuary Cities: Policies and Practices in International Perspective (2016), that new research could “... explore which particular national circumstances enable or constrain various aspects of urban sanctuary" (ibid: 182). Therefore, this literature review concludes by contextualising this research project, as well as highlighting its contribution to the scholarly landscape.

\subsection{Critical approaches to borders and migration}

In the field of Critical Geopolitics, John Agnew has pointed out that the "modern geopolitical imagination' (2004) strongly ties together the concepts of the border and the state: the border is understood as the territorial marker of sovereign authority. This idea organises global politics into two distinct realms: the 'inside' of the state, associated with order and security, and the anarchic 'outside' of the international. Vicki Squire emphasises in The Exclusionary Politics of Asylum (2009) how citizenship qua belonging is defined in relation to 'foreign' figures like asylum seekers. And while migration and mobility have increasingly been regarded as central features of globalisation, there has also been an increasing framing of those phenomena as 'problems' that need to be controlled. Monica W. Varsanyi (2006) identified this as a growing schism between de jure citizenship policies, linking a person's citizenship to the legal status and membership in a territorially defined nationstate, and the growing de facto presence and residence of non-citizens in those states. It is in relation to such disruptions, transgressions and dislocations that the phenomenon of migration constitutes for the territorial order that Squire (2011) and other scholars explore as the articulation of asylum as a problem or threat, in which refugees and asylum seekers represented as "harbingers of threats, dangers and social ills" (Watson 2009 in Nyers and Rygiel 2012). 
Moreover, the framing of irregular migration has been linked to processes of securitisation and criminalisation, which create exclusionary distinctions between 'desirable' and 'undesirable', or between 'productive' and 'threatening' forms of migration (see Bigo 2004; Huysmans 2006 in Squire 2011). And it is within this conceptual context of 'inside' and 'outside' that migration came to be read through the lens of security and as an existential threat to the nation-state, and that strengthening of border security came to be seen as the 'solution' to the 'problem' of 'irregular' migration (Vaughan-Williams 2015: 19). Moreover, this literature examined how the framing of asylum through security legitimises the extension of restriction (Squire 2011) through which populations are governed (Hindess 2000) within and beyond 'host' states (see Bigo 2002; Huysmans 2006). This focus is of interest for the empirical context of this research. Indeed, while the literature has analysed in detail the ever-expanding and excluding techniques of control that operate not only on the border but within territorial states, the conflicts those regime changes might create between different legal and territorial entities (cities, regions, devolved administration, and the sovereign nation-state) have been comparatively overlooked.

Following this securitisation of migration, which was developing at the end of the 1980's and the beginning of the 1990's (Huysmans 2000, 2006 in Vaughan-Williams 2015), Vaughan-Williams also pointed out that a humanitarian concern for 'irregular' migrants started to emerge in the context of border security and migration management (2015). He also emphasises that while the critical migration literature has tended to focus on securitisation, less attention has been paid to what William Walters has called the "birth of the humanitarian border" (2011 in Vaughan-Williams 2015: 28). This ambiguity stems from irregular migrants being framed by border security as problems and threats, while simultaneously being framed as lives in jeopardy and in need of saving. The deployment of more 'positive' notions of saving lives by European border agencies points here to a "co-optation of the language and posture of humanitarianism" (Vaughan-Williams 2015: 31). Considering how the long summer of migration culminated in the emotional reactions to the picture of the drowned body of Alain Kurdi, examining this literature on the ambiguities of humanitarianism is important for the background of this research project.

However, other critical scholars have emphasised how practices of mobility are themselves producing new forms of 'being political' (Isin 2002). The acts of 
citizenship perspective starts from the assumption that citizenship is more than a mere legal status (Nyers and Rygiel 2012), because it includes moment of political engagement by those lacking legal status, which means that by acting and claiming rights, they are in effect practicing citizenship (Isin 2007). Isin, who in Being Political (2002) undertakes a genealogy of citizenship, sees it as practice which constructs political privilege and marginalization. For Isin, citizenship implies a position of inclusion in any measure of political community, and the necessary exclusion of others. However, contesting claims, rights and obligations that constitute citizenship work differently in different sites and produce different actors, which means that rights, sites, actors and acts are all elements that constitute a given body politic (Isin 2007: 372). These sites and scales are not separated, but overlapping, and it is the intersection between different sites and scales which produces different rights and actors. This is a dynamic view of citizenship, as always being in flux, combining various elements like sites, scales, actors and rights (Isin 2007). This finally means that the spatial configuration in which citizenship is constructed is essential for the understanding of struggles contesting the exclusions it creates:

The city is neither background to these struggles against which groups wager, nor it is a foreground for which groups struggle for hegemony. Rather, the city is the battleground through which groups define their identity, stake their claims... and articulate citizenship rights, obligations and principles (Isin 2002 in McNevin 2006: 138).

In highlighting the notion of the city as not just a background but as a battleground, this chapter has examined two schools of thought: one concerned with securitisation and control, and one with agency and struggle. But some scholars also started to examine these forms of irregularity as a more ambivalent condition, that are created through both a politics of control as well as a politics of migration, each internally fractured (Squire 2011: 5). Anne McNevin develops this line of argument in her article Ambivalence and Citizenship: Theorising the Political Claims of Irregular Migrants (2013), pointing out that the notion of ambivalence provides a useful frame for coming to terms with the "transformative potential of claims that both resist and reinscribe the power relations associated with contemporary hierarchies of mobility" (2013: 183). Indeed, she cautions that some critical scholarship tends to ascribe an orientation to unauthorised mobility "as if it was necessarily geared towards system overhaul and 
normatively weighted towards more just arrangements", therefore implicitly attributing "an ambition to mobility and migrants which is not necessarily there" (McNevin 2013: 194). This attention to migration as a domain fraught with dilemmas and ambiguities has still affected scholarship on new discourses that shape and rationalise the phenomenon of migration in a 'positive' frame - one of them being the notion of offering sanctuary and/or hospitality. The second section will therefore show how the literature on the City of Sanctuary movement has deconstructed the power inequalities embedded in framings of hospitality. In the collection, Sanctuary Practices in International Perspectives (Lippert and Rehaag et al. 2013), William Walters emphasises how sanctuary is an ambiguous phenomenon, in asking:

Does the practice of sanctuary contest the sovereign power of the nationstate or does it function as a supplement, shoring it up? Does the provision of sanctuary unsettle the exclusionary logics that underwrite the state's policing of migrants and refugees, or does such a logic gets reproduced every time the offer of sanctuary is made conditional upon an assessment of the truth of its subject? Are the subjects of sanctuary guests to be hosted, a flock to be tended, victims to be protected, fugitives to be hidden, or political subjects to be engaged? (Walters 2013).

\subsection{The City of Sanctuary movement in the UK}

In addition to those questions concerned with the ambiguity and contradictions at the heart of the practice of sanctuary, Walters pointed out that studying them challenges "the idea that it is only states that can offer asylum" (2013: xi). Washington (2020) argues that while the modern concept of asylum is rooted in ancient religious traditions of sanctuary and primordial codes of welcoming the stranger, it was formed in a period of political state-crafting. The critical sanctuary literature has examined the urban as a potential alternative to the exclusionary asylum politics of the sovereign nation-state. But it has paid less attention on regional or subnational forms. The emergence of a 'Nation of Sanctuary' idea indicates the need to for further analysis. But while historical accounts of sanctuary are often found in association with older religious and biblical traditions, as spatially-fixed practices of offering protection in a certain territory, it can also be understood as more relational practices (Darling 2010). While the concept of sanctuary cities has attracted attention in the US and Canada, with longer traditions of sanctuary movements and the existence of urban collectives that 
assert rights to sanctuary within urban spaces, it is only recently that a movement entitled City of Sanctuary emerged across the UK.

The City of Sanctuary (CoS) movement in Britain originated in Sheffield in September 2005, following the initiative of two residents of the city (Darling 2010). Jonathan Darling explains in A city of sanctuary: the relational re-imagining of Sheffield's asylum politics (2010) that the central aim of the new movement was to alter the vision and identity of the city as a 'welcoming place', and through it hostile national debates on asylum, creating an intervention in the ways in which asylum was discussed and presented in Sheffield (p. 129). For Darling (2010: 129), "Sheffield CoS was therefore a campaign to alter geographical imaginations ...". Two years later, Sheffield became the first city in the UK to achieve the official status as City of Sanctuary, with gaining the support of the city council and over one hundred local organisations (Darling and Squire 2013: 192).

The city that would follow Sheffield as the second 'official' City of Sanctuary in the UK was Swansea. Jonathan Darling and Vicki Squire ask in this context: "So what precisely constitutes a place as a City of Sanctuary?” (2013: 192). They are pointing out that there are formal and informal answers to this question. The official aim of the movement is to "build a culture of hospitality for people seeking sanctuary in the UK" and to "influence policy-makers and public attitudes throughout the country" (Darling and Squire 2013a: 192). The movement thus avoids political campaigning, and favours the transformation of culture by fostering a bottom-up approach to political change at a local level (Barnett and Bhogal 2009). The founders explain what a place must do to become an 'official' City of Sanctuary as follows:

...gain resolutions of support from local groups and organisations, involve local refugee communities in the movement, achieve the support of the City Council and produce a strategy for greater inclusion of refugees and people seeking sanctuary in the city (2009 in Darling and Squire 2013: 193).

Darling (2010) describes how the success of the movement in Sheffield led to an expansion, which means that $\operatorname{CoS}$ now represents a national network of towns and cities. This was because in 2008, the national movement acquired funding to 'support local groups throughout the UK in developing their own Cities of Sanctuary' (CoS 
2008 in Darling 2010: 131), with the further aim of "growing a national City of Sanctuary movement that can start to influence policy-makers and public attitudes throughout the country" (ibid.). The aim of influencing policy makers has, in the movement as well as in the literature, often been assumed to be directed at the British government as they have reserved power over migration policy. This raises the question of whether new dynamics emerged when the movement started to address the Welsh administration, after Swansea became the first City of Sanctuary situating within one of the devolved nations of the UK.

Nevertheless, Darling and Squire (2013) have also pointed out that the 'official' requirements mean that a lot of work is going into creating a city of sanctuary before any official status can be gained, which means for them that "an understanding of the less formal dimensions of City of Sanctuary is central in understanding how a place is constituted as such" (p. 193). Despite local specificities, there are similarities in the activities of the different groups across the UK. There is a strong emphasis on events such as social meetings and community gatherings, with the intention of fostering relationships between those seeking sanctuary and other local people, creating volunteering opportunities as well as educating residents about the challenges that sanctuary seekers face. Darling and Squire (2013: 193) emphasise here that: "One aspect common to each activity is that they create opportunities for everyday encounters between individuals and groups present within the city". Their argument is that the movement itself a product of such encounters, which emerge for example from activities by already existing groups, or through personal and social connections formed within a dispersal city. This means for them that City of Sanctuary should not simply be understood as a movement with official statutes, aims and objectives, but also as a "patchwork formation that emerges from, and feeds into, less formal everyday encounters" (Darling and Squire 2013: 193).

But why is this focus on everyday encounters emerging in this recent literature? Vicki Squire (2011) argues in her article From Community Cohesion to Mobile Solidarities: The City of Sanctuary Network and the Strangers into Citizens Campaign that the numerous contradictions and exclusions of the UK government's policies on immigration are underpinned by several problematic assumptions regarding 'community' as cultural and legal membership. The British integration and cohesion agenda understands community in terms of legal membership and status, and culturally 
in terms of ethnic, religious or other forms of collective identification. This is reflected in "the assumption that there exist different groups which can be integrated within a cohesive yet differentiated whole" (ibid: 291). The conception of political community in terms of legal membership emerges from a territorial conception of citizenship, invoking a conception of sovereignty based on distinctions between 'inside' and 'outside'. While she argues that the emphasis on community in cultural or legal forms invokes a problematic conception of integration, she also points out that: "there remains work to be done in exploring the complexities of and tensions between these different notions of community as they are played out in the UK's integration and cohesion agenda" (ibid: 292). This project therefore contributes to the literature by exploring these tensions between different notions of community- with regards to not only the 'integration' of the migrant who is othered as the 'guest', but also between competing national imaginaries of who is constituted as a legitimate 'host'-state.

Squire's (2011) argument is that the cultural and legal understanding of community overlooks engagement and activities in which those distinctions are extraneous, privileging collective engagement of 'established' residents over those with a less established presence. She thus examines the engagements between arriving migrants or refugees and more 'established' residents, which contribute "toward the formation of solidarities which cut across such distinctions" (ibid: 296). These activities are based on what she calls "participation through presence" (ibid: 300), which often render cultural and legal distinctions insignificant. This can assist in the formation of more mobile forms of solidarity or engagement, shifting "attention away from the relatively static category of community towards the more dynamic category of citizenship" (ibid: 302). Here it became emergent that the existing literature on the City of Sanctuary movement started to problematise the distinctions between inside and outside.

In their article The Minor Politics of Rightful Presence: Justice and Relationality in City of Sanctuary (2013), Squire and Darling also expose what they consider to be the "limitations of conceptualising and enacting sanctuary through the frame of hospitality", and propose an analytical frame of "rightful presence" (ibid: 59). One argument put forward is that the concept of welcoming not only privileges some subjects as being able to welcome others, but also creates often an implied indebtedness of the 'guests' who are received by the 'hosts'. The notions of gratitude 
and indebtedness maintain subordinate positions for those offered hospitality (ibid). Even more problematic is this hospitable framing when it is bound to notions of contribution, as it might transform "embedded privileges into governmental practice by limiting the scope of welcome to those deemed morally or socially worthy" (ibid: 194).

Their alternative notion of rightful presence draws inspiration from Hannah Arendt's (1951) concept of the 'right to have rights', and is also developed through texts which explores the unexpected claiming of rights as politically significant (see Isin 2009). Squire and Darling (2013: 65) discuss how the enacting of a right to have rights is "articulated in terms of temporal and spatial relationalities of injustice that a frame of hospitality risks rendering invisible”. Migrants taking sanctuary play a central role in shaping the practices of City of Sanctuary and the urban environment in which these practices are located, through a set of encounters and activities like their involvement in the network, or through their presence within a range of urban sites (ibid). To explore the political significance of these activities, it is necessary to consider how those enacting sanctuaries bring histories and geographies of injustice to the forefront (ibid). Nevertheless, while Squire and Darling (ibid: 69) see the more disruptive articulation of rightful presence in the acts of giving testimony and in the content and exposure of such testimonies, they caution that there is still a risk of testimonies invoking "governmental-pastoral rationalities in which those seeking sanctuary are divided between responsible and irresponsible subjects...”.

What are those governmental-pastoral rationalities which were mentioned in the literature? In Taking not waiting: Space, temporality and politics in the City of Sanctuary movement (2012), Squire and Bagelman are drawing on Randy Lippert's Sanctuary, Sovereignty and Sacrifice (2005) to outline the intertwined assemblage of pastoral, sovereign and governmental power relations. The first aspect of this assemblage is identified by Lippert (2005) as governmental power, constituting freedom as a means of control, in the sense that it does not operate from above through directing subjects, but through processes and tactics of normalization and responsibilization as a form of self-governance. Lippert argues that sanctuary might also be read here as 'responsible' individuals seeking to support 'helpless' migrants which have been abandoned by the sovereign state, encouraging citizens to become responsible on their own (Squire and Bagelman 2012). Squire and Bagelman (2012) 
also argue that in addition to the governmental rational, a pastoral logic appears through attempts to draw hierarchical distinctions between 'protector' and 'protected'. The third aspect is that of sovereign power. They argue here that: "If governmentality and pastoralism are rationalities that function through the gaining of (official and personal) information, then sovereignty qua territorialisation can in some respects be conceived as a condition of possibility for these practices" (ibid).

In addition, Bagelman (2013) pointed out in her article Sanctuary: A Politics of Ease? that the urban movement exceeds a conventional understanding of sanctuary as being confined to a physical space. Instead, it operates more a "fluid network of practices aimed at shifting hostile attitudes towards asylum seekers and refugees" (ibid: 50). Nevertheless, in her ethnographic study in Glasgow, she examines how sanctuary is appropriated as a governmentality or politics of ease, in the sense of it "serving to ease and domesticate a serious problem that many asylum seekers and refugees face; namely, the problem of waiting in a state of limbo" (ibid: 50). This co-optation is conceptually and politically problematic, insofar as practices of sanctuary were often seen as an alternative to hostile state practices and the exclusionary politics of asylum.

Bagelman continued her critical investigation focusing on Glasgow as large dispersal area and celebrated sanctuary city with a range of support networks existing. This focus is also helpful because Glasgow has been portrayed (see Sim and Bowes 2007) as a model in the UK on how to promote a more hospitable form of settlement for dispersed asylum seekers. Bagelman (2016: 4) focuses on problematising such a simplified account of the sanctuary cities, also engaging with “... Glasgow”s complex, Janus-face reception”, which has nevertheless “... been posed within public discourse as alleviating the UK's hostile asylum process, especially its politics of dispersal". This research project therefore contributes to the literature, and specifically builds on Bagelman's work in examining in more detail the effects the subnational and devolved instituitional background can create for distinct sanctuary cities such as Glasgow or Swansea. Indeed, Bagelman briefly mentions that immigration in the form of entry and legal status are reserved matters, but that there is “... less certainty about the degree to which immigration policies after arrival are devolved, and which remain under the jurisdiction of Westminster" (Glasgow Refugee and Asylum Network 2014 in Bagelman 2016: 3). Neverthless, the effects of the particular devolved context, and how it might affect the creation sanctuary imaginaries between Glasgow, Scotland and 
the United Kingdom, remain comparatively unexplored. It is to this area where this research project, and its empirical focus on Swansea and Wales can contribute further scholarly insights to the literature on sanctuary cities. Moreover, this empirical context on sub-national imaginaries also speaks directly to Squire's (2011) enjoinder to carry out further exploration of the complexities and tensions between different notions of community in the UK integration and cohesion agenda. This work need not necessarily focus on the relationships between urban and nation, but between different and competing national imaginaries with regards to the politics of asylum. It is for this reason that critically engaging with the City of Sanctuary literature is instrumental in reflecting more broadly on what the idea of Wales as a Nation of Sanctuary means and does.

\subsection{Cities and re-scaling citizenship in an age of migration}

This chapter has investigated two sets of literature: the wider CMS literature, and the more detailed critical literature on the City of Sanctuary movement in Britain. Therefore, this third section will now examine the literature on the more explicit geographical aspects of the City of Sanctuary movement. This is on cities and the politics of urban citizenship and migration. It aims to find answers to questions such as: Why cities of sanctuary? And, how did urban citizenship come to be considered as an alternative frame for challenging the sovereign nation-state, and often exclusionary responses to the social phenomenon of asylum? This third section proceeds in a threefold manner. It starts by examining the literature on the relation between the city and citizenship. With regards to this, it reviews the literature on Sanctuary Cities (Bauder 2016) in North America and Europe, and examines what the more current literature (Darling 2016) emphasises when discussing the urban context and its centrality for the movement. Lastly, this section discusses the notion and potentialities of re-scaling citizenship (Varsanyi 2006), and outlines what conceptual shortcomings might emerge when considering a politics of re-scaling through a simple binary between the urban on the one hand, and the sovereign nation-state on the other.

The first section of this literature review began with Varsanyi's (2006) observation of a schism between de jure citizenship policies, and the growing de facto presence and residence of non-citizens in territorial states. It is this growing schism, she argues, 
which led to scholars of migration and citizenship considering the possibilities of rescaling citizenship. She categorised the literature on the topic into three realms: those exploring potentialities and shortcomings of a) global/cosmopolitan/post-national citizenship, b) supranational citizenship and c) transnational citizenship. However, another facet of this emerging literature, she argues, is the connection between the city and citizenship (Varsanyi 2006: 230). It is in attempting to avoid neglecting other forms of spatial politics, and more importantly in escaping what other scholars have termed the "territorial trap" (Agnew 1994) of the nation-state in political theory, that critical scholars started to (re)explore connections between the city and citizenship. Varsanyi argues that the main intent was that the city, before often viewed as "subservient to the nation-state", would be reconsidered as legitimate and new locus for citizenship in a more globalised world (2006: 230). Moreover, cities have increasingly come to be essential mediators in a more global and migratory field of politics and economics, as well as for the tensions that can emerge in living with diversity (see Amin 2012, Sassen 2006).

Darling (2016a: 1) has pointed out that the urban has only recently become an area of enquiry for scholars concerned with the political geography of asylum seekers and refugees. Nick Gill (2010: 626) has argued that there has always been "a strong association between the notion of a refugee and the notion of states" which then leads to what Darling (2016a: 2) identifies as the subsequent tendency to "reify the nationstate and its consistency, coherence and authority", or what scholars such as Malkki (1995: 496) have called the "national order of things". Therefore, Darling (2016a) argues in Forced migration and the city: Irregularity, informality, and the politics of presence the city should get more reflection as a space for refugee politics. From a conceptual point, this focus might offer more insight into refugee experiences without automatic recourse to fragmented forms of sovereign authority and control (ibid). But there is also political value, as Darling (ibid: 2) argues that such a focus "may offer a path to contest the exclusions of the nation-state through presenting the urban as a contested yet fertile ground for sequences of critique".

In Sanctuary Cities: Policies and Practices in International Perspective (2016), Bauder emphasises that while sanctuary cities in the UK, US and Canada all aim to accommodate refugees and asylum seekers in their communities, the concept of a sanctuary city itself is ambiguous and can refer to a range of different policies and 
practices depending on the national context. Therefore, he also emphasises the importance of the differences in the way illegalized migrants are treated at both urban and national scales. Moreover, while the concept of a sanctuary city in Canada and the US includes specifically the protection of illegalized migrants from federal law enforcement, in the UK, it refers to a rather general commitment to 'welcome' asylum seekers and refugees (Bauder 2016). Peter Nyer's article No One is Illegal between City and Nation (2010) investigates the action committees of non-status migrants and their activities in campaigning for the creation of sanctuary cities in the United States and Canada. For example, a common tactic there is to lobby municipalities to adopt a “Don't Ask, Don’t Tell” (DADT) policy, which would prohibit employees from asking about immigration status and stop them from sharing this information with government authorities (Nyers 2010: 137). While such a policy ensures that city services are available based on residency and need rather than legal status, many non-status migrants have still difficulties obtaining official documents, entailing that residency might nevertheless function as another form of border (Nyers 2010). This consideration is important to avoid setting up a strong conceptual distinction between the city and the nation, with the former assumed to be progressive and the latter being regressive. Instead, both have the potential to adopt either posture. But while some sanctuary practices might also have governmentalizing functions, Varsanyi argues that they still present various openings for 'local citizenship' (2008 in Darling 2016).

In Sanctuary Cities (2016), Bauder identified, despite the variations between national contexts, policies and practices, four distinct aspects of urban sanctuary, which correspond to legal, discursive, identity-formative or scalar themes. While statutory municipal DADT policies are not part of the urban sanctuary movement in the UK, a common aspect of sanctuary cities in North America and Europe is that the municipal legislative body, for example the city council, supports sanctuary initiatives (Bauder 2016: 180). And while it was mainly the literature on cities of sanctuary in Britain that has emphasised the discursive and identify-formation aspect of the movement, these aspects have also been highlighted as important to urban sanctuary initiatives in the US and Canada (see Ridgely 2008). The third theme that Bauder identifies as common to sanctuary city policies and practices in North America and the UK is that they often involve "rejecting national approaches towards migration and refugee admission", which he interprets as an "attempt to rescale migration and refugee policies and 
practices from national to urban scales (2016: 181). The extent to which such a rescaling of the politics of migration and belonging can assert "a form of power and politics at the sub-national level" (Sassen 2008) is therefore not only the subject of the next section, but also an underpinning concern of this research project on the Welsh 'Nation of Sanctuary' and the (devolved) politics of hospitality.

Of interest here is Isin's argument in his article City. State. Critique of Scalar Thought (2007) that the dominant understanding of modern bodies politic, for example cities, regions, nations or states, is underpinned by what he defines as 'scalar thought'. This thinking represents and institutes relations between the city and the state as if they were exclusive, as in contiguous and non-overlapping, hierarchical and ahistorical (ibid: 211). To explain, Isin thus sketches out how the history of scalar thought emerged through several core assumptions:

That the city and state always existed as distinct and opposing bodies (ahistoricity); that these two bodies constitute an exclusive relationship (exclusivity); and that it is a hierarchical relationship, that is to say, the state is the creator of all other scales; which are nested and tiered within it (hierarchy) (2007: 215).

These underpinning assumptions then have an important influence on dominant contemporary imaginaries concerning the relationship between the city and the (nation-) state. The city becomes the state "writ small", the state becomes the city "writ large", with identical features, and the subsequent imaginary that the state is the upper scale with the sovereign right to create other scales, including the city (Isin 2007: 215). Moreover, there is another essential element to this scalar thought: it "conceals the difference between the actual (physical and material) and virtual (symbolic, imaginary and ideal) states in which bodies politic exist" (ibid: 211). This brings Isin to the central aim of his essay, which is to first suggest that only the city exists as both as an actual and virtual space, while all other bodies politic, such as states or nations, only exist as virtual rather than as actual spaces, always in a fluid, impermanent and transient state of being (2007: 212). His core argument is thus that: "these virtual bodies are assemblages that are kept together by practices organized around and grounded in the city" (Isin 2007: 212). While Isin's critique of the concept of scalar thought has had a significant impact on scholarly discussions concerning the potentialities and shortcomings of attempts to re-scale citizenship, his essay is a mainly theoretical 
engagement with the imagined relationship between city and state. This research project therefore provides an empirical grounding to the claim that virtual bodies politic are kept together by practices organised and grounded in the city. Specifically, Chapter 6 will later show how the image of a Nation of Sanctuary appeared and exists primarily in relation to the urban City of Sanctuary context from which it originally emerged.

Isin's argumentation that nation-states are only virtual spaces, however, does not mean that they have no real effects, or that they are simply imagined. Drawing on Jacques Derrida (1994), his essay maintains that the virtual should not be opposed to the real but to the actual - that virtual spaces such as nation-states are inexistent (in an actual, material sense) means that they do not exist in and of themselves, but only in representations and effects (Isin 2007: 212). Nevertheless, scholars such as Bauder (2016) argue that the re-scaling of sanctuary practices constitutes a threat to national sovereignty through legal and discursive aspects. The legal threat to sovereignty appears, for example, when the US federal government attempts to deny municipal government funding should they enact local sanctuary policies such as DADT (ibid). Moreover, Varsanyi (2006) draws here then attention to the work of Rainer Bauboeck (2003) on re-scaled urban citizenship and its challenges, as his aim is to:

...criticize[s] postmodern perspectives that disregard the territorial bases and boundaries of democratic self-government. Without these, urban citizenship would be reduced to a bundle of universal negative liberties provided by national or supranational institutions and would lose its significance as a status of equal membership in a shared political space (ibid: 141)

This critique is interesting and important, as it addresses some conceptual developments in the broader literature this chapter has examined, for example the acts of citizenship approach. We have seen that it is important to conceptualise citizenship not just as a mere legal status or set of rights, but also as a continuing social process. In focusing on the actual enactment of citizenship, Varsanyi (2006) points out; we can start to see where citizenship is fraying at the edges, and what that offers to those marginalised in and through this institution. Nevertheless, she argues that it is also important to discuss "...how reconceptualising citizenship as a process should eventually be tied back in with the discounted structures of formal and legal 
citizenship" (ibid: 238). Her point is that the process of critiquing citizenship should not only deconstruct it, but also come back to influence the structure of the formal and legal institution (ibid). However, in addition to this rather theoretical matter, she also points out those transnational and rescaled conceptions of urban citizenship face a political challenge:

Institutions of political membership below and beyond the nation-state are not yet potent enough (and may not be in the medium term) to provide adequate protection or alternative structures of belonging to those who are in a country in which they are living without authorization (ibid: 238)

With those challenges in mind, Varsanyi proposes the idea of citizenship as no longer bounded, in the sense of it assuming a priori existing community, but instead as grounded. This means a form of citizenship in which full membership is not dependent upon explicit (legal) consent to enter and remain, but rather on the reality of residence and presence in a place (2006: 239). To elaborate on this idea, she describes emerging examples of local 'citizenship' policies for undocumented residents in the United States. While the US Congress criminalised noncitizens voting in federal elections in 1996, a range of states have permitted noncitizens to vote in local and state-wide elections (ibid). This notion of localised citizenship policies is also of interest for the institutionally devolved context of the empirical puzzle - the Welsh Nation of Sanctuary - and what it would mean, in theory and practice, for the Welsh state to declare oneself as such.

To summarise the outcomes of this literature review of the broader critical migration and border studies and the more specific City of Sanctuary literature, we will now follow two last steps. First, I will reiterate the contextualisation of this research project in the scholarly landscape, and what $I$ consider its main empirical contribution to be to this landscape. The second and last step will then be to assess briefly what the City of Sanctuary literature itself considers to be potential avenues for new and further research, and how this research project contributes to this self-assessment of the field of critical migration and boarder studies.

What is then missing in the current COS literature? Where and how does this research project contribute to this intellectual landscape? After reviewing the wider critical migration literature, and altogether five journal articles (Darling 2010, Squire 2011, 
Squire and Bagelman 2012, Darling and Squire 2013, Bauder 2016), and four books on sanctuary movements (Bagelman 2016, Lippert and Rehaag et al. 2013, Lippert 2005, Darling and Bauder et al. 2019) it has become clear that there are two distinct new elements on the emprirical context to which this research can contribute. First, we have seen that the literature on sanctuary movements has predominantly focused on urban imaginaries. While there has been a recent example in the literature that theorised sanctuary imaginaries with regards to the 'global' (Bagelman 2019), before the Welsh Nation of Sanctuary, no attempt had been made by the CoS movement itself to conceptualise sanctuary imaginaries on another geographical scale. This had another effect on the empirical context of the existing research. The focus on sanctuary cities in Britain, most notably Sheffield in England (Darling 2010) and Glasgow in Scotland (Bagelman 2016), has focused on the conflicts with the exclusionary politics of the British government and their hostile environment. While Bagelman (2016) mentions the uncertainty about the degree to which immigration policies after arrival are devolved, and which remain under the jurisdiction of Westminster, less attention has been allocated to the discursive effects of this uncertainty. This research project is therefore the first within the specific literature on the City of Sanctuary movement in the UK that explicitly addresses those devolved and sub-national imaginaries.

In addition to the fact that the empirical context of this specific national sanctuary imaginary is new - in the sense that it was articulated in such a manner by a (devolved) state administration - this research also contributes to a theoretical question that has been formulated by contributors to the CoS literature itself for further research. For instance, Bauder concluded his review article of different international perspective on sanctuary cities in Europe and North America by considering that "national sociodemographic factors, such as the size, proportion, growth and origin of the migrant and refugee population, as well as historical circumstances and political traditions, are likely to shape the possibility of implementing sanctuary", and that further research could thus "explore which particular national circumstances enable or constrain various aspects of urban sanctuary" (2016: 182). In addressing the empirical example of the sub-national context of the imagined Welsh Nation of Sanctuary, this research project therefore initiates exactly this exploration. The next chapter, and theoretical framework of this thesis, will now engage with the metaphor of hospitality underpinning sanctuary imaginaries, and examine how this theoretical discussion can 
also help us to explore what national circumstances enable or constrain sanctuary cities. 


\section{Chapter 3. Theoretical framework: Hospitality, domopolitics, and nationalism}

The first chapter described how, in response to the 'crisis' of refugees arriving in Europe over the summer of 2015, the Welsh Government held an emergency summit and committed that Wales should play a pioneering role as the world's first 'Nation of Sanctuary'. The response of the Welsh government to the long summer of migration, announcing their intention to become a "Nation of Sanctuary" through building a culture of hospitality, constitutes a new and unique empirical case, considering the urban origins of the Sanctuary movement and that this was the first-time a (devolved) state adopted this slogan to frame their responses to the phenomenon of migration. This new case constitutes the empirical puzzle underpinning this research project: What might it mean, in theory and practice, for a territorial unit to declare itself as the first Nation of Sanctuary? In other words, what does the idea of a Nation of Sanctuary mean, and what does it do (discursively speaking)? From this main question, three more detailed sub-questions emerge: What are the theoretical and political imaginaries of sanctuary, national identity and hospitality at work in this context? What are their historical precedents? How do they relate to political responses to the 'crisis' across the UK and Europe?

The preceding chapter contextualised this empirical puzzle, investigating the critical literature on migration that engages with the broader Sanctuary Cities movement, from which two recurrent arguments emerged. First, that sanctuary is an ambiguous phenomenon, and that its manifestations often "represent a means of governing through the assertion of humanitarian intentsions" (Darling 2016: 185), that sanctuary can be a governmentalizing process (Bagelman 2013) and that often "acts of resistance become ensured in a larger governmentality that recaptures places of sanctuary" (DeGenova 2016: xi). And second, that the official framing of 'building a culture of hospitality' that underpinned the movement was part of this process. This framing is argued to be "a limiting approach that is bound to the rationalities of power that produce uneven relations between guest and host" (Darling and Squire 2013: 193). 
In examining what the idea of a 'Nation of Sanctuary' means and does, this thesis therefore also investigates the role of the metaphor of hospitality in discourses around the phenomenon of migration and its relation to the nation-state. It does so by exploring how policies and public reactions to the long summer of migration where expressed, justified and responded to. This third chapter sets out a theoretical framework which outlines how those framings around the metaphor of hospitality, as a powerful means of governing, can be accompanied by different contradictions and challenges for the sovereign nation-state. It suggests that, alongside this empirical puzzle, there is also a new theoretical puzzle to be explored. The critical literature on migration has successfully explored the various limits of hospitality as a framing response to the exclusionary politics of asylum. Hospitality has been understood as a limiting response because of its inherent power relations between subjects, and because it has been used recurrently as a means of governing. If we follow Michel Foucault's famous premise that where there is power, there is resistance, the theoretical puzzle appears: To what extent can these hospitable discourses become a problem for the sovereign nation-state, for example as a discourse for counter-conducts? Introducing this theoretical puzzle is the task of this chapter.

This chapter has five sections: the first four introduce the concepts introduced in the literature review, and which will be of central importance for the analysis in this thesis: humanitarian government, hospitality, domopolitics and nationalism. The first theoretical concept introduced is Didier Fassin's (2012) notion of humanitarian government in combining elements of care and control. The second concept explored is that of hospitality, or the metaphor of hospitality as it used to describe the relation between states and the phenomenon of migration. The second section introduces Jacques Derrida's conceptualisation of hospitality as ethics (2000) between imperatives of the conditional and unconditional. This is followed by an account that conceptualises hospitality with regards to spatiality and home as a matter of "ethics, power and space" (Bulley 2017). Considering the cultural significance and hegemonic dominance of framing the immigrant as guest, and the state as host, introducing these theories is essential to explain why the empirical example under examination exists. The third concept introduced is domopolitics, which has been conceptualised by William Walters (2004) as the governance of the nation as a home. It has been used by Jonathan Darling (2013) to show how the language of hospitality can often enable the 
governmental ordering of responses to asylum, drawing on different examples from the context of the British asylum regime. This concept is important because it shows how the discourses of hospitality become a means of governing.

But who is governing through these hospitable discourses? Considering that it is the sovereign nation-state that drives the exclusionary politics of asylum, the fourth section will examine contemporary debates on the nation, nationhood and nationalism (Butler and Spivak 2010, Closs Stephens 2013). After having become familiar with those theories on the nation-state, the fourth section will then examine in more detail the interrelation between discourses of hospitality and the nation, and show how that opens a central question: Who can offer hospitality? The literature asked this question regarding how the offer of hospitality entrenches certain relations of power, ownership and sovereignty (Gibson et al 2007) between the migrant on the one hand, and the sovereign nation-state on the other. I argue that this consideration also paves the way for a theoretical puzzle. How does the metaphor of hospitality assist in the construction of discursive relations not just between the sovereign nation-state and migrants, but between different nation-states? The fifth section will summarise where the literature with regards to these concepts stands. It argues that the grounding of this research project in Wales, and the focus on the Welsh 'Nation of Sanctuary' phenomenon, not only constitutes a new empirical case, but also provides new theoretical ways of revisiting the metaphor of hospitality. While the literature has successfully explored the limits of hospitality as a response to the sovereign politics of asylum, this project also focuses on the potentially conflicting discourses between states regarding the expectations of what it means to be a 'good' (Amin 2006) host to refugees and asylum seekers.

\subsection{The emergence of sanctuary: Humanitarian reason and government}

The politics of sanctuary, and its practices and discourses, has been argued to be an ambiguous phenomenon, representing a "means of governing" (Darling 2013). Following from Foucault's (2004), conceptualisation of the term "governmentality" in his lectures, published in Security, Territory, Population an interdisciplinary field of governmentality studies emerged. This has strongly influenced the literature on migration, borders and mobility controls (Bigo 2002, Huysmans 2006, Vaughan- 
Williams 2015). Building on this literature, engaging with Foucault's development of the idea, William Walters (2012) traced in detail three emphases that Foucault adopted when talking of government. Two of those are of import for this theoretical framework and the subsequent discussion on hospitality.

The first important aspect is that governmentality is understood to be a project which examines the exercise of power in terms of what Foucault (2004) calls the "conduct of conducts", and that government is a widespread phenomenon which is not restricted to the hierarchical sphere of the state, but as something that takes place whenever individual subjects or groups are attempting to shape their own conduct or the conduct of others (Walters 2012: 11). While governmentality concerns itself with a range of power relations, it is important that it addresses something that is neither absolute domination nor a realm of equal negotiation between different liberties, but between two poles of 'strategic relations' and 'states of domination' (Walters 2012: 11).

The second aspect is that, even though this conceptualisation of governmentality can involve a wide range of different social contexts, Foucault (2004) discussed it in specific reference to the "genealogy of the modern state". Here, he is attempting to understand the state not as a simple ensemble of institutions or an invariant system, but rather how, through practices, techniques and discourses, something called 'the state' became thinkable and meaningful in the first place (Walters 2012). It is in this sense that governmentality can a be understood as the exploration of "the conditions of possibility of the modern state” (ibid:12). For Foucault (2007 in Walters 2012: 38), the "governmentalization of the state" meant that the modern state not only rules through mechanisms of discipline over territories or subjects, but also provides frameworks for conducting the life of its populations (Walters 2012: 38). While his concept of discipline drew more attention to how power is exercised on bodies, the conceptualisation of government with its attention on the "conduct of conducts" (Foucault 2004) as the techniques that underpin attempts to govern the self and others, emphasises also indirect dimensions, where elements of freedom, conscience and action play a role (Walters 2012: 38).

The third aspect is for Walters that governmentality always presupposes a degree of freedom, on the side of those who govern, and on the side of those whose conduct is the target of governance. This means that other ways of conducting oneself or others 
always remain possible (ibid:12). Considering the defining feature of hostile and negative emotions such as fear, anxiety or hate in discourses of migration, refugees and asylum seekers, the critical migration and security studies literature has focused on the 'securitization' of migration (see Bigo 2002, Huysmans 2006). Bigo (2002) outlined how the politics of internal and transnational security, with regards to migration, mobilises fear and unease to legitimise itself However, besides this politics of fear (Huysmans 2006) and politics of unease (Bigo 2002), which constitutes the more dominant technique of governing migrants, other migration and border scholars have started to investigate the rise of the humanitarian and care dimensions of contemporary asylum and border control regimes (see Vaughan-Williams 2015, Walters 2011). Fassin (2012: 148) argued that states have two means of resolving the tension between the discrediting of asylum and the inevitability of migration. These means are: the politics of repression, aimed at deterring migrants; and the politics of compassion, which needs to render the "undesirables acceptable".

Fassin (2012) uses the term "humanitarian government" to conceptualise the governmental deployment of moral sentiments, which he understands as emotions that direct attention to the suffering of others. Compassion comprises two elements: empathy with the suffering of others, and a desire to alleviate that suffering (Waite et al 2014 in Sirriyeh 2018: 28). His argument is that the vocabulary of suffering, compassion, and assistance which underpins moral sentiments often legitimizes dominant or hegemonic discourses and its practices, which are focused on the governance of the disadvantaged or dominated (Fassin 2012: 2). This approach understands humanitarian government therefore as a set of procedures and actions which are established and conducted to manage, regulate and support the existence of human beings (2012).

Moreover, Fassin conceptualises humanitarian reason as a moral economy, which is centred on the notion that an 'us' will 'help' and 'save' an 'other' 'them' (VaughanWilliams 2015: 40). This means for him that humanitarianism has become a language that connects values and affects, as well as defining and offering justifications for, discourses and practices of governing human beings (Fassin 2012: 2) While humanitarianism does often operate in such an ideological manner for the benefit of the powerful classes, it is still important to answer the question of why social issues of inequality are talked about in terms of suffering and compassion, rather than interest 
or justice, and how certain actions are thus legitimized by declaring them as humanitarian (ibid: 3).

Fassin moves the attention to an important paradox. On the one hand, moral sentiments often focus on the poor, the vulnerable and the precarious, which means that the politics of compassion is also a politics of inequality (2012: 3). On the other hand, what makes moral sentiments possible, is a recognition of others as fellow human beings. The politics of compassion is thus also a politics of solidarity (ibid). Therefore, he summarizes that: "This tension between inequality and solidarity, between a relation of domination and a relation of assistance, is constitutive of all humanitarian government" (ibid). Moreover, this problem is not just ethical but social and political. It is not the condescension of the subject giving aid or assistance, but the conditions of the social relation between the two parties that make compassion a moral sentiment which is used to govern (ibid). The political asymmetry emerges because compassion presupposes a relation of inequality. When compassion is exercised in the public realm, it is, per Fassin, directed from above to below. For Fassin (ibid: 4),, humanitarian reason governs precarious lives, which humanitarian government also "brings into existence by protecting and revealing them".

The issue of humanitarian reason is therefore sociological, political, contingent and historical. Or, as Edkins (2003 in Bulley 2017: 44) has pointed out: "Humanitarianism is not a timeless truth but an ideology that has had particular forms at different times in the contemporary world". Other theorists have also argued that humanitarianism often constitutes a way of both saving and technocratically governing the conduct of the disadvantaged and dominated, like in the context of asylum and border control regimes (see Vaughan-Williams 2015, Walters 2011). The ethos of humanitarianism is often an ethos of "care and control" (Malkki 1995). This focus on the effects of humanitarian reason brings Fassin to argue that humanitarianism and securitization, or compassion and repression, are not necessarily in contradiction with each other. They are often intertwined as part of the same terrains and logics of government (Fassin 2012). This intertwinement of opposite concepts is important for the broader examination of the Welsh Nation of Sanctuary, but specifically for the next concept that underpins its self-declared aim: building a culture of hospitality. The interrelation between these concepts has been examined by Mireille Rosello in Postcolonial Hospitality (2001), where she shows how the metaphor and laws of hospitality "form 
a significant part of national identity" (ibid: 6). Before this thesis proceeds to examining this interrelation, the next section will therefore engage with the theoretical concept of hospitality itself, and the intertwinement with its opposite: hostility - or more precisely, the application of hostile emotions by the sovereign nation-state in securitising refugees and asylum seekers.

\subsection{The Derridean notion of hospitality: Between the conditional and the unconditional}

What is the relation between the practice of hospitality and humanitarian government? To examine this question, it is necessary to introduce theoretical conceptualisations of hospitality. The first engagement that is of central importance for the humanitarianismhospitality nexus is Jacques Derrida's understanding of hospitality (2000) as a practice that is structured by two contradictory imperatives which reflect conditional and unconditional poles. Hospitality is for him a site of constant negotiation between imperatives of the conditional and unconditional (2000 in Darling 2013). Starting from the assumption that practices of hospitality are always torn between different degrees of closure and openness, this opens the divide between what he calls the law of unconditional and unrestricted hospitality, and the conditioning and restricting laws (in the plural) of hospitality (Derrida and Dufourmantelle 2000: 77). Derrida (1999 in Rosello 2001) draws a famous distinction between an ethics of (infinite) hospitality and a politics of (finite) hospitality. However, it is important to emphasise that this is not a proposed choice between ethics and politics. Indeed, while these regimes of hospitality - the singular, universal law of unconditional hospitality and the conditional, plural laws of hospitality - are distinct and irreducible, they cannot be separated as they resemble and require on another (Kakoliris 2015).

The first important argument is that without the law of unconditional hospitality underpinning them, the political laws of hospitality would cease to be just that: they would be removed from the realm of hospitality altogether and turn into pragmatic, political demands of the moment. For Kakoliris (2015: 148), to keep the plural laws of hospitality in progressive movement and keep them from collapsing, political and moral action needs to be based on a "moment of universality that exceeds the pragmatic demands of a certain context". Nevertheless, the conditions which are thus 
imposed - the political laws of hospitality - are problematic. This is because, as conditions on the unconditional, they will always be annulments of the law of unconditional hospitality that made them possible in the first place. They threaten to remove themselves from the domain of hospitality altogether (Bulley 2017: 6). However, without these conditional laws, the law of unconditional hospitality would remain abstract and ineffective (Kakoliris 2015). But conditional laws of hospitality, while establishing rights to and duties in hospitality, are also placing political, juridical and moral terms and conditions on hospitable practice (ibid: 146). Therefore, the practices of hospitality are always forced to negotiate and renegotiate between the law of unconditional hospitality and the conditional laws of hospitality (Bulley 2017). Kakoliris (2015: 148) explains how this "pervertability" of the law of hospitality emerges from the inseparability between hospitality and power: there cannot be hospitality without the sovereignty of the person offering the invitation into their home. The exercise of sovereignty through deciding who to offer the right to hospitality to shows that there is an element of hostility in hospitality. This hostile element is an aporia which Derrida (2000: 14) describes in the following manner:

It does not seem to me that I am able to open up or offer hospitality, however generous, even in order to be generous, without reaffirming: this is mine, I am at home, you are welcome in my home, without any implication of 'make yourself at home' but on the condition that you observe the rules of hospitality by respecting the being-at-home of my home, the being-itself of what I am. There is almost an axiom of selflimitation or self-contradiction in the law of hospitality

Without the possession of the home, there would be no right to and duties in hospitality, but rather indeterminate being and space. Without this sovereign mastery, the host would not be a host and could offer nothing to the guest by inviting them into their home. A politics of hospitality that is unconditional would be impossible to organise into a polity. This is because such an infinite openness would destroy the host as host: the master of the home that makes offering hospitality initially possible (Derrida 2002 in Bulley 2017). Throughout his theoretical engagements with hospitality, Derrida traces the concept to the question of the state. He equates the home with the state to talk about the relationship between the immigrant and the state, modelled on the relationship between guest and host (Derrida and Dufourmantelle 2000 in Hill 2016). The power that is exercised through hospitable practice is 
understood as a sovereign relation based on the possession of the home. More importantly, it is about the controlling of the threshold and the sovereign decision to include or exclude (Derrida 2000: 14).

Consequently, the second concept that is of importance for exploring the humanitarianism-hospitality nexus is Dan Bulley's (2017) understanding of hospitality as a spatial relational practice with affective dimensions. This focus on spatiality makes it possible to investigate what powers are exercised in the concrete practices of hospitality once the threshold between inside and outside is crossed. The first point is that hospitality is a spatial practice. To be practiced, it needs an inside and an outside, because it requires the existence and the crossing of borders, boundaries and thresholds (Still 2010). This might appear problematic at first, because dominant conceptualisations of geographical place often associate it with stasis, security and "apparently comforting bounded enclosure" (Massey 1994: 168). This conceptualisation, used in various instances ranging from different kinds of nationalisms to the neoliberal marketing of places, attempts to create fixed, static and singular identities for places. In so doing, it interprets them as bounded and enclosed entities which are understood in their opposition to 'the other' on the outside (Massey 1994). In challenging the dominant imaginations of spaces as bounded entities, Doreen Massey (2005) proposes the concept of places as "constellations of processes rather than things".

Building on this definition, Bulley (2017) argues that hospitality is a means of organising space. It turns space from a sphere of coexistence into something determined as it regulates, filters and controls trajectories as well as contacts. It is also a means of generating or producing space, in the sense that that it brings particular spaces into being as 'homes' (ibid: 4). Those practices of hospitality make spaces this rather than that, mine rather than yours, and create places of belonging and nonbelonging. These places need to be managed and their internal and external boundaries and rules need to be enforced (ibid: 4). The second argument is that what gives those determined spaces and boundaries their meaning is their affective dimension (ibid: 9). This dimension constitutes the lines between emotions of belonging and nonbelonging: the "space produced by hospitality is the home, along with its affective sense of being-at-home-with-oneself" (jibid: 9). However, in understanding those spaces as the spatial and affective articulation of an ethos, it is important to refrain 
from essentialising, depoliticising and romanticising home(s) as safe and homogenous places of natural belonging. Such an understanding of the identity of places, including of places as homes which are imagined as secure, safe and stable entities, is what requires them to have boundaries and enclosures in the first place. More importantly, it requires individuals to frame their identity through the negative opposition with 'the Other' who is associated with the outside beyond the boundaries (Massey 1994: 169).

But the home is neither politically neutral, nor the location of a stable ethos - a safe inside that stands in conceptual opposition to a chaotic outside and which is contaminated by movement and difference (Ahmed 2000 in Bulley 2017). For Massey (1994), the identity of places does not emerge from internalized history, but through its specific interaction with what is considered the outside. It is through this combination that debates about place and belonging, place and home, are linking up to more general discussions about identity (ibid: 169). The boundaries of the home are simultaneously the product and producer of continuous contestation (ibid). The home is always a product of specific inclusions and exclusions, it is always in negotiation. This process of political negotiation is hospitality, it is the process through which the subject and ethos are produced, and through which their boundaries and openings are managed and controlled (Bulley 2017: 9).

This process of negotiation is necessarily 'multi-scalar' (Bulley 2017). This notion is important for this research context. As we have seen, the dominant perception of hospitality is that it is a sovereign practice, including the possession of the home. Bulley adds that the practices of hospitality and hostility are "practices of relation" (2017: 10). This means that hospitality is always co-produced, and that host and guest are never stable subject positions or identities. The host emerges in relation to, and in confrontation with, the expected and invited, or unexpected and therefore uninvited guest (Bulley 2017). Moving from Derrida's engagement with hospitality as the moment on the threshold towards the concrete practices of constituting a home, Bulley is asking how power is exercised to "manage and control the space of the home and its affective relations of belonging and non-belonging" (ibid: 14). Derrida's focus on the sovereign decision between welcome and rejection, Bulley argues, limits the analysis of the relations between ethics and power to what he calls "the ever-deconstructing sovereign gift" (ibid). He argues for a move beyond the focus on the moment of sovereign decision towards the technologies, tactics, rules and laws of welcome and 
control. This is to understand them also as constitutive of hospitality. One should thus explore how hospitality is managed and controlled (ibid). Shifting the analytical focus when studying hospitality discourses away from the sovereign moment of inclusion or exclusion towards the tactics of managing hospitality is thus an appropriate underpinning to analyse the discursive use of the metaphor of hospitality. The appropriateness of this shift of theoretical focus becomes apparent further when one considers that the devolved nations in the UK are not sovereign in a legalistic sense, but still 'host' refugees and asylum seekers as part of the dispersal system or other resettlement programmes. They also use the metaphor for framing the dispersal. Therefore, what is interesting is not only the threshold and the sovereign decision, but also the practices and tactics of hospitality once the threshold is crossed, once migrants have been dispersed throughout the UK, including Scotland and Wales.

\subsection{The governmental deployment of hospitality: Domopolitics}

But how is hospitality managed and controlled? The first part of the theoretical framework set out in this chapter outlined how the deployment of moral sentiments has become a form of governing. Fassin (2012) identified it as 'humanitarian government' which operates through a range of techniques and tactics, including hospitable practices and discourses. One important tactic is the governing of the nation as a threatened home. This has been conceptualised by William Walters as domopolitics (2004). The concept has been used by Jonathan Darling (2013) to show how the language of hospitality can often enable the governmental ordering of responses to asylum. Foucauldian genealogies of government have traced the emergence of modern political economy back to the Greek notion of oikos, the imaginary of the household. For Walters, while modern political economy still echoes the project of governance in the image of the household, he argues that we are now in the presence of domopolitics: the government of the state, and other political spaces, as a home (Walters 2004: 241). What is important for Walters is the restructuring of the relation between citizenship, territory and state to justify and rationalise techniques and tactics of security in the name of a particular conception of home: the home as threatened from the outside. In the context of globalising neoliberalism, this conception of home offers renewed affinities with imaginaries of safe and bounded places: “...the home as hearth, a refuge or a sanctuary in a heartless world; the home 
as our place, where we belong naturally, and where, by definition, others do not..." (ibid).

This idea of home affects how one thinks of the encounter with externality, and subsequently, the notion of hospitality. If we belong naturally to our homes, and others do not, it follows that we may invite guests into our home - but they come at our invitation and do not stay indefinitely - while others are uninvited (Walters 2004: 241). What is important for this tactic is the image of the home as safe, secure, intimate and trusting place of reassuring boundedness. Homes need to be secured, as their contents are naturally 'our' property, which are envied from others from the outside (Walters 2004). These affinities create notions of 'us' and 'them', and domopolitics embodies a tactic that juxtaposes comforting formulations of community, trust and citizenship with an illegalised, dangerous and chaotic outside (Walters 2004). Subsequently, domopolitics is understood to be the governance and construction of the nation as a domesticated, secured and bounded space. This is understood to be a homely space, which needs to be secured through practices of filtering, classification, distinction and surveillance (Walters 2004 in Darling 2013).

In his article, Moral urbanism, asylum and the politics of critique (2013), Darling explores how the domopolitical logics of distinction, associated with the sovereign nation-state, presuppose and intersect with hospitable narratives and imaginaries on an urban level, through either official local government accounts or urban sanctuary movements. For him, the intersection with the logic of distinction "enacts and moralises domopolitics" (Darling 2013: 1786). How is this done? As we have seen, for Derrida, the concept of hospitality constitutes a site of constant negotiation between imperatives of the conditional and the unconditional, and distinguishes between the invited guest and unexpected (and uninvited) stranger (2002). If one traces the genealogies of humanitarian governmentalities exercised by the British state, what emerges is that this framing runs through their usage of hospitality metaphors. Indeed, the Derridean (2000) distinction between the laws of limited, conditional hospitality and the law of unconditional hospitality has been used to critically engage with the way nation-states construct responses to the social phenomenon of migration (see Ahmed 2004, Rosello 2001). 
For example, Gibson (2007) investigated the use and mobilization of the metaphor of hospitality in debates on migration and asylum in Britain, and their effects on imagining British national identities. In her case, the analytical context is the framing of responses to migration under the Labour administration at the beginning of this century. Here, the government was attempting to construct a British "multiculturalist nationalism" (Fortier 2005 in Gibson 2007: 161) around the imagined national ideal of a welcoming, hospitable, generous and tolerant nation (Ahmed 2004). The idea that it is "a matter of national pride that persecuted people have been able to find refuge in this country" (Pirouet 2001) can be found in media and public imaginations (see Darling 2013), and the emphasis of hospitable gestures in different historical contexts made the pride in British hospitality part of imagining a national identity (Gibson 2007: 161). However, while New Labour was framing those imaginaries of a multiculturalist nationalism, it was also contributing to a substantial moral panic over asylum. It did this by framing the figure of the asylum seeker as an object of fear, unease and distrust rather than compassion and hospitality. The Labour administration, while constructing a multiculturalist nationalism, also passed through Parliament a range of punitive and restricting measures on the immigration and asylum system. This ranged from the Immigration and Asylum Act (1998) to the publication of the Home Office White Paper Secure Border, Safe Haven (2000). The phrase "the abuse of hospitality" has been increasingly used since Labour came to power. In fact, it was used so much that it became one of the 'emotive' phrases commented upon in a report investigating the representation of asylum seekers in the British press (ICAR 2004 in Gibson 2007).

This is the political and historical context in which Darling (2013) explores how the language of hospitality enabled the domopolitical securitisation of asylum. His emprirical focus is on the Gateway Protection Programme, which was announced with the Secure Borders, Safe Haven document (Home Office: 2005). This took place two years after the establishment of the national dispersal system for all other arriving refugees. The Gateway programme was set up to "create a legal gateway for the most vulnerable refugees to enter the UK" (ibid: 2005). The Home Office asserted in their announcement that the programme would "offer a legal route for genuinely deserving cases", while stopping the so-called "abuse of the system by those who are not genuine refugees" (2005 in Darling 2013: 1794). 
This indicates that the domopolitical logic of the British asylum regime was based on the production of different subjects: the 'genuine' and deserving' vs. the 'undeserving' and bogus' asylum seeker (Darling 2013). Darling argued that this presentation was framed to distance this specific resettlement from the national dispersal system and the claims of other asylum seekers, legitimising the domopolitical classification and securitization of all other asylum claims (2013). Thus, hospitality is used to create a moral legitimacy for domopolitical practice. The affective and discursive governance of the nation as a home, and the necessary rejection of unwanted strangers, is here morally justified by a record of hospitality to a 'worthy' few. More importantly, this not only connects the right to decide who enters certain spaces with the image of the responsible citizen, but it moralises it as a responsible enactment of a set of obligations to some noncitizens (Darling 2013: 1796).

Moreover, Sales argues that the national pride in Britain's perceived hospitality is strengthened through the distinction between the 'genuine, deserving' refugees and the 'bogus, undeserving, abusive asylum seekers and economic migrants' (2002 in Gibson 2007: 162). In maintaining these binaries between the deserving and undeserving, Ahmed (2004) explains, Britain imagines itself as generous in welcoming some people. The nation can be imagined as hospitable because it allows the 'genuine' refugees to stay, while defining some as not genuine to place limits on their own hospitality. This point is important, it shows that while New Labour's legislation attempted to define the deserving and undeserving, genuine and non-genuine other in limiting the condition of Britain's hospitableness, such framing of legislation also works to define the national self-image as hospitable, generous and tolerant (Gibson 2007: 165).

But while more often migrants are framed as "abusing the hospitality" of the nation, sometimes the state is being framed as draconian and not fulfilling its duty of hospitality (Pirouet 2001). Campaigners for the rights of migrants have in the past used discourses of shame in 'crimes against hospitality' (Derrida 1997 in Still 2010). The publication of the picture of Aylan Kurdi and the reaction from the UK government under David Cameron to the long summer of migration come to mind. But this politics of shaming the British government on its record of supporting refugees and asylum seekers has here been mainly driven by civil society campaigners. If the discourses of hospitality have been so influential in constructing national identities through an 
othering of migrants as 'guests', have they affected the construction of discursive relationships between different nation-states? Beyond the question of who is framed as a host and who as a guest, another question appears: Who (in the sense of which nation-state) is considered a legitimate host to refugees and asylum seekers?

\subsection{Who is the 'host'? ... Debates on nations and nationalism}

This research project started by asking what a Nation of Sanctuary means and what it does. To address this discursive question, the literature review has engaged with sanctuary cities. The theoretical framework has examined the concepts of hospitality and domopolitics to investigate the moral politics of the exclusionary politics of asylum. But in considering the full empirical context of this research project, the imaginary of Wales as a Nation of Sanctuary, there is one more concept that needs to be explored: the notions of the nation, and of nationalism. What is the nation, and what are national imaginaries? Angharad Closs Stephens starts her critical investigation of the existing scholarship by pointing out that: "The idea that a nation forms an 'imagined community' continues to dominate critical entry points to the study of nations and nationalism" (2013: 15). This conceptualisation was first developed by Benedict Anderson in his book Imagined Communities (1991), where he argues that the nation "is an imagined political community - and imagined as both inherently limited and sovereign" (ibid: 6). It is imagined, because, while most members of even the smallest nations will never know or even meet most of their fellow members, in the minds of most of them "lives the image of their communion" (ibid: 6). It is imagined to be limited and sovereign because, even the largest nations are thought to require finite territorial boundaries, beyond which other nations exist (1991). And it is imagined as a community, because "regardless of the actual inequality and exploitation that may prevail in each, the nation is always conceived as a deep, horizontal comradeship" (ibid: 7).

Katherine Verdery argues, in Mapping the Nation (1996), that the nation is also a potent symbol of, and basis for, social classification. This means, for her, that nationalism is a "homogenizing, differentiating or classifying discourse" (ibid: 227). But she sees the nation also as a symbol, and therefore advises scholars to treat "any given nationalism as having multiple meanings, offered as alternatives and competed 
over by different groups manoeuvring to capture the symbol's definition and its legitimising effects" (ibid: 228). From this conceptual background, Angharad Closs Stephens, in her book The Persistence of Nationalism (2013), moves beyond the question of imagination. There, she argues that more is at stake than revealing the 'constructed' nature of national identities. This account situates nationalism as part of a modern geopolitical imaginary, which relies on the assumption of state sovereignty, and on the idea of political community as spatially bounded and orderable on a continues scale (2013: 5). She argues that the underpinning of the social constructivist approach around the 'imagined' nation remains often within familiar debates about the nation as old or new, real or invented, good or bad, which casts attention away from questions about the "force and politics of nationalism" (Closs Stephens 2013: 6).

In making this argument, she draws on two central theorists critiquing nationalist imaginaries. In his essay collection, Fear of Small Numbers (2006), Arjen Appadurai criticises the dominant distinction between an 'ethnic' (regressive) and a 'civic' (progressive) nationalism. He argues that there is rather an "inherent ethnicist tendency in all ideologies of nationalism" (2006: 4). Furthermore, Etienne Balibar argues in Race, Nation, Class: Ambiguous Identities (1991) that the question of the nation-form is not only one of invention, but also one of institution. In asking: "What makes the nation a 'community'?", he dispenses with the antithesis between real and imagined communities. He argues that "under certain conditions, only imaginary communities are real" (ibid: 93). These imaginaries of the nation need to become one "... of a community which recognizes itself in advance in the institution of the state, which recognizes the state as 'its own' in opposition to other states" (ibid). The fundamental problem, Balibar continues to argue, is therefore to "produce the people", as it is about creating "the effect of unity by virtue of which the people will appear" (ibid: 94). For Closs Stephens, these theoretical interventions are important for two reasons. First, because they show that all nationalisms must produce such a sense of unity. And second, because in doing so these accounts move beyond mere imagination towards the politics of this process. This describes the fact that the idea of a nation not only has to be invented, but also must be imposed (2013: 7).

But nationalist imaginaries often extend beyond self-conscious 'nationalistic' positions, and thus often form the terms of critique of nationalist thought (Closs Stephens 2013). Therefore, Closs Stephens asks about the relationship between 
critique and co-option, and "what forms a critical reworking of the nation and what risks reproducing another figure of nationalism" (2013: 86). These questions also underpinned a discussion between critical theorists Judith Butler and Gayatri Chakravorty Spivak, which was published under the title Who sings the Nation-State? (2010). The question emerged from an example that Butler had talked about in their debate on citizenship and the nation-state: in 2006, during a demonstration of illegalised residents in Los Angeles advocating for their right to residency, the US national anthem was sung in Spanish, leading to the emergence of the "nuestro hymno" (Butler and Spivak 2010: 58). This act of signing introduced for Butler the interesting questions of 'the plurality of the nation, of the 'we' and 'our': to whom does this anthem belong?" (Butler and Spivak 2010: 58), and to what extent this "does something to our notion of the nation" (2010: 59), in the sense of how non-nationalist or counter-nationalist modes of belonging would look like. Nevertheless, this is not an affirmation:

Of course, it is possible to be suspicious of all of this. After all, is it not simply the expression of a new nationalism? Is it a suspect nationalism, or does it actually fracture the 'we' in such a way that no single nationalism could take hold on the basis of that fracture? It's an open question to which I don't know the answer (Butler in Butler and Spivak 2010: 60-61)

But Butler still entertains the possibility that: "there can be no radical politics of change without performative contradiction" (2010: 66). But can there be a reworking of the nation-form without the language and imaginaries of 'us' and 'them'? Closs Stephens suggests that this is doubtful when she problematises how nationalism often form the terms of critique of nationalist thought (2013). This is not a new problem. There exist numerous examples of national movements which are attempting to resist the homogenising force of larger nation-states or global capital by demanding independence for their own nations. But the problem and the solution are still being understood in statist terms (Closs- Stephens 2013: 7). Michael Billig conceptualised 'banal nationalism' (1995) to describe how ideological habits reproduce the idea of the nation-state. Nationalism, rather than being the exception, is indicated daily in the life of the inhabitants of the state. Banal does not mean benign, but rather that there is a continual reminding or 'flagging' of nationhood. This "provides the continuous background for political discourse, for cultural products, and even for the structuring 
of newspapers" (Billig 1995: 8). These theoretical assessments on the persistence of nationalism are influential in the structure of the following empirical chapters. Indeed, Chapter 5 will begin the analysis of the assembled material with a focus on newspaper accounts and their role in emerging Welsh national imaginaries on to the new dispersal system for asylum seekers.

But where is the interrelation between hospitality and the nation-state? How is it important for examining the Welsh Nation of Sanctuary? Rosello (2001: 8) emphasised on this matter the following: "the parallels between the immigrant and the guest, and between the state and the host, are culturally significant, and they have consequences that will tend to remain unexplored as long as we do not question their invisibility and hegemonic transparency". Indeed, in contemporary debates on migration and nationalism, one of the arguments usually levelled against the rhetoric of hospitality is that it enables fantasies of control in the power to host and welcome (Gibson and Molz 2007: 9). However, while Rosello (2001) focuses on deconstructing the hegemonic assumptions underpinning the metaphor of hospitality, she does argue that this framing can also create disruptions and unplanned dynamics. For example: "when the host does not give what the rule expects him or her to give what, when the guest is mistreated rather than protected, or when the guest abuses the host rather than being grateful" (ibid 2001: viii). However, this rationale brings one still back to the practice of hospitality as being associated with only the sovereign nation-state. This is in the Derridean sense that only entities with full sovereign mastery over the household can practice hospitality, either in public or private for that matter. Rosello (2001: 1718) describes this underpinning logic with an appropriate example:

Being at home is being where you can not only eat and drink but also invite someone to eat, to drink, to chat. Being at home is being where you can be the host, where you can offer hospitality

The previous three section on domopolitics, hospitality and nationalism have shown that national discourses of hospitality often frame the sovereign nation-state as a 'home' that is open to some foreigners: home idealized as a space of hospitality (Dikec 2002). But for Gibson and Molz (2007), this opens another question: "Who is able to offer hospitality, and how does the offer of hospitality entrench certain relations of power, ownership and sovereignty? (ibid: 11). The critical literature has asked this 
question mainly with regards to how the offer of hospitality entrenches certain relations of power, ownership and sovereignty between the othered migrant on the one hand, and the sovereign nation-state on the other. The dominant analysis of hospitality as a metaphor for the relation between states and migrants is binary. But what if the United Kingdom is not the unified and coherent host state it is assumed to be? Following the argument that being home means being able to host (Rosello 2001), would that mean that the devolved territories of Wales and Scotland cannot be hosts in their 'own' homes? Are they therefore not really 'at home'? Interrogating this theoretical question and its subsequent political implications is important. This is because so far most of the literature on migration discourses which engaged with the metaphor of hospitality focused on the sovereign nation-state (see Rosello 2001, Gibson et.al 2007). This thesis therefore focuses on the devolved nation-state, and the image of the Nation of Sanctuary to examine the multi-scalar nature of hospitality as home-making. It also carves out the contradictions that accompany discourses of hospitality, rather than returning to the analysis of the "ever-deconstructing sovereign gift” (Bulley 2017).

\subsection{The Welsh "Nation of Sanctuary" as an empirical and theoretical puzzle}

Before attending the international relations conference in Barcelona, I had travelled to the city a couple of days earlier. I came across some things that gave me an idea for the research project. First, it was just before the referendum for Catalan independence, and the streets were filled with protesters covered in the national flags. This picture would not change over the following days - rather, there were more people in the streets, it seemed. I had originally started walking around the neighbourhoods to find out a bit more about Barcelona as a solidarity city supporting refugees and asylum seekers, but, over the next few days, when I observed an assemblage of Catalan independence supporters in the city centre, I saw some of them carrying signs saying: 'Refugees welcome' (Fieldnotes, September 2017)

These fieldnotes were written after I had come back from a conference Barcelona, returning to Scotland to keep working on my research project. It had begun one year prior, and was about the politics of hospitality for refugees and asylum seekers in Swansea as a City of Sanctuary. One of the things that had interested me from the beginning was the commitment of the Welsh Government from September 2015 that 
Wales should become a Nation of Sanctuary through building a culture of hospitality. With those impressions from Barcelona, I wondered: What was this relation between a call for national independence and the support for refugees and asylum seekers about? This interest was reiterated when I was walking alongside a march advocating for Scottish independence in Bannockburn at $23^{\text {rd }}$ June 2018, where banners reading 'Refugees welcome' and 'Hands off EU workers and migrants' abounded, and lastly, when I encountered the famous 'Refugees welcome' symbol on stickers that were stuck to objects in public places in the centre of Swansea, written in the Welsh language as: Croeso I Ffoaduriaid.

The preceding chapter has outlined that the response of the devolved Welsh government to the long summer of migration, in announcing their intention to become a "Nation of Sanctuary", constitutes a new phenomenon. This is because of the urban origins of the Sanctuary movement and because this was the first-time a (devolved) state government adopted this slogan to frame their response to the 'crisis'. In the remaining part of this theoretical framework, I argue that the Welsh response and the framing of the 'Nation of Sanctuary' also created a theoretical shift for the concept of hospitality. This is one that the literature on the discourses of migration and the metaphor hospitality has not considered in full.

The critical literature on migration discourse has tended to focus, as we have seen, on exploring the limits of hospitality as framing responses to the exclusionary politics of asylum. It has mainly conceptualised it as a "limiting approach that is bound to the rationalities of power that produce uneven relations between guest and host" (Darling 2013). It is therefore bound to sovereign practices (Derrida 2000) and discourses that reinforce distinctions between deserving and undeserving to securitise migrants. But there are additional questions to be asked. The sovereign nation-state, for example the United Kingdom, constructs and frames itself as a 'firm but hospitable nation', a generous host to some 'genuine' refugees. It does this to categorise, classify and securitise the larger number of arriving migrants. But it nevertheless creates imaginaries of itself as a host to some, however small that number may be, which carries with it obligations, or moral duties of hospitality, towards some of those who are framed as guests. That means the first question is: What expectations does the sovereign nation-state need to manage with regards to being a host, and how does it do so? And secondly: what forms of counter-conduct can emerge from managing those 
expectations? How does the need of the sovereign nation-state to manage those expectations create problems for the sovereign?

Indeed, after all, these expectations of what it means to be host can be challenged: either from migrants who are othered as guests in regards to the state and refuse to accept this framing, or from other potential hosts. The literature has understood hospitality as a practice of creating self and other, and thus a form of governing through constructing a binary opposition between the sovereign nation-state as the self-host, and the migrant as the guest-other. To deconstruct the hegemonic transparency of the metaphor of hospitality with regards to the exclusionary politics of asylum is of course central. But one should also pay attention to potential counter-conducts that can emerge from hospitable framings and power relations. In investigating the metaphor of hospitality through a different lens, one could move away from the Derridean moment of sovereign inclusion or exclusion. Instead, one could move towards the practices of managing the expectations of what it means to be a host to the other. This focus on the concrete practices that the sovereign needs to engage in, to be perceived as sovereign, as the generous and hostable host, might de-essentialise sovereignty as determined and coherent. It would also move the focus towards how it is held in place. This is theoretically interesting, because the literature has tended to understand hospitality as a sovereign practice, and analysed the tropes and metaphors through that lens. What does it mean, in theory and practice, when a devolved political entity such as the administrations of the nations of Wales and Scotland, use the metaphor of hospitality to frame their responses to migration? And can this self-framing as an independent host be potentially used to challenge the legitimacy of the British sovereign state and its exclusionary politics of asylum?

In summary, this last theoretical consideration momentarily moves away from the suggestion of the literature on sanctuary movements to approach migration through notions of "rightful presence" (Squire and Darling 2013) or "acts of citizenship" (Isin 2009) rather than hospitality. But it might help to address a question that Arjun Appadurai (2016) asked in his article Aspirational Maps - On migrant narratives and imagined future citizenship: "How can hospitality to the stranger be made a legitimate basis for the narrative of citizenship"? His argument is that citizenship in modern nation-states is based on the fitting together of what he calls plot and character, or story and actor, or narrative and identity. The goal of the nation-state is, through legal and 
bureaucratic means, to provide a territorial ground for connecting plot and character and verifying 'legitimate' citizens (2016). The problem for most illegalised migrants, however, is that their stories come with names, but no characters or identities which fulfil the legal narrative requirement of 'legitimate' migration. This is because:

The modern nation-state has no room for narratives based not in the past (blood, birth, parenthood, language etc.) or in the present (work, marriage, student status etc.) but primarily on the future: on the aspiration for a better home, a safer life, a more secure horizon. (ibid)

For him, the political task to make hospitality a legitimate narrative of citizenship, and to create the stories of imagined future citizenship in a world of nation-states where the past through notions like birth or blood are still the central underpinning of most citizenship laws. It therefore requires "re-thinking the very architecture of sovereignty" (Appadurai 2016). From here onwards, I will follow Karena Shaw's (2004: 166) definition of sovereignty as "the discourses and practices through which political authority has been constituted and legitimised, particularly [...] in the form of the sovereign state". This choice has been made because Shaw's theoretical engagement with the topic is unusual, in the sense that it does not only deconstructs the exclusionary politics inherent to the history of sovereign statehood, but also considers that:

The same discourses and practices through which the sovereign state was articulated, though, have also been seized and deployed in relation to other efforts to constitute legitimate authorities, not least those seeking to resist or delegitimize assertions of sovereign authority over them (ibid: 166)

To what extent the national sanctuary imaginaries at the heart of the notion of Wales as a Nation of Sanctuary in fact resist or delegitimize assertation of sovereign authority over them of course remains to be seen. Nevertheless, considering that the Nation of Sanctuary was identified as a new discursive and empirical phenomenon, her conception of sovereignty as a perhaps more ambivalent rather than outright regressive phenomenon will thus be helpful in examining both limitations and potentialities of this new discourse on migration. On the note of new discourses, Appadurai's engagement becomes important: What could such shared future stories and 
imaginaries be? Chapter 2 has shown how the idea of Wales as a Nation of Sanctuary is a new empirical phenomenon, and figuring out why this national imaginary emerged from an urban movement that was often concerned to differentiate itself from the discursive position of the sovereign nation-state is therefore the empirical puzzle. This chapter has revealed the theoretical puzzle: how this new empirical phenomenon forces us to rethink the discursive relationship between hospitality, sovereignty and asylum, and the political implications this has for the movement. In summary, now that we have finally have two puzzles, one empirical and one theoretical, the last and more practical question remains: How are we going to study the imaginary of the Welsh Nation of Sanctuary and its associated hospitality discourses? The research design for this scholarly undertaking is therefore the subject of the next chapter. 


\section{Chapter 4. The research design: Examining Wales as a 'Nation of Sanctuary'}

The first task of this methodological chapter is to define a research focus, from which a research design can be constructed. The focus of this research project emerged simultaneously from two different directions. This means that the interest was grounded both deductively and inductively. The first direction was coming, inductively, from an actual event, and how it was talked about. We have seen that in response to the 2015 European 'refugee crisis, the Welsh Government held an emergency summit, and committed there that Wales should become the world's first 'Nation of Sanctuary' by building a culture of welcome and hospitality to refugees and asylum seekers. This caught my interest for two reasons. The first was that Wales doesn't have responsibility for British borders. This led me to ask: What does it mean to offer hospitality as a nation-state without border control? The second reason was that the declaration referred to this as the world's first Nation of Sanctuary. My curiosity about this specific framing brought about the deductive direction for the research focus: a missing element in the literature on the sanctuary movement. After reading this literature, it became clear that the announcement to become the world's first Nation of Sanctuary constitutes a new empirical case, considering the urban origins of the sanctuary movement. The literature on different sanctuary movements had focused mainly on urban imaginaries and on the city level, as this was the first attempt to conceptualise sanctuary imaginaries on other geographical scales. Indeed, the Welsh government had adapted this framing from the City of Sanctuary movement. The interest for this framing was therefore grounded inductively, in the phrasing of a specific event, and deductively, through identifying gaps in the literature on scalar sanctuary imaginaries.

To show how I proceeded from this point, the chapter is structured into four section. The first section shows how the research focus was defined, and how a first research design was constructed. The second section shows how this led to the selection of the methodology. The third section justifies the data collection through what were considered appropriate methods: semi-structured interviews, archival research and 
document analysis, and participant observation and fieldnote taking. At last, the fourth section show what analytical frame was used to evaluate the assembled materials.

\subsection{Defining a research focus, constructing a research design}

Considering that the declared aim of building a culture of hospitality and welcome for refugees and asylum seekers is the considered yardstick for sanctuary cities (and nations) by the grassroots movement itself, the main research focus of this thesis is the role of the metaphor of hospitality in discourses around the topics of asylum and national communities. With regards to this broader focus, there were thus three central ontological aspects to be considered: the meaning of specific phenomena (hospitality), the processes of its specific discursive construction (Nation of Sanctuary), and the effects and consequences of producing those meanings for social relationships between people and place (national identity). However, based on the identification of certain gaps in the literature in Chapter 2, this broader research focus was narrowed into a central research question:

What might it mean, in theory and practice, to declare oneself the world's first Nation of Sanctuary?

After having defined the broader research focus, and the more specific research question, I was able to determine how I was going to study the imaginary of the Welsh Nation of Sanctuary. There were two initial interests that I wanted to follow: the emergence of the image of Wales as a 'Nation of Sanctuary' as an empirical phenomenon, and the relation between different scalar imaginaries of community and the commitment of hospitality to asylum seekers and refugees (see Chapter 3). The overarching framework of the research project was therefore built to examine the geographies of asylum seekers, refugees and their supporters.

The first decision in the construction of the detailed research was to ground the fieldwork in Swansea. Considering that Swansea had become the second official City of Sanctuary in the UK in 2010, and that the group was the first within the national network that advocated for Wales to become the world's first 'Nation of Sanctuary', grounding it there was a natural starting point. Following Bagelman, while I situate most of the research in the site of Swansea, this do not offer some fixed foundation upon which to extrapolate generalizable principles (2016: 111). But this contingent 
grounding should not be understood as being reducible to one site, rather as an attempt to investigate how broader rules of action and modes of relation manifest through these specific sites (ibid: 111). Grounding the fieldwork made it possible to explore a wider range of discursive trajectories: urban, regional and national imaginaries of community could be examined here. I therefore started volunteering with the local Swansea City of Sanctuary network in October 2016. During this time, I began to establish working relationships with several organisations, allowing me access to potential participants, and to gain a greater awareness of the current situation for asylum seekers in Wales specifically.

This exploratory stage of the process reaffirmed the research focus on the 'Nation of Sanctuary'. I started with a complementary set of questions to help direct the fieldwork stages of the process. Those first initial questions were designed to correspond with the sub-questions that followed the main research question (see Chapter 1), such as: What are you imagining a City of Sanctuary to be? Are there other or earlier examples of building a culture of hospitality? Subsequently, it became clear that the 'Nation of Sanctuary' idea was new, and threw up a series of questions, not least concerning how the urban groups in Swansea and Cardiff would coordinate to achieve this goal, and if I would be able to speak to other City of Sanctuary volunteers from other parts of Wales. This led me to adopt an approach to the recruitment and selection of participants that has been called "purposeful sampling" (Swenson et.al. 1992 in Longhurst 2003: 123). Moreover, with regards to this initial dual focus with which the fieldwork began (the Nation of Sanctuary as a discursive phenomenon and the relation between imaginaries of community and hospitality), I wanted the research to follow an intersubjective model of understanding in which identities are regarded as relational. Approaches such as hermeneutics, discourse analysis and critical theory have here posed the methodological question of how thought can begin with the processes, rather than the products, of intersubjective life (Jackson 2009).

\subsection{Selecting a research methodology}

The Nation of Sanctuary, it had become clear, was a new discursive and empirical phenomenon. The choice of methodology and methods was therefore influenced by the likely possibility of the emergence of unexpected topics that could counter the 
researcher's own preconceptions (Barbour 2008, Powles 2004 in Staniforth 2015). But before this chapter moves on to the practical issues of how the fieldwork was conducted, which research methods were adopted, and how the data was analyzed, it is necessary to engage briefly with the epistemological and ontological similarities and differences between the methodological approaches, and to elaborate on areas of complementarity between them. Hermeneutics is understood as the study of the interpretation of texts, for which the interpretation of meaning is the central theme in social research. It understands the purpose of interpretation to be the creation of common and valid understandings of the meaning of a text (Brinkmann and Kvale 2015: 60). While classical hermeneutics was focusing on written texts of religion or law, there has been an extension of the concept language itself (Robinson 1998). HansGeorg Gadamer (2013) understands human beings as conversational beings for whom language constitutes a reality. Meaning arises out of the relationship between a practice and those who are attempting to understand it, making it the product of an interaction (Fay 1996: 142).

This intersubjective model of understanding has implications for qualitative research practice. It understands knowledge as being produced socially (Brinkmann and Kvale 2015). In the field of Critical Geopolitics, methods of textual analysis have traditionally relied on interpretative forms of analysis, trying to reconstruct the rules, shared experiences and collective knowledge of different social actors (Angermueller 2005 in Mueller 2010: 7). Mueller (2010: 7) argues that while this interpretive research acknowledges these discourses as 'structures which are both enabling and constraining human agency', their analysis is more often concerned with the agency of individuals in creating meaning. Waitt (2005: 165) argues that in hermeneutics, emphasis is given to the analysis of the qualitative data as a mechanism of communication. In contrast, in critical discourse analysis focus is on the effects of texts on what subjects might think and do.

The methodological strength of discourse analysis is to move beyond the text and representation to unravel issues of power relationships (Waitt 2005: 166). Structuralist and post-structuralist methodologies have been concerned less with the interpretation of the content of discourse, or its intentionality, and stressed instead the processes and mechanisms of the construction of meanings and their social effects (Mueller 2010). These methodologies seem hard to reconcile. But Heracleous and Hendry argue that 
when discourse is treated at a societal level, the "tensions between structuralist and agent-centred perspectives can to a certain extent be bracketed out for the purpose of analysis" (2000 in Mueller 2010). Kress and Hodge (1979 in Wodak et.al 2000: 145) emphasised that discourse cannot exist without social meaning, and that therefore there must be a strong relation between linguistic and social structures. Indeed, critical discourse analysis asks how phenomena which are understood as hegemonic come about and effect the construction of the social world, and how such processes might be altered or imagined differently (van Dijk 2003 in Mueller 2010). This is central for Critical Geopolitics (Agnew 1994), which focuses on the interrelationships between states, and how associated imaginaries are created and sustained. Policy statements, for example, are concrete expressions of dominant foreign policy discourses. This methodological approach will therefore underpin the examination of the framing of Wales becoming the first 'Nation of Sanctuary': A new empirical and discursive phenomenon, which nevertheless relies on dominant narratives of nations, states and hospitality.

\subsection{Data collection and qualitative research methods}

With the initial focus on the process of the Nation of Sanctuary emerging as a new phenomenon, these methodologies call for the use of qualitative research methods. Both methodologies are using the idea of intertextuality, which "refers to the way in which meanings are sustained through mutually related verbal, written and visual texts" (Waitt 2005: 168). It is built on the use of a range of sources, requiring the researcher to adopt different research methods, such as archival research, semistructured interviews and participant observation (ibid: 176). This is because discourses are expressed through texts, representations and practices, and emerge from a coherent pattern of statements, which underscores the breadth of data required (Waitt 2005). Starting from the assumption that the analysis is reliant on 'unpacking' meanings that constitute understandings of the social world, like the idea of Wales as a Nation of Sanctuary, this research project identified interviews, oral histories, parliamentary discussion papers, political documents and newspaper articles as qualitatively rich material. 


\subsubsection{Semi-structured Interviews (Individual and joint interviews)}

This research project collected material from altogether twenty-five interviews: twenty-two of them individual, one-to-one, in-depth and semi-structured interviews, and three small group, or what I termed 'joined interviews', conducted over a period of ten months. Throughout the first part of the research process, the individual interviews acted as a means of developing ideas and research hypotheses, rather than as a means of generating facts or statistical representation (Oppenheim 1996 in Robinson 1998). Most of the individual interviews were undertaken with participants, volunteers, and campaigners of refugee support organisation. The two most important were the Swansea City of Sanctuary network, and the Swansea Bay Asylum Seeker Support Group (SBASSG). This selection included participants from local communities who are not migrants, as well as refugees and asylum seekers who are volunteering. Furthermore, the focus on selecting sources was not based on quantitative validity, but to enable rigour through Lincoln's and Guba's (1981 in Waitt 2005) criteria of credibility, demonstrating that each source is meaningful in the context of the research aim. The process of choosing participants for the interviews was thus based on their experience related to the research focus and question, called a “purposeful sampling” (Swenson et.al. 1992 in Longhurst 2003: 123). The fieldwork process started off with interviewing people who are involved in the Swansea City of Sanctuary network.

Throughout the process of interviewing, I was also volunteering with the Swansea network, and in a local drop-in for asylum seekers. While talking to people and hearing the stories about the histories of these support networks, it became apparent that SBASSG, the local support group that runs the drop-ins, had been operating since 2000, when Swansea first became a dispersal area for refugees and asylum seekers, and that the people involved were central for the later emergence of the Swansea City of Sanctuary network. Moreover, I had realised that there were quite a few volunteers who had joined following the events of the summer of 2015, and that other support networks, such as the support group called Bloom, emerged in Swansea during this period. Therefore, I conducted four additional interviews with volunteers who joined Swansea City of Sanctuary or Bloom during that period, to inquire more about their motivations and experiences. These later interviews nevertheless followed the same line of interest concerning, in response to increasing numbers of refugees arriving in 
Europe over the summer of 2015, the Welsh government's organisation of a summit during which it reiterated its commitment that Wales should play a leading role as a 'Nation of Sanctuary'. After retrieving stories and information about the emergence of the 'Nation of Sanctuary' idea from people within the urban network, I therefore conducted further interviews with people that shaped the emergence and imaginaries of the concept. That included individuals in other charities such as Displaced People in Action and Asylum Matters in Cardiff, and the Welsh Refugee Coalition and the Welsh Refugee Council. I also interviewed a member of the Hay, Brecon and Talgarth Town of Sanctuary group, to enquire about perspectives going beyond the urban networks of Swansea and Cardiff. Moreover, the Equality, Local Government and Communities committee of the National Assembly of Wales had included the suggestion that Wales should attempt to become a Nation of Sanctuary in their first policy report titled "I used to be someone"- Refugees and asylum seekers in Wales (2017). To find out more about the development of the committee including the idea, and the governmental deployment of the NOS concept, I therefore conducted interviews with an assembly member involved in the committee, as well as someone involved in researching the report for the Welsh assembly. These individual semistructured interviews were conducted face-to-face, lasted around one hour and were almost all undertaken in the premises of the Swansea City of Sanctuary network to make participants feel safe in a familiar environment. I used a pre-determined interview guide with a set of adapted question that would correspond with the research questions and its sub-question (see Example Interview Question Guide in Appendix) and thus covered most topics for all interviewees, but I also encouraged participants to expand upon topics which they felt were important (ibid).

Furthermore, the fieldwork of this research project also involved three joined or smallgroup interviews, which were more experimental, and combined aspects of focus groups and standard interviews to investigate "the intersubjective dynamics of thought, speech and understanding" (Cook and Crang 1995 in Robinson 1998: 418). The first joined interview was undertaken with three activists from the Socialist Worker's Party in Swansea, who had been involved in the early stages of setting up SBASSG. The other two joined interviews were conducted with participants of two hosting schemes, Share Tawe in Swansea and ShareDydd in Cardiff. These schemes connect volunteers, who provide a room in their home, with asylum seekers who are in danger of becoming 
destitute, and to whom the hosts are offering accommodation for a certain amount of time. These two joined interviews were conducted in addition to individual interviews with the organisers of the schemes. There are two reasons for this additional interest. During the fieldwork, the Welsh Refugee Council increasingly thematised 'destitution' as an issue to highlight the situation of refugees and asylum seekers in Wales, situating it on the research agenda with regards to the Nation of Sanctuary. I also felt that the assembled data should be supplemented with additional perspectives on practical forms of hospitality, and include the interactions and potential power discrepancies between host and guest involved in those forms of support. In short, this was an attempt to gather data not only on what asylum seekers and their supporters said about hospitality, but also on what they did. Therefore, the rationale for this form of joined interview, with both host and guest of the scheme present, was to capture the interaction between participants. Thus, ethical challenges emerged with regards to these joined interviews. Critical discourse analysis has provided valuable insight into power asymmetries and dynamics at play in more formalised communications settings (Wodak 1985 in Van Liempt \& Bilger 2009: 10). Considering that one rationale was the opportunity for hosts and guests to explore routines of interaction alongside one another, the joined interviews were meant to be social, through communication between the researcher, guest and host, were multiple meanings could be created and shared (Goss and Leinach 1996 in Robinson 1998: 420). The rationale was to also draw in voices and views of asylum seekers and refugees in the city, and to explore the relationships of hospitality and how they experience them. This was to ensure that asylum seeker's voices are represented alongside volunteers, activists and support organisations. Now, considering the potential power discrepancies between host and guest in this form of hosting, this form of joined conversation also has the potential to limit the topics host and guest would discuss in front of one another. Nevertheless, the more informal conversation exchange was considered appropriate in order to perhaps shed light on differential powers to define discourse (Brinkmann and Kvale 2015: 181). Nevertheless, because of the project's primary research focus being on prevailing discourses of hospitality and their statist deployment, these joined interviews were a complementary, rather than a central, element of the research.

The use of semi-structured interviews (individual and joined) involving the recording (audio or written) of personal information had ethical and legal implications for the 
research. Three practical implications had to be addressed before undertaking these interviews: consent, confidentiality, and data protection. Informed consent for all interview participants was secured through providing an information sheet and a consent form for this research project. Moreover, when researching (with) migrants, difficulties in communication can be reinforced through for example the need to deal with various languages (Van Liempt \& Bilger 2009: 10). For two joined interviews and one individual interview, with participants who spoke both Arabic and English, a volunteer from SBASSG assisted me in translating the information sheet into written Arabic (see Appendix), to make the information that was provided more accessible. Personal data and information were all anonymized, and the notebooks and transcripts were safely locked away. Electronic copies and audio-recordings of the interviews are kept on a password-secured laptop in accordance with both statutory requirements, including General and Data Protection Regulation and academic best practice.

\subsubsection{Archival research and document collection (Newspaper and policy documents)}

Through volunteering with SBASSG, I learned that the group was first established in 2000 , in reaction to Swansea becoming a dispersal area for refugees and asylum seekers. Considering the central role of this group for the emergence of other support networks and local hospitality discourses, I wanted to contextualize their emergence and stories, and explore this period further. In addition to interviewing informants who were involved in building the support network, I therefore conducted archival research, focusing primarily on media reports from national and regional newspapers, the Western Mail (Wales) and the South Wales Evening Post (Swansea). The newspaper articles are stored on microfilm at the West Glamorgan Archive Centre in Swansea, which I scanned and compiled into a data set.

This archival research was guided by two lines of thought. One the one hand, I wanted to draw on media reports to investigate local conflicts and discussion over the dispersal proposal, to investigate counter-discourses or conventional 'discourses of opposition' (Dunn 2001 in Waitt 2005: 177). On the other hand, I wanted to contextualize the period of these two years in terms of other themes that formed part of the production of imaginaries of community, and how those narrations are related to, or emerged alongside, discussions of migration. Initially, I therefore searched the archive for articles related to the implementation of the dispersal policies specifically, and on the topics of refugees, asylum, and immigration more broadly. For the time between 2000- 
2002, I collected almost one hundred articles concerned with the topic of refugees and asylum seekers. While I was researching the archive, it became apparent that during the time the topic of asylum was high on the local agenda, the topic of Welsh identity, specifically Welsh language, was also recurrent and highly salient in the media. This corresponds to the period just after the Welsh assembly had been established in 1999 . This prompted me to also compiled a data set of almost one hundred articles related to debates about Welsh nationality, identity and language from the two-year period between 2000 and 2002. One of the limitations of this archive was that the newspapers were saved on microfilm, and could be copied and scanned with an older machine, However, this was only within a certain possible frame. While I managed to capture most authorship and publications details on those microfilms, for some referenced articles page number or dates are missing (see Bibliography).

Considering the governmental adaption of the concept of the 'Nation of Sanctuary', and in addition to the archival research, I also collected a range of policy papers, parliamentary discussion papers, and political documents related to the concept. First, I included more than fifty official documents that held details of any meetings, papers, agenda and minutes that were relevant to the first major policy inquiry into refugees and asylum seekers in Wales, which had culminated in the report "I used to be someone"- Refugees and asylum seekers in Wales (2017) by the Equality, Local Government and Communities (ELGC) committee of the National Assembly of Wales. This report was also analysed in-depth. This was because it included the recommendation to the Welsh government that Wales should become a 'Nation of Sanctuary'. I also included five documents from inquiry briefings, which one interviewee had shared with me for the purposes of this research, to assist in understanding the process of the report emerging. Lastly, I assembled fifty documents that the ELGC committee itself brought together as evidence for their own report, from research in Wales and Scotland.

Together, these policy documents represent a data set of over one hundred and fifty texts. One advantage offered by documentary sources is that they enable one to see 'behind the scenes', especially in policy-making contexts, which is important for theoretical evaluation (Hoggart et.al 2002 :124). However, the choice of documents for this project was also inspired by Bloomfield and Vurdabakis's argument that textual communication practices are a central means for organisations to constitute 
reality and the forms of knowledge appropriate to it (1994 in Atkinson and Coffey 2004: 58). Because political documents are 'social facts', in the sense that they are produced, shared and used in socially organised settings, they also construct certain kinds of representations using their own conventions, and one should not treat such records, however official, as firm evidence of what they report (Atkinson and Coffey 2004: 58). Therefore, Atkinson and Coffey argue that we should not necessarily ask all the questions about whether documents and reports are true or can be used as valid evidence, but rather engage more with the form and function of texts itself (2005: 73). These notions also underpinned the choice of documents assembled: the report itself, the evidence that was collected by the committee to produce it, as well as the files that document its production. Finally, with regards to policy documents on Wales as a 'Nation of Sanctuary', it is important to think about them in relation to their production (authorship) and their consumption (readership). This should not just be about the individuals who wrote them, but also about implied readers and specifically when they claim a status as factual, objective or authoritative (Atkinson and Coffey 2004: 73).

\subsubsection{Participant observation and ethnographic fieldnotes}

Considering the research focus of this project on prevailing discourses and governmentalities of hospitality with regards to the nation-state, the first practices undertaken for collecting material were interviewing as well as archival and document research. Nevertheless, we have seen that discourses are expressed through texts, representations and practices (Waitt 2005). Therefore, this research project also undertook participant observation and documented those observations in written fieldnotes. This was done with regards to different activities during the course of attending six events organised by three refugee support organisations. It included events organised by the Welsh Refugee Council, Swansea City of Sanctuary and Share Tawe, where imaginaries of hospitality and the 'Nation of Sanctuary' were constituted through discussions, presentations and activities. This fieldwork method was popularised by geographers, ethnographers and anthropologists (Robinson 1998).

While the focus for ethnographers tends to be on routine experiences and habitual practices in 'natural' environments, participant observation does not necessarily need to mean long-term embedment or constant 'immersion' (Crang and Cook 2007: 39). Often communities formed within different networks are spatially dispersed and temporarily intermittent, coming together at different place and at different times 
(Crang and Cook 2007). This was the case with the events in which the imaginaries of a hospitable nation were constituted, making such a 'snapshot' approach to ethnography and participant observation appropriate for the purposes of this research. One-off descriptions allow one to bring into view types of phenomena that are quite contingent. Indeed, material from participant observation can consist of instances of some practice or event that is of interest (Laurier 2003: 145).

The first of these 'snapshots' I attended and documented was the 'Wales- Nation of Sanctuary' conference in Cardiff at the 29 April 2017.This event had been organised by Swansea City of Sanctuary, and brought together one hundred participants from ten different organisations from all parts of Wales. Participating was important to me, as I wanted examine how the urban sanctuary groups in Wales would coordinate with one another to become a 'Nation of Sanctuary'. Indeed, in retrospect, participating was essential for the research project. After the conference, a 'Nation of Sanctuary Steering Group' had been set up to continue this beginning work. As I had been volunteering with Swansea City of Sanctuary, I was invited participate and take minutes for this steering group. This steering group consisted of ten to fifteen volunteers from City of Sanctuary groups from different parts of Wales, and was chaired by one of the member from Swansea City of Sanctuary. Because of the geographical distance between the volunteers and participants, the meetings were conducted as phone conferences every two months. Because I took the minutes of those meetings for the COS movement as more of a participant than a researcher, I treated those fieldnotes as deeper background, which informed more specified data collection, rather than to be quoted. The group members agreed to this and my participation. From this participation, subsequent interviews emerged with the head of the Nation of Sanctuary steering group and other people who had worked on Wales becoming a 'Nation of Sanctuary before. On the same topic, and in line with my approach of 'snapshot' ethnography, I attended the 'Sanctuary in the Senedd' event at the 28 January 2018, which included presentations from asylum seekers and refugees in the Welsh assembly. Finally, concerning the issue of destitution, I attended the first meeting of a re-established destitution working group in Swansea and a hosting event organised by Share Tawe the same month, through which people who had hosted asylum seekers or refugees before could connect with new hosts who were interested in offering support through accommodation. In summary, the table provides an overview of the main sources: 


\begin{tabular}{|c|c|c|c|}
\hline & Type of Source & & \\
\hline $\begin{array}{c}\text { Research } \\
\text { Subjects } \\
\text { (Social Actors) }\end{array}$ & $\begin{array}{c}\text { Semi-structured } \\
\text { Interviews, } \\
\text { Individual and Joint } \\
\text { (Primary) }\end{array}$ & $\begin{array}{c}\text { Archival Research } \\
\text { and Document } \\
\text { Analysis (Primary) }\end{array}$ & $\begin{array}{c}\text { Fieldnotes and } \\
\text { Participant } \\
\text { Observation } \\
\text { (Secondary) }\end{array}$ \\
\hline $\begin{array}{c}\text { Civil Society, } \\
\text { Volunteer, } \\
\text { Activism }\end{array}$ & $\begin{array}{c}\text { SBASSG (4), } \\
\text { Swansea City of } \\
\text { Sanctuary (3), Share } \\
\text { Tawe (2), Share } \\
\text { Dydd (2), Bloom } \\
\text { (1), Hay, Brecon and } \\
\text { Talgarth Town of } \\
\text { Sanctuary (1) }\end{array}$ & $\begin{array}{c}\text { Application from } \\
\text { Swansea City of } \\
\text { Sanctuary for } \\
\text { national recognition, } \\
\text { Swansea City of } \\
\text { Sanctuary Annual } \\
\text { Report 2013-2014 }\end{array}$ & $\begin{array}{c}\text { SCOS Destitution } \\
\text { Working Group, } 24 \\
\text { July } 2017 \text {, Swansea }\end{array}$ \\
\hline $\begin{array}{l}\text { Third Sector } \\
\text { and Charities }\end{array}$ & $\begin{array}{c}\text { Welsh Refugee } \\
\text { Council (2), Welsh } \\
\text { Refugee Coalition } \\
\text { (1), DPIA (1), } \\
\text { Asylum Matters (1), } \\
\text { EYST (1) }\end{array}$ & $\begin{array}{l}\text { Evidence documents } \\
\text { from Third Sector } \\
\text { for ELGC report } \\
\text { (50) }\end{array}$ & $\begin{array}{c}\text { Wales- Nation of } \\
\text { Sanctuary } \\
\text { Conference, } 29 \\
\text { April 2017, Cardiff }\end{array}$ \\
\hline $\begin{array}{c}\text { Government and } \\
\text { Politics }\end{array}$ & $\begin{array}{c}\text { National Assembly } \\
\text { of Wales (2), } \\
\text { Equality Local } \\
\text { Government and } \\
\text { Communities } \\
\text { Committee of the } \\
\text { Assembly (ELGC) } \\
\text { (1 researcher, } 1 \mathrm{AM})\end{array}$ & $\begin{array}{l}\text { ELGC Report I used } \\
\text { to be someone } 2017 \text {, } \\
\text { Research Briefings } \\
\text { (5), Written response } \\
\text { and evidence by the } \\
\text { Welsh Government } \\
\text { (2), HoC and Home } \\
\text { Office reports (4) }\end{array}$ & $\begin{array}{l}\text { Sanctuary in the } \\
\text { Senedd Event, } 28 \\
\text { January 2018, } \\
\text { Cardiff }\end{array}$ \\
\hline $\begin{array}{c}\text { Newspaper and } \\
\text { Media }\end{array}$ & & $\begin{array}{c}\text { Western Mail } \\
\text { (Cardiff), South } \\
\text { Wales Evening Post } \\
\text { (Swansea), } 100 \\
\text { archived articles }\end{array}$ & \\
\hline
\end{tabular}




\subsection{Exploring positionality in the analytical process}

I have outlined in Chapter 1, in describing the moments and events that motivated and anchored this research for me, that I do not claim neutrality in my motivations for conducting this study. This is because, while I have attempted to approach the analytical process in an open manner, the research process necessarily reflects the positionality of the researcher in choosing, organising and prioritising data. This highlights the importance of transparency (Staniforth 2015).

The earlier description of how the material for this project was identified, and how the research process emerged as an ongoing process, points towards an important element of analysis. This is that it is "a less rigid research process in which research method is not so clearly divided into set phases, but rather there is a constant reference from information gathered to analysis to theory to information" (Robinson 1998: 425). Sometimes defined as analytical induction, this form of research begins with general theoretical settings, from which the research questions and fieldwork requirements are identified, and as material is assembled, and from which other theories are developed that emerge from the setting under study (Robinson 1998).

This analytical process began for me with the transcription of the recorded data derived from such a process: specifically, semi-structured interviews and ethnographic 'snapshot' fieldnotes. The categorisation of observations is one of the main routes for analysing qualitative data. This process focuses on coding and sorting information, using categorisation (Robinson 1998: 428). But Crang (1997 in Robinson 1998: 428) explains that what is of interest in codes is: "the text they denote, not how often they occur but what is in them. The codes are not there to be rigidly reproduced, nor to be counted, but as an aid to the researcher in making sense of the material". Coding should therefore be understood as a means of evaluating and organising data to understand meanings and discursive patterns in the text (Cope 2003). This process involves consistent reading and rereading, thinking and rethinking, developing and redeveloping themes and patterns. Strauss (Strauss \& Corbin 1990 in Brinkmann and Kvale 2015: 227) calls this practice open coding, referring to the "process of breaking down, examining, comparing, conceptualising and categorising data". I began this process by making notes of themes and what I considered interesting quotes, in-text, while I was transcribing. When coding, the first step was to read through the interview transcripts and textual materials, and code the relevant passages, which involves 
attaching one or more keywords to a text section to permit the identification of different statements later (Brinkmann and Kvale 2015). I used the computer program NVivo 12 to assist and facilitate the analysis of interview transcripts and other documents, in addition to manual coding. While not the full analytical process relied on using the software, it was helpful at the beginning to classify, sort and arrange large amounts of yet unstructured information. Moreover, the software allows the linking, shaping and searching of this information, as well as the cross-examination of data through queries requests and search engines. For the coding, it was possible to use memos attached to the codes to build a more coherent structure. The full transcripts went through a second, more intensive round of coding that used a wider range of categories, which emerged from two directions: through the data itself, or from conceptual sources, either inductively or deductively (see NV Coding Scheme 1 in Appendices).

This approach to the program was another way to conceptualise the different stages of coding, from the first descriptive level to the next analytical level. The descriptive codes contain what Cope (2003: 452) calls in vivo codes, meaning that they appear in the text and are the respondent's own words as codes. The analytical codes emerge from the second level of coding that followed reflecting on the descriptive codes and the theoretical literature (Cope 2003). As indicated above, I have included screenshots of those NVivo coding schemes in the Appendix to show how the analytical codes emerged from the first set of in vivo codes (or alongside). Once the categories were consistently compared for similarities and differences, the third step concerned the process through which the analysis moved from descriptive to theoretical "saturation" of the material through that coding process (Brinkmann and Kvale 2015: 227). In this process, I followed Staniforth (2015) by copying and pasting relevant data into labelled documents for the different codes, thus forming bodies of text, or 'corpora', that were to be read and re-read for "convergent and divergent narratives" (ibid). This process went on until I had a longer list of codes that reflected the nuances of the data, convergent or divergent (see NVivo Coding Scheme 2 in Appendices). The last step was to organise this list of codes into a far smaller number of main categories for the research aim and the emerging argument, collapsing or reorganising codes when necessary. 
For this research project, the coding process is meant to be a preparation for the qualitative analysis proper, using hermeneutic interpretation and critical discourse analysis. This means that the interpretation of the meaning of the interview texts and other documents will go beyond the structuring of the different meanings of what is said. In contrast to decontextualizing statements through categorisation and coding, interpretation then proceeds to recontextualise statements within broader terms of reference, to draw out structures and relations of meaning that are not apparent at first sight (Brinkmann and Kvale 2015: 235). There are numerous approaches for doing critical discourse analysis, some more formal and technical, others less prescribed. Parker (2005) applies a rather informal approach that becomes aligned with the study of ideology and a dialectical focus. The analysis in the empirical chapter will therefore also address three theoretical questions, which Parker (2005 in Brinkmann and Kvale 2015: 261) suggests should be posed about a text: "Why is the text interesting? [...] What are the effects of different readings of the text? How does the text relate to patterns of power?"

The analytical framework of this project will follow Fairclough's (1993 in Wodak et.al 2000) model and draw a distinction between text and discourse, using the term text for written texts, such as policy documents from the ELGC committee and the interview transcripts, and the term discourse to refer to the wider process of social interaction (1989 in Wodak et.al 2000: 147). The analysis uses this distinction to investigate the mediating link between the communicative event, the declaration by the Welsh Government that Wales should become the first 'Nation of Sanctuary', and the wider social structures: the nation, the state, discourses of migration and the exclusionary politics of asylum. The analysis is concerned with the way subjects produce and interpret texts, but also with the relationship of the communicative event to an order of discourse (Fairclough 1993 in Wodak et.al 2000: 150). To analyse the third dimension of a discursive event, that of social practice, it is necessary to consider different levels of social organisation, as well as the situation, the institutional context, and the group context (Wodak et.al 2000). Furthermore, Wodak (2000 et.al: 165) and other critical theorists have argued that Fairclough's model is suited for the analysis of the contexts of social and discursive change, specifically with regards to the restructuring between discursive practices within and beyond institutions. This argument makes this analysis appropriate for the following empirical chapters, 
considering the urban origins of the social movement (a grassroots institution), and that this was the first-time a state institution, the devolved Welsh government, adopted this slogan to frame their responses.

In conclusion, this research project employs in-depth qualitative methods and a multisited methodology to explore what the declaration of becoming a 'Nation of Sanctuary' means and does. One of the central arguments that emerged through my fieldwork and the review of the literature is that the Nation of Sanctuary is also a means of performing identity, and that it does this through a discursive politics of differentiation. However, the subsequent aim of the thesis is not to state with full certainty what a Nation of Sanctuary could be defined as or what it would look like. Rather, I hope to cast more light on the processes of such imaginaries coming about and creating meaning, and how this perhaps changes in time. The challenge of presenting these findings in writing is the 'messiness' of the research and how the findings came about. Halfacree and Boyle describe this as a "literary fallacy" (1993: 341), as that the act of writing "adds a linear order", which does not necessarily reflect the reality of that process. But the imperative to make research findings accessible to readers almost renders such linearity inevitable (Staniforth 2015: 91).

This research design chapter is primarily intended to make transparent the research process, especially with regards to how choices were made concerning methodology and methods, as well as what motivations affected the choice of participants, how the data was collected and lastly how this data was analysed. Nevertheless, I want to add a last section to elaborate on which examples of the raw qualitative data have been included in the Appendices (A, B, C, D, E, F, G) of this thesis, with a view to giving readers a better idea of what the larger body of data looked like, and how it was analysed. Regarding the large volume on material assembled, the material included represents examples and sections of interviews, fieldnotes or archive scans. I chose these examples to show that the research was an ongoing and changing process, in that the collection of data affected the subsequent collection of more data, in the sense of it snowballing. In the Appendix A, I have included the interview questions, and in Appendix B, sections of the transcripts from four example interviews. Two of them were with activists and members of Swansea City of Sanctuary, one with a former chair of the Welsh Refugee Council, and with a member of the Welsh Assembly administration. These four show how the instances of the collection of data affected 
each other. The first set is from the very first interview I ever conducted after I had begun volunteering in Swansea. The example shows that the interview was focused on finding out the history of the urban movement, and getting a sense of the background. The second set of questions and transcripts is from an interview with a member of Swansea City of Sanctuary and the head of the Nation of Sanctuary steering group, who I had met through volunteering. It shows that the questions had evolved to become more targeted on the 'Nation of Sanctuary' issue, while still corresponding with the broader research questions. The thirds set is from an interview with the former head of the Welsh Refugee Council and head of the DPIA. This interview came about because of a suggestion in the previous interview.

The last set of questions and transcript examples included stem from an interview with a researcher in the Welsh Assembly. I included this data to show how I used commentaries and insights from previous interviews direct the questions in the subsequent interviews. Following, in Appendix $\mathrm{C}$ there are two example sections from ethnographic fieldnotes, to communicate a sense of how that original data looked like. After these interviews, I have added Appendix D as example of the inquiry briefings of the committee report: first, to give the reader a sense of their structure and purpose, and second, because without the last interviewee I would not have had access to those rich materials. Appendix $\mathrm{F}$ includes four scans of newspapers from the West Glamorgan Archive in Swansea, three from the South Wales Evening Post and one from the Western Mail. Their inclusion is to give the reader a sense of how the scans looked like, but I have also chosen them because they represent conceptual 'themes' that emerged through the assembled media set: the idea of a 'warm welcome', the notion of asylum as a financial 'burden', the hunger strike in Cardiff as a 'event', and the existing language around 'sanctuary'. Considering the different forms of texts shown, Appendix F are screenshots of the NVivo coding to show how these materials were beginning to be distilled into concepts. 


\section{Part II: Wales as a Nation of}

\section{Sanctuary- The emergence of a} concept between the scales 


\section{Chapter 5. "A warm Welsh welcome"? - The emergence of the UK national dispersal programme for asylum seekers, and of national (self-) imaginaries in Welsh newspapers}

This research project started by asking what might it mean for a political, sub-national territorial unit like Wales to declare itself as a Nation of Sanctuary: what does the idea mean, and what does a 'Nation of Sanctuary' do? This question arose when the Welsh government committed in September 2015 that Wales should play an increasing role in supporting refugees as the world's first Nation of Sanctuary. Moreover, the chapters comprising Part I of this thesis have shown that this underpinning question immediately opens the door to a new range of related sub-questions. These subquestions concern what the theoretical and political imaginaries of sanctuary and national identity in this specific context would be, what historical precedents there are, and how they would relate to other political responses to the 'crisis'. Therefore, to outline the historical, political and institutional context for the empirical analysis of those imaginaries of sanctuary between urban and national scales, the aim of this chapter is to examine the historical precedents of political imaginaries of sanctuary and national identity.

Specifically, the objective is to trace the implementation of, and debates about, the national dispersal policy, from the time it was announced in December 1999, until asylum seekers and refugees started first to be dispersed to Swansea in January 2002. There are important reasons for choosing this historical period and context. First, the introduction of the dispersal programme "marked a sea change in British asylum policy, but it also marked a turning point for Wales" (Robinson 2003: 189), because for the first-time Wales became an official reception area for asylum seekers while they awaited the outcome of their application. Second, because the aim is to examine historical precedents of sanctuary and spatial identity, this chapter also addresses the literature that has investigated the discursive effects of dispersal policies on urban imaginaries (Darling: 2013), and this literature has focused specifically on the developments in this period. Thirdly, for the time, this period also saw the emergence of a permanent grassroots and civil society support group for asylum seekers, the 
Swansea Bay Asylum Seeker Support Group (SBASSG). Because the presence of this grassroots base would be of importance for the emergence of the local City of Sanctuary network and their urban imaginaries, contextualising the time around this first institutionalised 'Moment of Welcome' will help to understand the specific discursive context from which the notion of a Welsh Nation of Sanctuary would later emerge. Therefore, to trace the implementation and the public debates around the new dispersal policy in Wales, this chapter will draw mostly on archival research into newspaper reports from the two largest Welsh newspapers with a nation-wide circulation, the Western Mail (WM) in Cardiff and the South Wales Evening Post (SWEP) in Swansea between 2000 and 20002, with some additional material from local government documents and interviews that concerned the public debates in Welsh newspapers on the dispersal policy. Considering that the aim is to examine historical precedents of political imaginaries of sanctuary and national identity, an analysis of the national media and their framing of those imaginaries, with the case study of the Welsh newspaper press, is an appropriate starting point. There are two main arguments for this. First, the theoretical framework set out how Billig's (1995: ) work showing how national identity is also reinforced in a banal and everyday-sense, including in such a way as to provide the background for political discourse and "even for the structuring of newspapers". An analysis of this media discourse will be helpful to find precedents of the relation between imaginaries of sanctuary and national identity. Moreover, as Vaughan Robinson (2003: 191) argues, an important element to understand public responses to migration is the analysis of how the media approached the topic, "since this is an important determinant of public attitudes and a reflection of such attitudes".

The archival material that underpins this chapter draws on a thematic analysis of the newspaper articles in the West Glamorgan Archive in Swansea, bringing together local and Welsh national newspapers. The material that was assembled was chosen because of their appropriate subject headings for this research, archived under the topics of 'refugees', 'asylum' and 'immigration'. I also wanted to contextualize the period of these two years in terms of other themes that formed part of the wider production of imaginaries of community, and how those narrations are related to and emerged alongside, discussions of immigration. Therefore, I initially searched the archive for articles related to the implementation of the dispersal policies specifically, and on the 
topics of refugees, asylum, immigration and their alleged effects on community more broadly. For the time between 2000 and 2002, I collected more than 100 articles concerned with those themes.

This chapter is structured into five sections. The first section will introduce the political and constitutional background for the implementation of the national dispersal policy in Wales. This includes the creation of an increasingly hostile asylum regime under the (New) Labour Government with the 1999 Immigration and Asylum Act, and the parallel emergence of the National Assembly for Wales in 1999 and devolution of public services, which were intended to become part of that new asylum regime. The second section will investigate how the new dispersal policy was narrated and discussed in Swansea, and how it fits into broader debates about immigration and community, drawing on the news coverage of the dispersal policy from the SWEP. The third section will examine a discursive theme which emerged in the reporting of the two newspapers: the idea of a "Warm Welsh Welcome", a precedent for subsequent imaginaries of sanctuary and national identity. The central argument made in this chapter, and which will be set out in sections two to five, is that the public debates around this new policy both affected and shaped emerging new national selfimaginaries in Wales, and that the media narration was accompanied by what will be called a 'politics of differentiation'. The fourth section examines the presence of the British National Party (BNP) in Swansea. This section will investigate how their presence was reported on, and how such discourse fits into a politics of differentiation from a more hostile other that is not imagined to be part of the nation. The fifth section will examine a hunger strike by detained asylum seekers in a prison in Cardiff in August 2001, which was reported on in detail by the WM, and would start to affect the emergence of new political imaginaries with regards to the process of political devolution. The conclusion will summarise a central new insight that has arisen from examining these historical precedents of sanctuary imaginaries: the narration of the dispersal element saw an emerging national element. 


\title{
5.1. The political background: New Labour, the Immigration and Asylum Act (1999) and the emergence of the new Welsh National Assembly
}

Through volunteering with the Swansea City of Sanctuary network from the beginning of this research project, I discovered that the local network had emerged in 2008. The other big refugee support group in Swansea, SBASSG, had existed far longer - in fact since it was first announced that the city would become a dispersal area. I was also volunteering at one of the drop-ins that the group was running, and thus came to know some of the people who were involved in setting the group up. One of the activists describes the circumstances out of which this first civil society response emerged:

\begin{abstract}
What happened was: the dispersal policy was announced. And there was immediately some kind of, there was lots of local discussion, local paper, local groups and so on. And, I wasn't at it, but a public meeting was called, which was basically 'Unitarian church'. Which was the traditional meeting place of the left. The kind of multiple left: Socialist Workers, Trade Unionists, Quakers etcetera. And it was attacked by a bunch of hard-right fascists. And out of that came the decision to set up a support group for asylum seekers, getting ready for...that was before any arrived, and before there was any kind of support system at all (Interview, 2 November 2017)
\end{abstract}

This contextualising statement is interesting, because it assembles a range of themes that were subject to wider public debates, and which will assist in structuring this chapter. These are first the announcement of the dispersal policy, second the following local discussion in local papers, third a public meeting in response, fourth an attack by a "bunch of hard-right fascists" and last the decision out of those factors to set up a new support group. Therefore, the media analysis starts with the announcement of the new dispersal policy and the political context from which it emerged. That is not just for structural reasons. The first article I found which was filed under the heading of 'immigration' in the archive was from the Local Government Information UnitEqualities News, titled: "New Labour, new immigration controls" (Mynott 1999). The piece summarises that: "When the Immigration and Asylum Bill was introduced to Parliament in February 1999 it provided confirmation that Labour is not repealing previous Conservative legislation but strengthening and extending it" (Mynott 1999: 9). This political (re)orientation followed an increasing 'moral panic' over the topic of immigration, as the number of people claiming asylum in-country or at the port of entry had risen from 3,998 people in 1988 to 46,000 people in 1998. 
This affected public opinion and then policy - in 2000 a poll found that a large majority in the UK thought that asylum seekers came to Britain because it was considered a "soft touch" (Robinson 2003: 181). Therefore, the dispersal system was announced with the publication of the 1998 Home Office White Paper entitled Faster, Fairer, Firmer: A Modern Approach to Immigration and Asylum, which accompanied the introduction of the new Act the following year. The securitising logic of distinction, and the hierarchisation of migrants into 'genuine' refugees and 'bogus' asylum seekers is written into this document. The summary emphasises that the goal is to "modernise the whole approach to immigration", and that operations will be more integrated to "maximise efficiency and minimise the scope for abuse" (Home Office: 1998). But the focus was placed on targeting alleged abuses of the system, intended to reinforce the discursive distinctions between genuine and non-genuine migrants. The intention to "speed the passage of genuine travellers and target resources on potential abuse" is mentioned twice, and the document states that the policy's main goals are to "minimise the incentive to economic migration" through "removing access to social security benefits" (1998). Mynott(1999: 9) emphasises how this removal of benefits with a food voucher system marked people out, indicating that: "The message that many (if not most of them) are abusing Britain's hospitality will have the stamp of government authority".

However, another argument of the article was that the more important implications for local authorities and councils was the taking over of the responsibility for supporting asylum seekers by a new national agency run by the Home Office, which would then contract with consortia made up of local authorities, private sector landlords, and the voluntary sector to provide accommodation and subsistence. Indeed, an article from Housing Today in August 2000 describes how the new National Asylum Support Service (NASS), set up in December 1998, was taking on responsibility for all asylum seekers who applied after their arrival in the United Kingdom (Murray 2000). In December 1998, the Home Office approached local authorities to formulate a nationwide dispersal policy, and Wales was for the first time declared one of the ten consortia responsible for dispersing asylum seekers from the south-east of England (Robinson 2003). However, the Home Office intervened in this process in December 1999, and imposed a centrally planned and managed dispersal policy (Robinson 2003: 189). The 
act proposed that local authorities and organisations would come together in consortia, and were expected to provide a range of services, including housing.

Therefore, thirteen cluster regions were defined, and dispersal to those regions, as well as responsibility for services, was contracted out to the consortia, including to two in Wales: one Cardiff consortium and one All-Wales consortium (Robinson 2003: 190). This coincided with the period during which, following the Government of Wales Act 1998, the Welsh National Assembly was established in 1999, which initially only had the power to amend secondary legislation (Deacon 2014: 232). However, while it could only amend secondary legislation, it was also made responsible for running public services such as health and education, which are both relevant to the dispersal of asylum seekers as well as refugee resettlement. Furthermore, Mynott (1999: 9) points out that with the asylum legislation following the Immigration and Asylum Act, there was a "real danger that local authorities and their staff may be expected to act much more as immigration officials" This would also be the case with some public services, such as health which were involved in the provision of support for dispersed asylum seekers, and which were now under devolved jurisdiction. Moreover, this led to what Mooney and Williams (2003: 620) describe as the "growing perception that some UK-wide policies are increasingly unable to address more 'localized' needs".

The examination of those archived documents and articles gives us an insight into the political background from which the dispersal policy emerged. It also illuminates the themes that concerned the institutional discourses, namely the role that local authorities and public services were expected to play in the securitisation of migrants. However, a problem for Tammy Speers (2001) is that an 'official' discourse of asylum seekers and refugees is created in newspapers by using government officials in articles. Therefore, the following sections focus on narrations that also include civil society actors, first the local media and then activists. Refugees and asylum seekers themselves were not quoted in any of these assembled newspaper articles. I have attempted to partly fill this absence by talking to former refugees who were involved in supporting new arrivals doing this period between 2000 and 2002, and integrated their accounts into the next empirical chapter. 


\subsection{Newspaper narratives of the dispersal programme in Swansea and Wales}

The Immigration and Asylum Act marked the introduction of the new dispersal system, of which the local authorities, newspapers and communities became increasingly aware. Early mentions of the scheme included a South Wales Evening Post article from the $10^{\text {th }}$ of April 2000 reporting that Swansea Council was preparing to receive up to one thousand asylum seekers, from a share of five thousand people who were supposed to be dispersed across Wales altogether (Greaney 2000). The first media narrative of migration that emerged in the context of the scheme focused on an emerging conflict between the Home Office and the Welsh local authorities with regards to financial support, funding and the responsibility for support services for asylum seekers and refugees. In May 2000, the planned arrival of asylum seekers into different Welsh localities, including Neath and Port Talbot, were reported to have been delayed until the late summer as a result of these tensions. Indeed, the director of social services had stated as a reason that: "We have expressed our concern to the Home Office about the involvement of private landlords who have an interest in the scheme" (SWEP: 2000).

Moreover, this conflict between the Home Office and the local authorities concerning how the dispersal system was to be implemented and managed is also reflected in another Swansea Council archive document: a piece of correspondence, sent from the Chief Executive of the City and County of Swansea (Sugar 2000) to the Chairman of the Commission for Racial Equality in London, and marked as having been received on the $21^{\text {st }}$ August 2000. In it, the Chief Executive of Swansea Council, also speaking as part of the Welsh Consortium, outlines some of her concerns about the implementation of the dispersal scheme. In the first section, she warns that the "stereotyped negative image of an asylum seeker does not sit easily with the latent racism in some of our communities" (p.1), and that the arrival of asylum seekers and refugees in the area would need to be handled "sensitively" (ibid). The remainder of this document concerns negotiations over costs and funding. In particular, the third section argues that the planning of the Welsh Consortium could be "put in jeopardy by the Home Office agreeing contracts with private sector providers without proper consultation with either Regional consortia or with local agencies in local areas" (ibid). In addition to the lack of consultation, the Council and their partners were concerned over the issue of unit pricing of accommodation and services. This is ostensibly 
because, for the consortium, the negotiations appeared to be "almost exclusively price led with a lack of understanding of the difference between providing these particular services in an area as large and diverse as Wales and providing similar services in London and the South East" (ibid). In this way, the policy document strongly echoes the first theme to emerge in media accounts of the new dispersal scheme, that is to say the financial cost of dispersal.

This focus on cost and its allocation among different actors and areas continued to be central for local newspapers. Reports continued to grow about the impact this financial wrangling between the UK Government and Welsh Councils over housing would have on delaying the arrival of asylum seekers in Swansea, Neath, Port Talbot and Carmarthenshire (Bailey 2001: 5). Gower Assembly Member (AM) Edwina Hart also stated to the Welsh Assembly that the debate between the All-Wales Local Authority Consortium and NASS concerned the level of funding it was willing to allocate for accommodation (ibid). The sources for this section of the analysis primarily consist of newspaper articles by the SWEP that dealt with the topic of the new dispersal policy. This is supplemented by a scholarly analysis by Tammy Speers of all Welsh local newspaper and their articles on the topic of asylum between April and December 2000 entitled Welcome or Overreaction? Refugees and Asylum Seekers in the Welsh Media (2001). Her work shows that almost half the articles took as their main theme the national or local cost of dispersal (Speer in Robinson 2003: 192). Speers found that many of the articles labelled asylum seekers as a 'burden', with almost half of the articles thematically emphasising the cost of the dispersal policy and an alleged adverse impact on housing and education, while other articles "carried the message that dispersal was being foisted on Wales to relive the pressure in the south-east of England" (Robinson 2003: 192).

Nevertheless, the conflict between the Home Office and Welsh Local Government was not just restricted to funding levels and resource allocation, but carried over to other aspects of the British asylum regime. At the time, the South Wales Evening Post and Western Mail began reporting stories on the detention of asylum seekers, who had already arrived in Cardiff and were placed in a prison, and were being transported to the hospital in handcuffs (Bailey 2001). Edwina Hart stated here that: "I will be suggesting to the Equal Opportunities Committee that it conducts an evidencegathering, questioning the Home Office, the Immigration Service, and NASS among 
others" (ibid: 5). Moreover, at another meeting of the Welsh Assembly's Equal Opportunities Committee, the all-Wales consortium began putting pressure on the Assembly to meet the cost of addressing significant funding gaps. The lead officer of the consortium explained that funding for additional costs had been agreed for England and not for Wales, and that this was a major concern for local authorities which would “inhibit appropriate provision" (Walters 2001). Edwina Hart stated that the Welsh Assembly should not be paying for a UK Government problem, and that the: "Home Office should be paying the Assembly the additional money needed for health and local government" (ibid: 10). This is the second narrative theme: the dispersal policy framed as a 'burden' in combination with a new politics of differentiation from those seen to be imposing it, namely the Home Office and the British Government.

Moreover, while the debate around the dispersal of refugees and asylum seekers into Cardiff and Swansea was in full swing by April 2000, another contentious topic also being discussed in the local community and the local press: that of Welsh language and identity. Over a three-week period in April, the SWEP published a total of twelve articles on the topic. Seven of them were readers' letters, indicating a wide resonance of the topic among the public in Swansea. The two main arguments expressed in the articles were diametrically opposed. On the one hand, a group expressed a felt enforcement of the Welsh language: "Sick of having Welsh rammed down throat" (SWEP: 3 April 2000), "Time to end this intrusion into our lives" (Woodman 2000) and "Cost of language are forced upon us" (Dallmore 2000). On the other hand, another group expressed either support for protecting a threatened minority language - "Be grateful for status of Welsh" (SWEP: 27 April 2000) and "Taking pride in national tongue" (Jones 2000) - or as an issue that should be voted on - "Voters must decide on Welsh" (Daniel 2000) and "Welsh language vote welcome by majority" (SWEP : 19 April 2000).

That same summer, the debate focusing on the role of the Welsh language in public life would broaden its scope towards identity, and more interestingly, towards questions of majority and minority groups as well what was felt to be either "antiEnglish discrimination" (Malik 2000) or "anti-Welsh bias" (SWEP: 14 August 2000). Indeed, between 2000 and 2002, another central debate on the topic of migration in Wales concerned rather in-migration and implications for Welsh cultural identity and language with regards to the second significant 'other': the English (Mooney and 
Williams 2003: 622). At the beginning of August 2000, the SWEP published an article entitled "Racism grows against English", and reported that the number of cases referred to the Swansea Bay Racial Equality Council, and specifically complaints of so-called anti-English racism, were "more prevalent than cases of racism against Pakistani, Bangladeshi, Arabic and Caribbean people" (SWEP: 7 August 2000). The same day, the Council Chairman and race equality chief Naz Malik stated that: "We won't tolerate racism of any kind", and that the "Swansea Bay Racial Equality Council does not service Black and Asia ethnic minorities only" (2000). It is highly debatable to what extent the term 'racism' is here an appropriate description, but what is interesting is that soon after these newspaper reports, the Plaid Cymru Swansea Councillor Ion Richards asked the Equality Council to consider the prosecution of the Sunday Times under equalities legislation for alleged "anti-Welsh bias" (Stoakes 2000).

To contextualise the background: the political party of which Ion Richards is a member, Plaid Cymru, constitutes the formal political party of Welsh nationalism, following a parliamentary and constitutional road to a potential Welsh independence (Butt Philip 1975 in Adamson 1991). The main cultural issues of the Welsh language and bilingualism have held a strong place for this party since the 1960s, but they have since then consistently moved to also include a more economically orientated body of policy (Adamson 1991: 128). Nevertheless, the debate around Welsh language and racism would continue and re-emerge, driven in part by Plaid Cymru politicians. For instance, in a letter written to the SWEP, the Plaid Cymru Member of the European Parliament (MEP) Eurig Wyn (2001) answered allegations of anti-English racism by stating that "using the Welsh language and racism as a political stick with which to attack Plaid Cymru... is the only device left to the British Labour Party in Wales" (p.1). In addition to this language debate, he argued in the same article that neither Plaid Cymru nor the Welsh National Assembly controlled the Welsh economy, stating: "While the Labour administration panders to Blair's free market London agenda, the communities of Wales, rural and urban, face calamity" (ibid).

The interesting issue is again the emergence of a politics of differentiation, but with a national component to the other. Here, the 'London' agenda, associated with a British other, is imagined to impose neoliberal strictures on Wales. But attention to the process of political devolution was also often more critical in Welsh newspapers. For example, 
it was argued in the SWEP that the "Welsh assembly has been criticised for not being Welsh enough - having distinctive policies which set Wales apart from the rest of Britain" (Walters 2000: 10). The Assembly under First Minister Rhodri Morgan therefore brought forward a new policy document entitled "Better Wales", which was imagined to create specific Welsh policies, and had been developed under Gower AM and the Assembly's Finance secretary Edwina Hart (ibid). This process was welcomed by Plaid Cymru, which at the time had some influence in the re-drafting of the strategy. Nevertheless, they argued that the paper did not go far enough, and that there are "significant defects" in the model of self-rule of the Welsh assembly (ibid).

In summary, what this narration of a missing 'Welsh-ness' points towards is that national identity is not necessarily reinforced through direct ideological support, but rather through a continuous discursive background that structures the media narration. This reflects what Billig (1995) conceptualised as ‘banal nationalism'. Specifically, there are three themes that recur: the financial cost of dispersal, the notion of this logistical cost as a 'burden', and the imagined imposition of this burden from the outside (i.e. by the British state). Nevertheless, Mooney and Williams (2003: 609) argue that discourses of 'the nation' permeate not just this kind policy making and political debates, but also parts of civil society. The next section therefore examines the relations between media narrations and civil society accounts on imaginaries of sanctuary and identity.

This chapter started with an activist's interview account that described how after the initial emergence of discussions in the local papers, a public meeting followed in the Unitarian church, described as "the traditional meeting place of the kind of multiple left: Socialist Workers, Trade Unionists, Quakers” (Interview, 2 November 2017). It was from this meeting that the first large refugee support organisation in Swansea would eventually emerge. The next chapter will therefore draw on interview accounts to examine in more detail this civil society response and how it affected subsequent sanctuary imaginaries. For now, as our focus is on media narrations, it is important to note that both the meeting and the subsequent emergence of the group was reported on by the South Wales Evening Post on several occasions.

The first time this meeting was reported was on June $5^{\text {th }} 2000$, when the Swanseabased paper ran the headline "Meeting in aid of asylum seekers" referring to this public 
meeting (Speers 2001: 22), followed by a second article at the $23^{\text {rd }}$ August 2000, which stated that asylum seekers "will get a warm welcome" (Drakefield: 2000). The Council's Chairman of Housing, John Davies, stated that Swansea would give a "warm Welsh welcome to all asylum seekers", but that the local council should still be: "compensated by the Home Office" (Greaney 2000: 5). This statement indicates the emergence of another theme that would accompany the local narratives around the dispersal programme: the framing of Swansea and Wales as places, as a city and a nation, imbued with characteristics of welcome and hospitality. But this begs the following question: What exactly is this so-called "warm Welsh welcome" that all asylum seekers can expect in Wales?

First, what is interesting to note is that the precise formulation of a "warm Welsh welcome' returned numerous times in Welsh newspapers reports on the dispersal policy, with a specific focus on the Welsh-ness of this welcoming. In her analysis of newspaper articles between April and December 2000, Speers (2001) found that the Welsh press, in comparison to papers with a Britain-wide circulation, gave significant space to those who wanted to welcome asylum seekers - mostly quoted to be government officials or local councillors. Some examples of this national framing she assembles include: to 'Give a warm Welsh welcome' (Herald of Wales, April 13 in Speers 2001) or the 'desire to promote understanding of the plight of refugees and asylum seekers and to build on Wales' tradition as a 'welcoming nation' (South Wales Argus, November 11 in Speers 2001). She references here Edwina Hart, the former Assembly Minister with responsibility for asylum seekers and John Griffiths AM for Newport East as politicians who have attempted to frame the discussion in terms of giving asylum seekers a 'Welsh welcome' (Speers 2001: 39). Robinson (2003) summarises Speers' analysis thus:

She also praised certain Welsh politicians for adopting and disseminating a more positive attitude towards dispersal than their English counterparts and notes how the press and politicians had made a good deal of the warm Welsh welcome being offered to asylum seekers, and how this formed part of the tradition of Welsh tolerance (ibid: 191-192).

There are two important statements to deconstruct, which will help us to identify the different elements that are meant to constitute this 'warm Welsh welcome'. The statement ends by claiming that this national welcome forms part of a 'tradition' of 
Welsh tolerance. A central element that one can see returning in this framing of a warm Welsh welcome is the argument that it forms part of a long and continuous history. Speers (2001) references here an example from the Denbighshire Free Press and the Evening Leader, which reiterate that: "There is in Wales a strong tradition of humanitarian action in response to persecution and injustice" (ibid). Moreover, this argument also appears several times in the SWEP. This is not just an illuminating example of historical precedents of (national) sanctuary imaginaries, but also a clear example of narrating the nation through the idea of time as unbroken and continuous, which Anderson (1991) has reiterated in his examination about nations form in Imagined Communities.

In his discussion on 'moral urbanism', Darling (2013) argued that discourses of hospitality and asylum in the city have often been framed through the production of a distinct narrative suggesting that a place possesses a 'proud record' and 'long history' of hospitality (ibid: 1789). He described how a 'tradition of welcome' and a sense of a place embodying those virtues took place in Sheffield, shifting the formation of identities from that of a 'dispersal city' to one of a 'welcoming city' through resonating memories (2013). This imagined tradition is often foregrounded on behalf of the city by politicians, councillors or the local press, through which the city's relation to its past is presented as homogenous, clear and benevolent (ibid: 1789). Massey (1995 in Darling 2013) has also argued that: "the identity of places is very much bound up with the histories which are told of them, how those histories are told, and which histories turn out to be dominant" (ibid: 186). This literature helps us to identify the first constitutive element of the 'warm Welsh welcome'. This is that self-imaginaries are constructed through a similar discursive dynamic to that of moral urbanism, referencing an 'tradition' of welcoming, but which is constituted through a national frame foregrounding Welsh-ness.

Once again, this framing of a distinctively Welsh tradition of welcome and hospitality is a recurrent but not a general phenomenon for a 'Welsh' media narration. In fact, the data suggests that there is no uniform or coherent narrative of a 'warm Welsh welcome'. For example, when Powys Council was asked by the Home Office to prepare accommodation for twenty families, the council officers chose ten flats in the Penybryn area of Ystradgynlais, and then called a public meeting to discuss the implementation with the local community. The SWEP reported that "Asylum seekers 
plan sparks fury", with residents in the valley described as being furious, and claiming that the families would not be welcomed (Davies 2000a). The paper continued to report on the hostile developments, with a second article entitled: "Asylum seekers no threat claim". It describes how, at a packed meeting, the residents were assured that asylum seekers "descending" on their town would not threaten their lives (Davies 2000b: 4).

However, what is also interesting is the second element of the 'warm Welsh welcome' narrative. Robinson's (2003: 191) earlier summary argued that Welsh politicians had adopted a more positive attitude to the new dispersal policy, specifically more so "... than their English counterparts". The emphasis of the framing here is on the more positive attitude than their English counterparts. In this way, these welcoming selfimaginaries are also constructed through a politics of differentiation from a less hospitable other. What, then, is a "warm Welsh welcome" exactly? First, it is the desire to promote the understanding of the plight of refugees and asylum seekers - a framing like that of the City of Sanctuary network, making this a historical precedent of such imaginaries. Second, for the newspapers, it is through such promotion that one builds on the 'tradition' of Wales as a 'welcoming nation'. And third, the warm and specifically Welsh welcome is one that is characterised as being a 'more' form of welcoming than the British equivalent. This conceptualisation is supported by other empirical examples. For example, Robinson (2003), in concluding a survey on attitudes towards refugees and asylum seekers in Wales in 1999, posited that these were also shaped by a 'culture of denial', which "assumed that racism and exclusion were less virulent in Wales than in England, and therefore that refugees did not face any unusual or noteworthy problems living in Wales" (ibid: 188-189). These historical precedents of place-making and identity formation will be helpful in examining further what it means to declare oneself as a "Nation of Sanctuary. The next section will therefore examine in more detail this politics of differentiation from a more hostile other.

\subsection{The British National Party in Swansea and Wales}

These narratives of a homogenous, welcoming place run into difficulties with regards to stories from activists themselves, including members of migrant support groups. These groups were established to welcome asylum seekers, as well as to transform 
urban imaginaries, and provide contrasting perspectives to those often reported in the media. Indeed, activists frequently alluded to the fact that the SBASSG was in large part established in direct reaction to hostile public responses to migrants. Indeed, formal organisation was largely motivated after an informal meeting of individuals seeking to discuss ways to support newly arrived migrants in the area "was attacked by a bunch of hard-right fascists", going on to explain that "out of that came the decision to set up a support group for asylum seekers" (Interview, 2 November 2017). Moreover, this was not a singular incident or isolated experience. Rather, these experiences of hostility, and the responses they provoked, are part of the broader story of the implementation of the dispersal system in Wales. Indeed, there were several instances in which the implementation of the national dispersal system, the formation of refugee support groups, and the presence and reaction of the BNP and other fascist groups overlapped and collided in Wales. To contextualise this group: The British National Party (BNP) is far-right, nationalist-populist and neo-fascist (Copsey 2007) political party that had emerged in the Britain in 1982, with its greatest presence level of electoral success in the early 2000s and their stance on the politics of asylum seekers and refugees thoroughly exclusionary, xenophobic and racist.

For instance, on $9^{\text {th }}$ April 2001, the police in Swansea separated one-hundred antifascist demonstrators from twenty BNP supporters which were marching down High Street to attend a meeting. The BNP had organised a public meeting at the Unitarian Church in High Street to "discuss asylum seekers" (Dicks 2001a). The counter-protest that had formed comprised representatives from the Transport and General Workers Union, the Anti-Nazi League, the SWP, and Welsh Labour and Plaid Cymru (ibid). The following month, there was another alert that the BNP was planning to march in Swansea. Protesters from the Welsh Labour Party, Plaid Cymru and the Welsh Socialist Alliance assembled outside a community hub in the city centre to leaflet, petition, and voice their concern that BNP supporters were planning to gather in St. Helen's Road, an area that is home to many migrant communities (SWEP: May 2001). As a result, more than one hundred protesters assembled in St. Helen's Road. Ultimately, while the BNP meeting ended up not taking place, the protesters still warned that Swansea was being made a target for fascist rallies (SWEP: May 2001). Robinson argues here that "increasing street activity by the BNP in Wales" suggested 
that they started to realize to what extent "public attitudes are in a state of flux and can be manipulated" (2003: 198).

The presence and electoral success of the BNP at the time was a phenomenon that stretched to different British regions. But, in the specific case of Swansea and Wales, it constitutes a challenge to the discursive framing of Swansea and Wales as a more welcoming place in comparison to others. Yet, this political dynamic of comparison was sustained and widespread. Two other notable examples stand out. The first concerns the so-called 'race-riots' that had erupted in Oldham and Burnley in May 2000, mainly between people from poor white and Asian communities. These altercations had been whipped up by BNP activists feeding false information about the financial support being received by migrant communities. Here, the South Wales Evening Post published an article stating that there was "No reason for riots over race" in Wales (Dicks 2001b). The paper had interviewed the Welsh race equality chief Naz Malik, who stated that there was no evidence to suggest potential social unrest in South-West Wales. He called for political unity and the inclusion of all communities, and stated that:

I believe that the difference in Wales is that there is no underlying resentment between the white population and ethnic minorities. And I believe that is because in England, New Labour has forgotten the poor. But in Wales the main political parties are to the left of their English counterpart's position, and therefore have not forgotten the poor areas (in Dicks 2001b).

The statement emphasises two notions that are associated with this picturing of 'Wales'. There is the imagined absence of racist sentiments, and the imagined differentiation of a Welsh socio-economic framework from neoliberalism, which is associated with New Labour and England. As we had seen with Plaid Cymru's MEP Eurig Wyn statement in the SWEP in September 2001, we can observe a similar politics of differentiation from the British state at a sub-national level, associated often with the national equivalent of England. However, the statement by the then Welsh race equality chief is also interesting for this discursive politics of differentiation. In actual fact, Malik's belief that there was "no underlying resentment" between different groups and that there was no basis for conflict in Wales was not borne out in fact. Indeed, Wales would later turn out to experience notable instances of racist violence. 
An infamous example is the Caia Park race riots in Wrexham in 2003. These began with an attack on a refugee in front of a pub, which led to attacks from 200 residents on refugees and police over a two-day period following the incident (al-Yafai 2003). Another example is the racially-motivated murder of Kalan Kawa Karim in the city centre of Swansea in September 2004.

Nevertheless, many mainstream policy actors in Wales continued to represent the influence of groups and parties such as the BNP as exceptions in the Welsh social and political landscape. For example, after the BNP organised a youth-camp weekend for teenagers in Mid-Wales, the then Welsh First Minister Rhodri Morgan stated in response that: "The fact that the only BNP candidate standing in Wales at the recent General Election got the lowest votes of his party anywhere in Britain was testimony to Welsh good sense" (SWEP: September 2001). One can see a trope of the "Welsh good sense" emerging, which parallels that of the exceptionalism of the "warm Welsh welcome". Here, the "Welsh good sense" combines notions of Welsh-ness with liberal cosmopolitanism, serving to exclude the BNP - their members, their representatives, and their ideology - from the 'imagined national community' (Anderson 1991). But it also frames this response also in comparison to a different 'other' - one not within Wales but rather outside of it. Indeed, the reference to the BNP receiving the lowest vote "anywhere in Britain" structures a comparison of Welsh national identity in opposition to Britain. Ultimately, this discursive politics of differentiation would also affect debates concerning the institutional process of political devolution, a process which the next section will engage with in detail.

\subsection{The Cardiff Prison hunger strike and emerging (Welsh) national self- imaginaries}

While the regional debate over the BNP in Wales was taking place, the new national dispersal system had started to attract criticism across the UK. The Home Secretary David Blunkett had ordered a report and review of the dispersal system, which followed the killing of a Kurdish refugee in the Sighthill Estate in Glasgow in August 2001. The focus of the media reporting during this period was on the internal operational review, focusing on "how well refugees are integrating into local communities" and suggesting that the government "must now accept the case for 
secure detention centres for all newly-arrived asylum seekers" (WM: 11 August 2001: 4). On the one hand, in such framing, the blame for a racist murder of a Kurdish refugee in Glasgow is discursively put on the alleged inability of migrants to "integrate". On the other hand, the instance seems to constitute a challenge to the evolving narrative that the devolved nations of the UK, namely Scotland and Wales, were in fact more welcoming than the sovereign British state.

In April 2001, a few months before the incident in Glasgow, the first dispersed asylum seekers had started to arrive in Cardiff. The integration of the devolved public services into the emerging hostile asylum regime had already begun to be recognised. For example, the South Wales Evening Post reported that these dispersed migrants' "treatment in the capital has been controversial because of their detention in the capital's prison, with trips to hospitals in handcuffs" (Bailey 2001: 5). Thus, a group of asylum seekers being held in Cardiff prison began protesting their detention while their asylum applications were being processed. This protest took the form of a hunger strike, which would turn out to be essential for shaping emerging Welsh narratives. The hunger strike lasted one week, from the $8^{\text {th }}$ August 2001 until the $15^{\text {th }}$ August 2001. The protest was a collective endeavour. All but one of thirty-one asylum seekers from Kosovo, Sudan and Afghanistan, which were housed together in a wing in Cardiff Prison, started their hunger strike with a refusal to eat their breakfast, and continued to abandon their meals throughout the day, while the Home Office and prison staff were trying to establish the reason for the strike (James 2001a). The strike captured the attention of the Welsh and British press. The Western Mail in Cardiff published six articles on the topic during the course of the protest, the South Wales Evening Post also reported on their plight, and the British $B B C$ online section published four articles covering the strike.

The first media engagement with the hunger strike emerged the day after it began, when the WM reported that National Assembly members from different parties had expressed concern on the issue. Even the leader of the Welsh Conservatives, Nick Bourne AM, called the detention a "clear scandal ... inhumane, degrading and quite frankly disgusting" (WM: 10 August 2001). The Labour AM for Newport East, John Griffiths, and Plaid Cymru argued that the asylum seekers were treated as prisoners. Increasingly, it seemed, the detention of the asylum seekers in Cardiff Prison had, as the Western Mail wrote, "angered the assembly" (Mason 2001: 8). Interestingly, these 
political reactions correspond closely with those to similar debates in Scotland in 2001, when the Scottish Executive was forced to respond to public concerns over the detention of children, and to allegation that this "was not, for want of better words, the 'Scottish way"' (Mooney and Williams 2003: 620).

In the case of the Cardiff Prison hunger strike, the staff refused to acknowledge what was taking place was in fact a hunger strike and spoke instead of "food refusal", emphasising that they had not been given a reason for the hunger strike. However, the $\mathrm{BBC}$ reported at the time that the detainees claimed they had been deceived by immigration officials, having been they were being sent to Cardiff, but not told they would be housed in a prison (11 August 2001). The Home Office responded by reiterating that their policy of housing asylum seekers in prisons, in place since December 2000, was a "temporary measure" while specialist detention centres were being built (BBC: 14 August 2001). Nevertheless, the phenomenon of detention, included instances such as these, has been conceptualised as rationalities to regulate mobility through techniques of exclusion. The techniques that accompany detention reconfigure territorial sovereignty in reaching beyond national borders. But they also move internally into everyday spaces, and creating confinements for migrants that operate outside of institutional structures (Mountz et.al 2012: 534).

In protesting this form of treatment, the hunger strike in Cardiff Prison emulated similar protests across the country. For example, one month earlier, detained asylumseekers in Liverpool Prison refused their food to protest their detention. Similarly, the year before, two asylum-seekers in Rochester Prison in Kent were hospitalised after refusing food for more than thirty days (Carey 2001). Back in Cardiff, after the remaining thirty asylum-seekers in the prison had lasted one week, they ended their hunger strike the following day. Ultimately, the Cardiff prison staff continued to deny that what had taken place was a hunger strike, and finally announced that the asylum seekers had their appeal turned down and were appropriately housed in prison while awaiting deportation (Sherna 2001).

The hunger strike in Cardiff nevertheless distinguishes itself from those in Liverpool and Rochester in England. Three months before the hunger strike in Cardiff Prison took place, the South Wales Evening Post had already reported on the handcuffing and detention of asylum seekers in a hospital in Cardiff during routine screenings. This 
treatment of asylum-seekers as prisoners and detainees had become public because of accounts made by healthcare staff in the hospital in Cardiff. When I talked to Aled Edwards, the former Chair of the Welsh Refugee Council, member of the Equal Opportunities Wales Advisory Committee and former Wales' Commissioner on the Commission for Racial Equality, about how he came to be involved in supporting migrants when the new dispersal policy began to be implemented, he told me about the strike. In fact, I had not heard of the detention of asylum seekers in Cardiff Prison before this interview about his experiences of working for several Welsh institutions. I therefore asked him how he became aware of the hunger strike taking place:

It was on the news. And it came from the health providers. And they raised concern. And it was at that time that I think there was a strong sense of civic society saying: In Wales, we don't deal with this, you know, we don't do it this way (Interview, 11 December 2017)

The first element is the reiteration that the strike was picked up by the media, specifically the national newspapers in Wales. This was an important element to create a discursive politics of differentiation from such an inhospitable detention. Moreover, the fact that the healthcare staff in the hospital in Cardiff brought the practices of handcuffing asylum seekers to the attention of the local press is interesting. It stands out as the first protest in response to the co-option of (devolved) public services into the emerging British detention regime. I was nevertheless curious about whether such a small act of protest really went hand in hand with the emergence of distinct Welsh civic society response, as Aled Edwards seems to suggest. In describing how emerging activities developed from a "strong sense of a devolved value base", he therefore elaborated on the political context of those values in response to the hunger strike in Cardiff:

And we used the committee structure of the National Assembly, to call UK officers to account. And I think, that was possibly the first time that this had been done, with any clarity of thought. And, you know, that gave you a sense of, of the beginning of a discourse. That in Wales, in a devolved setting, we would do things differently (Interview, 11 December 2017)

Moreover, this "beginning of a discourse" was not limited to refugee and asylumseeker support groups that were part of the third-sector and civil society in Wales. It 
also included individuals in the emerging realm of devolved Welsh politics, who were willing to drive this agenda, as Edwards reiterates. He mentions Assembly Member Edwina Hart, who played an important role in the newspaper narrations of a 'warm Welsh welcome', and further explains that:

I think Edwina always had this sense of what was going on in Swansea. So, she developed this narrative, as we all did, that in Wales, we do this. And in Wales, we don't do that. So, I think the mantra around the kind of prison thing was: in Wales, we don't wish this to happen here (Interview, 11 December 2017)

This summarising narrative of “in Wales, we don't wish this to happen here" resonates with earlier statements by Edwina Hart on the detention of asylum seekers in Wales. There, she declared she "will be suggesting to the equal opportunities committee that it conducts and evidence-gathering, questioning the Home Office, the Immigration Service, and NASS among others" (Bailey 2001: 5). This approach is interesting for two reasons. The first reason is that one can detect a politics of differentiation from an inhospitable British other, through the prism of asylum and migration - "we don't wish this to happen here", implying 'unlike in other places'. The second reason is that there is a new element to this rather discursive politics of differentiation, one that includes a conflictual side. Aled Edwards had reiterated in his statement that they sued the committee structure of the new Welsh National Assembly to hold British officers to account. This correspond here to Hart's statement that she was intending to use a committee of the Welsh National Assembly to critically question British institutions responsible for border control enforcement.

But what does the statement of "In Wales, we don't wish this to happen here" do, discursively? One could argue that it promotes the idea that discrimination and detention should not happen, but frames this point through a specific territorial logic of 'here' and 'there'. Therefore, one should still be wary of a potential implication that 'it can happen there, but not here'. Indeed, what is most interesting is that this narrative can work for progressive ends - such as attempting to take on the British government on asylum - but its logical corollary is that it may also be used as a means of absolving actors from challenging certain practices beyond the threshold or border. Indeed, this discourse keeps certain narratives of us and them intact. In this logic, the "national order of things' (Malkki 1996) is so pervasive, banal (Billig 1995) and ordinary that it 
becomes the very language of critique (see Closs Stephens 2013) that is targeting the exclusionary politics of asylum.

In summary, this hunger strike by detained and imprisoned asylum seekers in Cardiff, and the political reaction by Welsh politicians and newspapers offers a historical context that helps to further critically examine the new national imaginaries of sanctuary. Engin Isin argues that the emergence of new sites and scales of citizenship produces new actors that claim political rights. As he puts it: "What we need to understand is how these sites, scales and acts produce new actors who enact political subjectivities and transform themselves and others into citizens" (2009: 368). But who are the new actors in this context? The detained asylum seekers in Cardiff Prison challenged the new sites into which they had been forcibly moved with a hunger strike. However, their right to speak and to claim political rights was denied with the argument that this was not a political act ('food refusal'). But another example of new actors emerging on this scene is the civil society actors and Welsh politicians framing the hunger strike through the prism of the welcoming Welsh nation poised to challenge aspects of an emerging British asylum regime, thereby establishing new sites and scales for mounting a challenge to the Home Office. This was a more formal and recognisable way of acting politically, and appealing to the language of nationhood ensured that the critique was heard. However, challenging the exclusionary politics of asylum using this national frame has its own limits. Whilst it promotes a welcoming narrative, it also reinforces the territorial logic that produces the very idea of some populations as without territory (asylum seekers and refugees), and therefore not fully political actors.

This chapter also traced the emergence of two themes and narratives: first, the discursive construction and encouragement of the idea that Swansea and Wales were places that inherently welcomed people, and second, the implicit construction of emerging urban and national self-imaginaries against a more inhospitable British 'other'. These two narratives will assist us in further examining the emergence of the City of Sanctuary network in Swansea (Chapter 6), and the emergence of the notion of Wales as a Nation of Sanctuary (Chapter 7) afterwards. The former can be seen as a culmination of the first discursive attempts to frame Swansea as a 'welcoming place' that began with the announcement that the Home Office was planning the dispersal of asylum seekers to Swansea and South-West Wales, and the emergence of local debates 
in April 2000. These debates emerged following a strong sense of an imminent arrival of around one thousand asylum seekers. These numbers and this immediacy turned out to be exaggerated. It was almost two full years later, in February 2002 (see Bailey 2002a, 2002b) that around three hundred people started to arrive in Swansea. The social, political effects and geographical that then followed the moment of arrival are the subject of the following chapter. 


\section{Chapter 6. The 'revolution of generosity'? The emergence and development of Swansea City of Sanctuary until the "long summer of migration"}

Chapter 5 examined historical precedents of sanctuary imaginaries and the process of their emergence. But this has not given us a lot of information yet on what being a City or Nation of Sanctuary is meant to designate. This sixth chapter will therefore now investigate the moral dimension of different sanctuary imaginaries. What makes the "good city" (Amin 2006)? What makes the welcoming nation? To address these questions, this chapter traces the emergence of the City of Sanctuary movement in Swansea in 2008, and its development until the long summer of migration in 2015. The establishment of this movement lead to the emergence of numerous new sanctuary groups across Wales. This context is of importance, as it was from these local urban networks that the 'Nation of Sanctuary' image was adapted by the Welsh government.

The first section of the chapter begins by introducing the historical background and discursive precedent to the emergence of the local Swansea City of Sanctuary network, which was the founding of the Swansea Bay Asylum Seeker Support Group (SBASSG). The second section then investigates the emergence of the City of Sanctuary movement in Swansea in 2008, and the subsequent announcement that made Swansea the second official City of Sanctuary in the UK. The section will draw on both interview data and on documents retracing the application of the Swansea activist network to become an official City of Sanctuary. The theme of this section will be what one interviewee described as the "multicultural vs. doing" distinction regarding the focus of the movement. This refers to what acts and activities were imagined and pursued by the movement in relation to making the good city. This examination will therefore help identify what a welcome to newly arriving migrants is supposed to be, and what the welcoming city (or nation) might practically look like.

Subsequently, the third section will take a closer look at the network's further development after Swansea became a City of Sanctuary. The section will also investigate how this process was affected by the politics of austerity from 2010 onwards. It traces the neoliberal processes of professionalization and a moral 
responsibilization (Rose 1999) that emerged with financial cuts imposed on formal and informal support services for refugees and asylum seekers. The section uses interview data, which frequently referenced these processes. This is identified as a basis for the framing of moral responsibilities of the host, associated with the delivery of key support services by civil society rather than by the state. The politics in this process is situated in the management of expectations, which are gradually shifted from the state to civil society. The section uses these insights to examine the argument (Darling 2013) that such an internalisation of moral (b)ordering is an 'ethopolitics' (Rose 1999) of classification, through which local citizens (classified as 'hosts') are directed to decide upon the worth of sanctuary seekers.

The fourth section then describes in detail the long summer of migration in 2015, which is argued to be an important rupture for moral discourses, tactics and techniques on governing migration. It first investigates the brief but important discursive and political shift that the publication of the picture of the Syrian child-refugee Aylan Kurdi initiated in September 2015. This is being followed by an investigation of the effects this shift in mood had on the volunteers in Swansea, through what volunteers described as the "revolution of generosity". The section draws on interviews with people who were already involved in support groups, as well as on interviews with "new volunteers" who had joined and become engaged after this shift in public sentiment. The argument foregrounds how one recurrent theme in interviews with 'new' volunteers concerned how they saw their engagement in considerable part as a reaction and response to a perceived hostile and inhospitable climate. Specifically, this feeling was often associated with the limited support of the UK government for a population they saw as particularly vulnerable.

Finally, the last section will discuss in detail the important effects the events of September 2015 had on the moral dimension of the emerging devolved and national self-imaginaries and on the geographical and political implications. The first argument is that the moral dimension of those self-imaginaries developed from a form of moral self-governance towards a new form of moral antagonism during and after 2015. The first sections on the emergence of Swansea City of Sanctuary, and the neoliberal processes of professionalization and responsibilisation, trace how the imagined good city was created through a moral urbanism (Darling 2013). This urbanism had been co-opted through neoliberal rationalities of responsibility, a self-regarding and de- 
politicising framing with less need for political antagonism or an 'other'. The last section shows how new self-imaginaries after the 'revolution of generosity' emerged more in response to a perceived sovereign in-hospitality. The second argument is that this development from moral self-regard towards moral antagonism affected the arrival of a new spatial imaginary - that is, the image of Wales as a Nation of Sanctuary - which emerged from urban sanctuary imaginaries. This is a new discursive development, from city to nation, that has not yet been thematised in the critical literature on sanctuary imaginaries. But the following examination also contributes to the more theoretical literature on cities and citizenship. Isin (2007) suggests that only the city exists as both as an actual and virtual space, while all other bodies politic, such as states or nations, only exist as virtual rather than as actual spaces. This research project therefore provides an empirical grounding to the claim that virtual bodies politic such as the nation-state are kept together by practices organised and grounded in the city.

\section{1. "A meeting was called..." - SBASSG and campaigning vs. practicalities}

The discussions around the implementation of the dispersal system formed the political context in which the dispersal of asylum seekers to Swansea was announced. In the introduction to the last chapter, we heard an activist tell us about the context and motivation for the founding of SBASSG. In the initial interview, he continued to describe the first meeting of the group, and explained that "it was basically dominated by the SWP, with some actual refugees there". He mentioned the presence of a few Chilean families, who had gotten refugee status in the 1970s, and who were involved. The involvement of the Socialist Workers Party (SWP) and the Chilean community was new to me, which led me to inquire about the group's membership:

The membership was always quite fluid and fluctuating. There were people in various...various trade unionists, and leftist alliances, and whoever, you know, finding common cause in anti-racism and antifascism, supporting the idea of the slogan: 'Refugees are welcome here'. That was very important. And initially, we were producing leaflets, and getting stories into the Evening Post, and what...the way that I remember it, what happened is, about 2001, after eighteen month or so of this kind of work, the Welsh Refugee Council opened an office, and actual asylum seekers started to arrive (Interview, 2 November 2017) 
There are two central aspects here: the importance of leftist alliances and other various groups, with the common support of the slogan "Refugees are welcome here"; and the initial focus of the group in the first eighteen month of campaigning before dispersal came into effect, through producing leaflets and getting stories into the local paper (the SWEP). Indeed, in addition to Welsh politicians and local councillors, the SBASSG, in its nascent stages, was also instrumental in affecting newspaper narrations of the 'warm Welsh welcome' (see Speers 2001). Moreover, that no asylum seekers were yet dispersed to Swansea had two important effects for the group - one with regards to its legitimacy, and one with regards to its main function. Specifically, in the relative absence of refugees being resettled in the city to whom they could offer practical support, the organisation developed campaigning activities to raise awareness and protect their rights. The importance of this aspect was reiterated when I talked to three members of the SWP, who had been involved in the network since the beginning. One of the participants in the joint interview remembered that "it was a bit of an odd position", being conscious of how "refugees, migrants, were started to be scapegoated at the time", while there were not many refugees present who could participate (Interview, 15 April 2018) This self-identification as a "pro-refugee campaigning organisation" followed as a specific reaction to a political climate associated with New Labour. But the initial absence of a larger number of asylum seekers also influenced what group imagined its function to be, and how its organising principles would be imagined and affected once the dispersal policy came into effect. On this point, the interviewee described: “. . a bit of a tension between campaigning and practicalities. And it is not either or, it is about the balance between the two things. But sometimes people don't want to make things too political ..." (ibid).

While this tension between campaigning and practicalities became more immediate once the dispersal system came into effect, the discussion had followed the group since its first official public meeting at the Unitarian Church in Swansea during the summer 2000. Jose Cifuentes, a former political refugee from Chile who talked about his experience at this meeting, described people coming from "ethnic minorities, from the Socialist Worker's Party, from the Labour Party, from Chile Solidarity Campaign, from trade unions, people from different churches, and ordinary people" (Interview, 8 March 2018). In addition, a member of the SWP stated in the shared interview with regards to the motivation of the meeting that: "I think there was a sense that what we 
wanted to do, was to ... and it is a long way from City of Sanctuary, but, encourage the idea that Swansea was a place that welcomed people" (Joint Interview, 15 April 2018). These reiterations of the idea that Swansea was a 'welcoming place' is here described as a clear historical precedent to the motivation of the broader City of Sanctuary movement.

\subsection{The second city: The emergence of the City of Sanctuary movement in Swansea}

Chapter 2 had shown that the City of Sanctuary movement's aim is to 'build a culture of hospitality and welcome for asylum seekers and refugees' in different local contexts. But how did the formation of those imaginaries develop in Swansea specifically, which would follow Sheffield to become the second official City of Sanctuary? To unearth similarities and differences of this process in Swansea, in comparison with Sheffield and Glasgow, this section moves back and forth between the fieldwork and the literature on urban sanctuary. This helps to analyse the distinct elements that made national sanctuary imaginaries emerge from this specific spatial context $-\mathrm{a}$ theme that has not been examined in the literature in the topic. The formal process started with the setting up of the Swansea City of Sanctuary (SCOS) Steering Group in June 2008 through Alan Thomas and other activists, which had followed the first national conference of the new City of Sanctuary movement in Sheffield the same year. The aim for the local network that emerged from this conference is stated in detail in the official application to become a City of Sanctuary:

While building on the work of specialist refugee and asylum organisations, both voluntary and statutory, it aims to go beyond them, using the 'City of Sanctuary' process to promote a culture of welcome more broadly and adding to the already existing support for those seeking sanctuary (SCOS: 2010).

Alan Thomas, one of the founders of Swansea City of Sanctuary network, described that, not unlike in Sheffield, there were a range of people working for volunteering organisations as well as for the council. Those refugees and asylum seekers in Swansea and the people working with them formed "a little bubble" (Interview, 27 July 2017). The fact that this professional support staff seemed to have formed a little bubble with 
the asylum seekers and refugees they were working with, appeared to the early activists of Swansea City of Sanctuary as a problem. This was primarily in the sense that "nobody else in the city knows much about" the specific topic and issues faced by asylum seekers and refugees (ibid). Even those among the local population that were sympathetic to welcoming migrants would have little knowledge on how many asylum seekers were living in the city, and what their living circumstances were (ibid). In light of the increasing number of asylum seekers in Swansea, the founder summarised:

Basically, the point of this exercise is to promote a culture of welcome, it is not actually about doing welcome. Because other people do that ... You would say they promote culture rather than doing, because doing was happening anyway..." (ibid).

The distinction between fostering and 'doing' welcome serves to set apart the provision of formal services to asylum seekers and refugees, many of which were provided through the City and County of Swansea and its Asylum Team and Housing Options Services (SCOS: 2010), from that which ordinary citizens could do to welcome them. Indeed, in addition to housing management, the council team had expertise and knowledge about asylum, which meant they would cover a range of other formal activities associated with welcoming: meeting people, showing them around, and following up if there were initial problems (Interview, 27 July 2017). This is the context in which the 'culture rather than doing' emerged:

So, there were people whose job was to welcome, is what I am saying. Now, that didn't link them into the community. You know, because it was a job done. But it linked into at least this bubble of people who it was trying to work with. And so, it was trying to go beyond that (ibid)

The subsequent privatisation of the housing of asylum seekers and the effects on those services would be of big importance, and we will return to them in the next section. For now, what we can summarise is the specificity of the 'culture and doing' that is emerging in this framing. Indeed, by 'going beyond', the CoS movement was trying to affect broader self-imaginaries. The application of the Swansea movement for national recognition was largely based on listing and emphasising main activities and achievements, such as seeking pledges of support from organisations, encouraging organisations to take welcoming actions and include those seeking sanctuary, creating 
communication between both supporters and the public, as well as getting support from the City and County of Swansea (SCOS: 2010).

To understand why the City and County of Swansea passed a unanimous resolution of support in December 2008 (ibid) one needs to investigate the last aim in more detail. At the time, SBASSG was organising events around the topic of asylum, and as one of the founders of COS reiterated, "there has been quite a lot of input from, I call them SBASSG members, in the founding of the City of Sanctuary movement in Swansea" (Interview, 28 March 2018). During one of their events, the steering group managed to include two local councillors, and one of them voiced his immediate support:

"Oh well, I'll get the council to pass a resolution". But he was very, very keen that it should not, that it shouldn't ... He didn't want there to be even one independent who abstained, you know. He wanted it to be completely unanimous. And he wouldn't put this resolution forward until he was sure that it would be (Interview, 27 July 2017)

The second important aspect that needs to be considered is the sense of pride that would follow. In their application, the Swansea movement emphasised: "We hope to utilise the achievement of national recognition as an occasion for civic pride" (SCOS: 2010). The concept of civic pride as a grounding for gaining official recognition was also something referred to in the interviews. Whenever someone would need a reference to multiculturalism, Alan Thomas explained, they would use the terminology:

\begin{abstract}
"Swansea as a proud City of Sanctuary", they would say it in passing. Once I heard somebody, some politician say that they we were proud that Swansea is a City of Sanctuary since 1990 [Laughing] So, I think it became part of that, that level...I wouldn't say the general population knows about it. But at the level of the political class (Interview, 27 July 2017)
\end{abstract}

This is an appropriate point to return to the literature on the sanctuary movement to determine the similarities and perhaps differences from this process in Swansea, compared to other places. To do this, we need to return to the historical context during which this movement emerged and organised. In September 2005, the social movement City of Sanctuary had been set up in Sheffield, with the aim of building a "culture of welcome and hospitality towards asylum seekers and refugees" (Darling: 
2010). The movement also has the aim of altering the identity of the city as a 'welcoming place', and to form geographical (self-) imaginations that challenge debates on asylum cast in the language of territorialised fear and unease (Darling 2010: 129). With this context in mind, Darling (2013: 1785) thus examined how the city of Sheffield discussed, narrated and constructed an account of its own relations to refugees and asylum seekers in the form of a moral urbanism - the "discursive and affective construction of particular cities as being imbued with moral characteristics".

One aspect of this moral urbanism is the creation of a narrative of Sheffield possessing a long history of hospitality, which signals an imaginative geography that connects imagined past and projected future of the city to a set of moral registers around the hospitable accommodation of (some) refugees and asylum seekers (Darling 2013). This imaginative geography is embedding moral norms around hospitality into what Sheffield means, creating the sense of the city as a space which is attached to, or embodies, moral virtues (Darling 2013). This can also be seen in the case of Swansea, with the recurrent encouragement of the notion that "Swansea was a place that welcomed people" (Interview, April 2018). Amin enquired here about the nature of such a "good city" (2006). He imagines a habit of solidarity and ethic of care towards the stranger, through building and maintaining a "certain ease with unassimilated difference and agonistic disagreement" with the help of local media, politicians and the broader civil society (2006: 1016).

There are other similarities in this process between Swansea and other cities. Darling (2010) argued that this spatial re-imagining of Sheffield as a City of Sanctuary has been successful because it managed to provide a unifying force for different interests in the city. It provided a "unifying sense of ethical value", and it added a "sense of pride" to Sheffield's identity (Darling 2010: 133). This is also the case in Swansea, made apparent in the focus on securing a unanimous decision for official support, around which different interests in the city could assemble a unifying sense of ethical value. The importance of imagined unity and coherence for the formation of territorialised identities seems to be of importance, so that a place can be constructed as being 'behind' a resolution (in the sense of lending it its support). Malpass et al. (2007: 639) argues that such forms of political identification could also be detected in Bristol' campaign to become a Fairtrade town: "By connecting place imagination to fair-trade, the local authority gains a sense of worthiness...". 
This constituted an attempt at re-imagining Sheffield as a space of virtue (Darling 2010) from which demands for moral responsibilities could be formulated. Thus, the literature on moral place-frames argued that these geographies of responsibilities resonate with Massey's (1991) notion of a 'global sense of place'. Tuma et. al (2018: 98) reiterate in their summary of this literature that: "place-based responses to the global issue of refugees necessarily involves a negotiation of scale". This has the effect that the: "assertion of progressive, humanitarian values in the framing of places may conflict with the immigration policies of the nation state" (Ibid) Thus, place identity in designations such as "welcoming cities" and "cities of sanctuary" may be statements also intended to differentiate cities and towns from the discursive position of the nation (McDaniel, 2018 in Tuma et. al 2018).

The first issue in Swansea is the idea of 'proud records' and histories of hospitality. The second theme is the interpretation that follows the description: that the notion of Swansea as a City of Sanctuary, and the associated 'civic pride', was anchored in the 'political class', and not the 'general population'. This resonates with the goal of going beyond the work of the existing support services towards affecting a broader culture. The goal of affecting a broader culture is for Alan Thomas also a distinguishing element between different groups of the movement: "the other big difference, between the different cities, is this thing about Multiculture versus doing" (Interview, August 2017). This reiterates an important difference of the process as it was taking place in Swansea, in comparison to Sheffield. Moreover, when the new movement started, the process of recognising cities "was a bit modelled on Fairtrade towns" (ibid). Following this model, Swansea became the UK's second official City of Sanctuary in 2010, with the support of one hundred local organisations. This included Welsh refugee charities, various community and voluntary groups, different churches and mosques, university departments, schools, the police, the Swansea Council for Voluntary Service, the South Wales Evening Post, and the City and County of Swansea (SCOS: 2014). The following table (SCOS 2010) lists all the organisations and instituions that had pledged support to Swansea City of Sanctuary in May 2010, before the official application of the Swansea movement for national recognition was presented and ultimately accepted at a conference of the wider national movement in Sheffield: 


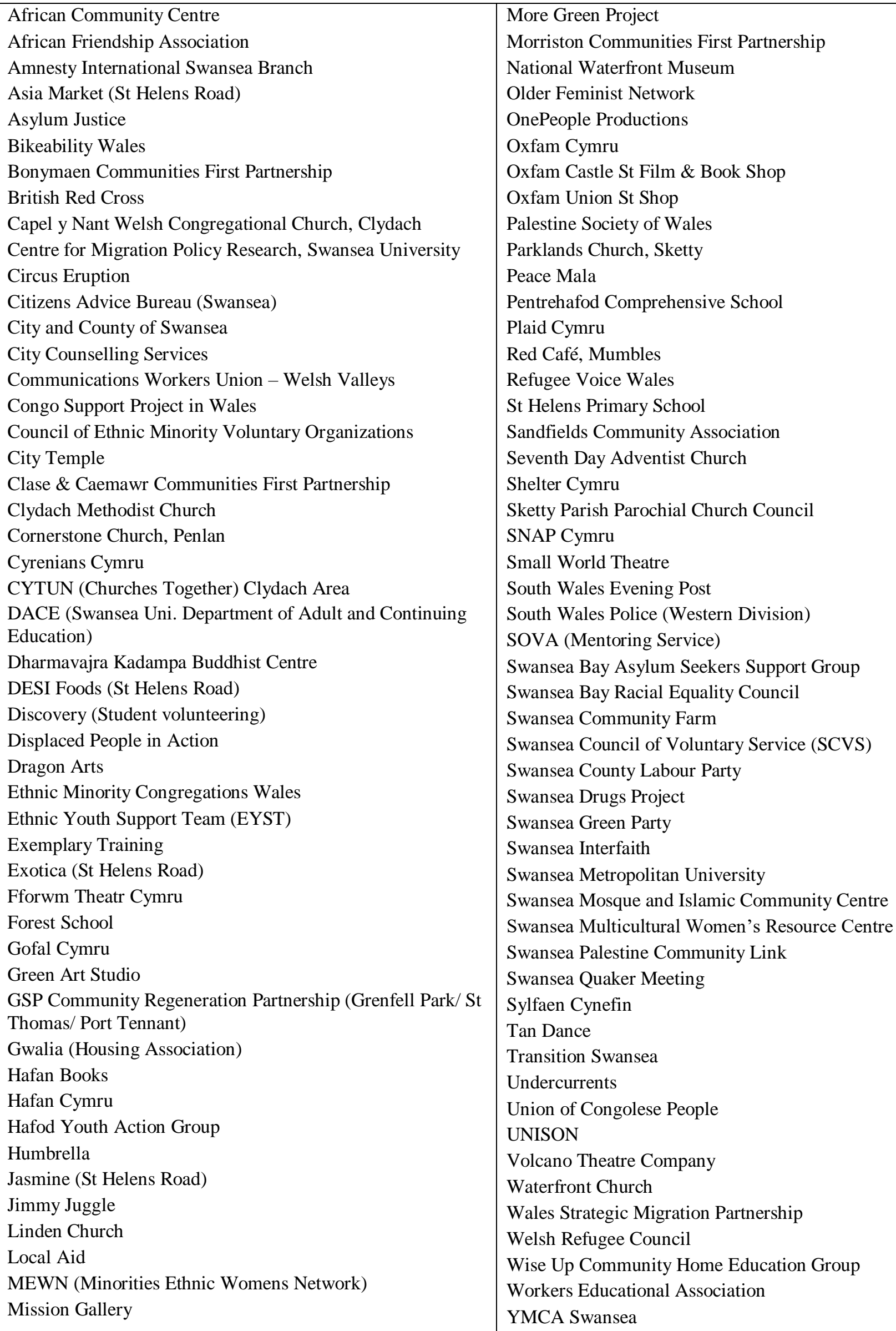


The aim of the sanctuary network was also to 'build a culture of welcome and hospitality'. Nick Gill (2018) argues in this context that welcome has an emotional and relational character:

Welcome is more than simply permitting entry. It involves conveying to the newcomer the positive reception of their presence. Welcome relies upon human warmth and, to a degree, the vulnerability of the welcomer. As such it cannot be mechanistic and unfeeling (Ibid: 91).

For Gill (2018: 88), this means that it is possible to distinguish between a bureaucratic tendency to abstract welcome into a specific problem or policy issue, and a different tendency to welcome in more emotional, solidaristic and autonomous ways. This resonates with the distinction of 'Multiculture vs. doing', or between 'campaigning and practicalities' we see in the case of Swansea. This is of importance for the theoretical discussion on imaginaries of hospitality, as sanctuary movements have used the culture of welcome and a culture of hospitality interchangeably. Gill (2018) points out that hospitality has often been understood more in terms of rights and duties (Derrida 2000) with practical rather than emotional focus, instead emphasising the provision of food, drink and shelter (Lynch et al. 2011 in Gill 2018). This prompts the following questions: Is the welcoming city one that focuses on a culture of welcome with a more emotional component? Or is it a focus on the preparation of welcome in terms of services, or rights and duties towards the stranger that is more resonating with the concept of hospitality? Perhaps there is not a clear-cut answer to this question. Indeed, perhaps it is both. In his work on the notion of the good city, Amin was unsure of the likelihood that such an expanded urbanism would include equal duties of care towards the stranger:

The ethos of unconditional hospitality that Jacques Derrida (2001) has invoked from Europe's cities in the name of their old duty of sanctuary when life outside the city was barely protected has either been long forgotten by modern-day universal welfare systems or it has been gradually redirected by states towards targeted social groups under the pressure from neoliberalism (2006: 1015)

Moreover, during the period when the movement began to formalise, and especially during its application for Swansea to receive City of Sanctuary status, changes to the envisioned distinction between culture and doing began to emerge. For instance, the 
second founder of the Swansea City of Sanctuary group described part of her rationale for setting up the application at the time: "And I am afraid a lot of my initial motivation with City of Sanctuary was, we just needed money, and we just needed a bigger movement to draw on if things were going to happen. I think that's something that still needs remembering" (Interview, 28 March 2018). While the moral self-imaginaries of this movement had initially developed around a "unifying sense of ethical value" (Darling 2010), emerging external pressures would assist in the co-option of these imaginaries as a new means of governing. It is thus the pressure of neoliberalism the chapter will now turn towards.

\section{3. "Two huge changes": Professionalization and neoliberalism in the City of}

\section{Sanctuary}

The fact that Swansea had been a dispersal area for asylum seekers since 2000, during which the first larger support group SBASSG was established, meant that the emerging Swansea City of Sanctuary movement could build on an existing network of supporters and activists. One of the founders of the COS network, who later became a member of the management committee, had previously been involved with SBASSG, which she described as: “...it was small numbers, it was genuine friendships, real partnerships" (Interview, 28 March 2018). She and another activist from this time described fluctuating numbers of people, which meant that the movement quickly outgrew the small café they were meeting in. After I asked her more about the 'changes in culture' she had mentioned, she explained that there had been structural changes:

There were two things that happened, that were huge changes, and I mean, they certainly made a big difference to my volunteer involvement. And made it much harder. Much, much harder. More satisfying, but much harder. So, two contracts changed. One was, the housing contract changed. [...] Which meant that it was just Clearsprings. So, it was monolithic. G4S, Clearsprings, all over the UK. So, and Clearsprings didn't ... and, you know, the Swansea team, the local asylum, the local authority team, as well as running the houses, they did support. And they had a different ethic. And then, of course, there was the fact that the support contract was again barned out to one national organisation (ibid)

We should start by noting that what the activist identified as "huge" changes to her volunteer involvement - namely changes relating to service providers - coincided with 
two other developments: the emergence of the City of Sanctuary network in Swansea, as well as the beginning politics of austerity. In 2010, the Home Office first announced that it would pass contracts for accommodation and reception of asylum seekers to private companies. This meant the beginning of the end of local authority control over housing (Darling 2016b). The 2013-2014 annual report by the CoS network provides here more context and explanation, and dedicates a whole section to what is called an "Upheaval in the Official Refugee Sector" (SCOS: 2014). This report states that the process begun with large cuts to the professional refugee sector in 2011, followed by accommodation contracts for asylum seekers being exclusively awarded to private firms and providers (ibid). The signing of those six accommodation contracts in March 2012 marked for Darling the "latest phase" of dispersal politics on a no-choice basis which had started with the 1999 Immigration and Asylum Act (2016a: 230). Moreover, he argued that it marked a significant change for asylum support in the UK, as it transferred the provision of accommodation for asylum seekers from "a mixture of consortiums of local authorities, social housing associations and private providers to just three private contractors" (2016a: 230).

The political context to this development had been a Conservative-Liberal Democrat coalition which had started to implement a politics of austerity in reaction to the financial crisis in 2008. Thus, the changes to the housing contracts were accompanied by cuts across the sector, as well as important changes to asylum advice contracts (SCOS: 2014). Those advice contracts, which had previously been held by the Welsh Refugee Council and an Asylum Support Partnership Consortium were lost in 2014, and replaced with a single advice service across the whole of the UK (ibid). Here we see the initial and significant effect the politics of austerity had on the "professional" refugee sector, and especially for statutory support services. The Chief Executive Officer of the British Refugee Council, Maurice Wren, argued that the refugee councils and other non-governmental organisations should: "No longer think in terms of a comprehensive professionalised service, but must start giving increased importance to grassroots movements like City of Sanctuary and working more through local partnerships" (ibid).

I argue that the sentiment which emerges here with regards to the role of the City of Sanctuary network coincides with a parallel neoliberal economisation of political and social life, including the management of expectations, behaviours and ethical values 
(Bulley 2013, Walters 2004) and the increasing governance of subjects through moral justifications (Rose 1999). This was by no means a process that was deterministic, or that developed neatly from a moral urbanism towards a moral nationalism. The point is rather to assemble the different contextual elements that came together at a certain place and time to produce a distinct discursive outcome. The focus is therefore on how these very contextual moral imaginaries were integrated and used in broader neoliberal paradigms. The section shows that there is an emerging shift towards "doing" in substituting for those cut services, rationalised through a 'professionalization' of those informal support networks. This is followed by a moralised 'responsibilisation' of that support (Rose 1999). Wendy Brown argues (2016) that a crucial feature of neoliberalism is the conversion of non-economic activities and subjects into economic ones. Neoliberalism aims to undermine state regulation or intervention, exploiting liberal notions of autonomy and freedom to devolve decision-making and responsibility to the individual subject. It also integrates them into a different set of socio-economic imperatives: the predicaments of capital (Brown 2016).

This neoliberalisation is exercised through two techniques. First, an emphasis on implementing practical solutions for technically defined questions, which supersedes political or normative dimensions of policy with technical approaches (Brown 2016). William Walters (2004: 36) notes that this technical discourse on 'governance' seeks here to redefine the political field in terms of liberal assimilation and consensus. This discourse builds on the post-ideological claim to be more pragmatic and solutionsoriented It also emphasises the consultation of different actors that are now subjectified as "communities", "partners" and "stakeholders", to facilitate consensus and "multiparty cooperation" (Walters 2004). However, without creating any meaningful collectivisation through such forms of integration and cooperation, neoliberal governance isolates and entrepreneurialises individual units by devolving responsibility and decision making, through locally implemented norms of conduct (Brown 2016: 5). Considering the comment from the activist, these critical conceptualisations are important to evaluate what structural challenges exercising the idea of a Welsh Nation of Sanctuary might face in practice.

\subsubsection{The 'Welcome to Swansea' Scheme: Professionalising informal support groups} For one of the founders of SCOS, two structural changes affected the development of the local movement after the adoption of austerity measures by the UK Government. 
First, the changes to the housing contract for asylum accommodation, and second, the centralisation of the asylum support contracts. It is therefore necessary to investigate more closely how the new City of Sanctuary movement reacted to those two structural changes to draw out the impact that wider political processes had on shaping local activities. Before the changes to the housing contract, the City and County of Swansea was one of the main providers of accommodation for asylum seekers, through their Asylum Team and Housing Options Services (SCOS: 2010). Changes to such service provision demonstrates again that the emergence of a neoliberal moral urbanism was not pre-determined, and that it could have been different at various turns and points in time. Moreover, in addition to housing management, this local team would cover a range of other activities associated with 'welcoming': meeting people, showing them around, and following up if there were problems. This form of support was what one founder identified as "a different ethic" (Interview, 23 March 2018). While the private housing provider - Clearsprings - had held asylum housing contracts in Swansea before, it was only from 2012 onwards that the local authority lost their remaining contracts, and all asylum accommodation in Swansea was privatised. Following this, the quality of the housing for asylum seekers became poorer. This effect has been widely documented by other migration scholars (see Darling 2016a, 2016b). In addition to a degradation of housing services, another difference pointed out is this:

The Clearsprings contract includes something about welcome, but, as far as I can see it, it doesn't happen. It may happen on paper, they may produce, you know, a pack of information. Which is not necessarily very much use to a person who is somewhat traumatised and doesn't speak English. [...] So, they may do something that allows them to tick, but they don't do it in a real way, which is the reason behind the thing like the mentoring, or the Welcome to Swansea scheme now. But at the time, the council did do it, I would say (Interview, 27 July 2017)

This comment raises two interesting points. First, the difference between the private provider and the council team is pointed out and, in particular, the fact that Clearsprings is not doing the welcoming "in a real way" is emphasised. The second is the mentioning that this lack of activities, as compared to the council team, is the reason for setting up the 'Welcome to Swansea' scheme as a meaningful alternative, to address a perceived gap. The 'Welcome to Swansea' scheme is a mentoring scheme which sees volunteer mentors meet with participants for two to eight times and support 
and "encourage participants to develop knowledge, skills and confidence" (SCOS: 2015). In time, mentees may go on to become mentors themselves for new arrivals. Mentoring might involve, for example, explaining and showing bus routes, access to services, or safe places to meet. Sarah*, a former asylum seeker, volunteer and member of City of Sanctuary, who had arrived some time before the changes to the refugee support sector started to be implemented, described in detail the kind of support she received from the local authority support team:

So, you had a support worker. They're the person from Cardiff in [...House], once you've been dispersed. They bring you to your house. Kind of like show you around: "Okay, this is what you do, this is what you don't do", let you sign your contract for the house. And then they'll come back and kind of show you where you collect your money, where to do your shopping. Kind of like just the most important stuff. (Interview, 28 July 2017)

The similarities of the activities of the Welcome to Swansea mentoring scheme with the local authority support team are apparent here, suggesting a keen sense, across the organization, of what needs are no longer being met through statutory services. In addition, what is interesting is that Sarah*, who is also a former mentor with this scheme, describes these to service provision over time: "When I arrived in Swansea, they used to have an Asylum seeker support group, within the Swansea council. So, they did, kind of, what we do now" (ibid).

Moreover, a similar process of substituting for increasingly patchy services can be detected with regards to the second significant structural change: the centralization of the asylum support contracts. During our interview, a second long-term member of the movement explained that, not unlike the housing contracts, the asylum advice contracts were originally divided between different agencies across the country. The Welsh Refugee Council (WRC) held the contracts in Swansea and Cardiff, the two larger dispersal areas in Wales. The WRC ran a one-stop-service, which she described in the following manner: "everybody knew, all the asylum seekers knew, that if they needed some help, navigating the system, they went to Welsh Refugee Council”" (Interview, 28 March 2018). This service was described as well-staffed: "they had an office, dedicated to this. They had a manager, and two or three case workers devoted to helping people negotiate the system" (ibid). This service was forced to close in 2014. 
This had a significant impact on the volunteering. The interviewee explains: "that was done by a team, a specialist team, employed by the Welsh Refugee Council before. So, a huge reduction in service. And it had a huge effect on the pressures on volunteers on the ground" (ibid).

But how did the cuts to professional, statutory services became an issue for a social movement that was intending to affect a broader cultural change? One more example from another interview illuminates this dynamic. The director of the Ethnic Youth Support Team (EYST) in Swansea, Rocio Cifuentes, explained how the support was dropped and replaced by a phone-line service run by Migrant Help. This neoliberal rationalisation also affected her work:

So, they are just trying to centralise and rationalise these services but they are not as effective. And people picking up, compensating for that are services like ours where we spend hours and hours on the phone to Migrant Help, just on hold, waiting in a queue, with the client next to us. So how many man hours are being lost in that process? (Interview, 8 February 2018)

The extent to which the aim was to rationalise those services as part of a neoliberal imaginary, or rather justify the politics of austerity in those terms is less important. What is more interesting is the effect it had on organisations such as EYST, who are forced to substitute for part of those cut services. The structural change that followed the politics of austerity, and primarily the fact that informal groups and third sector organisation were forced to take on additional work to substitute for those cuts, created a more discursive change. The structural changes were being accompanied by moral justifications in terms of 'responsibility'. These imaginaries resonate with what Nikolas Rose called an 'etho-politics' as the "double movement of autonomisation and responsibilization" (1999: 476). And neither the formal nor informal support groups for refugees and asylum seekers were immune to this pervasive politics of autonomisation and responsibilisation that neoliberalism would bring to Swansea.

\subsubsection{Responsibility and informal support: Moral justifications for neoliberal change} One of the founders of $\mathrm{CoS}$, and long-term members of SBASSG, interprets the effects of this neoliberalisation on the groups as follows: "Before, we were there as friends. But now there seems to be more responsibility ... There are more people wandering around not knowing what to do. And that puts more pressure on us, as volunteers" 
(Interview, 28 March 2018). This statement brings us back to the start of this section, where she had described her memories of the movement starting in terms of 'genuine friendships and partnerships'. This seems to have changed for her, not just because of the additional pressure on the members as volunteers, but also because there seems to be more "responsibility" that emerges with covering for such services. She states: "If you withdraw entitled support, it changes the nature of voluntary organisations. We become case workers, rather than friends. You can become friends as well, but... you know?" (ibid) What returns is the perceived change from friendship towards being a case worker who is 'responsible'. The topic of those structural changes returned in other interviews, for example with a long-term member of SBASSG, who explained how a lot of additional work that appeared consisted of applications for financial grants and various employment regulations rather than focusing on organising and running informal drop-ins for refugees and asylum seekers. The comment highlights the institutional and financial pressure to adapt and develop, which seems to be used as a justification for the increasing workload. Moreover, this statement by a member of Swansea City of Sanctuary who, with regards to the mentoring scheme, explains: "In an ideal world, it wouldn't be us delivering it, it would just be part of Home Office policy” (Interview, 19 January 2018).

This indicates a feeling of responsibility that drives those activists to step in and pick up the additional work they feel is not being done, even in the face of exhausting circumstances, or in conflict with personal preferences. The statement also suggests that, according to this volunteer, we do not, in fact, live in an ideal world. Instead, part of this politics of managing expectations of what it means to be host have shifted, and increasingly placed at the feet of civil society rather than the sovereign state. The implied sentiment here is: If we don't do it, who will? The moral self-imaginaries of urban hospitality move from the unifying sense of ethical value, towards a form of neoliberal responsibilisation and self-governance. This ongoing process of professionalization and responsibilisation also creates a third effect, as grant givers require groups to groups be effective and professionalised. An activist describes how as a further effect: "A small, informal volunteer organisation ends up excluding refugees from their management. Not excluding, because we would take good people. But, you know?" (Interview, 2 November 2017). 
This is an important point, because what you can see the emergence of unequal power relations between almost professionalised volunteers and new arrivals, often asylum seekers and refugees. This potential exclusion that was mentioned supports Squire's (2011) argument from Chapter 2, that the sanctuary movement can end up privileging the collective engagement of 'established' residents over those with a less established presence.

This is perhaps a good moment to summarise the similarities and differences in the process of an emerging moral urbanism in Swansea and other places, as the data suggests this was not a determinate process. In the literature on the topic of moral urbanism, Darling (2013) had stated that the inherent internalisation of a moral (b)ordering that accompanies such a process is an etho-politics of classification into deserving and undeserving migrants, through which "citizens are directed to decide upon the worth of sanctuary seekers" (ibid: 1789). He developed this argument with regards to how sanctuary framings by local media and politicians reinforce the notion of conditional hospitality and the distinction into deserving and undeserving. Yet, here what is interesting is that this etho-politics of responsibilisation went beyond translating the average citizen into the host. Instead, the same discourse that framed the volunteers as responsible for refugees and asylum seekers in their town also professionalised their activities and friendship-building, and ended up excluding migrants from those networks.

Squire (2011) argued that, in such contexts, it is therefore more informal aspects, such as the social interaction and everyday activities between community members and refugees that hold the more radical political potential. Her argument is that: "they trouble assumptions about who does and who does not have the right to be present in the city, and in so doing undermine the territorial hierarchies of inclusion/ exclusion on which a frame of hospitality rests" (ibid: 298). This is interesting for recurrent complaint, from volunteers, that they were forced to become case workers rather than friends to arriving asylum seekers and refugees, and raises the political potential of 'friendship'. In her article, Michelle Peterie (2018) challenges the constructed opposition between 'personal' domains of volunteering and the 'political' real of activism. She shows that volunteers in friendship groups not only understand their actions as a response to and intervention in a political situation that they find morally reprehensible (ibid: 400), but also that the relationships they facilitate are often just 
one step in a longer journey from the identity of caring "volunteer" to politically engaged "activist" (ibid: 404). But in addition to challenging such exclusionary frames from within the grassroots, change can also emerge from an unexpected outside event that affects established forms of governing migrants. September 2015 was such a moment.

\subsection{From the "revolution of generosity" towards a new moral nationalism}

In the morning hours of the $2^{\text {nd }}$ September 2015, Nilüfer Demir reached the beach of the Turkish town of Bodrum to document migrants starting their dangerous journeys to Greece. The "long summer of migration" (Hess et al: 2017) was already attracting attention in Europe. But what she documented during that morning would become the perhaps most well-known and powerful image of that summer. Three-year-old Aylan Kurdi, a Syrian boy of Kurdish-ethnic background, had drowned that day during his family's attempt to reach safety in Europe. His lifeless body was lying on the shore when she arrived to take pictures. While hostility had been the dominant feature of political and public discourses of the so-called "refugee-crisis", for a brief period the haunting picture became the "catalyst for an unprecedented outpouring of sentiments of compassion among media, the public and politicians" (Sirriyeh 2018: 55).

In Western Europe, the tone of dominant media coverage on refugees changed almost overnight (European Journalism Observatory 2015 in Sirriyeh 2018), even among British newspapers which are known for their hostile reporting on immigration (Philo et al 2013 in Sirriyeh 2018). Luca Mavelli (2017) argues that a reason for this response was that Aylan represented the 'ideal refugee': a child, an innocent, apolitical victim who would have 'deserved' to be helped. The emerging sentiment of compassion among the British public became itself a news story, appearing as a momentary rupture to the hostile feelings that dominate discourses on migration (Sirriyeh 2018). The invocation of compassion did not only interrupt and problematize hostile political discourses on immigration, but "succeeded in mobilising a temporary shift in public attitudes, media reporting and government policy" (Sirriyeh 2018: 53). Nevertheless, in considering that different emotions form a central role in political and public discourses on migration, campaigns for the rights of refugees and asylum seekers often 
seek to invoke the notion of compassion, commonly perceived as the antidote emotion to hostility (Sirriyeh 2018).

Since 2011, there had been civil war in Syria, and the UK had continued to decline to take part in a resettlement programme which had been organised by the UN High Commissioner for Refugees (UNHCR). But with the war growing more deadly, the British government faced increasing pressure from over twenty-five migrant charities and different politicians to participate in the programme. In January 2014, the Home Secretary Theresa May announced the launching of the Syrian Vulnerable Persons Resettlement Programme (SVPRP). This separate resettlement programme was established to provide a legal route for selected Syrian refugees deemed to be "vulnerable" to come to the UK (Sirriyeh 2018: 100). However, no fixed quota commitment was established, and when the picture of Aylan Kurdi appeared on the $2^{\text {nd }}$ September 2015, only 239 refugees had been resettled under the scheme (Gower and Cromarty 2016 in Sirriyeh 2018: 57). In consideration of this limited humanitarian resettlement, pressure from civil society and the media mounted after $2^{\text {nd }}$ September 2015 on the government to increase refugee resettlement, and to provide a more welcoming approach to the new arrivals (Sirriyeh 2018). This pressure from civil society groups and campaigners continued to grow specifically after the publication of the picture of Aylan Kurdi. Sirriyeh (2018: 57) argues that in this context: "expressions or actions from politicians or public commentators that drew on hostile emotions were now interpreted by many members of the public, the media and other commentators as disgusting, inappropriate and therefore shameful".

\subsection{1 "The revolution of generosity": The summer of migration for Swansea City of} Sanctuary

This unpredicted shift in public emotion towards compassion also had important effects in Swansea, and for the national City of Sanctuary movement. When describing the summer of 2015, Alan Thomas remembered his experiences and other national trustees: "all the trustees called it the revolution of generosity" [italics added] (Interview, 27 July 2017). He continued to describe how he experienced the effect for the local network in Swansea: "there is this sudden, massive number of people, with wanting to help. In a completely unfocused way, really ... (ibid) There were two main effects that could be detected, and which will be examined. First, the overwhelming effect of this shift in public emotion for the local network, and second, how this shift 
would be instrumental in the emergence of new support groups. Another staff member explained that the publication of the picture constituted a "pivotal change" (Interview, 19 January 2018) in the external circumstances of the group. She said: "And, it was really challenging ... We were used to begging for support, and then suddenly, the phone would not stop ringing, emails would not stop coming in [...] It was hard work. We used to be an unpopular sort of charity, or cause" (ibid). This perception of her experience in Swansea resonates with a wider development, which saw a substantial rise in public donations to charities working with refugees, and increases in enquires about volunteering, after the publication of the picture (Merrill 2015 in Sirriyeh 2018). Nevertheless, one should still remark that this pivotal change was perhaps experienced in this intense manner because it stood in contrast to the more hostile feelings that had dominated discourses of immigration in the UK.

Framings of refugees and asylum seekers as a financial 'burden' to communities had been part of the justifications for the politics of austerity and the neoliberal assault on the refugee support sector (see Darling 2016). Nevertheless, during that time, several new support groups emerged in Swansea in reaction to the events, including SHARP (Swansea Humanitarian Aid Response Project) and Bloom. The support group 'Bloom' works through "home visits, friendship, creating volunteering opportunities". Rachel, the woman who set up the friendship group, shared her experiences and how it motivated her:

I saw a picture of a little boy called AylanKurdi who'd drowned and he'd been washed up on a beach, and it was all over Facebook. And I was really upset by it. And at first I was quite angry and I thought, 'that shouldn't be on, people shouldn't be looking at that, that's a little boy that's dead, and ...what about his family?' But it stayed in my head all the time, and I knew I wanted to do something about it. I'm a single Mum I've got two little boys... (Interview, 24 April 2018)

Two things come to mind that were mentioned. The notion of the intolerable, that which causes a fundamental rupture of how we see the world ("that shouldn't be on"). Here, it's in combination with the reference to the social identity of childhood and vulnerability ("I've got two little boys") and familiarity ('I'm a single mum"). However, I want to argue that there is a third important notion in the moral politics surrounding the picture of Aylan Kurdi. The argument is that a recurrent theme in the 
interviews with 'new' volunteers was that they saw their engagement also as a reaction to an inhospitable climate, associated with some more hostile reactions from civic society, and the limited support of the UK government for refugees and asylum seekers. Following her description of the summer, Rachel explained how the name 'Bloom' originated:

The name came from an argument I kept having on Facebook. Or other social media, where people would say: 'they've got a roof over their head, they're safe, what more do they want?' And I just thought: people deserve so much more, and after going through all that they deserve to come here and for their lives to flourish and bloom and be happy (Interview, April 2018)

A recurrent theme in the interviews with new volunteers was that they saw their engagement also as a reaction and response to an inhospitable climate. This was also associated with perceptions of continued hostile reactions from some parts of civil society, and with regards to the limited support of the UK government towards refugees and asylum seekers. Even the name for a friendship group such as Bloom emerged from a response and challenge to a hostile framing of refugees, even during the long summer of migration (“...What more do they want?”). This moral politics that emerges as a reaction ("at first I was quite angry"), and operates as a moral antagonism to in-hospitality, is what I want to explore in more detail. This does not necessarily exclude sovereign logics. Rather, an aspect of this emerging sentiment of compassion was the narrowing focus on the plight of specifically Syrian refugees. A member of the group remarked here that: “... everyone, not just in Swansea, the general populations' focus was very much on Syria” (Interview, 19 January 2018). The outpouring of the sentiment of compassion on Syrian refugees, and the resonance of this framing with the distinction between the 'deserving' refugee and the 'undeserving' asylum seeker (Sales 2002) indicates that the sovereign politics of distinction is implicitly accompanying the SVPRP, and refugee resettlement more broadly. But despite these significant limitations, the outpouring of sentiment that followed the picture of Aylan Kurdi exhibited one more development: the (re) association of inhospitality. 


\subsubsection{From moral urbanism to moral nationalism? The Sanctuary movement between} the scales

One additional aspect pointing to the importance of the September 2015 was the growing number of sanctuary groups in the UK. The former volunteer and staff member of the Swansea network said that: "When I started my job in 2015, there were forty City of Sanctuary groups. Now, there's are over a hundred. And they exist in places where ... there are not just dispersal areas" (Interview, 19 January 2018). Dispersal areas for asylum seekers that have been set up since by the Home Office through the 1999 Immigration and Asylum Act tended to be larger urban areas (for example Glasgow, Sheffield, Cardiff, Swansea etc.). The emergence of support networks and activist movements outside of these large urban areas aspect is interesting. What happens when the 'City' of Sanctuary movement starts to develop beyond the urban? To answer that question, this section will draw on interview material from members of sanctuary groups in Wales outside of Swansea and Cardiff, for example the Hay, Brecon and Talgarth Town of Sanctuary Group.

One of the early members and founder of the Hay, Brecon and Talgarth Town of Sanctuary Group in the rural area of Breconshire at the edge of the South-Wales Valleys described the motivation for the its emergence:

I would say $[\ldots]$ for most of the members, if not all, it is compassion and sense of injustice. Compassion for the people involved, that found themselves involved in this situation. And then as we got more and more involved, raging injustice at the way the UK government structures things to the detriment of those seeking sanctuary (Interview, 26 March 2018)

There is a strong indication here of how, in addition to the politics of compassion, the engagement of these new activists in 2015 was as much a reaction and response to a felt inhospitable climate associated with the limited support and hostile responses of the UK government towards refugees and asylum seekers. While the process of neoliberalisation had shifted the discourse on those responsibilities towards civil society and the 'responsible' individual citizen, the publication of the picture of Aylan Kurdi constituted a rupture to those responsibility framings. This is because only a sovereign decree on opening border control or immigration law could have prevented his death. This discursive development is a double-edged sword. The argument I am 
making is that part of the politics of hospitality lies in the management of the expectations of what it means to be host. That means that on the one hand, the shifting back of those expectations, from civil society towards the sovereign state, might constitute a rupture for neoliberal forms of governing. On the other hand, it is questionable if challenging the sovereign state on those expectations around hospitality, which it itself created, challenges the deeper structures of inclusion and exclusion that underpins the contemporary British asylum regime. Nevertheless, the association of hospitality as a response to hostility returned a second time in the interview, when she referenced the change of the discursive climate as part of the motivation:

I would say, obviously 2015 was the catalyst. But I think again, one of the things that came through strongly, and almost gave us like a surge, and momentum of the people involved, or becoming involved in our group, was the rhetoric around Brexit. And we felt that part of our role was to actually combat some of the hate language that was around. (ibid)

This notion of acting in response to also translated to the group's activities, which can be separated into three categories. First, the "practical side with funds and goods", which includes fundraising and collection of donations, and the "political side", writing and campaigning to the Home Office on the Dublin III and the Dubs Amendment. And second the "respite side", where dispersed asylum seekers from across Wales are invited for an organised day-out to the rural countryside (ibid). However, the third aspect of the group's activities points to another interesting aspect. Specifically: that the new support group between Hay, Brecon and Talgarth operated in a county that is not an official dispersal area. In September 2015, the county had no immediate institutional contact with refugees or asylum seekers. Indeed, in a broader sense, with regards to the dispersal of asylum seekers whose legal claims were ongoing, to arrival of asylum seekers was a social phenomenon was largely restricted to urban areas in Wales: Swansea, Cardiff, Newport, and Wrexham. However, with the expansion of the SVPRP announced in September 2015, this was due to change, although the resettlement scheme was limited to Syrian refugees which had been deemed 'vulnerable' via the UNHCR. Most local authorities across Wales, who had not previously been dispersal areas, were slowly starting to engage with, or even 
participate in, the scheme. The local authority in which the non-urban 'Town' of Sanctuary group emerged, responded quickly:

I think it was something like sixty-odd families. They are just about to resettle another six, five families into Llandrindod Wells. Newtown is Powys County Council. And then [...]. So, there is at least three areas where they are resettling Syrian families [...] So, the [...] to the Powys council was very proactive, taking at least three batches of Syrian resettlements (Ibid)

Despite the politics of distinction embedded in the SVPRP, and despite the small number of Syrian refugees concerned by this scheme, the expansion meant that local authorities across Wales and beyond the urban centres of Swansea and Cardiff, such as Powys, were starting to engage with the topic of migration and with the discourses (such as hospitality) through which the politics of asylum are justified, either through hostility and/or compassion.

This can also be a seen as a step in a new discursive development from a moral urbanism towards something resembling more of a moral nationalism. This emerged when, from September 2015 onwards, the vocabulary of a Welsh 'Nation of Sanctuary' started being used in official statist discourses. This is a new discursive development, from city to nation, that has not yet been thematised in the literature on sanctuary imaginaries, at least regarding the movement itself. The next chapter will therefore engage with what is new and what is familiar in this concept of a moral (sanctuary) nationalism, and how it differs from familiar sovereign framings of migration, using the notion of hospitality. For now, it is important to summarise here that this is not just an empirically new phenomenon with regards to sanctuary imaginaries, but its examination also contributes to the more theoretical literature on cities and citizenship.

In his work, Isin (2007) argued that there is an essential element to this scalar thought: it "conceals the difference between the actual (physical and material) and virtual (symbolic, imaginary and ideal) states in which bodies politic exist" (ibid: 211). Thus, he suggests that only the city exists as both as an actual and virtual space, while all other bodies politic, such as states or nations, only exist as virtual rather than as actual spaces ..." (ibid: 212). His argument is that: "these virtual bodies are assemblages that are kept together by practices organized around and grounded in the city" (ibid). In showing how the image of a Nation of Sanctuary emerged from an urban sanctuary 
movement, this research project therefore provides an empirical grounding to the claim that virtual bodies politic are indeed kept together by practices organised and grounded in the city.

In conclusion, this chapter has shown that the moral dimension of the urban selfimaginaries around the concept of a City of Sanctuary emerged as a form of moral urbanism such as Darling (2013) has described, but with the focus on the 'unifying sense of ethical value' (Darling 2010) for identity construction. With the external changes through the politics of neoliberalism, this dimension would eventually merge with forms of professionalization and responsibilisation, that unintentionally assisted austerity as a moral justification. But there is an element that the literature on moral place-making and its associated concepts such as moral urbanism could not fully explain. This unexplained element, for the politics of sanctuary imaginaries, is that "place-based responses to the global issue of refugees necessarily involves a negotiation of scale" (Tuma et. al 2018). Indeed, different scholars (e.g. Tuma et. al 2018) had argued that place-framing through humanitarian values can conflict with the hostile immigration policies of the nation-state. McDaniel (2018) had therefore concluded that "designations such as "welcoming cities" and "cities of sanctuary" may be statements intended to differentiate cities and towns from the discursive position of the nation. This assumes a discursive binary between the welcoming, liberal and open city on the one hand, and the hostile and exclusionary nation-state on the other. There have been studies on national imaginaries of sanctuary and hospitality, as Bagelman (2019) has argued, but there have not been any national sanctuary imaginaries that were constructed to differentiate a place from the discourses of another nation-state.

This point is essential for understanding what it might mean to declare oneself as a Nation of Sanctuary. Indeed, what happens when these sanctuary imaginaries begin to be framed through the concept of the nation, for example in the case of Wales as Nation of Sanctuary? What are the implications of this national sanctuary image for the argument that sanctuary imaginaries are often intended to differentiate a place from the discursive position of the nation-state? From whom or what is the Welsh Nation of Sanctuary differentiating itself? How would that affect the sovereign framing of hospitality in sanctuary imaginaries? The critical literature we encountered has not examined this new empirical phenomenon or, therefore, answered those questions. Moreover, the moral dimension that turned into a self-regarding form of governance 
around responsibility was ruptured with the emergence of the picture of Ayan Kurdi. Self-imaginaries around hospitality were constructed as a reaction to perceived hostility or in-hospitality. But there is one more thing:

In September 2015, the world was rocked by the photo of Ayland Kurdi. And lots of City of Sanctuary groups, or affiliated groups, have sprung up as a result of that kind of 'revolution of generosity'. So, there is now at least ten groups in Wales. So, what I really don't know is how Wales had this idea of being a Nation of Sanctuary before there were even other groups in Wales, apart from Cardiff and Swansea (Interview, 24 November 2017)

Another member of the network stated that in September 2015, with regards to the idea of Wales a Nation of Sanctuary, she felt that: "For the first time, ever, it wasn't just something that was like an abstract concept in the future, it seemed like actually there was some buy in. Which was really interesting. I don't think anyone was prepared for this" (Interview, 19 January 2018). Answering those two questions will therefore be the task for the next chapter. 


\section{Chapter 7. Othering the 'Host' - The Welsh Nation of Sanctuary and the British politics of refugee resettlement after the long summer of migration}

How did the idea of becoming a Nation of Sanctuary come about? Indeed, in response to the 'refugee crisis', the devolved Welsh Government held an emergency summit in September 2015 and reiterated its commitment that Wales should play a leading role as a 'Nation of Sanctuary' (NOS) in supporting refugees and asylum seekers. This is particularly interesting given that Wales does not have sovereign responsibility for British borders. What might it then mean, in practice and in theory, for Wales to declare itself as such a 'Nation of Sanctuary'? What are the theoretical and political imaginaries of sanctuary, national identity and sovereignty at work in this context? And how do they relate to political responses to the crisis across the UK and Europe more generally?

To answer those questions, this chapter has a twofold purpose. First, to examine how the image of the Welsh 'Nation of Sanctuary' emerged and what it is understood to mean, and second, how this national sanctuary image compares to other sovereign framings of hospitality. Indeed, this thesis also examines the theoretical role of the metaphor of hospitality in discourses around migration and the sovereign nation-state. It does this through exploring the different ways in which policies and public reactions to the long summer of migration were expressed, justified and responded to. To answer the questions in that scholarly context, this chapter explores how the administrations of the nation-states nested in the devolved context of Britain used different moral imaginaries around hospitality to frame their political responses to the refugee 'crisis'. With this context in mind, the main aim of this chapter is to compare the discursive responses of the British and devolved Welsh government and civil service to the long summer of migration through the example of the Syrian Vulnerable Persons Resettlement Programme (SVPRP).

The chapter also examines how the contrasting discourses and narratives provide new theoretical ways of revisiting the metaphor of hospitality, and its role in sovereign 
framings of the politics of asylum. While the literature on migration and the sanctuary movement has explored the limits of hospitality as a framing and response to the exclusionary politics of asylum (Darling 2013), this chapter argues that it is also used to challenge $a$ given sovereign nation-state (Hill 2016) on the moral expectations of what it means to be a good (Amin 2006) and responsible 'host' to refugees and asylum seekers. The new argument developed here is that the hospitality discourse of the Welsh government uses at times a discursive and national politics of differentiation from the British state that relies on what will be called a 'second othering'.

The first section will trace the re-emergence and development of the idea of a Wales as a 'Nation of Sanctuary', and how this was related to the British expansion of the SVPRP. The section will also trace its discursive adaptations with regards to "placemaking' (Tuma et. al 2019) and nation-building - considering the urban origins of the Sanctuary Cities movement and the fact that this was the first-time a (devolved) state administration adopted this slogan to frame their response to the social phenomenon of migration. The argument developed in this section is that this represents a new discursive development from a moral urbanism towards something resembling more of a 'moral nationalism'. The section will explain what is new and what is familiar in this concept of such a moral (sanctuary) nationalism, and how it differs from other sovereign framings of hospitality.

For such a comparison, the subsequent sections will examine different statist discourses around the same policy of refugee resettlement. The second section will start to examine similarities and differences between the SVPRP and the earlier British resettlement schemes. It explores the discursive framing of the SVPRP under three main categories. First, the construction of 'Britishness' with regards to a selfidentification as a generous host. Second, the emphasis on those "most in need" and the subsequent politics of deserving and undeserving. And third, the focus on "rigorous" selection criteria which shows how hospitality discourses can indeed moralise the securitisation of migrants. To do that, it examines in detail three documents to see how the scheme was framed within the British administration and parliament: one House of Commons committee report from December 2016; one House of Commons briefing paper on the scheme from June 2017; and Home Office Guidance sheets on the SVPRP from July 2017. 
The third section examines two institutional responses: from the Equalities, Local Government and Communities Committee (ELCC) of the National Assembly of Wales, who are supposed to scrutinise the devolved government; and from the Welsh government itself. In doing so, this section proceeds in three steps. The first step is to introduce the context for the committee inquiry that led to their first Welsh policy report on the topic of refugees and asylum seekers. The second step is to examine the report in more detail, focusing on what is called a "Welsh approach" to welcoming refugees and asylum seekers (ELCC: 2017), and how it needs to be read in terms of a politics of differentiation from the UK. The third and final step is to examine the response of the Welsh Government to this committee report, and to analyse what their justifications can tell us about subnational framings of hospitality with regards to the politics of asylum. The argument in this section is that the hospitality discourse of the Welsh government uses a politics of differentiation from Britain that relies on a second othering, but that it does not fundamentally challenge the moral and political legitimacy of the sovereign (and exclusionary) politics of asylum.

The fourth section will explore if and how this discursive second othering could move beyond the narrow focus on the construction of national self-imaginaries. These mainly reiterate the sovereign und unequal distinctions between the nation-state as the host-self, and the refugee or asylum seeker as the guest-other. But there is a move towards a politics that is concerned with challenging the sovereign asylum regimes with regards to what else it could mean to be a host to new arrivals, and who therefore should have the moral and political legitimacy to host. This is an interesting trope that emerged in numerous interviews with activists in Wales who pointed to efforts and discourses of the devolved Scottish government led by the Scottish National Party. The conclusion will summarise how those discursive developments call for more research into the relations between the nation-state, national independence and the phenomenon of migration.

\subsection{The emergence of the Nation of Sanctuary phenomenon}

On 17 September 2015, during an emergency summit following David Cameron's response to the long summer of migration, the Welsh government reiterated their commitment that Wales should become a 'Nation of Sanctuary'. While this was the 
first (devolved) national administration which had adopted this phrase originating from the City of Sanctuary movement, the emergence of this imaginary goes back further, to 2012. Two individuals were involved with generating this idea: Inderjit Bhogal, one of the two founders of the national City of Sanctuary movement from Sheffield, and Reverend Aled Edwards, who stated that it was the former "who ... promoted the idea to either Carwyn Jones or his predecessor" (Interview, 27 July 2017). This mentioning is important, because Carwyn Jones was the First Minister of Wales from 2009 till 2018. Aled Edwards described this process further:

It was when my organisation, Cytun - Churches together in Wales invited Inderjit Bhogal, who was one of the key players in the City of Sanctuary concept, to come over and speak to use, as a board. And we floated the idea with him, then, that it would perhaps be possible for Wales to become a 'Nation of Sanctuary'. And, the model behind that, was the way in which Wales had gained a badge as the first Fair Trade nation. (Interview, 11 December 2017)

The first noteworthy aspect here is that Darling described how the moral claims of Fairtrade cities (Malpass et al: 2017), and sanctuary cities (Darling 2010) "speak to the promotion of specific cities as attached to, or embodying, particular moral registers (2013: 1786). Following Massey (1991) and the perspective on place as made through framing and describing spatially-located constellations of social relations as having coherence and collective identities that are distinct from other constellations, what underpins the Fair-Trade Nation and the Nation of Sanctuary is the politics of placemaking and place-framing through moral registers. Other scholars showed how the intensity and variation of pro-refugee civil society responses to the long summer of migration in Wales was "informed by and closely intervened with processes of placemaking and place-framing", and hospitable responses can also be understood as "practices of locality production" (Tuma et al 2019: 96). The second aspect emerging with the Fair-Trade status underpinning for the Nation of Sanctuary is the politics of distinction that seems to emerge when Wales is reiterated as being the "first Nation of Sanctuary". Darling (2013: 1790) described similar attempts to mark specific cities as embodying the 'good' life in discursive comparison with others. Those are seen as strategies of "civic competitiveness" (McCann 2004 in Darling 2013). This politics of distinction from other places is of importance for this national 'place-making'. Moreover, we have seen that the NOS idea emerged from the CoS movement and other 
civil society actors, and was taken on by the Welsh government as a framing device. The notion that the idea behind the 'Nation of Sanctuary' emerged from a grassroots initiative was confirmed by Bethan Jenkins (now Sayed), an Assembly Member, describing a packed stakeholder meeting for the committee in Swansea, after the summer of migration in 2015:

But there they were talking about the Nation of Sanctuary, it was an amalgamation of campaign groups, it was City Sanctuary campaign in Swansea, Welsh Refugee Council, but also individual asylum seekers and refugees understanding what that meant as well and saying 'look, we could do this'. So, it was a sort of a more grassroots thing, it wasn't a concerted lobby to get this into the report (Interview, 13 January 2018)

The first conclusion is that there seemed to be an ambiguity between the urban and grassroots background of the CoS movement from which the idea of the NOS emerged, and its national and governmental adaptation. Place identities in designations such as "cities of sanctuary" were after all also statements meant to differentiate cities and towns from the "discursive position of the nation" (McDaniel 2018 in Tuma et. al 2019: 98). The second conclusion is the renewed "we could do this" (Interview, January 2018) approach that emerged in the stakeholder meetings. With regards to what the NOS idea meant before and after the long summer of migration, Alan Thomas describes what he thought:

It means getting all the cities that could be, which really would only be ....although, in theory, there could be City of Sanctuary group outside a dispersal city, but that never was likely to happen. So, there could be four. And then you would want support from the... national organisations, if you like. And that would be as far as it would go, probably. Whereas after that revolution of generosity, you suddenly realised it would be possible ...

You could think of that on the Welsh level, not just in each city separately...That's simply the picture I got about it. Because now, suddenly within two years, there are not two, but ten City of Sanctuary groups in Wales. And obviously, the majority of them are not urban.

So, not only have you got this people wishing to help somehow, you also got David Cameron's scheme for resettling... refugees from Syria, which means that the whole of Wales [...] so everywhere in Wales, there will be some Syrian refugees, in the same council, not necessarily in the same place ... (Interview, 27 July 2017) 
NOS was imagined as a host to refugees in a geographical sense. The second condition, in addition to having this civil society response ("people wishing to help"), is indicated as being the SVPRP. Indeed, one of the new and interesting effects of long summer of migration was that refugees were now more widely dispersed, in a geographical sense, including in rural or semi-urban localities who had little or no previous experience with refugee resettlement or migration more broadly (Challinor 2018 in Tuma et al 2019: 97). The reason behind this geographic broadening was that the UK government invited "any local authority" to participate in the SVPRP (HO: 2017). This marked a shift away from settling refugees and asylum seekers only in urban dispersal areas (Piacentinit 2012 in Tuma et al 2019). While the distribution of most asylum seekers was continued under the established dispersal policy and was limited to Cardiff, Swansea, Newport and Wrexham, Syrian refugees arriving through the SVPRP were dispersed to volunteering local authorities. This meant that by November 2017, twenty of the twenty-two local authorities in Wales had together accepted 725 Syrian refugees as part of the programme (Houghton 2017 in Tuma et al 2019: 99). The importance of this geographical influence of refugee resettlement for the 'national' idea of the Welsh NOS was reiterated by Aled Edwards:

I think one of the things since 2015, that has made that more possible, paradoxically, is the Syrian Resettlement Programme. Which required all the local authorities in Wales to have a view on receiving Syrian refugees. So, where you got those four distinct bubbles of the dispersal areas, you are now getting places like Aberystwyth [....]

So, those areas now have acquired, or began to acquire, an expertise and an experience base in receiving asylum seekers and refugees. ... So, I think what we found since 2015 is that there is now a genuine, all-Wales experience of receiving asylum seekers and refugees, that wasn't there before ... (Interview, 11 December 2017)

The main difference between the two resettlement programmes is that Gateway was limited to cities, whereas the SVPRP created now the image of a 'Wales-wide' and therefore 'national' culture of hospitality that included non-urban local authorities. This also supports William E. Connolly's (2004) argument that: “To be a sovereign, territorial people, it is necessary to become a highly-unified nation" (ibid: 25). Aled Edwards continued elaborating on the "paradox" of the idea of the NOS emerging out of a resettlement scheme, which had been perceived as rather "reluctant": 
A: .... that wasn't there before. And that, for me, was one of the key areas, because Wales had been for a number of reasons reluctant to take the Gateway project on. But that has now been superseded by the Syrian schemes.

Researcher: Can I, maybe, I don't know, if you know so much about why they were reluctant? Do you know why they, initially, didn't want the Gateway project?

A: I was one of them. And the main reason was that we were fearful that the Home Office would try to press down on spontaneous arrivals. And bring in people that were cherry picked. And the numbers would be fewer. They would be more privileged, than those in the dispersal areas. And I think, you know, although, you know, I now have been part of enabling communities to do this sponsorship scheme, I still have concerns about how that impacts on general dispersal policy. Because, unless you're careful, you are going to have a two-tier, or another three or four tier system. And, you know, there has always been a narrative in British politics, that you can abandon the human rights framework, and then cherry pick from the Third World (Interview, 11 December 2017)

This description is important as it indicates what was necessary for people who had been long active in the movement to consider that the idea of a Welsh NOS "would be possible". The first condition was the notion that there are now local sanctuary groups beyond the urban dispersal cities. In other words, it became possible to talk of a 'Welsh' movement. The discursive emphasis that is important here is that Wales is imagined as 'reluctant' to take on the earlier Gateway resettlement scheme not because it is reluctant to welcome refugees, but because participating in the scheme could be understood as legitimising and enabling a two-tier asylum system. The argument developed is that this 'uneasiness' of the devolved institutions in being associated with notions of inequality and inhospitality of the two-tier asylum system ('a narrative in British politics') is of great importance for the discussion on domopolitics and hospitality. The first effect that followed the long summer of migration, the reemergence and re-iteration of the idea of Wales as a 'Nation of Sanctuary', was embedded in a 'moral nationalism'. The language of host and guest (self and other) was being used to create a national self-identification, constructing an image of oneself as generous 'host' (Wales) to arriving refugees (guest). Because this first step with regards to the Nation of Sanctuary was more about creating a Welsh self-image, the subsequent politics of hospitality remains discursively in the binaries between host and guest, state and migrant. It has been pointed out before that the articulations of place 
identity in sanctuary designations can be read as attempts to differentiate those cities from the discursive position of the nation (McDaniel 2018 in Tuma et al 2019: 99). But what happens when those affective articulations of place-identity are used by one (devolved) nation-state to differentiate it from another (sovereign) nation-state? Before we can investigate this difference, we must therefore examine those affective articulations from the British sovereign state.

\subsection{The UK government's justification for refugee resettlement}

The initial establishment, and expansion, of resettlement was not the British government's first nor favourite choice when responding to the increasing number of refugees that the civil war in Syria had produced since 2011. But as with earlier resettlement programmes for some selected refugees, they made it part of the moral justification for the exclusionary politics underpinning the British asylum regime (see Darling 2013). For the first three years of the war, the policy of the UK government was to assist with humanitarian aid, and not to participate in UNHCR resettlement programmes. This was justified with the argument that participation would "act as a magnet for those seeking refugee" (House of Commons: 2016). But the continuous refusal to assist other states in 'hosting' refugees became the target of criticism both at home and abroad. After pressure from charities, the UNHCR and individual politicians, the Home Secretary Theresa May announced on the 29 January 2014 the establishment of the Syrian Vulnerable Persons Resettlement Programme (SVPRP) for "some of the most vulnerable Syrian refugees" (McGuinness 2017). This scheme, which provided legal routes for selected refugees and was established as separate from the dispersal system for other asylum seekers, was small in scale with no fixed quota, and by September 2015 only 239 refugees had been resettled (House of Commons: 2016).

In consideration of this rather limited engagement, civil society pressure mounted after the $2^{\text {nd }}$ September 2015, when the publication of the picture of Aylan Kurdi, a threeyear old Kurdish refugee from Syria who had drowned of the coast of Turkey when trying to reach Europe with his family "provoked a remarkable and transnationally articulated demand for responsibility" (Perl and Strasser 2018: 508). After the publication of the harrowing picture, the UK Prime Minister David Cameron then 
announced that Britain would "fulfil its moral responsibilities" by expanding the SVPRP and taking in 20,000 Syrian refugees over a period of five years until 2020. Nevertheless, it is important to note that this expansion was still taking place in the context of an overall hostile asylum regime. Jenny Edkins and Pin-Fat (2004: 18) have argued here: "that sovereign power is not, despite appearances, a form of power relation but rather a relationship of violence". Consequently, the following section will examine this relationship of violence.

\subsubsection{To identify those most at risk...: The construction of 'deserving' and 'undeserving' subjects}

In his statement announcing the expansion of the SVPRP by taking in 20,000 Syrian refugees over the period of five years, the British Prime Minister David Cameron would not wait long before emphasising that they would be selected based on need. He stated that: "We will take the most vulnerable: ... disabled children, ... women who have been raped...men who suffered torture" (2015 in Mavelli 2017). The emphasis returns in a Home Office Guidance sheet on the SVPRP. It explains that through the scheme the British administration is working with the UNHCR to "identify those most at risk", and that the scheme "has helped those in the greatest need, including people requiring urgent medical treatment, survivors of violence and torture, and women and children at risk" (Home Office: 2017) In a similar manner, one of the detailed House of Commons report on the SVPRP starts with stating that the scheme was: "providing support to some of the most vulnerable Syrian refugees" (House of Commons: 2016).

What is emerging are two important aspects that underpin the logic of the resettlement scheme. First, the emphasised focus on 'criteria of vulnerable groups', and second the focus on 'Syrians registered as refugees'. The limited literature on the scheme has pointed out how the humanitarian configuration of the SVPRP "also worked to exceptionalise the figure of the refugee worthy of care" (Armbruster 2018: 2). Other theorists have written in detail about the humanitarian governing of the so-called deserving and undeserving refugees (Ticktin 2016) or what Fassin called the "tension between compassion and repression in the management of immigrants" (2005: 16), and how this has been central to resettlement schemes (Darling 2013). While the existing literature has identified the politics of constructing genuine and non-genuine subjects and how they are part of the underpinning logic of such narrow resettlement schemes, what can be argued to be more distinct about the SVPRP is the narrower 
focus on the Syrian refugee. While the Gateway programme created a similar logic of deserving and undeserving, it creates such a 'deserving' group from various backgrounds and nationalities - making the underpinning logics of distinction less clear. What the SVPRP is doing is giving the 'deserving refugee' a 'nationality', and therefore making them more identifiable and governable. This process of 'nationalising' the deserving subject - giving those considered genuine a national signifier to make them identifiable - returns in various documents of the British administration. One of the House of Commons briefing papers on the programme shows that as of March 2017, eighty-six percent of initial asylum decisions in Syrian cases gave permission to remain in the UK, which " ... is the highest rate of recognition among the top ten nationalities applying for asylum in that year” (McGuinness 2017). This phrasing indicates that the construction of deserving and undeserving subjects is associated with different 'nationalities' applying for refugee status. This focus was reinforced when one of the first steps taken after Cameron's announcement was that Richard Harrington was appointed as a joint Home Office/Department for International Development/Department for Communities and Local Government Minister for Syrian refugees, tasked with coordinating the SVPRP across the UK (McGuinness 2017).

Elena Fiddian-Qasmiyeh (2016) explains in this context how Syrian refugees as a group were initially framed as the 'good refugees', as 'both legitimate and priority "candidates" for international protection'. The effect was that they were 'fast- tracked' and given precedence over Iraqis and Afghans, who have been treated as 'second-tier refugees' (ibid.). This politics of distinction also affected the scheme in a practical sense with regards to the provision of services. Armbruster (2018: 13) indicates how the programme "provided families with immediate rights to stay in the country, bank accounts, housing and social welfare support which, as some volunteers stated, was "quite a privilege" in the larger landscape of neoliberal welfare reform and antiimmigrant legislation". This exception to the wider neoliberalisation of the national dispersal scheme (discussed in Chapter 6) points to the underpinning rationale of creating different categories of support within the asylum regime, and the importance for the Home Office of creating the subsequent associations of deserving and undeserving migrants. 


\subsubsection{Rigorous criteria to identify those most in need: Moralising domopolitical} distinctions

The SVPRP was established within the context of a restrictive British immigration policy. Armbruster summarises that: "its very exceptionality was formulated against the backdrop of restrictive state policies on immigration and an increasingly hostile anti-immigrant and anti-refugee rhetoric" (2018: 7). The distinction between different categories of migrants, genuine and non-genuine, to prevent an 'exploitation of the system' (or the 'abuse of hospitality') appeared in the Home Office document that informs local authorities and partners about the SVPRP. In it, the Home Office explains how they work with the UNHCR to choose eligible refugees, and that they “...have developed rigorous criteria to identify those most in need of support and we apply these criteria to determine who would benefit most from our assistance" (2017). The term 'rigorous' is not accidental, as it reiterates both the discursive construction of the 'deserving' refugee and the moralisation of its domopolitical enactment.

First, as Armbruster (2018: 15) shows, the aim to benefit those most in need "underwrites principles of selective admission for some refugees whilst legitimizing the exclusion of others". This is because the emphasis on 'rigorous criteria' in this process of identification creates an imagination of those subjects as checked, identified and screened, and therefore also as deserving because they have been shown to be 'in genuine need' and are not 'exploiting the system'. What is implied is that the larger number of migrants who are not entering through such a narrow scheme are not known in this manner and are therefore potentially non-genuine. The securitisation and exclusion of those who are identified as non-genuine is not only justified through offering hospitality to a 'worthy' few, indeed it also moralises this distinction as a responsible enactment of a set of obligations to some noncitizens (Darling 2013: 1796).

The determining logic of the genuine 'Syrian refugee' as the deserving subject also translated into the scheme's implementation by affecting the provision of services. While the dispersal system continued to be subjected to neoliberal assault, a 'community sponsorship' scheme was launched in July 2016 to "assist Syrians' integration into UK society" (McGuinness 2017). This sponsorship means that community groups act as sponsors in supporting the resettlement of some selected refugees that are deemed vulnerable. The community sponsors are allocated a family, 
and it is their responsibility to support the resettled family, also financially, from the moment of arrival in the UK (Home Office: 2016). On the on hand, the Syrian refugees are considered 'worthy' to receive additional means that would assist their settling process, and are thus discursively set apart from other asylum seekers. On the other hand, they are still perceived of as the guest-other who needs to be 'integrated' into British society. This translated into the political geographies of the scheme. While the dispersal system is limited to larger urban centres, the SVPRP would include rural local authorities which had not previously been part of the refugee and asylum seeker dispersal system. A senior local authority officer described this change as being part of the British government's aim to "stop ghettoization" and to "spread [dispersed people] out thinly so to better enable them to integrate" (in Armbruster 2018: 14). Moreover, the small number of selected Syrian refugees were a convenient group around which the Home Office could construct a role as those 'most in need' and as deserving subjects whose support legitimises the exclusion of other migrants. This preferential treatment within a domopolitical hierarchy of deserving and undeserving is based on the identification and construction of the migrants as 'guest' and thus fundamentally as the 'other'.

This is not just apparent in the discursive justifications of the SVPRP, but also in its practical implementation, for example with regards to the granting of legal status to those who had been selected for resettlement. The first comprehensive House of Commons report on the scheme explains that the Home Office "...chose to grant humanitarian protection status rather than refugee status" (2016). The formulation might suggest that this is a question of mere wording, but there are important legal differences between these two statuses, with the former entailing exclusion from access to higher education and other social services. The justification given by the Permanent Secretary while being questioned as a witness (ibid) is revealing in that sense:

Mark Sedwill: ... Part of the reason for going for humanitarian protection at first was that of course the Government's overall strategy is to bring an end to the Syrian civil war and enable refugees, whether they are here or in the neighbouring countries, which is where most of them are, with a lot of support from this country, to go home, rebuild their lives and rebuild their country. In those circumstances, humanitarian protection is the natural grant of status, because it enables people to return to their country, where- 
Chair: But the problem is, as we are seeing, it is not giving people access to certain services.

Mark Sedwill: Exactly, but there are still pros and cons to that. Humanitarian protection makes it easier to go back to your country of origin, but it is less easy to travel elsewhere. Refugee status makes it easier to travel elsewhere, but harder to go back to the country of origin (ibid: Q75-Q76)

What stands out most from this exchange is that even the migrant who is deemed as 'most in need' and framed as the 'deserving refugee' (in this case through the symbolic nationalisation of the Syrian refugee) is considered as a 'guest' - the 'return home' is never far from the host's mind. Moreover, this is not just a discursive move but also a real distinction in a legal sense. While considered as the deserving and appropriate victim, their full access to all services is deemed to be less necessary than their eventual ability to 'go home'. Furthermore, what becomes apparent is that the British government's preferred position is and always remains for people to 'return to their country, and that humanitarian commitments are still implemented under the main rationale of an exclusionary politics of asylum (Squire 2011).

\subsection{3. "The whole country has been deeply moved": The construction of "Britishness"}

The third element that was a recurrent feature in official documents was an association between an emotive category and a 'national character' (Armbruster 2018). In addition to calling the scheme a fulfilment of moral responsibilities, David Cameron elaborated that the extension was going "... to show the world that this is a country of extraordinary compassion always standing up for our values and helping those in need" (2015 in Armbruster 2018: 1). The first aspect is the self-identification of 'Britishness' in association with emotive registers - "this is a county of extraordinary compassion" - with an image of itself as a 'generous host' that is 'always helping others'. The need to emphasise that this is always how the British state would react constructs here a naturalised (and ahistorical) association between the nation-state, compassion and moral responsibility. This is interesting considering that the expansion of the SVPRP only followed mounting public pressure, and that the resulting policy was criticised for still comparing poorly with that of other European countries. For Mavelli (2017: 10), it "raises a series of questions about British identity, the crisis of British values, and the extent to which Britain was failing the test of compassion". Therefore, it is 
necessary to engage in more detail with the narrative of the moral and hospitable nation in the context of Government responses to criticism that the UK had not responded to the crisis in an appropriate or responsible manner (Sirriyeh 2018: 73). For instance, the statement that Britain is "extraordinary" in its compassion, one can argue, implies that it does more than others: taking more than its supposed 'fair share'. Indeed, similar tropes are to be found in the documents that the Whitehall and Westminster administrations would formulate on the SVPRP scheme after its expansion. The official guidance sheet that the Home Office had formulated on the SVPRP stated, for example, that: "The UK has been at the forefront of the response to the crisis" (2017), emphasising how the Prime Minister had doubled the pledges of humanitarian aid to the Syrian refugee crisis, and how they were "one of the largest donors" in the region.

In a similar manner, a House of Commons briefing paper described that, at the start of the civil war, "the then Government's policy was to be generous with humanitarian aid to Syria's neighbours rather than accepting fleeing Syrians for resettlement" (McGuinness 2017). While the context of this policy was thus more the unwillingness of the British government to take part in UNHCR or European schemes to resettle refugees, the identity formation still resonated around the concept of generosity. First, as a generous state giving humanitarian aid and, after the implementation of the scheme, as a generous 'host' now taking in Syrian refugees. The Home Office reiterated that the expansion of the scheme was in addition to those resettled under the Vulnerable Children's resettlement and Gateway, as well as "the thousands who receive protection in the UK under normal asylum procedures" (2017).

In addition to the familiar framing of Britain as generous and compassionate, the second aspect is the emphasis made by the Permanent Secretary in the exchange on the UK being at the "forefront" of international responses. That this statement is questionable is apparent in a House of Commons report on the SVPRP (2016), where the same policy actor acknowledged that: “...there was a Syrian vulnerable person's resettlement programme already, but it was running at a trickle essentially" (ibid). Nevertheless, the imagination of being on the forefront is perhaps the first insight one can draw from this examination of the British justifications for the resettlement of some selected Syrian refugees. This language of hospitality, when used by the governmental bodies of states to frame their relationalities to migrants, is not always just about the relation between the state and migrant, between imagined self and other, 
guest and host, but sometimes also about the relation between those imagined hosts (nation-states).

\subsection{Framings by the devolved government: "The Welsh approach"}

The first section of this chapter has provided a genealogy of the idea of a Nation of Sanctuary: it emerged from grassroots initiatives that were committed to building a 'culture of welcome and hospitality' for refugees and asylum seekers. Until the emergence of the Welsh NOS case, those discourses of sanctuary and hospitality were used by urban movements to differentiate themselves from "the discursive position of the nation" (McDaniel 2018 in Tuma et al 2019: 99). Nevertheless, to understand the new element that has emerged with the 'Nation of Sanctuary' for domopolitics and the discourse of hospitality, one needs to understand how this framing fits into an imagined institutional 'Welsh approach'. This is not to suggest that there is a coherent and unified nation-state and 'Welsh' approach that can be distinguished from the exclusionary politics of asylum of the sovereign state. The intention instead is to examine devolved institutional and governmental responses to the long summer of migration that were framed in 'national' terms, and what politics of differentiation this framing implies.

The first important thing to note is that the long summer of migration had an effect that would turn out to last beyond the immediate reaction of the Welsh government in September 2015. After the assembly election in Wales which had taken place in May 2016, the Equality, Local Government and Communities (ELGC) Committee had begun to work with their new members and the research service to identify what issues they wanted to scrutinise the Welsh government on (Interview, 9 February 2018). In September 2016, during a strategic exercise of the new committee, the so-called European 'refugee crisis' came up as a potential issue.

The context of this strategic exercise was that the European 'refugee-crisis' was neither a one-time event that had ended, nor was it 'solved' - and the heightened political and civic interest that had emerged with the long summer of migration did not quickly abate. The continued interested had an effect on the Welsh assembly members that were part of the committee. Bethan Jenkins, Assembly Member for Plaid Cymru and member of the ELGC Committee, stated in an interview that "it was something natural 
that I wanted us to look at because I don't think really, we'd done much work on it before (Interview, 13 January 2018). One of the researchers on the committee report said: "I think, press and public and political interest got a lot stronger in the most recent years. And the Welsh government, again, have to respond to that" (Interview, 9 February 2018). But in addition to this growing interest on the topic of migration, there was a second more immediate reason for this inquiry. This had to do with the British response to the long summer of migration and the expansion of the SVPRP. Bethan Jenkins reiterated that the Committee was interested in "the official resettlement scheme, because there was discussion around this two-tier system..." (Interview, 13 January 2018).

The importance of this issue of the two-tier asylum system can also be seen in the recurrence of the topic in all research briefings and most documents that were assembled by the Committee. The full Committee report was built on information from a total of 46 written submissions, oral evidence from 14 witnesses across nine evidence sessions, and research visits to Scotland and to refugee support projects in Swansea and Cardiff (RS: 2017a). The Committee report was entitled "I used to be someone"refugees and asylum seekers in Wales (ELCC: 2017). The report starts with a short three-page section that describes the "context for this inquiry". In this section, the first two headings that are examined are the "standard asylum route" and the SVPRP. Moreover, another set of briefing documents from the research service of the Welsh national assembly (Jones and Johnson 2017a) indicates that strategic leadership and the 'Two-Tier system' are the first main themes on the list of topics that were raised in the evidence sessions. First, the reiterated importance of strategic leadership can be attributed to the increasing interest in the topic of asylum, and the expansion of the SVPRP. The Welsh government could now no longer, as a researcher put it: "have like a rubbish delivery plan anymore, that's just a bit vague". They also explained that another topic in the press at the time concerned "Welsh local councils, and the ones that had taken Syrian refugees through the resettlement programme, and which ones hadn't' (Interview, 9 February 2018). The distinction between council who did or did not take in people concerns the internal politics of the devolved Welsh state with regards to refugee resettlement, more precisely, on how government dealt with the SVPRP resettlement in its own local authorities. To create the self-imaginaries of a unified and responsible nation-state through the metaphor of being a host that offers 
sanctuary to refugees, the devolved administration needed to seriously and methodically engage with the topic of refugee resettlement. However, the second aspect, the discursive concern of the assembly committee report with the 'two-tier' asylum system points to something new. Indeed, while the British government and administration used the metaphor of hospitality to frame the British nation-state as 'generous host' in distinction to migrants as guests, the Welsh Assembly Committee, and later the Welsh Government, framed these national self-imaginaries (devolved, non-sovereign host) also in distinction to the UK government and their sovereign asylum regime (sovereign host). This discursive focus on the politics of the two-tier asylum system relates here to the notion that: “... the questions of who is responsible and who is to blame for what are continuous objects of struggle" (Hage and Eckersly 2012).

The enquiry of the Welsh National Assembly committee was as much an exercise by the devolved state administration in constructing and defining its relationship to refugees and asylum seekers, as it was an exercise in constructing and differentiating its relation to the British sovereign state. The first section of the Committee report is entitled "The Welsh approach" (ELCC 2017: 16), demonstrating clearly how this document is about refugees and asylum seekers, but also about the relation of the devolved Welsh nation-state to the United Kingdom regarding the (sovereign) politics of asylum. This 'national' approach that the Committee is following is: while asylum is the responsibility of the British government (the Home Office), the devolved Government is responsible for several services that support refugees and asylum seekers in Wales, such as health, education and housing (ibid). What emerges is that: "...this can create significant challenges because two governments with different approaches $[\ldots]$ are responsible for different areas of refugee's and asylum seekers' lives" (ibid). The politics of differentiation is therefore constructed in a twofold sense. First, it is implied that the Welsh government follows "a different approach" from the UK government, and second, that this is limited by distinctive responsibilities towards refugees between sovereign and devolved host-states. The second notion was also mentioned in an interview with a researcher working with the Assembly Committee, who stated that: "And, as I remember, the Welsh government's opinion had already been: we don't have the devolved powers to make this happen" (Interview, 9 February 2018). The view that immigration and asylum are matters of sovereign control firmly 
reserved to UK Government underpins the argument that Wales has limited abilities to be the welcoming host it wishes to be. The Welsh Government's argument is that they can fundamentally disagree with the British Government when it decides to take only a very small number of people, or provide them with little financial assistance, but they cannot prevent it from happening. The devolved Government therefore considers its legitimate role to be limited to devolved matters, like health or education, which affect the lives of asylum seekers living in Wales, rather than sovereign matters of inclusion and exclusion.

However, what the Welsh Government's emphasis on their limited responsibility, and the committee's emphasis on a distinctive 'Welsh approach' share is that they allow a nationalised politics of differentiation: The Welsh government is imagined to follow a 'different approach' from the UK, with 'different' and limited responsibilities because of the UK government. Moreover, this discursive emphasis of the Welsh Assembly Committee on constructing the relation to, and more importantly, the differences from the United Kingdom as the sovereign host-state, returned several times in the research briefings and documents that were used in writing the finalised committee report. For example, the first of five briefings that the research service of the National Assembly for Wales wrote in preparation for the report (Jones and Johnson 2016a) reiterates how "policies on other matters that affect asylum seekers and refugees, such as health, differ across the UK".

The example that is also emphasised in the briefing document is that asylum seekers living in Wales are entitled to free NHS treatment if their asylum application is under consideration, and "this entitlement to free healthcare continues for an asylum seeker who has been refused leave to remain in the UK", while this is not the case when living in England (ibid). What is important here is that this institutional separation of responsibilities is accompanied by a moralised national discourse on the treatment of refugees, which emphasis and reiterates those distinctions to create a politics of differentiation between hospitable and inhospitable. After all, against whom is the Welsh 'Nation of Sanctuary' differentiated? First, there is the construction of a 'self' - the Welsh nation-state that is a welcoming 'host' to refugees who are resettled within its borders. But, who is the other? The first reading would have this be the Syrian refugee as a guest to be hosted and resettled. But, upon closer examination, is the other 
not also the UK with its "different approach" - imposing conditions on what forms of hospitality the Welsh nation as a potential 'host'-state would offer?

This discursive construction of the (British) sovereign state as an 'other' that imposes conditions on, and interferes with, the exercise of hospitality becomes apparent in two other research briefings of the committee. The first explained: "Witnesses highlighted that the Home Office is communicating directly with local authorities, effectively short-circuiting the Welsh Government" (Jones and Johnson 2017a). The second document emphasised this "short-circuiting" and: "that the Home Office liaises directly with local authorities to resettle refugees through the SVPRS" (Jones and Johnson 2017b). This critical notion of Welsh institutions being ignored on the matter of asylum was repeated in the 'Welsh approach' section of the Committee report, when Rocio Cifuentes from EYST reiterated that she was not clear on what role the Welsh Government had in the resettlement, that "it's direct between the local authority and the Home Office, which, to me, doesn't seem right", and she wanted the Welsh government to "aim to be much stronger and much more of an equal partner" (ELCC 2017: 17).

One can also read these calls for more strategic leadership as being part of the discursive formation of a coherent and unified self. This is in the sense of it being a nation-state that would be able to control and govern its relation to refugees, and its relation to the sovereign host-state. This seems to correspond with the inherent tendency of the state to strive for homogeneity and unity. Connolly's theoretical work reiterates here that: "To be a sovereign, territorial people, it is necessary to become a highly unified nation" (2004: 25).

\subsubsection{A "two-tier" system ...in Wales?}

The attempt of showing that a unified and coherent Welsh approach existed can also be detected in the immediate reaction of the Welsh Government to the announced expansion of the SVPRP. Their first measure was to establish a Syrian Refugee Task Force and Operations Board (Sargeant 2017a). This was also considered crucial for a "Wales-wide-approach" (ELCC: 2017) that would ensure that public services across Welsh local authorities would coordinate their efforts to take in refugees. Nevertheless, while some third-sector organisations like Oxfam initially welcomed the "Welsh Government's aspiration to provide a coordination role for the SVPRP" (Evidence 
submission), the first research briefing of the Committee had pointed out that "...pieces of evidence highlight concerns that there is now a two-tier system for asylum seekers and refugees, which risks causing division in the asylum seeker and refugee community" (Jones and Johnson 2016a). The same briefing document draws concludes from this by offering the following suggestion for further work and discussion: "elaborate on the claim that there's now a two-tier asylum system, and how this affects devolved issues" ([emphasis added] ibid). The formulations are of importance, because in asking how 'this' (two-tier asylum system) affects the Welsh devolved services, what seems to be implied here is that this is something coming from the outside, something that is caused and imposed by the (inhospitable) asylum policies of the UK government, and that interferes with the attempts of 'Welsh' devolved services to be hospitable towards refugees and asylum seekers.

When considering the potential effectiveness of this discursive framing, the insights that the second briefing document, and subsequently the Committee report, provided on the role of the Welsh Government in perpetuating these two-tier distinctions, constituted a real problem. The Committee's second research focused on evidence received from Oxfam Cymru, the Red Cross, the Welsh Refugee Council and a refugee, and stated that: "There was a feeling that the Welsh Government and the media are continuing the 'two tier' system into devolved areas for example, by having a Syrian Taskforce, rather than a refugee and asylum seeker taskforce" (Jones and Johnson 2016a). Subsequently, the Committee report summarised:

Stakeholders highlighted that the Welsh Government's Syrian Refugee Task Force and Operations Board perpetuated in Welsh policy the 'twotier-system' of asylum which they said had been created by the establishment of the UK government's SVPRP (ELCC 2017: 21).

And this was not just the position of the third-sector organisations and pro-refugee grassroots initiatives. Indeed, the third research briefing that followed focused on the evidence received from representatives of local government and health organisations, and stated that: “... all witnesses again highlighted that the Welsh Government's choice to focus strategy groups on the Syrian programme are embedding the 'two-tier' system of asylum" (Jones and Johnson 2016a). Therefore, in consideration of the evidence assembled by the Committee research over the course of its inquiry, the last 
research briefing before the publication of the inquiry report in February 2017 summarised the problems with this two-tier asylum system in Wales were perceived to be, and how they could be addressed.

These formulations are again quite revealing for our examination of the 'national' and devolved politics of differentiation in the context of the British asylum regime. The first aspect that is emphasised in the research briefing is that witnesses argued that it was the establishment of the "UK government's Syrian Vulnerable Person Resettlement Programme" which "created the two-tier asylum system" (Jones and Johnson 2017c). But what is reiterated in this formulation is that the UK government (and the sovereign British state) is the creator of the two-tier system. This formulation therefore builds a discursive association between the exclusionary elements of the sovereign politics of asylum (inhospitality) and the British nation-state. The implicit underpinning that follows is that the two-tier asylum system, and subsequently the unequal and exclusionary elements of border control more broadly, are not 'Welsh' but 'British' - they are something created outside, and imposed upon the imagined welcoming 'Nation of Sanctuary'.

This is not to say that the Welsh Assembly Committee report and inquiry is constituted of mainly uncritical praise. The second argument that is highlighted in the later briefing documents is that the Welsh government's Syrian Refugee Taskforce and Operations Board "perpetuates this two-tier system in Welsh policy" (ibid). While this is an important criticism, it is interesting that there is still a discursive distinction being built between 'creation' and 'perpetuation'. This supports the underpinning national politics of differentiation between imagined inhospitable and hospitable nation-state-hosts. Nevertheless, the consistent criticism that the Welsh Government, which had reiterated only two years prior that it wanted to become a Nation of Sanctuary, was "perpetuating" such an unequal asylum system was not without effect. The report mentions that the Welsh Cabinet Secretary later assured the Committee that "if there is a two-tier system, it's not intentional" (ELCC 2017: 22). But the Committee had discovered that the "Welsh Government's community cohesion co-ordinators work directly with refugees resettled through the SVPRP" but not with spontaneous arrivals (Jones and Johnson 2017c). Therefore, the Assembly Committee recommended in their report to the Welsh Government that it should expand the role of the community cohesion co-ordinators beyond the SVPRP to all refugees and asylum seekers residing 
in Wales (2017: 8). What is more interesting is that, as the Chair of the Committee, John Griffiths, reiterates in the report, this suggestion was taken on before the report was even finalised:

...the role of the Welsh Government's Operations Board has been expanded beyond the Syrian Vulnerable Persons Resettlement Programme to cover all refugees and asylum seekers, to help overcome the two-tier asylum system ... (ELCC 2017: 6).

The initial justification by the Welsh Cabinet Secretary for Communities and Children Carl Sergeant, and the quick change of a narrow policy detail, can still tell us a lot about the governmental and national self-imaginaries at work here. The main problem that this allegation of perpetuating an unjust two-tier system constituted for the Welsh government was that it conflicted with the discursive framing of Wales as 'Nation of Sanctuary'. It also conflicted with a national politics of differentiation that framed it as a generous and welcoming nation-state-host in opposition to what is implied to be a more inhospitable sovereign British asylum regime. And while this change with regards to the operations board was arguably rather narrow, one can nevertheless argue that it indicates that the Welsh government was bothered by claims it was perpetuating inhospitable elements of sovereign asylum politics.

\subsubsection{The impact of the UK Immigration Act 2016}

The second main theme of the proclaimed 'Welsh approach' is the UK Immigration Act 2016. Here, the relation between the devolved Welsh institutions and the sovereign British state is discussed, and differentiated through framing (national) 'different approaches' with regards to the politics of asylum and refugee resettlement. One should remember that the expansion of the SVPRP from September 2015 onwards was (and is) taking place on a background of an overall British asylum regime that has grown ever more hostile and exclusionary.

This 2016 Immigration Act is a good example of the broader "politics of unease" (Bigo 2002). The declared purpose of the act was to "tackle illegal immigration by making it harder to live and work illegally in the UK" (ELCC: 2017). The underpinning principle of this 'making it harder to live and work' was to further restrict access to housing, different services and benefits for migrants who had been illegalised. The emerging issue is that a sovereign (British) policy to create a hostile environment was 
depending, in Wales, on devolved public services to make this happen. Therefore, the first of the five research briefings of the Assembly report determined that an area for suggested consideration could be: "How people move between non-devolved and devolved services as asylum seekers and refugees, and where the inconsistencies [my emphasis] lie..." (Jones and Johnson 2016a). What is meant with 'inconsistencies'? The second briefing suggested that it means that such a policy change from the UK government regarding the politics of asylum will affect services that are supposed to be delivered and controlled by the devolved administrations, whose politics and preferences may not align with those of the (sovereign) nation-state. It argues: "The Immigration Act 2016 is likely to have a big impact on devolved areas including housing and looked after children" (Jones and Johnson 2016b). An example that was discussed in the following research briefing documents and the Committee report, were the so-called "right-to rent-checks". The scope of those checks was significantly extended with the Act, as it made it an offence to rent to a person "who is disqualified because of their immigration status" (ELCC 2017: 25). For the purposes of our examination, what is particularly interesting is that the report emphasises how: "This is currently only applicable in England, but the UK Secretary of State has the power to enable any of the residential tenancy provisions to apply in relation to Wales, Scotland and Northern Ireland" (ibid: 25). This emphasises the sense of subordination perceived by the devolved administration with regards to a policy area that it considers to be clearly within its remit.

Indeed, in addition to this (nationalised) politics of differentiation concerning asylum, there is a second element that is discussed. This concerns potential conflicts between devolved and sovereign control, regarding areas where there are overlaps between devolution settlements and sovereign border politics. There is the question of whether such a legalistic distinction can be neatly drawn in this context. When a territorial unit posits itself in such a manner as non-sovereign, is it necessarily the case? The conceptual distinction by Edkins and Pin-Fat (2004) is of theoretical assistance. They advocate to not just focus on debates concerning sovereign statehood, but also to trace the "continuance of certain grammars of power and resistance, irrespective of the site or sites in which they are located" (ibid: 3). Their conceptual suggestion is to break away from equating a notion of sovereignty with 'sovereign statehood', which is clearly reappearing in this context, but insist upon an engagement with the term 
"sovereign power" (2004: 3). Nevertheless, this potential conflict was still a major criticism. One aspect that was reiterated in another research briefing was that some witnesses thought that the Welsh government did not possess a sufficient understanding of the implications and the impact of the act for Wales, including the high likelihood of increasing destitution (Jones and Johnson 2017a). One of the researchers on the Assembly Committee remembered the context of this conflictual debate:

We got the feeling that the Welsh government had made a decision to not prioritise the grey areas in-between devolution settlements.

So, the Immigration Act and all the right-to-rent stuff was a really good example of them not considering the devolved impact of a thing that would have a huge impact. And, so, we still don't know when this right to rent checks might be forced upon ...

You know, housing is a devolved area, I mean, it's a clear sort of conflict. But I think that's the difficult thing with, particularly with refugees and asylum seekers, the issue sits completely in-between the two devolved powers (Interview, 9 February 2018)

In addition to the trope that there is an imposition of sovereign asylum politics and it is outside of the Welsh government's control to do something about that, a second theme emerged in the evidence sessions. Here, it was emphasised that this imposition conflicted with legal devolution settlements. The housing charity Tai Pawb suggested that the Home Office "should" share the number of expected applications to enable local authorities in Wales to prevent refugees from becoming homeless. This was stated "especially in light of the new homelessness prevention duties introduced by the Housing (Wales) Act 2015" (Jones and Johnson 2017a). In the same document, however, it is emphasised how the Joint Council for the Welfare of Immigrants found out that this policy had also effected people with a 'right to rent', which means for them that "...this works against the measure in Housing (Wales) Act 2014 which allows Welsh local authorities to discharge the duty of homelessness prevention to the private rented sector" (ibid). These arguments and considerations on potential conflicts between devolved power and the sovereign politics of asylum had a considerable impact. The research briefing mentioned for example that: "many witnesses thought that it was the responsibility of the Welsh Government to "enforce the rights of all asylum seekers and refugees in Wales" (ibid). Similarly, the research briefing had 
created suggestions for questioning of the Welsh Cabinet Secretary if he considers that the Welsh government has a "responsibility to enforce the human rights of all people living in Wales, including refugees" (Jones and Johnson 2017b).

\subsubsection{The response of the Welsh Government to the Committee report}

How did the Welsh government react to this committee report on the situations of refugees and asylum seekers in Wales? And what does this reaction tell us about the framings of national self-imaginaries accompanying those responses? In the first instance, the Welsh government acted itself also as a witness to the National Assembly Committee report, and provided an evidence paper to assist in the creation of the report. This first response by the Welsh Cabinet Secretary for Communities and Children Carl Sergeant, reached the committee in January 2017. The introduction starts with the following sentence:

The Welsh government welcomes this inquiry into support for refugees and asylum seekers in Wales as an opportunity to recognise the long standing and continuing positive response of the Welsh people and the Welsh government towards those who had to flee war, persecution or natural disaster and rebuilt their lives in Wales (2017a).

This reiteration of an imagined long-standing history or continuous 'record of hospitality', which has been discussed in Chapter 1 and 2, (see also Darling 2013), right at the start of their evidence paper points to the importance that the framing (recognition') of national (the positive response of the Welsh people and the Welsh government) self-imaginaries had with regards to how the devolved government saw the inquiry. But this formation of national self-imaginaries in this document was not just limited to the reiteration of distinct and partial histories to be remembered (Massey 1991), but also concerned the more recent reaction to the long summer of migration.

The establishment of the Ministerial Syrian Refugee Taskforce was described as "crucial to ensure that public services across Wales coordinated...", since quite a few of the Welsh local authorities participating had not previously resettled refugees. But it was reasserted that: "All 22 Welsh local authorities have committed to playing their part in the SRP..." (Sargeant: 2017a). The first theme is the concern with a coherent and unified internal politics of the devolved Welsh state with regards to refugee resettlement. This is important because what we see reappearing is the emphasis on a 
response and coordination across Wales, despite the fact the participation of local authorities in the SVPRP was voluntary, and most of the organisation took place between the Home Office and the concerned local authorities. The reiteration of the fact that the level of participation that occurred was, geographically speaking, a 'Wales-wide' approach in which all local authorities within Welsh borders "committed to playing their part", points to the attempt to frame this as first and foremost a national Welsh response, and the subsequent need for the imagination of the nation-state (even when devolved) to achieve internal coherence and unity.

However, in addition to this initial larger attempt at creating national self-imaginaries of Wales through discussing the topic of hospitality to refugees, the written response of the Welsh government to the finalised committee report also reveals a second rationale essential for this form of national identity-formation. This involved negotiating the relationship to the UK as the sovereign and second other who determines the sovereign politics of asylum. After reiterating the pride for "Wales' history" on providing hospitality to refugees, the report continues with this statement:

The report notes that much of the responsibility relating to asylum policy is reserved to the UK government. There are also substantial challenges to achieving effective inclusion of refugees and asylum seekers in a climate of reducing resources (Sargeant 2017b: 1).

There is once again a twofold implication. First, the emphasis on the limitation of what the devolved Welsh state can institutionally achieve, thereby absolving it of the potential allegation of not being a responsible or 'generous' host to refugees and asylum seekers. But there is also a politics of blame that accompanies this emphasis on responsibility. The notion of "substantial challenges to achieve inclusion" is combined with an emphasis on the politics of austerity implemented by the UK government. And this national-devolved politics of blaming the British government on the topic of what constitutes an 'responsible' host returned in the Welsh Government's response to the report. The Cabinet Secretary for Communities and Children Carl Sergeant reiterated that they were "keenly aware" of the concerns about the two-tier asylum system, and that:

The Welsh Government aims to minimise the effect of the UK Government's prioritisation of Syrian refugees, where this can be done within the constraints imposed by programme and funding conditions. 
The extension of the Board's remit should help us to monitor this more effectively and ensure that all refugees in Wales are treated as consistently and fairly as possible (ibid: 2 )

What we can see is a (national-devolved) politics of shaming the British government on the topic of responsibility "when measured against the values and national character promoted in the celebratory narrative of British hospitality and humanitarianism" (Sirriyeh 2018: 71). The prioritisation of Syrian refugees (the two-tier logic) is here associated with the UK government, while the Welsh government is associated with the "attempt to minimise" the effects (imposed upon them) and the subsequent extension of the (originally limited Syrian) board to all refugees in Wales, in order for them to be treated "as consistently and fairly as possible". This narrative therefore moves further than pointing out the sovereign responsibility (and accountability) for the politics of asylum as resting with the UK government. The second association that is built is of the Welsh treatment of refugees as fair and consistent, and the British treatment as prioritising and thus unequal. There is a discursive distinction being built between an imagined hospitable and welcoming host (Wales) and an inhospitable and hostile host that fails with regards to what David Cameron called its "moral responsibilities" (BBC: 2015a) to refugees and asylum seekers.

This framing has theoretical implications for our discussion on hospitality. The first theoretical implication is a second othering. The discursive framing of responses to migration through the metaphor of hospitality is not only created through a binary relationship between sovereign state (host) and the migrant 'other' (guest), but it also involves an othering between imagined 'hosts', for example different political or administrative units. One form that this second othering takes is when a subnational territorial unit, one that is devolved for example, enables itself against a sovereign nation-state through managing, adapting and constructing expectations of what it means to be a host to the 'other'. Darling (2013: 1792) had argued that 'the categorisation of the stranger as the identifiable guest is critical to both the practice of conditional hospitality and the securitising impulses of domopolitics as a concern with ordering the 'homely' nation. While the British government's response was framed through the domopolitical logics of categorisation and classification, the Welsh and Scottish cases involved a second othering, as on immigration, they are not in control of their borders. Moreover, a third implicit assumption could be read from this 
reiteration. This is the implication that the Welsh nation-state would be a generous and hospitable host to refugees if it were allowed to act in such a manner by the British government, and that it is therefore prevented from being a 'host' in its own 'home'. This is a form of political discourse which Emma Hill (2016) explored with regards to narratives of the Scottish Government, describing, on the topic of immigration, how: "Scotland is a guest in its own country" (ibid: 203).

\subsection{A Second Othering: The politics of differentiation}

Hill (2016) explored how in the Scottish and British context the usage of hospitality tropes has become systems of cultural signification. The migrant 'other' imagined by the state opposes and creates national identity as an "imagined community" (Anderson 1991). National and migrant identity are understood to be "defined and redefined in accordance with the shifting needs of the sovereign state" (Hill 2016: 197). Sovereignty has been understood as "the discourses and practices through which political authority has been constituted and legitimised, particularly [...] in the form of the sovereign state" (Shaw 2004: 166). Nevertheless, in moving away from the literature's central focus on how sovereign power is operating to the detriment of migrants, the following analysis of a second othering will use Karena Shaw's (2004) consideration that:

The same discourses and practices through which the sovereign state was articulated, though, have also been seized and deployed in relation to other efforts to constitute legitimate authorities, not least those seeking to resist or delegitimize assertions of sovereign authority over them (166)

It is important to reiterate Hill's caution to pay attention to the "political nuances" connected to asylum in the Scottish context. This is also the case in Wales. She states: "devolved arrangements mean that Holyrood cannot legally control who they host and [...] these factors are directly relevant to the meanings and use of the hospitality metaphor" (2016: 200). This means that the hospitality metaphor is here less concerned with the Derridean (2000) moment of inclusion or exclusion at the threshold of the nation, but more with the subsequent practices of hospitality in terms of 'hosting' refugees and asylum seekers. This conceptual change of focus is apparent in the 
following comment by the researcher of the Assembly, who described how she saw the 'Welsh approach' when the enquiry was designed:

And if you look at refugees and asylum seekers as just people that live in Wales, and, you know, lots of the things that they ... their interactions with the state: education, housing, transport, healthcare: that's all devolved. So, when we were designing this enquiry, that was forefront in my mind (Interview, 9 February 2018)

On the one hand, the notion of refugees and asylum seekers as "just people that live in Wales" is fascinating in moving away from the focus of the access to services (and rights) as being bound to legal status. It almost moves towards what Squire and Darling (2013) have called a conception of "rightful presence" (discussed in more detail in Chapter 2). This also has a conceptual effect: in investigating the metaphor of hospitality through this lens, one moves away from the moment of sovereign inclusion or exclusion, towards the practices of managing the expectations of what it means to be a host to the other. On the other hand, it is still necessary to caution that this conceptual focus on the practices rather than the moment of hospitality does not necessarily translate into a challenge to the exclusionary politics of asylum. Rather, it often remains the focus of the limited debate on what exact 'responsibilities' the different 'hosts' hold. In talking to a member of the 'Asylum Matters' project, he considered this to be one reason for the support of the Welsh Government regarding the concept of a NOS:

Because they don't have primary responsibility for dealing with the controversial issues around asylum and immigration, and only have, kind of, responsibility for what you would could term 'secondary' [...] issues, you have a general level of sympathy and support, which is never tested at the level of making difficult decisions (Interview, 23 April 2018)

The additional argument that this support for more hospitable immigration policies remained only on the discursive level of discussing devolved and non-devolved responsibilities, and was not translated into a challenge to the British asylum regime was a recurrent criticism in the interviews with representatives from refugee support organizations and the third sector. The member of 'Asylum Matters' continued to describe his experiences on discussing the topic of asylum with officials from the devolved Welsh Government: 
We were saying: We would like Welsh Government to take a more public stance on this. And they were saying: Oh, its non-devolved, so we are never really going to comment on that. And then the next day, Carwyn Jones, the Welsh Government, Welsh Labour, published a paper on what they think immigration should look like after Brexit. So, there is a huge contradiction (Ibid)

The first issue is that this resonates with Hill's caution that the hospitality is often used as a "proxy for expressing anxieties about national identity for the gain of political capital and at the expense of immigrants themselves" (2016: 194). The Welsh Government, while less hostile than the British government, still uses the affective language of hospitality on migration mainly for the creation of national selfimaginaries. The impact of this is that it does not challenge the exclusionary asylum regime by emphasizing what it could do to mitigate its effects, but rather reiterates what it cannot do due to institutional limitations.

In a similar manner, Maria* from the Welsh Refugee Council argued that one of the organisation's criticisms of the Welsh Government when giving evidence was that "they could be more vocal in going back to the Home Office, in saying 'this is unacceptable in Wales', you have to talk to us about things that impact upon devolved areas of responsibility" (Interview, 9 May 2018). This second intervention from the third sector is interesting because it calls for two things to happen: first, to move beyond the reiteration of devolved and non-devolved responsibilities towards emphasising how the sovereign politics of asylum impacts upon devolved areas of control; and second, that the exclusionary elements of the sovereign politics of asylum should be marked as "unacceptable in Wales". This draws an implicit discursive distinction between a hospitable Wales in which such hostility would be deemed morally unacceptable, and a more inhospitable other (Britain) where it is morally accepted. The 'moral nationalism' of the Welsh devolved state is here not only constructed with regards to the refugee-guest-other, but also with regards to the UK as the sovereign host-state-other, a form of second othering: a positive national selfimage is constructed around the affective language of hospitality with regards to their own relationality to migrants and with regards to an imagined (un)hospitable sovereign host-state. But this discursive politics of a second othering remains, in the case of the Welsh government, often concerned with the creation of national self-imaginaries as a 
generous host to refugees - it does not challenge the exclusionary politics of asylum of the sovereign other, it is fundamentally not an antagonistic form of politics.

This therefore raises the question: Can the devolved nation mount a challenge to the sovereign state and its exclusionary asylum regime? The following section will begin to answer this question, and the process of this more theoretical consideration will finish with the conclusion. For now, it is important to emphasise the reason for the importance of this question. Specifically, if we focus only on the shifting needs of the sovereign state, this leads us conceptually back to the migrant who is othered as the guest of the host-state, and back to the domopolitical distinctions of deserving and undeserving migrant. The devolved territories and their national self-imaginaries as hosts, for example Wales or Scotland, add a second level of othering. This second level of othering still returns to the problematic idea of place as bounded, but entails the possibility of challenging the legitimacy of the sovereign host-states, and their exclusionary asylum regimes. My argument is that the progressive potential of the politics of a second othering is dependent upon what role this discourse plays in managing the devolved relationship to the sovereign nation-state: specifically, to what extent it wants to differentiate itself from the sovereign in an antagonistic or consensual manner.

What could such a discursively more antagonistic politics look like? In her chapter, Hill (2016) contrasted discourses on migration under David Cameron with a speech by Alex Salmond on his election as the First Minister of Scotland in 2011, who would then be the head of the devolved Scottish Government lead by the Scottish National Party (SNP). In his speech, the first instance of a single party in the Scottish Parliament setting out its governmental agenda (Hill 2016: 200), Salmond framed imaginaries of what he called the 'new' Scotland, and of national imaginaries:

It belongs to all who choose to call it home. That includes new Scots who have escaped persecution or conflict in Africa or the Middle East. That is who belongs here but let us be clear about what does not belong here. As the song tells us for Scotland to flourish then 'Let us be rid of those bigots and fools. Who will not let Scotland, live and let live'. Our new Scotland is built on the old custom of hospitality (2011 in Hill 2016: 200). 
While this speech does of course construct a certain image of Scottish identity as generous and welcoming, it seems that there is a second and more subtle logic underpinning this framing. Hill points out that those 'bigots and fools' who will not let Scotland live can be understood here in a twofold manner. First, those intolerant against new Scots who choose to call Scotland home, but also, more implicitly, against those who would deny the 'new' Scotland their 'old' custom of hospitality (2016). In considering the SNP advocating for Scotland's secession from the United Kingdom, commentators have identified in this rhetoric a tendency to associate historical acts of oppression with the Anglo-British element of the United Kingdom (Mycock 2012). Hill (2016: 201) argues that this reference to a denial of this custom of hospitality can also be understood to "evoke the silent spectre of Anglo-British governance which has curtailed Scottish autonomy". In this reading, the Anglo-British element is the host and the Scottish element as the 'other', not as the traditional guest-other which is often associated with the migrant, but in the imagined sense that "the nation that would so freely host its immigrants - is Othered in its own country by the invocation of the Anglo-British figure" (Hill 2016: 201). This begs the question of how the political effort for national independence affects attitudes towards immigration and the politics of asylum of the sovereign nation-state. This issue has not been examined in the critical literature on migration (or the nation-state). The argument developed here is that the extent of the political wish for (national) autonomy, and potentially separation from, the sovereign nation-state affects the extent of the antagonistic element of the second othering, and therefore its progressive potential to challenge some parts of the dominant exclusionary asylum regimes.

This is apparent in the comparison between the Welsh and Scottish devolved governments and their approaches to managing their relationship to the UK with regards to the politics of asylum. The difference between the two is something that was emphasised numerous times in interviews and fieldwork conversations with activists from refugee support groups and the third sector. When I was interviewing a member of the Asylum Matters project, for example, he described the situation in Wales as "unique". This was followed by an afterthought where he reformulated: "Well, it is not truly unique, because there it is often similar, in Glasgow recently [...] there are similar dynamics that play up there..." (Interview, 23 April 2018). The similarity that is talked about refers to the existence of devolved governments and the 
cultural notion of the existence of separate nation-states in both cases. However, he continued to describe that, with regards to the politics of asylum, there are significant differences between the two cases:

The Welsh government and the Scottish government have taken divergent approaches to how they manage their relationship with the UK government. The Scottish government make a big play-off the difference between the two. Whereas I think, the perception, an accurate selfperception, of the Welsh government is that of the good unionist. And if they are seen as behaving now and not causing too much trouble to the UK government, they think that this can somehow improve their position, or get them favours from the UK government. And I am not sure how effective that is, as a technique. I think the Scottish Government's approach has worked out better (ibid)

In considering that the devolved Welsh Government has historically been led by Welsh Labour whereas the devolved Scottish Government has, for the most part, been led by the Scottish National Party (while there has not been further devolution in either for a long time), this reiterates the earlier argument that the extent to which the discourse of a second othering on asylum takes an antagonistic or more consensual political form is dependent on the extent to which the politics of differentiation is meant to create some form of separate political autonomy. Its subsequent effectiveness in challenging the sovereign politics of asylum depends on that. Bethan Jenkins, being a party member of Plaid Cymru and member of the National Assembly, described here:

I think from knowing what Scotland's attitude is as a government and as a civil society, you know you can see the difference in that, even though they haven't got power over immigration, they say 'if we had power over immigration we would do XYZ', whereas with the Welsh Government they always just say 'well, we don't have powers over immigration, our hands are tied, if they gave us X amount of children, fine but we can't control that'. There's a difference in tone and I think that's quite significant (Interview, 13 January 2018)

The discursive distinction, the "difference in tone", that Jenkins describes here, relates to the earlier point about the different discursive emphasis: what could be done for refugees and asylum seekers if more powers would be devolved, and what cannot be done due to institutional limitations. But is also of theoretical interest to rethink the architecture of sovereignty itself. Shaw (2004) acknowledges how "sovereignty 
remains at best an ambivalent discourse for marginalized peoples, deeply embedded as it is in an ontology that assumes and reproduces their marginalization" (ibid: 165). But she also states that "this is not to say Aboriginal peoples have only been the victims of sovereignty" (Shaw 2004: 166). Indeed, her argument is that the discourses and practices of sovereignty have not just articulated movements of nationalism, but also anti-colonialism and self-determination, therefore "enabling and legitimating resistances to hegemony and the emergence of new political agents and subjectivities" (ibid: 166). This is not supporting the case of Wales and the Welsh people as a colonised or oppressed minority. Nevertheless, this conceptualisation of sovereignty, theoretically speaking, reiterates the argument regarding the potentiality of the second othering to challenge the (British) sovereign asylum regime in its discursive legitimacy.

To summarise what has been argued: The Welsh and Scottish position rely on a discursive politics of differentiation, the second othering, for the formation of national self-imaginaries. The main difference is this: the former's position, while occasionally relying on a politics of differentiation on who constitutes the more hospitable host, does not challenge the legitimacy of this sovereign asylum regime and its exclusionary politics. It rather implicitly treats it as an unchangeable institutional fact when it chooses to emphasise that those powers are not theirs, and that therefore their hands are tied. The latter position, in emphasising that 'if we had power over immigration, we could do...' draws a stronger discursive distinction between an imagined hospitable self and the inhospitable other, therefore creating a moral challenge to the legitimacy of the sovereign asylum regime on what it means to be a host. But it goes further than that. It implies that this second other, as Hill formulated it, prevents the "nation that would so freely host its immigrants" (2016) from doing that. This emphasis claims itself to be "othered in its own country" (ibid) which means that the discourse of differentiation between the imagined hospitable and unhospitable hosts turns into a question of political legitimacy regarding who should be allowed to be a host to new arrivals. 


\subsection{Conclusion}

In conclusion, this chapter has shown that the second othering which accompanied the sanctuary framings by the Welsh government, did not fully escape dominant national and statist imaginaries regarding the exclusionary politics of asylum, instead repositioning and promoting Wales as a 'welcoming place' to refugees and asylum seekers (see Tuma et al 2019). This is an ongoing process, and has most recently culminated in the Welsh Government calling its recent refugee and asylum seekers plan, which was published in January 2019, Nation of Sanctuary. But the question remains: Is this framing of Wales becoming a Nation of Sanctuary not just another form of nation-building, as Hill (2016: 194) has cautioned against, "set against and built at the expense of the immigrant Other"?

My answer is this: While it does not escape national and statist imaginaries, the second othering in the Nation of Sanctuary image perhaps constitutes a starting point from which to theorise a more progressive politics on the relations between the nation-state and migratory movements. Philo (2014). reminds us that the nation-state has "yet to be deconstructed out of existence". However, considering that this remains rather speculative, it will be engaged with in the concluding chapter. Thus, before moving on to this question for the future, there is another theoretical element to consider in our engagement with national sanctuary imaginaries. Edkins and Pin-Fat (2004) have suggested to move away from equating sovereignty with sovereign 'statehood', examining instead the concept of 'sovereign power'. Their approach focuses on how day-to-day social interactions - lived lives - are productive of both power and subjectivities (ibid: 3 ). These considerations open for them new questions:

What forms of life do particular power relations make possible? What does this mean for people caught up in these power relations? ... Can subjects contest their subjectification, and if so, how? What counts as resistance? Is there any escape from power relations? (ibid).

These questions on those sovereign lives (ibid) of migrants are also of interest for a critical examination and analysis of national sanctuary imaginaries. There are two reasons for that. First, if the empirical focus of this examination is only on different scalar imaginaries of hospitality, the analysis might yield a too narrow focus on sovereign 'statehood', leaving underexplored the issue sovereign 'power' that is 
entangled with most hospitable framings. Therefore, the focus of the next chapter will be on hospitable practices and relations, on the interactions productive of the power relations and subjectivities associated with hospitality. The second reason is that what has been suspiciously absent from a lot of the national sanctuary imaginaries have been examined so far are the voices and self-imaginaries of those that are framed as 'guests': refugees, asylum seekers and other migrants living in Wales. It is therefore their perspectives and (self-) imaginaries that will be the central topic of the next chapter. 


\section{Chapter 8. At the limit of the hospitable nation: Hosting schemes and asylum seeker's perspectives on destitution and 'home'-lessness}

Chapter 7 examined hospitable sanctuary imaginaries, but from the perspective of the state, defining themselves as the host. We have not heard from those who are framed as the guests. Therefore, this eighth chapter has a twofold purpose. The first task is to examine 'hospitality in practice'. The second task is to use this chapter as a platform for the underrepresented voices of those who have so far been framed only as "guests" in those official discourses and narratives of state hospitality: refugees and asylum seekers who live in the UK, and specifically in Wales. The importance of those two tasks for the final chapter is apparent when one looks back at what has been examined in this thesis so far. The second and third chapter demonstrated how the critical literature on migration and the sanctuary movement (Darling and Squire 2011, Darling 2013) has explored the limits of hospitality as a framing and response to the exclusionary politics of asylum (Squire 2011). The last three empirical chapters have then shown that such a moral-discursive politics can also be used to challenge the sovereign nation-state on the expectations of what it means to be a 'host' to refugees and asylum seekers. And while this examination contributes to the literature in providing new theoretical concepts for revisiting hospitality, there are still political ambivalences and problems to be thematised.

One such problem is that the empirical focus so far has been predominantly on discourses, narratives and imaginaries of hospitality. The issue is that the empirical focus on scalar imaginaries might return a theoretical analysis of hospitality to the conception of the 'home' as stable, natural(ised) and ahistorical entity. Therefore, this last chapter will focus on practices of hospitality in examining two private hosting schemes for destitute asylum seekers in Cardiff and Swansea, called Share Tawe and ShareDydd. Including an examination of practices of hosting will support a critical geography that understands political notions of 'home' not as pre-given, but as contingent, as subject to change, and as necessarily multi-scalar. 
Another problem is that the empirical focus on different imaginaries of hospitality might privilege the subjects who benefit from framing migrants like this (even if wellmeant). It might end up offering a platform for people who, in dominant hospitable framings, are constructed as the 'hosts': the civil society actors, activists, and state institutions. This would also privilege the collective engagement of 'established' residents over those with a less established presence (Squire 2011). And it not only forces those who are framed as 'guests', asylum seekers and refugees, into a rather passive role and silences their voices, but might also reinforce and entrench unequal relations of power and domination that are associated with those terms. Drawing on small group interviews and ethnographic fieldnotes, the following sections will therefore focus on how destitute asylum seekers and refugees experienced hospitality in the context of the two hosting schemes. It will also examine the extent to which the encounters and interactions between those framed as hosts and guests might resist or transform the framing of hospitality altogether. The benefit of focusing on practices is in unearthing the ambivalences and power discrepancies inherent to hospitality, which are often ignored in dominant imaginaries.

This last empirical chapter is structured into three sections. In examining the hosting schemes, the first section looks at the broader interlinking issues of asylum accommodation, destitution and hospitality. It will begin with showing that the relation between these topics is not new, but that destitution has in fact accompanied the social, political and discursive developments we have been tracing since the announcement that Swansea would become a dispersal area for asylum seekers, using additional material from the media examination in Chapter 5. Moreover, there is now a considerable literature on the accommodation policy for asylum seekers and refugees in the UK (see Netto 2011a, 2011b), and some scholars are examining the regulation of asylum accommodation as a form of domopolitics (Darling 2011a). However, this emerging literature has focused almost entirely on 'official' accommodation provided by the Home Office, through private companies such as G4S or Clearsprings. With the number of asylum seekers and refugees facing homelessness on the rise, however, there has been an increasing emergence of private hosting initiatives that attempt to support those migrants made destitute by the 'hostile environment'. Therefore, the second section will examine those hosting schemes and the relation of domopolitics, hospitality and non-official accommodation. This chapter shows how the private 
offering of hospitality can entrench the unequal distinctions between established and less established residents, but also challenges the hostile environment for refugees and asylum seekers in the UK. It also shows the importance of the debate around destitution and homelessness for the ongoing process of different actors attempting to define what a Welsh Nation of Sanctuary might mean and do.

\subsection{Asylum accommodation, destitution and the 'nation as home'}

The previous empirical chapters have shown in detail how almost all the Home Office policy papers that followed the 1999 Immigration and Asylum Act are discursive representations of a governmental attempt to control, manage and securitise various patterns of migration. At the same time, they are "maintaining the politically salient image of the cohesive and homely nation" (Hage 1998 in Darling 2011: 263). Domopolitics is understood as the governance of the nation-state as a home, with a safe inside and a dangerous outside. But Darling (2011: 267) has pointed out that it also requires and produces what he calls "spaces offiltering". He argues that after the assignment of categories to securitise, there is "a more specific, and spatial, process of assigning locations to those individuals categorised", and that domopolitics "is also of need to accommodate those categorised as suspicious subjects" (2011: 267).

This additional domopolitical need becomes most apparent in the dispersal system for the allocation of accommodation for asylum seekers. Dispersal, which had started with the 1999 Immigration and Asylum Act, had marked a shift from a decentralised system, in which asylum seekers were free to choose where to live, to a centralised and national support and accommodation system in which they lost this freedom to choose. In the previous system, the asylum accommodation was provided by both local authorities and private landlords, while in the latter, as Chapter 5 and 6 have shown, private providers held exclusive contracts across a series of cluster zones introduced to avoid an excessive 'burden' on the south-east of England (Darling 2011). The most important change was therefore that this dispersal system provided accommodation now on a no-choice basis, and that eligibility for welfare provision was now linked to the decision to accept dispersed housing (Schuster 2005 in Darling 2011). And, while it is obvious how the dispersal allocation on a no-choice basis presents a form spatial power through the ability to 'place' people (Gill 2009a in Darling 2011), Darling 
argues that accommodation itself could be a form of governance, one which forges an "affective politics of discomfort" (2011: 268). This affectivepolitics of discomfort for arrivals also went beyond accommodation. When asylum seekers had started to arrive in Swansea in February 2002, three asylum seekers where caught stealing in clothes stores. They stated at their court appearance that they were driven to these acts out of poverty, resulting from the Home Office voucher system (Butler 2002). The court case got subsequently a lot of attention in the local press in Swansea, as the SWEP printed another full-page article on the topic of the dispersal policy, entitled: "Safe haven- or poverty in the land of sanctuary?" (Peregrine 2002). The second part to that newspaper headline on the arrival of asylum seekers, which questions poverty, is then throwing up questions for hospitable self-imaginaries, in the sense of how the self-image of a safe have or Nation of Sanctuary conflicts with the existence of destitution. Chapter 6 demonstrated afterwards how those elements have continued to intensify during the past decade with the continuing processes of neoliberalisation. Other migration scholars highlight how the enforced movement of asylum seekers between accommodation is meant to disrupt feelings of belonging and security, and to "deprive asylum seeking communities of geographical stillness ..." (Gill 2009b in Darling 2011: 268). The political rationale is to create measures of discomfort and insecurity, so that "those not yet subjectified as either the 'genuine refugee' or the 'bogus illegal immigrants' are held at the limits of the 'homely' nation" (Darling 2011: 269). This rationale is also present in the current refugee resettlement programmes. The last chapter has shown that while Syrian refugees were considered by the British government to be the deserving and appropriate victim, their full access to all services is deemed to be less necessary than their eventual ability to 'go home'. Furthermore, what becomes apparent is that the British government's preferred position is and has always remained for people to 'return to their country, and that humanitarian commitments are still implemented under the main rationale of an exclusionary politics of asylum (Squire 2011).

For Darling (2016b: 269)., this framing of being at the limit of the homely nation also "enables and legitimises the unannounced entry of houses, the enforced mobility of individuals and the threat of destitution which hangs over many asylum seekers". In this context, the issue of destitution can assist in investigating the interrelation between domopolitics and asylum accommodation further, but also in looking for emerging 
opportunities for counter-conduct. An inquiry by the Joseph Rowntree Charitable Trust has defined destitution as: "lacking the means to meet the basic means of shelter, warmth, food, water and health" (Lewis 2007). The argument this chapter puts forward is that, in the recent context of the 'hostile environment', since the beginning of the so-called European 'refugee crisis', there is a new space emerging. This space emerges between the urge to control migrants through the domopolitics of dispersal accommodation, and the urge to continue a politics of discomfort, through the threat of destitution and homelessness. This twofold logic, one the one hand, attempting to control migrants through 'placing' them in accommodation, and on the other hand, attempting to continue a politics of discomfort that might end with them being destitute and homeless, is then accompanied by new ambivalences.

The following ethnographic fieldnotes from two meetings in Cardiff and Swansea can assist us in shedding light on those ambivalences emerging from this new space. The first issue they reveal is the effect that the hostile environment had in increasing the number of asylum seekers and refugees in danger of becoming destitute in Wales to somewhere between 500 and 1000 people, as described during the 'Sanctuary in the Senedd' event in Cardiff (Fieldnotes: 24.01.2018). While this might be a comparatively small number, it is conflicting with different discursive politics of place-making, such as moral urbanism or moral nationalism. There, states or cities define themselves through moral imaginaries of being hospitable and homely, and it is with regards to this self-image that the 'home'-lessness of the migrant 'guest' constitutes a problem. The unacceptability of destitution for this moral politics of place-making became obvious during the first meeting of the 'Destitution Working Group', a subgroup of the Swansea City of Sanctuary network. While discussing the importance of local networks in supporting asylum seekers and refugees, the organiser of the new group, a former asylum seeker themselves, talks of the city of Swansea and the support initiatives within it, and states: "We are good at welcoming. But what is at the end of welcoming? Destitution?" (Fieldnotes: 24.07.2017). The second issue revealed during these meetings stems from a specific response to the hostile environment and increasing destitution. Indeed, at the time, the organiser of the destitution working group was also working for a hosting scheme called Share Tawe, which finds local people who are willing to house destitute asylum seekers in their homes. The emergence of those private hosting schemes thus constitutes a reaction to 
enforced statist inhospitality. It is therefore the similarities and differences between state and private forms of hospitality with regards to accommodation and housing, and the conflictual and productive space in-between, to which the next section turns.

\subsection{Hosting schemes and hospitable practice}

The introduction of the dispersal system was meant to be a punitive measure for deterring asylum claims (see Darling 2016b). The social housing that was being chosen in cluster zones was described as 'unpopular' and 'hard to let' as it was concentrated in deprived areas (Sales 2007). This politics of discomfort has since then been continued and even increased. The hostile environment, enforced through the Immigration Acts of 2014 and 2016, was designed to deprive undocumented migrants of access to social services such as housing (through the 'right to rent' checks), employment, or healthcare, and to make life so difficult for them that they might consider leaving. Unable or unwilling to leave, these measures instead led to a substantial increase in poverty and homelessness among this community (Lewis: 2007). It was in response to this steep increase in destitution and homelessness among the asylum seeker community that the hosting scheme Share Tawe was set up in Swansea in 2012 (Interview, 1 December 2017).

The aim of Share Tawe is to "offer hospitality, in the form of accommodation, meals, welcome and solidarity to destitute asylum seekers in Swansea ... through volunteers who offer a room in their home..." (SCOS 2020). The second objective of this form of hospitality, as Johanna* describes it, is "to prevent homelessness while the individuals pursue their legal claim, because normally they have exhausted their appeal right" (Interview: 1 December 2017). This twofold task of the hosting scheme, in preventing homelessness while supporting destitute migrants to pursue their legal claim for documented status, is characterised by ambivalence. Ambivalence, as McNevin has termed it, can "...both resist and reinscribe the power relations associated with contemporary hierarchies of mobility" (2013: 183). This political ambivalence is apparent in the theoretical rationale and in the practical execution of the hosting scheme. The first issue is the rationale to prevent homelessness so that people can refile their legal claim for status. Johanna* explained this specific context 
and how, in addition to offering hospitality through finding private accommodation, they are doing this:

Part of our job is to try and help them find a legal support. So, whether they are hosted or not, I do try to refer them to the solicitors who are picking, you know, who are available. Because that way, they can pursue their case, and once they have a case in the Home Office, they can apply for support. Because it's really Home Office obligation to support these people...

So, what we are doing ... I think it is helping the community and the state, to get them back to the (...), as it were. Because that is the only way these persons can have sustainable support. And when the Home Office know where they are, if they give them house and support that will mean: they can eventually be granted leave to remain, or ... it can, in many cases, be a deportation at the end.

But at least this person, you know, is not homeless in the streets, isn't he? So, in the long run, this scheme, it is a little bridge. That it gives to people a chance to find their way around. Because I have seen a few people, regain their confidence, when they have something $[\ldots]$ because, somewhere to sleep is a very basic human need. Somewhere to eat, somewhere to dress (Interview, 1 December 2017)

Of course, the immediate practical rationale is to first get people out of a legal limbo after having been rejected, and then to allow them to regain an institutional status - as an asylum seeker with an ongoing legal case - which allows them to reapply for social welfare provision. From this position of having a minimum of social support, one can pursue their legal claim with the ultimate intention of being granted leave to remain and refugee status. But there are further implications embedded in this detailed description. The first interesting one is the acknowledgement that the additional goal to assist destitute migrants with their legal cases is also "helping the community and the state, to get them back into the system". While the statement begins with an implicit attack on the failure of the British state to provide adequate support ("it's really Home Office obligation to support these people"), it continues to state that the clarification of their legal status is "the only way to have sustainable support" (Interview, 1 December 2017). One could argue that the acceptance of a legal status as the main determinant for such citizenship rights reinforces the distinctions between insider and outsider (Isin 2009), between the deserving and undeserving 'guest', and the exclusionary politics of asylum. Rather than highlighting the illegalisation of migrants 
through those legal distinctions, the aim of getting them back into the process to acquire status implicitly accepts and legitimises the categories that have been set by the state in the first place. It does not attempt to challenge the broader asylum system and its politics of legal categorisation in this regard ("helping the community and the state"). But it is acknowledged that the hosting scheme offers only a small respite for destitute migrants from the effects of this exclusionary asylum regime, rather than constituting a fundamental challenge ("it is a little bridge...gives people a chance to find their way around").

However, just because the broader legal, political and moral categorisations of migrants is not explicitly challenged does not mean that the hosting scheme and the offer of private hospitality just reinforces the statist and hospitable justifications for domopolitical securitisation. The support that is offered by Share Tawe to destitute asylum seekers is rather characterised through ambivalence. It can indeed "... both resist and reinscribe the power relations associated with contemporary hierarchies of mobility" (McNevin 2013: 183). The implicit reinforcement of unequal power relations can be seen within the rationale of offering (temporary) private accommodation so that destitute asylum seekers can use it to re-make their legal case to prove that they 'deserve' refugee status. But there is an element within this description that shows how the offering of private hospitality in the context of state inhospitality might resist those attempts of domopolitical securitisation.

Johanna* has described that: "I have seen a few people, regain their confidence, when they have something [...] somewhere to sleep, to eat, to dress" (Interview, 1 December 2017). Considering that one of the main rationales underpinning the notion of the hostile environment is to create a "politics of discomfort" (Darling 2011), one could argue that the 'minor acts' (Squire and Darling 2013) of offering even temporary respite from the most severe effects of that asylum regime begin to constitute a form of resistance to the element of discomfort that keeps this regime 'efficient'. After all, the hostile environment and the subsequent exclusion of refused asylum seekers from welfare provision puts them into a state of destitution, and thus in a state where it is significantly harder to continue fighting the case for legal status when the immediate concern is day-to-day survival without basic state provisions. This is of importance, as asylum seekers are entitled to appeal against rejected applications. This is crucial because data suggests that appeals can be relatively successful. Indeed, between April 
2017 and March 2018, from 11,974 appeal cases determined in court, a total of 4,332 rejections by the Home Office were eventually overturned (Taylor 2018a). With one third of appeals being overturned, it is perhaps not too farfetched to assume that another rationale of the hostile environment is to prevent migrants from being in a state of even minimal support and security, from which they could find the time, energy and information to claiming those rights. While hosting might not directly challenge the politics of distinction that underpins the broader exclusionary politics of asylum (Squire 2011), it still challenges the politics of discomfort as a central rationale of the hostile environment. The importance of alleviating the most immediate effects of the politics of discomfort became clear during an interview with Ali*, an asylum seeker who was being hosted through the scheme. He describes being destitute:

While my case was still open, I lived in Home Office house. And after that, I get refused, 2016. They take me out, from the Home Office house. It was a very difficult time. You know, I don't have a place to stay, and it was very hard, you know. I didn't have any friends here. ... I get refused, and after that, I will be homeless now. I don't have any place to stay $[\ldots]$

I am very happy to stay with $[\ldots] *$ and help here sometimes, and, you know, I am in a big challenge, but when I came here, to [...] *s house, I was very happy... ... I say thanks for everyone to help me, also (...) and (...), you know, all this Share Tawe group ....

And you know, I am, just so sad also, my friend, his name is (...) he ... killed himself. He was the same, like my situation. He also got refused. Twice refused from the Home Office, and, you know, after that he was angry, and killed himself. And some people, you know, when I meet some people, they are like: are you also sad? The same situation like him $[\ldots]$ but you know ... I came here, to [...] *s house, and I am happy. I am focusing on my learning. Improving my English, it's much better now. Before, I didn't speak any, but now, my English is improving (Joint Interview, 2018a)

Ali*'s description of the struggle with destitution reiterates the argument that the offering of private hospitality in the hostile environment of the state is still characterised by ambivalence: resisting and reinscribing power relations and hierarchies associated with migration (McNevin 2013). On the one hand, he explains how, in comparison to a fellow friend facing a similar situation, the support he received to avoid homelessness and destitution was important for his mental wellbeing ("The same situation like him [...] but you know ... I came here, to [...] *s house, and I am 
happy") and his ability to take steps that are central for continuing to fight to achieve leave to remain (“Before, I didn't speak any, but now, my English is improving”). $\mathrm{He}$ is resisting a politics of discomfort designed to prevent him from doing precisely that. On the other hand, the elevation of this politics of discomfort comes through an initial offer of private hospitality ("I say thanks for everyone to help me ... all this Share Tawe group"), and could be read as being on behalf of migrants, reinscribing unequal power relations between the hospitable 'local' offering a room, and the 'passive' asylum seeker. This might reinforce what Squire (2011) identified, in her discussion on the UK integration and cohesion agenda, as the "privileging of the collective engagements of citizens or 'established' residents over those whose presence may be more fleeting or less definite" (ibid: 292) Furthermore, this structural ambivalence is not just apparent in the theoretical justification of the hosting scheme, but also in the execution of the hosting and in the practices of hospitality. The following section will therefore engage with the initial 'matching' and the interactions between 'guest' and 'host', and what implications appear with regards to the ambivalent politics of hospitality.

The first task of the networks is then to find people with empty rooms in their homes who are willing to host someone (Interview, 11 April 2018). The people willing to host are either, in the case of ShareDydd, put into contact through the larger national 'Refugees at Home' network, or themselves initiate contact with the hosting networks. These then spend time addressing potential fears and concerns from hosts (ibid). Johanna* mentioned challenges in the process, which she clarified in more detail after I asked her about them:

So, it's daunting, even from the first step. How do I cope with that stranger? Now, both sides, the guest and the host, they don't know each other. So, there is a case of the guest, the asylum seeker, feeling shame. That: Oh, I left. I came to a country, and now I am ending up in someone's house, someone that I don't know. So, there is that bad feeling. Or feeling also weight, you are becoming a weight to somebody. You know, you're becoming a burden, perhaps, to somebody else.

And on the case of the host, as much as they don't know this person, and the issue is: How long will I keep this person? Now, we know the UK asylum process can be very long, it's unpredictable. So, some hosts may wonder: How long will I keep this person, if I take them? What if they have issues? [...] They don't have money, so, who is going to support them, you know? So, all these questions come up with local people, and 
amazingly, we found very compassionate people. People willing to give a place, a room in their home. But that doesn't mean, they don't have these questions (Interview, 1 December 2017)

The beginning of this account is here indeed reminiscent of what Derrida had identified as the danger that is always involved in acts of hospitality - the 'daunting' notion of letting the stranger into the home. This daunting prospect is responded towards through a set process that addresses the questions of the 'host' concern the yet unknown 'guest'. The implicit intention is to transform the unknown stranger into the identifiable and categorised guest. This is achieved through the requirement of a written reference from someone who knows both the guest and host, to "reduce the risk, of anything" (ibid) before the placement can proceed. This is followed by an interview with the 'guest', and finally an initial meeting between both parties, and where both decide if they want to go ahead with the placement. What this shows is that private hospitality, initiated as a response to state inhospitality, does not escape this politics of identification that accompanies Derrida's distinction between the ethics of unconditional, and the politics of conditional, hospitality. This also means that this private offering of hospitality is neither free from the power discrepancies that make it in Derrida's account a "sovereign practice". This difference in the power becomes perhaps most apparent when Hannah* explains that the meeting normally ends in a placement, mainly because: "the guests are so appreciative, you know, they are in a dire situation, of course..." (ibid).

This dire situation of being in a state of destitution, and potentially facing homelessness when accepting this offer of hospitality, might then affect the power positionalities of both subjects beyond the meeting, and merge into the interactions and dynamics during the hosting period. Johanna* had already mentioned that there might be a feeling of shame involved for the asylum seeker as the 'guest', a feeling of being perhaps a weight or a burden, in having to rely on someone's generosity for housing. However, while the underpinning relation of dependence that emerges with such a starting position from the state of destitution will affect the shared dwelling, those hospitable relations are themselves subject to interactions and dynamics that might transform the initial framing of hospitality altogether. This potential might be of interest when considering the following account of the changing dynamic between 'host' and 'guest'. During a shared interview with participants of the ShareDydd 
scheme in Cardiff, Markus* who had offered Abba* a room, told me that he went together with him to his martial arts practice. With this example, they described to me how they felt about their interactions in living together:

M: From when we were doing the (...) martial arts, like, I always felt that when we sparred together, we were doing fight techniques that he would hold off, because of the dynamic. Because of the fact that he wouldn't want to hurt, or wouldn't want to annoy maybe even ...

Researcher: That was something you felt?

M: I felt ... or maybe you felt as well...? [Directed at $\mathrm{A}^{*}$ ]

A: Yeah.

M: That you didn't want to ... because perhaps there was this dynamic of me providing housing for you and things like that. But there was a point in it, where I was like: No, push me A., come on buddy. We are friends here, we got to get to know each other, and if we are going to spar together, then you need to show me some aggression, because I need to learn how to deal with it [...] I think that was one of the turning points in our relationship as well, was the point at which he felt comfortable enough to hurt me [...Laughing...] (Joint Interview, 2018b)

What is perhaps most interesting about this description is that Markus* is recognising how the potential power discrepancies between 'host' and 'guest' are influencing their dynamic, but he is also uncomfortable with this relationality, and how it influences their private interactions. Their shared dwelling seems for Markus* to be more than a (sovereign) practice of hospitality. In offering to be pushed during practice, he is voicing the wish to invoke the hierarchical guest-host relationship ("show me some aggression... I need to learn how to deal with it") and to establish a more egalitarian relation of 'friendship' ("push me ... we are friends here”). Kye Askins has identified a similar tendency in her research on a befriending scheme that brings together asylum seekers, refugees and residents in Newcastle, where participants almost always stopped talking about befriending and shifted the discourse to 'being friends' (2015: 476). This change seems to be established once Abba* takes the offer: "that was one of the turning points in our relationship... at which he felt comfortable enough to hurt me". It seems that the shared practices of living together, even if they have begun from a situation of dependency and an offer of hospitality as a sovereign practice, have created here new forms of relations that are perhaps not captured or described by the 
metaphor of hospitality. They might momentarily even invert the original guest-host relation. Nevertheless, there remains a strong ambivalence with regards to the potential endurance of such transformations from 'guest' to 'friend'. It is still dependent on the initial offer by the 'host', and can perhaps even be revoked if needed. To what extent the everyday interactions in shared dwelling have the potential to create an enduring disruption to the power discrepancies of hospitable framings remains thus to be seen.

\subsection{Statist versus private hospitality? Disrupting imaginaries of the hospitable nation}

We have seen how there is an inherent ambivalence to both the theoretical rationalisation and the practical execution of the work of the two hosting schemes, rooted in the framing of hospitality. The last section will show how this ambivalence also affects the challenges that these practices of hosting might create for the exclusionary politics of asylum. The first issue is that the critical literature on the politics underpinning asylum accommodation has focused only on official social housing allocated by the state. The emergence of those private hosting schemes has the critical effect that it adds a third element to, and partly disrupts, the nationalist imaginary of hospitality as a binary opposition between the state and the migrant. Rosello (2001) identified a similar dynamic regarding dominant framings of hospitality, and one essential consequence:

One of the eminently problematic consequences of the analogy between what we think of as state hospitality and private hospitality is that each citizen is implicitly required to abide by the laws of (in)hospitality dictated by the current philosophy of the nation, regardless of whether they correspond to his or her personal set of ethics (ibid: 35 ).

In her account, she uses the specific example of a French women called Jaqueline Deltombe, who was arrested in February 1997, being accused of housing an illegal(ised) immigrant from Zaire in her home, and of neglecting to ask her guest for their identification papers. For Rosello (2001), this reveals a conflict between a private sense of hospitality and immigration policies, and the "vulnerability of foreigners and nationals" (ibid: 35) if they are caught between them. The Debre Bill, on which her arrest was based, and which required citizens to inform the state authorities of the presence of foreign visitors in their homes (Waters 2003: 91), turned the symbolism 
of hospitality as an opposition between the immigrant and the state into a triangular structure. The 'guest' (migrant) and host (citizen) are accountable to the state's definition and practice of hospitality, turning the host into an immigration officer and transforming the house into the new threshold of the national border (ibid). While, to the best of my knowledge, there has not (yet) been a case in the context of the hosting schemes in Britain in which a private host was arrested, what is important is that it resembles a similar case to the Deltombe affair as a triangular setting between the guest, host and state, with the potential to generate a similar controversy "about the relationship between state hospitality and civic responsibility" (ibid: 38 ).

However, in addition to this potential for disrupting dominant national framings of hospitality, we identified the ambivalence inherent in private hosting as a form of political activism on behalf of destitute migrants and, with it, the danger of reproducing social relations aligned with "a politically passive and marginalised vision of the asylum seeker" (Darling 2011). It is therefore the disruptions to those hospitable framings which are created by refugees and asylum seekers themselves to which we will now turn. It is important to note that since asylum accommodation was turned into a form of governance with the introduction of dispersal policies and allocated housing, asylum seekers have also resisted these attempts to control them in various forms. Rosemary Sales describes here how: "Many people have left the NASS system rather than face compulsory dispersal, often returning to London where they have friends and networks of fellow nationals" (2007: 198). In the current context of the hostile environment and the constant danger of destitution when one is illegalised, refused asylum seekers often help each other first without the assistance of support groups or hosting schemes. When Johanna* from Share Tawe explained how she connects with people through referrals, she also mentioned that: "I haven't met anybody who has been sleeping out. So, they are either sleeping at a friend's house, or they are sofasurfing from one friend to another" (Interview, 1 December 2017).

These small-scale forms of self-organisation such as sofa-surfing, emerging from the situation of being destitute and the danger of becoming homeless, might not necessarily be subversive political acts. The point is rather to emphasise the agency of those portrayed as merely passive and silent subjects, even in such oppressive circumstances. In this context, it is therefore important to find other forms of migrant's self-organisation in resisting the current hostile environment and its politics of 
discomfort, and how they challenge dominant imaginaries of state hospitality. Interesting example can also be found in the Welcome to Swansea mentoring scheme, which was introduced by the local City of Sanctuary network to welcome asylum seekers and refugees when they first arrive in Swansea. Through this scheme, participants meet with a volunteer mentor, who introduces them to places, peoples and groups in the city. The scheme emerged from within the COS network, and according to Sarah*, who is a former asylum seeker involved in the scheme, at least half of the volunteer mentors are asylum seekers and refugees themselves (Interview, 28 July 2017). With regards to their everyday activities, Sarah* describes that: "When I arrived in Swansea, they used to have an asylum seeker support group, within Swansea council. So, they did... what we do now" (ibid). This comment regarding the everyday activities of supporting new arrivals begs another question: Who is doing the hosting? Bulley (2017: 70) has argued in his work on hospitality as a spatial practice that: "While there need not to be a singular 'host' to ensure and govern this welcome, the idea of cities as spaces of hospitality begs the question of who performs the everyday acts of hosting". It is often asylum seekers and refugees themselves who perform those everyday acts, the same people who are usually framed as passive 'guests' within scalar imaginaries of hospitality. Askins (2018: 475) identified a similar dynamic in Newcastle, as the participation of refugees in the befriending scheme was often an enactment of a desire to belong in Newcastle, rather than simply 'asking for help' from a position of powerlessness.

This enactment of a politics of belonging by refugees and asylum seekers themselves therefore also disrupts dominant imaginaries of the hospitable nation in a twofold sense. First, it disrupts the imagined binary opposition between the nation-state as 'host' and the migrant as 'guest', as it is those who are usually framed as 'guests' who are here acting as 'hosts' for new arrivals. Second, one can argue that this form of enactment even goes beyond merely disrupting dominant hospitable framings by making obvious the broader political limitations of hospitable imaginaries as such, including the representation of migrants as passive 'guests'. It therefore inverts the hierarchical guest-host relationship altogether. This is perhaps how the everyday activities of the Welcome to Swansea scheme go beyond promoting a culture of hospitality, as they "trouble assumptions about who does and who does not have the right to be present in the city" (Squire 2011: 298). 
Therefore, the last important element to discuss in this chapter are the political implications of these forms of self-organisation, where refugees and asylum seekers are taking on 'hosting' activities for newly arriving migrants. In this context, Squire and Darling (2013) have argued that while the City of Sanctuary network in its "major" articulation can indeed be defined as a hospitality movement, the political significance of its activities should be understood in the terms of its "minor" politics of rightful presence (ibid: 61). This distinction between major articulations and minor acts of rightful presence is helpful to address some of the problems and shortcomings within the urban sanctuary networks we have encountered. For example, in Chapter 6 we saw how the ongoing process of professionalization and responsibilisation as part of neoliberal restructuring of the third sector led to a structural (and less intentional) exclusion of refugees and asylum seekers from influencing those support groups. In this way, a volunteer describes how "a small, informal volunteer organisation ends up excluding refugees from their management. Not excluding, because we would take good people. But, you know?" (Interview, 2 November 2017). Nevertheless, the examples of migrants welcoming new arrivals, or supporting destitute asylum seekers by offering a sofa showed that, in addition to this structural exclusion from the management of 'official' support groups, refugees and asylum seekers themselves are regularly doing the 'hosting' activities that frame scalar sanctuary imaginaries.

This is of importance for more formal yet migrant-centred challenges to the asylum regime. In 2004, four years after the establishment of the national dispersal system, the UK introduced legislation that denies asylum seekers the right to work while waiting for their refugee status to be confirmed. This hostile reform went together with the provision of a weekly cash support, which was capped significantly below other forms of social welfare (Darling 2019: 252). For refused asylum seekers, who are often in a legal limbo between the official refusal of status in the UK, and the inability to return to the countries from which they have fled, this often means that they must rely on charities and support of friends to survive (Darling 2019). Darling (2019: 253) argues that destitution is here: "less an accidental or procedural gap within the asylum system and more an intentional and insecure position imposed on those no longer wanted by the state". To challenge the active use of destitution as a deterrent, in 2009 a campaign called Dignity Not Destitution was initiated in Bristol and Glasgow by asylum seekers, advocates and support groups. The campaign pushed for asylum 
seekers to be given sufficient support for essential living needs and the right to work after six months, and attempted to gain local political support in opposition of government policy on destitution (Darling 2019: 253).

The Swansea City of Sanctuary network has aligned itself with and supported this campaign. On 28 November 2017, nine delegates from the Swansea and Cardiff City of Sanctuary groups, including members of the Share Tawe hosting scheme, attended the annual 'Sanctuary in Parliament' event in Westminster to raise awareness of the campaign and their demands (SCOS: 2017). This is a good point to summarise two main arguments we can draw from this empirical chapter. The first is that the NOS notion represents itself through moral imaginaries of being hospitable and homely. It is this moral self-image that makes the homelessness of the asylum seeker 'guest' a problem. Indeed, two months after the Swansea City of Sanctuary movement had advocated for the Dignity Not Destitution campaign in Westminster, the topic of destitution was also the theme of an event titled 'Sanctuary in the Senedd' held on 24 January 2018 in Cardiff Bay. During the presentations, Rocio Cifuentes, chair of the Welsh Refugee Coalition delivered a speech in which she described Wales as a welcoming and cohesive country, but "that it would not be such a nation when in it there are people who live in destitution" (Fieldnotes: 24 January 2018). A member of the Welsh Refugee Council followed with arguing that destitution: "is not only inhuman and shameful, but also economically and in the sense of well-being detrimental for our nation" (ibid).

The second argument is that minor acts of hospitality by migrants are alsopolitically important. This is because they resonate with an implicit refusal of the victimization and subordination that often accompanies the framing of refugees and asylum seekers as 'guests'. Instead, these minor acts, could be understood as fixed to an account of equality (see Ranciere 1999, Dikec 2005) as 'hosts'. In this context, they also suggest that a notion of rightful presence provides a better frame than hospitality "for a political analysis concerned with highlighting the significance of minor-acts that potentially challenge such categories" (Squire and Darling 2013: 71). This is argued to "not entrench the victimization of refugees through rendering them dependent on the hospitality of the "host." (ibid: 72). Squire and Darling (2013) expressed concern on the replication of the categories of host and guest, through questioning the political expediency of addressing sanctuary through the frame of hospitality (ibid: 66). 
In conclusion, the examination of 'hospitality in practice' had a twofold effect. First, it showed that the private offering of hospitality can certainly entrench the unequal discurisve distinctions between established and less established residents. Neverthless, in focusing on hospitality practices rather than discourses, this chapter foregrounds an important argument, which is that minor acts of hospitality by the refugees and asylum seekers themselves are politically important. They resonate with an implicit refusal of the victimization and subordination that often accompanies the framing of refugees and asylum seekers as 'guests' in official politicsal discourses and narratives of state hospitality. What this chapter has also shown is that minor acts of hospitality can resist entrenching refugee's vicitimization, instead of creating dependency on the sovereign 'host'. Practices of hospitality between refugees and asylum seekers can also be read as an implicit challenge to statist attempts that frame the sovereign nation-state as the generous 'host', and the refugee as the passive and silent 'guest'. When it is refugees and asylum seekers themselves who take on the practical work of welcoming (e.g. the scheme in Swansea) and even hosting (e.g. sofa-surfing or the Share Tawe hosting scheme), the imaginaries of a generous nation welcoming silent refugees might run into serious difficulties. 


\section{Chapter 9. Conclusion: Asylum, nationalism, and independence}

The first chapter of this thesis began with the stories of three different lives of asylum seekers and refugees who had all, in one way or another been othered by the state. One of those lives was lost in Swansea, but one of those lives was also saved in this urban community. The last story was about Otis Bolamu, an asylum seeker living in Swansea, who was detained and threatened with deportation to the DRC over Christmas 2018. He was released and returned to Swansea in January 2019, after more than 3,000 people signed a petition for him to be allowed to stay. Almost a full year after this first release, The Guardian reported that the Home Office had made a U-turn on his case, and that Otis Bolamu had been granted asylum in the UK.

One of the arguments that this thesis has developed is that, while the critical literature on migration has successfully explored the limits of hospitality as a discursive framing and response towards the broader exclusionary politics of asylum, this analytical focus might miss how the framing of hospitality is also used to challenge the sovereign nation-state on the moral expectations of what it means to be a hospitable 'host' to refugees and asylum seekers. For me, this process is well represented by Otis Bolamu's story.

First, the reference to moral expectations on hospitality appeared when the South Wales West AM Bethan Sayed, member of Plaid Cymru, talked about Otis in the Welsh Senedd and stated: "We have a duty to support people who need our support and ensure Wales is the nation of sanctuary that we purport to be". But what was more interesting about the case was not just the relation between securitisation and humanitarianism in the rejection and then U-turn acceptance of his case by the Home Office, which still reiterated that: "The UK has a proud history of granting asylum to those who need our protection" (BBC 2018). The second issue was rather how part of the political reaction in support of the petition was engaged in a moral politics of placemaking that was national in form and framed in response to the exclusionary asylum 
politics of a sovereign state. This became apparent with a Tweet from the official Plaid Cymru account that Otis as someone "based in Wales" was at risk of deportation on the hands of a "hostile UK Government" (2019). Therefore, the task of this conclusion chapter is to first summarise the key theoretical and empirical contributions made by this thesis, but also, second, to show how the discursive developments examined in this thesis, namely the concepts of a second othering and a moral nationalism, call for further research into the discursive relations between the concepts of the sovereignty, national independence and statist politics of asylum and migration.

This chapter will therefore first summarise the empirical research and arguments presented in the thesis. The empirical puzzle driving this research project concerned the emerging image of Wales as the world's first 'Nation of Sanctuary'. This pronouncement is particularly interesting in light of the fact that Wales does not have direct responsibility for UK borders. This consideration led to the following questions: What might it mean, in practice and in theory, for Wales to declare itself a "Nation of Sanctuary'? What are the theoretical and political imaginaries of sanctuary, national identity and hospitality at work? What are their historical precedents? And how do they relate to political responses to the so-called 'refugee crisis' across the UK and Europe more generally? Therefore, the subsequent sections will summarise how this thesis answered each of those questions in the different chapters. In doing so, it will reiterate how the findings from this project contribute to both the current critical literature on sanctuary cities and migration. Indeed, what this research project found, and the primary contribution it makes to theoretical understandings of hospitality, is that some subnational imaginaries of community used hospitable sanctuary imaginaries regarding migration for an 'othering' of the sovereign (host-) state.

Then, the third section will sketch out specific areas for further research, made all the more timely and possible as a result of the theoretical developments and empirical insights presented in this thesis. Indeed, the literature review had examined how Harald Bauder (2016) concluded his discussion on sanctuary cities by arguing that that further research "could explore which particular national circumstances enable or constrain various aspects of urban sanctuary" (ibid: 182). This section will argue that the theoretical conceptualisation of a second othering can provide an answer. In summary, it can be argued that national circumstances with an effort for 'new' nationhood might 
enable more effectively various aspects of urban, regional and (sub)national sanctuary. The third section therefore will show how this helps to address the question posed by Arjun Appadurai (2016), and with which the introduction to this thesis ended: "How can hospitality to the stranger be made a legitimate basis for the narrative of citizenship"? Consequently, the fourth and final section of this chapter will evaluate what hospitality to the stranger as a legitimate basis for the narrative of an imagined future citizenship might mean for further examinations of the relationships between the sovereign nation-state, national independence, and the exclusionary politics of asylum.

\subsection{Theoretical and political imaginaries of asylum in the 'Nation of Sanctuary'}

In September 2015, in response to the 'crisis' of refugees arriving in Europe during the summer, the Welsh Government had held an emergency summit where it then reiterated its commitment that Wales should play a leading role as a 'Nation of Sanctuary'. This thesis has examined the emergence and development of this first national sanctuary imaginary in detail. Having done so, it is now in a position to answer the theoretical questions that had emerged with the first appearance of this empirical phenomenon. But before we can evaluate what it would mean in theory and practice for Wales to declare itself as such a Nation of Sanctuary, we should summarise first the theoretical and political imaginaries of sanctuary, hospitality and national identity at work, as well as their historical precedents and how they relate to political responses to the 'crisis' across the UK and Europe more generally.

The first theoretical element highlighted in this thesis, outlined in Chapter 2, is that there has always been "a strong association between the notion of a refugee and the notion of states" (Gill 2010: 626). This is because the modern concept of asylum, while rooted in ancient religious traditions of sanctuary and codes of welcoming the stranger, was still formed in a historical period of political state-building (Washington 2020: 11). These rooting historical accounts of sanctuary are often found in association with religious and biblical traditions, in which they are understood to be spatially-fixed practices of offering protection in a certain territory. This has subsequently affected the theoretical imaginaries of sanctuary at work in this context. Indeed, critical scholars have outlined the intertwined assemblage of pastoral, sovereign and 
governmental power relations within sanctuary practices. The first aspect of this assemblage is identified by Lippert (2005) as governmental power. Bagelman and Squire (2012) showed that in addition to such a governmental rationale, a pastoral logic was apparent in attempts to draw hierarchical distinctions between 'protector' and 'protected'. The third aspect of is that "sovereignty qua territorialisation can in some respects be conceived as a condition of possibility for these practices" (ibid: 2012). Nevertheless, Bagelman (2013) and other scholars have shown that the City of Sanctuary movement exceeds the historical understanding of sanctuary as being confined to a physical space, and operates a "fluid network of practices aimed at shifting hostile attitudes towards asylum seekers and refugees" (ibid 2013: 50). Moreover, while the concept of a sanctuary city as it is understood in Canada and the United States includes the protection of illegalized migrants from federal law enforcement, in Britain it refers more to a rather general commitment to 'welcome' asylum seekers and refugees (Bauder 2016).

The second theoretical imaginary at work that should be reiterated is that of hospitality. This is because the official aim of the urban sanctuary movement, which was essential for the emergence of the national sanctuary imaginaries, is to "build a culture of hospitality for people seeking sanctuary in the UK" (Darling and Squire 2013: 192). As we have also seen, for Jacques Derrida (2002) the concept of hospitality constitutes a site of constant negotiation between imperatives of the conditional and the unconditional welcome, and distinguishes between the invited guest and unexpected (and uninvited) stranger. Therefore, the practices of hospitality are always forced to negotiate and renegotiate between the law of unconditional hospitality and the conditional laws of hospitality (Bulley 2017). Kakoliris (2015) explained how this "pervertability" of the law of hospitality emerges from the inseparability between hospitality and power. For him, there cannot be hospitality without the sovereignty of the person offering the invitation into their home (ibid: 148). The exercise of sovereignty through deciding who to offer the right to hospitality shows that there is an element of hostility in hospitality.

Therefore, the theoretical literature on discourses of migration tended to focus on exploring the limits of hospitality as framing responses to the exclusionary politics of asylum (Squire 2011). It understands this as a "limiting approach that is bound to the 
rationalities of power that produce uneven relations between guest and host" (Darling 2013), and as bound to sovereign practices (Derrida 2000) that reinforce moralising distinctions of deserving and undeserving migrants. An important tactic of such a humanitarian government is the governing of the nation as a threatened home. This was conceptualised by Walters as domopolitics (2004), and it has been used to show how the language of hospitality often enables the governmental ordering of responses to asylum. Darling (2013) argued here that the domopolitical logics of distinction, often associated with the sovereign nation-state, often presuppose and intersect with hospitable imaginaries and therefore "enacts and moralises domopolitics" (ibid: 1786). This is because the affective and discursive governance of the nation as a secure home, and the necessary rejection of unwanted strangers, is morally justified by a record of hospitality to a small number of 'worthy' refugees. Moreover, this internalisation of moral (b)ordering is, for Darling (2013) part of a politics of classification, through which citizens are directed to decide upon the moral worth of those seeking sanctuary. This translates the citizen into the 'host' (Derrida 2001). The empirical chapter on the decision of the British government to extend the SVPRP has shown how this moral (b)ordering is an essential part of the theoretical (national) imaginaries of sanctuary at work in this context. While the literature on the theoretical imaginaries of sanctuary focused on the process of translating the citizen into the host, the rest of the conclusion will summarise to what extent the 'guest' could become a citizen.

However, before one can move on to examining if the 'guest' could ever also be a citizen, which would assist in answering Appadurai's question on hospitality as a narrative for citizenship, this chapter will summarise one more theoretical imaginary at work in the empirical context of the Welsh Nation of Sanctuary: that of national identity. Indeed, as explained in Chapter 3, Rosello (2001) had successfully shown how the metaphor and laws of hospitality "form a significant part of national identity" (ibid: 6). This was the case for both British and Welsh national imaginaries. First, the theoretical Part I of the thesis also investigated the use and mobilization of the metaphor of hospitality in debates on asylum in Britain, and their effects on imagining national identities. The historical context was the framing of responses to migration under the Blair administration, which was attempting to construct a British "multiculturalist nationalism" (Fortier 2005) on the imagined ideal of a welcoming, hospitable and generous nation (Ahmed 2004). 
However, the theoretical engagement with the topic in Chapter 3 and the empirical examination of the response of the British government under David Cameron to the long summer of migration in Chapter 6 have shown how maintaining the binaries between deserving and undeserving was essential for statist British imaginaries of hospitality. Indeed, Ahmed (2004) explained here how Britain imagines itself as generous in welcoming some people. The nation can be imagined as hospitable because it allows the 'genuine' refugees to stay, while defining some as not genuine to place limits on their own hospitality. This theoretical point is important, because it shows that such legislation attempted to define the deserving and undeserving, genuine and 'bogus' refugee, and to limiting the condition of Britain's hospitableness, and how this works to define the national self-image as hospitable and generous in the first place. Moreover, Part I and Part II have shown that it is often refugee resettlement programs that fulfil this discursive function to classify migrants.

However, Chapter 6 and 7 revealed that the expansion of the SVPRP, which the British government announced in response to the long summer of migration, also affected the emergence of other national imaginaries of hospitality, specifically that of the Welsh Nation of Sanctuary. But this empirical point on other emerging national imaginaries of hospitality, specifically the first national sanctuary framing, opens a question for the theoretical imaginaries of national identity. Considering how influential these hospitable discourses were in constructing national identities through an othering of migrants as 'guests', have they also affected the construction of discursive relationships between different nation-states? A first initial answer to this question was provided in Chapter 5 on the media narrations of asylum in Wales. This chapter examined the historical precedents of political and theoretical imaginaries of sanctuary and national identity. The objective of Chapter 5 was to trace the debates about the national dispersal policy, from its announcement until asylum seekers and refugees first started being dispersed to Swansea. The aim was to unearth historical precedents of such theoretical imaginaries of sanctuary and national identity. The period between 1999 and 2002 is important for these historical precedents, because this was the firsttime Wales became an official reception area for asylum seekers (Robinson 2003). Retracing this period made it possible to identify not just historical precedents for urban sanctuary imaginaries, like the emergence of SBASSG as the first refugee support group in the city, but also for new national sanctuary imaginaries. Indeed, an 
interesting element was that the formulation of a 'warm Welsh welcome' was reiterated in the reporting of Welsh newspapers on the dispersal policy, with a specific focus on the Welsh-ness of this welcoming. Speers (2001) found in her scholarly analysis of newspaper articles between April and December 2000 that the Welsh press, in comparison to papers with a British-wide circulation, gave more space to those articulating a welcome to asylum seekers and refugees. An example of this national framing was phrased as the "desire to promote understanding of the plight of refugees and asylum seekers and to build on Wales's tradition as a welcoming nation" (South Wales Argus in Speers 2001). In this context, Darling (2013) had pointed out that discussions of hospitality and asylum in the city have often been framed through the production of a narrative that a place possesses a 'proud record' and 'long history' of hospitality. This element concerning such an imagined history could therefore also be detected in historical precedents of national imaginaries of hospitality in Wales.

However, it was also shown that, at the same time, another debate on the topic of migration in Wales concerned in-migration and the implications for Welsh cultural identity and language with regards to the second significant 'other' - the English (Mooney and Williams 2003: 622). This relates to the second element of the "warm Welsh welcome' as a historical precedent to the Welsh Nation of Sanctuary which is of interest. Here, in a summary of the national media narratives, the chapter highlighted how Welsh politicians had adapted a more positive attitude to the dispersal policy "than their English counterparts" (Robinson 2003: 191). This was not just to frame the proud record of hospitality for the construction of national self-imaginaries, but also constituted a building element for a discursive politics of differentiation from the British sovereign state. Yet, while this politics of differentiation remained rather implicit in these media narrations of asylum, this agonistic element would become important beyond the theoretical underpinnings examined, and would affect also the political imageries of sanctuary, hospitality and national identity in Wales.

What are those more political imaginaries of sanctuary, hospitality and national identity at work in the Nation of Sanctuary? An answer to this question was provided in Chapter 6, beginning by investigating the explicitly moral dimension of different sanctuary imaginaries. This was important because the City of Sanctuary movement has the aim of altering the identity of the city as a 'welcoming place', and to form 
geographical (self-) imaginations that challenge debates on asylum cast in the language of territorialised fear or unease (Darling 2010: 129). Thus, Darling examined how the city of Sheffield narrated and constructed an account of its relations to refugees and asylum seekers in the form of a moral urbanism - the "discursive and affective construction of particular cities as being imbued with moral characteristics" (2013: 1785). Chapter 6 identified common elements in the process of Swansea becoming the second City of Sanctuary in the UK. With the external changes brought about by the politics of neoliberalism, this moral dimension would eventually merge with forms of professionalization and responsibilisation, that unintentionally assisted austerity as a moral justification. However, there is an element that the literature on moral placemaking and its concepts such as moral urbanism could not fully explain. This unexplained element, for the politics of sanctuary imaginaries, is that "place-based responses to the global issue of refugees necessarily involves a negotiation of scale" (Tuma et. al 2018).

Different critical scholars (Tuma et. al 2018) argue that place-framing through humanitarian values often conflict with the hostile immigration policies of the nationstate. McDaniel (2018) therefore concluded that "designations such as "welcoming cities" and "cities of sanctuary" may be statements intended to differentiate cities and towns from the discursive position of the nation. However, there is a danger of implicitly assuming a discursive binary between the welcoming, liberal and open city on the one hand, and the hostile and exclusionary sovereign nation-state on the other. There have been studies on national imaginaries of sanctuary and hospitality, as Bagelman (2019) has argued, but there have not been any national sanctuary imaginaries that were constructed to differentiate a place from discourses of another nation-state. This is of central importance for the political imaginaries of sanctuary, hospitality and national identity. During September 2015, following the publication of the picture of Aylan Kurdi's drowned body, the UK Prime Minister David Cameron announced that Britain would "fulfil its moral responsibilities" by expanding the SVPRP and taking in 20,000 Syrian refugees over a period of five years until May 2020. But, as we have seen, the expansion of the SVPRP only followed mounting public pressure. Moreover, this policy reversal continued to be criticised for comparing poorly with other European countries. For Mavelli, this then "raises a series of 
questions about British identity, the crisis of British values, and the extent to which Britain was failing the test of compassion" (2017: 10).

And therein lies the interesting element. On 17 September 2015, during an emergency summit following Cameron's response to the long summer of migration, the Welsh government reiterated their commitment that Wales should become a 'Nation of Sanctuary'. This reaction followed the announcement that the SVPRP was now being expanded, and more importantly, it followed the mounting public pressure and discussion on the extent to which the British state had failed the test of compassion. This specific context of pressure on the British government, in which this announcement of the Welsh government emerged, is of conceptual importance. This is because it moves beyond the question of what happens when these sanctuary imaginaries are beginning to be framed through the concept of the nation itself - for example: Wales as Nation of Sanctuary. Rather, the question becomes: What are the implications of this national sanctuary framing for the argument that sanctuary imaginaries often differentiate a place from the discursive position of the nation-state?

This process of discursive differentiation has been essential for understanding the more political imaginaries of sanctuary, hospitality and national identity at work in the Nation of Sanctuary. But from whom or what is the Welsh Nation of Sanctuary then differentiating itself? The moral nationalism of the Welsh devolved state is not only constructed with regards to the refugee-guest-other, but also with regards to the UK as the sovereign host-state-other. The main finding this research project contributes, through the empirical work in Chapter 7 , is that the discursive framing of responses to migration through hospitality frames is not only created through a binary relationship between sovereign state (host) and the migrant 'other' (guest). Indeed, it involves an othering between imagined 'hosts', for example different political or administrative units. A subnational territorial unit, for example devolved Wales, enables itself against a sovereign British nation-state through managing, adapting and constructing expectations of what it means to be a host to the 'other'. But this discursive politics of a second othering remains, in the case of the Welsh government, often concerned with the creation of national self-imaginaries as a generous host to refugees. It does not challenge the exclusionary politics of asylum of the sovereign other - in other words, it is fundamentally not an antagonistic form of politics. Still, understanding those 
political imaginaries at work was essential for two reasons. First, for empirically answering the question of how they relate to political responses to the long summer of migration across the UK and Europe more generally. And second, to theoretically examine how the imaginary of a Nation of Sanctuary might differ from other hospitality frames used by sovereign nation-states.

\subsection{Sanctuary imaginaries between the sovereign and the devolved nation-state}

How does the announcement of the Welsh Government to make Wales a Nation of Sanctuary, compare to the response of its 'host' state, the UK, and other sovereign nation-states in Europe faced with the effects of the long summer of migration? The thesis answered this question in Chapter 7 with its empirical findings concerning the SVPRP. As with earlier resettlement programmes for some selected refugees such as Gateway, the UK government under David Cameron had made the SVPRP part of the moral justification for the exclusionary politics underpinning the British asylum regime. Syrian refugees were framed as the 'good refugees', as legitimate priority candidates who have been 'fast- tracked' (Fiddian-Qasmiyeh 2016). The distinction between different categories of migrants - genuine and non-genuine - to prevent an 'exploitation of the system' (the 'abuse of hospitality') appeared in almost all the Home Office documents that informs local authorities and other partners about the SVPRP. The securitisation and exclusion of those who were identified as non-genuine was again not only justified through offering hospitality to a 'worthy' few. Instead, hospitality was used to moralise this distinction as a responsible enactment of a set of moral obligations to some noncitizens (see Darling 2013).

But there was a third element that made the British response to the long summer of migration interesting, specifically with regards to the subsequent response of the Welsh government. This recurrent feature in official documents was an association between an emotive category and a 'national character' (Armbruster 2018). In addition to calling the scheme a fulfilment of moral responsibilities, David Cameron elaborated in September 2015 that the extension was going "to show the world that this is a country of extraordinary compassion always standing up for our values and helping those in need" (2015 in Armbruster 2018: 1). This becomes interesting when we are 
considering how the expansion of the SVPRP only followed mounting public pressure. This had raised questions about questions of British identity and value, and to what extent the UK was 'failing a test of compassion' (Mavelli 2017) in comparison to other European countries. The language of hospitality, when used by the British government to frame their relationalities to refugees and asylum seekers, is then perhaps not just about the relation between the state and the migrant, between the imagined host and the guest. It is here also about the relation between those sovereign nation-states as those self-imagined hosts.

But how is the image of the Welsh Nation of Sanctuary thus different from the British framing of itself as a generous and hospitable? Is it not the same form of nationalidentity construction? While the literature on the sanctuary movement has explored the limits of hospitality as a framing and response to the exclusionary politics of asylum (Darling 2013), this thesis has argued that the image of a Nation of Sanctuary has also been used to challenge a given sovereign nation-state on the moral expectations of what it means to be a responsible 'host' to refugees and asylum seekers. The argument is that the hospitality discourse of the Welsh government uses a discursive, national politics of differentiation from the British state. This differentiation relied on a second othering, where a positive national self-image was constructed around the affective language of hospitality regarding their own relation to migrants, and with regards to an imagined (un)hospitable sovereign host-state.

Darling (2013: 1792) has argued with regards to hospitality that "the categorisation of the stranger as the identifiable guest is critical to both the practice of conditional hospitality and the securitising impulses of domopolitics as a concern with ordering the 'homely' nation". But while the British government response was framed through these domopolitical logics of categorisation and classification, because they are in control of a sovereign nation-state, the Welsh response involved a second form of othering, because they are not fully sovereign on asylum. This second othering makes the Nation of Sanctuary frame different from other hospitable imaginaries - if one considers sovereignty in terms of sovereign statehood rather than sovereign power, which still comes with its own set of theoretical problems (see Jenkins 2016). It also makes it possible to answer the question how the framing of Wales as a Nation of Sanctuary relates to other political responses in the UK and Europe. While the 
expansion of the SVPRP in the UK and its hospitality discourses, or the temporary support of the Wilkommenskultur by the German state (Hess et al. 2017) were concerned with the creation of national self-imaginaries, through the construction of a binary between refugees and the sovereign state, the Welsh Nation of Sanctuary image was constructed to differentiate a certain (sub-national devolved) place from the discourses of another nation-state. With this finding, I also further developed Hill's (2016: 197) argument that national and migrant identities are "defined and redefined in accordance with the shifting needs of the sovereign state". This was done through answering this main research question throughout the thesis:

What does it then mean, in theory and practice, when a political entity without sovereign border control, for example the devolved governments of the national territories of Wales or Scotland, use the metaphor of hospitality to frame their responses to the social phenomenon of asylum?

To declare oneself a Nation of Sanctuary means therefore to build a discursive relationship that goes beyond the imagined binary between the migrant as 'guest' and the nation- state as 'host', which we have seen to be predominant in statist hospitable framings. For Wales to declare itself as such a sanctuary nation included a second othering. This included building a triangular discursive relationship between refugees as guests, the British state as the host-other, and lastly the devolved national territory of Wales as a legitimate 'host' to refugees and asylum seekers. I have termed the first theoretical shift a 'second othering', in the sense that the framing of responses to asylum through the metaphor of hospitality is sometimes used not only by creating a binary relationship between sovereign state (host) and the migrant 'other' (guest), but involves a second othering between potential hosts, meaning different political or administrative units. One form this second othering takes, as part of the framing of hospitality, is that a subnational territorial unit, for example devolved Wales, enables itself against their own sovereign British nation-state host through managing, constructing and challenging expectations of what it means to be a hospitable host to those who are framed as the 'other', in this case asylum seekers and refugees. It is in this manner that I believe this empirical phenomenon of a Nation of Sanctuary differs in part from the Cities of Sanctuary network and the imaginaries from which it emerged. 
Other scholars have pointed out that place identity in designations such as "welcoming cities" and "cities of sanctuary" may be statements also intended to differentiate cities and towns from the discursive position of the nation (McDaniel 2018 in Guma et. al 2018). And while this politics of differentiation from the discursive position of the sovereign nation-state is most certainly an element of the City of Sanctuary frame, the process of a second othering is almost a necessity for (sub)national sanctuary imaginaries, because of the need to establish themselves discursively as legitimate and perhaps future host-states. While 'official' cities of sanctuary such as Swansea can define themselves as welcoming urban hosts to refugees and asylum seekers, it is then still commonly assumed that they are smaller 'containers' (Darling 2017: 183) within an overarching national, sovereign and territorial 'container' (Sassen 2006 in Darling 2017). For a territorial and political unit, whose national and sovereign character is more disputed, this discursive status as a 'host' to refugees and asylum seekers is not as easily given.

The concept of the second othering also further develops the argument that national and migrant identities are "defined and redefined in accordance with the shifting needs of the sovereign state" (Hill 2016: 197). If we only focus on the shifting needs of the 'sovereign' state, understanding sovereignty as sovereign statehood rather than sovereign power, it tends to lead us back to the guest-other - the migrant who is othered as guest with regards to the host-state - and back to the domopolitical distinctions of deserving and undeserving. But if we also focus on devolved territories and their national self-imaginaries as hosts, for example Wales or Scotland, there is perhaps a second othering taking place. This still returns to the problematic idea of place as bounded and coherent. But it entails the possibility of challenging the legitimacy of a sovereign host-state, and their exclusionary asylum regimes This focus also has another conceptual effect. In investigating the metaphor of hospitality through this lens, one moves away from the Derridean moment of sovereign inclusion or exclusion, towards the practices of managing the expectations of what it means to be a host to the other. This focus on the concrete practices that (devolved or sovereign) states need to engage in to be perceived as sovereign hosts, might then de-essentialise sovereignty as pre-determined and coherent. 
But one should also be aware of the possibility that there are different forms in which this second othering might emerge, and that perhaps some of them are more ambiguous, radical or repressive than others. It is possible that the othering of a hoststate returns us to just another form of state sovereignty, and domopolitical distinctions of deserving and undeserving. It is possible that a national competitiveness along moral imperatives would reinforce the neoliberal marketing of bounded and fixed place-identities, which Massey (1994) criticised. Is this second othering not just another form of nation-building that is: "Set against and built at the expense of the immigrant other" (Hill 2016: 194)? Or could it also open spaces and possibilities for a more progressive politics regarding the rights of asylum seekers? While the second othering most certainly does not escape statist imaginaries, the concept might still constitute a starting point from which to theorise a more progressive politics for refugees and their supporters. Subsequently, in the following and final section of this conclusion, I want to address Harald Bauder (2016) and his discussion on sanctuary cities in an international perspective. It concluded that "national socio-demographic factors ... as well as historical circumstances and political traditions" shape the possibility of implementing them, and that further research "could explore which particular national circumstances enable or constrain various aspects of urban sanctuary" (ibid: 182). Therefore, the last section shows how this thesis also contributed to the literature in assessing which national circumstances might shape, and more importantly, enable the possibility of implementing aspects of urban sanctuary.

\subsection{Hospitality, rightful presence and the question of national circumstances}

Before moving on to conclude which national circumstances might enable various aspects of urban sanctuary, it is important to reiterate an awareness of the ambivalent discursive relations that exist between nationalism, hospitality and the exclusionary politics of asylum. This suggested research focus is therefore explicitly not an attempt to counter the exploration of other radical and perhaps more challenging political possibilities that move away from hospitable framings towards a politics of "rightful presence" (Squire and Darling 2013). This potential examination should instead be understood as a small and practical attempt to further understand how different national discourses of asylum are reproduced, and where disruptions of attempts to 
govern asylum through exclusion within those national sanctuary discourses might emerge, however small. While Squire (2011) has argued that the emphasis on community in cultural or legal forms invokes a problematic conception of integration, she also points out that: "there remains work to be done in exploring the complexities of and tensions between these different notions of community as they are played out in the UK's integration and cohesion agenda" (ibid: 292). Examining which national imaginaries and circumstances might enable urban sanctuary addressed this point.

The concept of a second othering provides the critical literature on sanctuary movements with a means to identify such enabling national circumstances. How is this done? First, it was shown how the idea of Wales as a Nation of Sanctuary was not only constructed with regards to the refugee-guest-other, but also relating to the UK as the sovereign host-state-other. A positive national self-image was constructed around the affective langue of hospitality regarding their own relation to refugees and asylum seekers and with regards to an imagined more (un)hospitable sovereign British hoststate. Therefore, one can argue that what enables the emergence of scalar sanctuary imaginaries is the context of a territorial unit with an existing political concern for (new) nation hood in combination with a sovereign host-state that exhibits a hostile and exclusionary politics of asylum. This is because the political elements striving for such new nationhood have a greater need for such a virtual status as a host to migrants. But would this second othering then not be: "Set against and built at the expense of the immigrant other" (Hill 2016: 194)? There is no definite answer to this question. This remains speculative, but one could conclude that a second othering could also be opening new spaces with new possibilities. Hill (2016: 203) explored this with regards to narratives of the Scottish Government, and that on the topic of immigration: "Scotland is a guest in its own country".

This rationale, in combination with the concept of the second othering helps to address a question that Arjun Appadurai asked in Aspirational Maps - On migrant narratives and imagined future citizenship (2016): "How can hospitality to the stranger be made a legitimate basis for the narrative of citizenship"? His argument is that citizenship in modern nation-states is based on the fitting together of plot and character, of narrative and identity. The goal of the nation-state is, through legal and bureaucratic means, to provide a territorial ground for connecting plot and character and verifying 'legitimate' citizens. One example of this would be the (occasional) changes in a person's status 
first from asylum seeker, then to refugee, and finally to citizenship by 'naturalising' their connection to a national territory. However, the problem for most illegalised migrants is that their stories come with names, but no characters or identities which fulfil the legal narrative requirement of 'legitimate' migration. This is because: "The modern nation-state has no room for narratives based not in the past (blood, birth, parenthood, language etc.) or in the present (work, marriage, student status etc.) but primarily on the future: on the aspiration for a better home, a safer life, a more secure horizon" (ibid: 2016). For Appadurai, the central political task is thus to make hospitality a legitimate narrative of citizenship, and to create the stories of imagined future citizenship in a world of nation-states where the past through notions like birth or blood is still the central underpinning of most citizenship laws (ibid). How could that be done?

The first condition for this, which Hill has touched, is that Wales could claim a "horizontal comradeship" (Law 2012 in Hill 2016: 201) with migrants living within its borders based on a shared experience of external rule (cf. Hussein and Miller 2006 in Hill 2016). To what extent those experiences are comparable is less important. What is important is that the second othering does not remain within the rather limited process of national identity formation on who constitutes a more generous host to the imagined migrant-other. This would only be a return to the unequal politics of hospitality that the literature has criticised. While othering the sovereign state as well, it is still othering the migrant without offering any political role or agency for those who are imagined as 'guests' in the new nation-state. Therefore, the second essential condition is that the second other is not simply associated with another national identity (such as the English 'nation') but explicitly with the regressive elements that have underpinned the specific nation-building project of the larger sovereign hoststate. In the case of the British nation-state, this would be the long histories of colonialism, racial discrimination of migrant communities and the oppression of anticolonial and national liberation movements.

This distinct discourse of a second othering would open new spaces for a more progressive politics of agonism (Mouffe 2018) through a threefold effect. The association of an 'other', which the self-imaginaries of the new nation-state requires, would start to be associated less with the notions of the migrant 'other' and more with 
the regressive political histories of colonialism and racism that underpin a lot of British national imaginaries. Moreover, it needs to do two more things. First, offer a story (being a guest in your own home) that does not just depoliticises refugees and asylum seekers as apolitical victims (Malkki 1996) and silent 'guests' that should not make themselves heard. This is because the focus of the second othering is more on an imagined, but nonetheless shared, political experience (being a 'guest in their own country'), which offers possibilities for a horizontal comradeship beyond the bounded distinctions of self and other that likely emerge when the phenomena of migration and of (virtual) nation-states existing meet another. Secondly, it needs a story set in the future that is shared. Hospitality can potentially become a narrative for citizenship if the 'local' and the 'migrant' share an imagined common experience - having been treated as a guest in their own home - and therefore share the desire for a new home where both can be host.

To what extent such a horizontal comradeship could be of assistance in the creation of a common political project - the creation of a new home, with a new social, cultural, political and economic meaning - remains to be seen. But what has become clear in this last chapter is that to start thinking about what a Nation of Sanctuary would practically look like, it is necessary to have an accompanying narrative that tells a story of hospitality and imagined future citizenship. For all the inherent violence and exclusion of the sovereign nation-state, for those who are attempting to strengthen the rights of migrants, it is worth considering that if there is one thing the national order of things does well, it is offering a story. Hannah Arendt (1973 in Bagelman 2019: 152) highlights how the art of 'storytelling' is an essential medium that provokes engagement with the complex and often contradicting qualities of our political lives. But there are new potential ambiguities. Hill (2016) suggests that the 2014 referendum for Scottish national independence ensures for now:

That Holyrood's rhetorical hospitable stance will not be put to the test of the practicalities of the immigration system- and the practice and rhetoric of state hospitality inevitably becomes much more complex when they become indelibly inscribed with the hierarchies and violence of border control and enforcement. One would hope that in any future for Scotland, solidarity of the 'guest' remains (although, one must then also ask, what vision for a relationship with the 'host'?) (203) 
Challenging the exclusionary politics of asylum using this national frame has its own limits. Whilst it promotes a welcoming narrative, it also reinforces the territorial logic that produces the idea of some populations as without territory (asylum seekers and refugees). Indeed, what is most interesting is that this narrative can work for progressive ends - such as attempting to take on the British government on asylum. We have seen historical as well as more current examples of that: from the interventions on behalf of the hunger strike in Cardiff in 2001 (see Chapter 5), to debates about devolved housing for asylum seekers in Wales after the long summer of migration in 2015 (see Chapter 7). But these national sanctuary frames keep a narrative of us and them in place. Here, the 'national order of things' (Malkki 1996) is so embedded that it becomes the language of critique (Closs Stephens 2013) that is targeting the exclusionary politics of asylum.

What this shows is that the question of what a Nation of Sanctuary would practically look like is inevitably connected to questions regarding the nation, sovereignty, citizenship and asylum, with all the inherent ambiguity of these concepts. Indeed, other critical scholars worried about those ambiguities of the nation-state therefore advocated for citizenship to be understood as grounded rather than bounded, with membership that should not be dependent upon legal consent to enter and remain, but on the reality of residence and presence in a certain place (Varsanyi 2006: 239). And it is often this very politics of rightful presence (Squire and Darling 2013) by migrants that continuously problematises, challenges, and sometimes even overturns hospitable framings. The last empirical chapter has shown that when refugees and asylum seekers present in the city take on the practical work of welcoming and hosting, the imaginaries of a generous nation welcoming silent refugees run into conceptual difficulties.

This is therefore a good point to conclude through contextualising the shortcomings and potentialities of a second othering through the frame of hospitality in the more current literature on the sanctuary movement. In the conclusion to the book Sanctuary cities and urban struggle: Rescaling migration, citizenship and rights, Darling (2019) summarises the author's position on the relation between hospitality and rightful presence:

In this context, the role of an ethics focused on hospitality can never be to assert a politics of rights based around urban presence, as such an ethics can never fully escape its association with a model of 'care' and 
support. However, such an ethics may be significant in shaping the public and political context in which assertive claims for rights and political voice are responded to differently. This is to view the role of sanctuary and hospitality as more than simply piecemeal reprieves for those suffering the violence of the state, but as opportunities to influence the tenor and tone of debate around refuge. It is also to see the politics of advocacy, campaigning, and assertation around migration as necessarily comprised of multiple, and at times inconsistent and contradictory, political claims and positions (ibid: 260)

There are two final arguments by which we should contextualise the discursive phenomena of a Nation of Sanctuary and the second othering. The first is that the role of hospitality framings is perhaps not to assert the rights of refugees and asylum seekers, but to create the discursive conditions, the "tenor and tone of debate", in which the assertation of rights becomes more likely or possible. The second is that the assertation of such rights can often emerge from contradicting political positions and claims. One such contradiction might be that the affirmation of a culture of welcome and hospitality through scalar imaginaries, for example that of Wales as a Nation of Sanctuary, is a first potential step towards fostering a political and discursive context where refugees and asylum seekers assert their rights in a manner that abolishes the hospitable framings that forever others them as either invited or uninvited 'guests' in their own (nation-state) homes. 


\section{Appendices}

\section{Appendix A. Interviews cited}

Interview, 27 July 2017, Alan Thomas, One of the founders of Swansea City of Sanctuary

Interview, 28 July 2017, Sarah*, Refugee and member of Swansea City of Sanctuary Interview, 2 November 2017, Thomas Cheesman, Long-term member and activist in SBASSG

Interview, 24 November 2017, Daniella*, Development worker for Swansea City of Sanctuary and Head of the Nation of Sanctuary Steering Group

Interview, 1 December 2017, Johanna*, Refugee and Development worker for Share Tawe

Interview, 11 December 2017, Aled Edwards, Former Chair of the Welsh Refugee Council, Member of the Equal Opportunities Wales Advisory Committee, Former Wales' Commissioner on the Commission for Racial Equality, Chair of Displaced People in Action (DPIA)

Interview, 13 January 2018: Bethan Jenkins, Member of Plaid Cymru, Assembly Member of the National Assembly for Wales and the Equalities, Local Government and Communities Committee of the National Assembly for Wales

Interview, 19 January 2018, Emily*, Development worker for Swansea City of Sanctuary

Interview 9 February 2018: Clara*, Researcher at the National Assembly for Wales, working on the Equalities, Local Government and Communities committee report Interview, 8 February 2018, Rocio Cifuentes, Refugee and Director of Ethnic Minorities and Youth Support Team (EYST) in Swansea

Interview, 8 March 2018, Jose Cifuentes, Refugee, author and early member of SBASSG

Interview, 26 March 2018, Julianne*, Member and volunteer organizer in Hay, Brecon and Talgarth Town of Sanctuary 
Interview, 28 March 2018, Margaretta*, Trustee and member of SBASSG and Share Tawe

Interview, 11 April 2018, Frank* Member, organiser and treasurer of ShareDydd Interview 23 April 2018: Frank*, Member and employee of 'Asylum Matters' in Wales

Interview, 24 April 2018, Rosanne*, Founder of Bloom, Friendship support group in Swansea

Interview, 9 May 2018: Maria*, Employee of the Welsh Refugee Council

Joint Interview, 15 April 2018, Three members of the Socialist Workers Party (SWP) and early members of SBASSG

Joint Interview, 2018a, Martha* and Ali*, 'Host' Martha, and 'Guest' Ali (Asylum seeker) Participants of Share Tawe

Joint Interview, 2018b, Markus* and Abba*, Host' Markus and 'Guest' Abba (asylum seeker) Participants of ShareDydd

*: The names of some of those interviewees have been anonymized for ethical reasons. For all people who had wished for anonymization on the interview consent form, this was of course implemented. In some cases, it was stated that real names could be used, but were I still decided to use anonymizations after considering the individual examples from a scholarly perspective. In cases where it was explicitly stated that real names could be used, those were left unchanged. 


\section{Appendix B. Example interview questions}

Interview: Alan Thomas, Co-founder of Swansea City of Sanctuary, former chair of trustees of National City of Sanctuary charity (2011-2016)

Theme: Historical Background and emergence of SCOS and NOS

1) Do you mind introducing yourself briefly, and telling me a little bit about your background as a co-founder of Swansea City of Sanctuary?

2) So how did the network start of? What was the initial motivation, who helped setting it up?

3) What was the historical context? How was the general mood with regards to asylum seekers when the movement started?

4) How did the process of becoming a City of Sanctuary took place? And how did Swansea city and the public react when Swansea became a City of Sanctuary?

5) Where there certain moments, here in Swansea, when issues of asylum and migration were talked about more broadly? For example, out of experience with arriving migrants?

6) How did you experience these moments, and how they were talked about in Swansea?

7) From your personal experience, is there a history of this kind of activism, like City of Sanctuary, here in Swansea or is it a relatively new phenomenon?

8) Did the city or the council support the network initially? What was their role? Was there a role?

9) Was there any involvement, help, support or resistance from the Welsh government to the network?

10) You were from 2011 until 2016 the chair of trustees of the 'national' city of network. Did you have the feeling, during this time, that there were differences between the Wales network and the broader UK network?

11) The newest project is the "Nation of Sanctuary" concept. Why do you think this idea took of here in Swansea and in Wales more broadly? 
Interview: Daniella*, Swansea City of Sanctuary coordinator and Head of the Nation of Sanctuary Steering Group

-Themes: Nation of Sanctuary, the 'revolution of generosity'

1) How did you first come to know about the NoS idea?

2) Driving force behind project, or emerged differently?

3) What was the initial motivation to come up with the NoS concept?

4) How did the idea of NoS first emerge? When did it first emerge?

5) Is NoS mainly driven by the urban CoS groups in Swansea and Cardiff, or do they coordinate with other groups in Wales?

6) Which groups are involved in the project?

7) If so, how do they coordinate with one another to achieve goals?

8) Are there sort of different aspects or pints, the valleys or other regions raise in comparison to Swansea and Cardiff?

9) How are the non-dispersal counties involved in NoS? What are the differences? Other regions and non-dispersal counties?

10) City of Sanctuary as a grassroots initiative and support of WG? How do you feel about that?

11) In steering group, point of movement building was raised. Do you think there might be conflicts there?

12) How did the WG, and the Assembly committee ("Equality, Local government and Communities committee), picked up on the idea of NoS? What is their role?

13) Has the WG longer adopted the idea, or is it a relatively recent thing?

Interview: Aled Edwards, Chair of DPIA, Wales Committee of the Equalities and Human Rights Commission

Themes: Nation of Sanctuary, Welsh governance and context

1) Do you mind telling me a little bit how you came to be involved in supporting refugees here in Wales, for example now with DPIA?

2) Swansea became a dispersal area in April 2000, while the first people arrived in May 2001, and DPIA started around the same time. Considering that you 
were involved early on, do you have any recollections of this time and the discussions around it?

3) Part of the Wales Cities of Sanctuary project is working towards Wales as a 'Nation of Sanctuary'. Do you mind telling me a little bit how this idea of a 'Nation of Sanctuary' originally came about? (Where did it come from?)

4) Where there certain moments or events that shaped this emergence of this idea of a Nation of Sanctuary? How has it developed?

5) What are you imagining this Nation of Sanctuary to be, and how did this image started taking shape, for yourself?

6) How did the WG, and the Assembly committee ("Equality, Local government and Communities committee), picked up on the idea of NoS?

7) Considering that you have been working on Welsh devolved governance since the National Assembly was established in 1999, maybe we could talk about this topic a bit. What potential role do you see for the Welsh government, and devolution more broadly, with regards to asylum issues?

8) During discussions of the NoS steering group, the issue of movement building was mentioned, and that $\operatorname{CoS}$ is a grassroots initiative, almost cautioning on how closely to work with the WG. How do you feel about that?

Interview: Clara* Welsh National Assembly Researcher, $9^{\text {th }}$ February 2018

Themes: Nation of Sanctuary, 'Equality, Local Government and Communities committee'

1) The 'I used to be someone' report in 2017: How did the report emerge from the committee?

2) How did the committee pick up on, and included, the idea of the 'Nation of Sanctuary'? 
3) In the report, it is mentioned that: "Community cohesion plan should include a communication strategy ... Rocio from EYST in Swansea elaborated that it is as important to discuss how asylum seekers are "perceived" "Do you mind elaborating a bit on how this notion emerged, and how a Welsh communication strategy could look like?

4) There were calls for a "publicity campaign like Scotland". The committee was visiting Glasgow and Edinburgh. What do you think of the "New Scots" Integration strategy? How couldn't or could it relate to Wales?

5) Someone long involved in support networks I interviewed: "even in the early days, there was a sense of Wales shaping a distinct way". He talked about a "distinctive" Welsh policy in the sense of an inclusion rather than integration strategy. Do you know a little bit about that?

6) When talking with someone from the Nation of Sanctuary steering group: "The important thing is to distinguish the current work from that manifesto...manifesto didn't draw line at devolved matters. And what that means, I suppose, Wales can become a Nation of Sanctuary, even within the context of hostile UK policy. That's the thinking". The idea, if I understand it right, is that it is phrased to focus on devolved response to asylum, rather than asylum policy itself. What role do you see for devolution with regards to asylum? (Only rely on devolved public services?)

7) EYST on the current refugee deliver plan: "However, it appears that local authorities liaise directly with the $\mathrm{HO}$ rather than the WG, to agree... So, we are unclear what influence and role the WG has played in the process". With regards to Wales: What is the role and influence of the National Assembly? (Which level of local government is responsible for what?)

8) Through the Syrian Vulnerable Persons Resettlement Programme (SVPRP) all 22 local authorities in Wales have received refugees. What effect do you think that had for the perception of the issue? (Beyond Cardiff and Swansea?) 


\section{Appendix C. Example interview transcripts}

Interview transcript: Alan Thomas, Co-Founder of Swansea City of Sanctuary

Researcher: That's interesting, because it is essentially, effectively leads me to one of my last questions, that was, you said you were the chair of trustees of the national [emphasising] City of Sanctuary network from 2011 till 2016. I wonder if you could elaborate a bit more on that. Did you have the feeling during this time that there were, sort of, differences between the Wales network and the broader UK network? Something distinctive about...

AT: I mean, obviously, the other big moment, in a way, was the, when there was huge international publicity about the, you know, European refugee crisis, which, when was it, end of 2015 ?

R: Yeah, 2015.

AT: The summer of 2015. And what we...there was a phrase coined by a guy called Roger Nyantou from Leeds, and all the trustees called it the "revolution of generosity" [Short laughing] So, there is this sudden, there is this sudden, massive number of people, with wanting to help. In a completely unfocused way, really. Which, if they were in touch, or they found out about a City of Sanctuary group, it would mean there is a massive number of people wanting to assist, and the administrative City of Sanctuary groups wouldn't have the capacity to [...] them [Short laughing] So there is a problem, rather than a $[\ldots]$ problem.

I forgotten the question again.

R: That's okay. It was about if there was any difference between sort of national, UK context and the Wales context?

AT: So, okay, I think, before that, in Wales, you are only talking about [...] and Scotland. You are talking about dispersal areas. So, that geography, which is a policy kind of geography, affects it. Because in England, dispersal is outside London. I never quit understood how this worked, actually. But I think, asylum seekers living in London, on the whole, are those who were not officially destitute.

AT: Because you come as a ...you apply for asylum, and if you are destitute, then you will be found accommodation and you will be dispersed. And if you're not destitute, 
that would be if you happen to unfortunately, to accidently mention your sister in law, who lives in London.

AT: Who could look after you then [Short laughing]. You wouldn't get support. I mean, that's probably very, very crude. That's not exactly what's happening. But however, the ...dispersal policy is basically outside the South East of England.

AT: But all over the Midlands, South-West, North, East you would find quit a lot of smaller cities, plus the bigger ones, actually. So, the network in England is quite dispersed, is what I am saying.

AT: The network in Wales, I mean there are only four dispersal areas, [...], one of which is Wrexham, which is much smaller than the others. So, Swansea, Cardiff, Newport, Wrexham. Very soon there was a Cardiff group, as well as a Swansea one, although the Cardiff group is very different, but every place is different. And Newport, has had several times people of...there were contacts. There were people who will come up and say: "[...]", and they never come through with it, yet.

AT: However, if you were to talk about "Nation of Sanctuary" ...now, as far as I know, the idea of a Nation of Sanctuary in Wales, originally came [Thinking] when, also I don't know how long ago, but Inderjit Bhogal, who I mentioned before [... ] in Sheffield, and he is a, quite a senior Methodist. He moved away from Sheffield and got a job with the, sort of fellowship, what is it called, centre? Very well know place in Northern Ireland, that did a fellowship, peace fellowship sort of work. And then he moved back. Anyway, he would be invited here and there, he still is around, he will do preaching and [referend] churches all over the place, because he is a well-known person who does that. And he...so he will be visiting lots of places all the time. And at one point he was in Cardiff, and promoted the idea of "City of Sanctuary" to Aled Edwards, who is chair of DPIA, and also now the chief executive of Cytun, which is "Churches Together", that is the Welsh name for "Churches Together".

AT: And Aled Edwards promoted the idea to either Carwyn Jones or his predecessor. And there was a moment where the First Minister announced the idea that he supported Wales as a "Nation of Sanctuary" before anybody in the City of Sanctuary movement had heard about it.

$\mathrm{R}: \mathrm{Oh}$, really? 
AT: "Oh, what's that?" [Laughing] So we got this, [...] a report, you know. "What's that?" Very strange. And of course, we had all...one of the original principles was that you don't want it to be a top-down initiative, you want it to be a grassroots initiative. If you can get the support of the council or the government, that's great, but it is not their initiative.

AT: So, anyway... but at that point, it was thought of, well, Wales as a "Nation of Sanctuary", what does it mean? It means getting all the cities that could be, which really would only be ....although, in theory, there could be City of Sanctuary group outside a dispersal city, but never was likely to happen.

AT: So, there could be four. And then you would want support from the ...[Thinking].... You know, from the national organisations, if you like. And that would be as far as it would go, probably. Whereas after that "revolution of generosity", you suddenly realised it would be possible. This little model which I had in mind, of the little bubble?

AT: And then the whole...it's like three circles. Little bubble, the whole population of the city, and trying to get an intermediate one, which is all these people that support the idea, get it to be as big as possible. You could think of that on the Welsh level, not just in each city separately...That's simply the picture I got about it. Because now, suddenly within two years, there are not two, but ten City of Sanctuary groups in Wales. And obviously, the majority of them are not urban. So, not only have you got this people wishing to help somehow, you also got David Cameron's scheme for resettling...

AT: ...refugees from Syria, which means that the whole in Wales, well, Wales has taken that up, more than England, I think. You know, there will be exceptions to this, cause Coventry, for example, has taken more than any other council. But, Wales has taken it up in the sense that every [...] ...so everywhere in Wales, there will be some Syrian refugees, in the same council, not necessarily in the same place, because the council places people wherever cheap housing is, you know.

AT: So, that does change, I mean...[Thinking]...I would say that's the reason why the Welsh response is possibly different [Asking] I mean...[Thinking]...I can't really think...is there anything about Welsh culture, well, I don't know. Because like, you 
know, Wales still got areas where, you know, Wales voted to leave the EU, and there are certain areas of post-industrial decline and ....

Interview transcript: Aled Edwards, Former Chair Welsh Refugee Council, Chair DPIA

Researcher: Okay. Thank you very much. Still, the framework is really interesting, maybe we can get back to that in a bit. For now, what you said, I found really interesting, just through my own research I came...because, that Swansea became a dispersal area in April 2000, and then the first people arrived in May 2001, and you said, DPIA starting around the same time. You told a little bit, but considering that you were involved early on, at this stage already, do you have any recollections of that time? And, the discussions around it? Because it seemed, in Swansea at least, there was a little bit of a discussion of, you know, Swansea becoming a dispersal area. Do you have any, sort of, remembering how that was here in Cardiff, maybe?

A: I arrived on the scene when that decision was well under way. But obviously, we had a sense at the time, that people were coming through to Cardiff, to Swansea, to Newport, and also to Wrexham. So, that North Wales dimension was there. And we, even in those early days, we tried to have a sense of Wales shaping things in a distinct way. That added value to the care that we provided. So, at the time, for example, we started the Welsh Refugees Doctor's Training scheme. About 2001, 2002. And, it is amazing now. We are fifteen years on into the project, and we've trained and equipped over a hundred GMC registered doctors, to work in the NHS, with that distinctive scheme. And that, if you like, came from a very strong sense of devolved value base. And I can remember that we even, in those early days as well, began to press [Edwina Hard], because she was the minister in the Welsh government. A: to get the release of the asylum detainees in Cardiff prison, sooner than any other part of the UK. And we used the committee structure of the National Assembly, to call UK officers to account. And I think, that was possibly the first time that this had been done, with any clarity of thought. And, you know, that gave you a sense of, of the beginning of a discourse. That in Wales, in a devolved setting, we would do things differently.

R: Yeah. Thank you. No, that is...Again, I have section here, were maybe on the framework, but on the committee structure, I found that really interesting, maybe we 
can, in a bit, get back to that. How you said, that was, sort of, little bit the start of the discourse around...So, I read a bit through the documents, and part of the Wales Cities of Sanctuary project, which is obviously, sort of, you know, with the Big Lottery funding. But there, already there was mentioned that there is an idea to work towards Wales being a 'Nation of Sanctuary'. Do you mind telling me a little bit how this idea of a 'Nation of Sanctuary' originally came about? Where did it come from?

A: It came, if my memory serves me right... it would be interesting to have a conversation with people like A.T., from Swansea. Because A. was one of those early pioneers with it. And it may be that we thought the same thing, at the same time. But, my recollection was, I can't remember the year now. But it was when my organisation, Cytun- Churches together in Wales, invited Inderjit Bhogal, who was one of the key players in the City of Sanctuary concept, to come over and speak to use, as a board. And we floated the idea with him, then, that it would perhaps be possible for Wales to become a 'Nation of Sanctuary'. And, the model behind that, was the way in which Wales had gained a badge as the first 'Free [sic] Trade' nation. So, that was informed by that dynamic.

$\mathrm{R}$ : Sorry, free trade or fair trade?

A: Oh, no, its Free Trade...Fair Trade. Fair Trade.

R: Sorry, I just wanted to clarify.

A: Yeah, Fair Trade Nation. And that, in a way, informed that aspiration. So, I think, that's where it came from. And we, incidentally, thought through that the Churches couldn't deliver that by themselves. So, we began to build bridges nationally in Wales, with other faith communities, such as the [Muslim] Council for Wales. And we already, at that time, began to think through having a faith communities' forum, which also [...] But it really gathered pace when DPIA took a lead, four or five years ago, with the Big Lottery funding. And that's obviously been shaped very much with what happened in Swansea. Particularly in Swansea, but not exclusively so. 
Interview transcript: Clara* Researcher for the Equality, Local Government and Communities committee at the Welsh Assembly

Researcher: Thank you. One thing I found quite interesting reading through the report, there is this phrase, I realised started being bounced around both the voluntary sector and the kind of Welsh approach to asylum is this notion of a 'Nation of Sanctuary' Can you sort of remember, while working on the report, how the committee picked up on that, and included the idea?

C: So, as I remember, at the time the Welsh Refugee Coalition were campaigning quite heavily on that. So, there was a lot of external influence. It wasn't something that just came about organically through the committee, there were concerted efforts from stakeholders. So, I think the coalition had released the Seven Steps to ... which I have on my screen, just in case I forget. And, as I remember, the Welsh government's opinion had already been: we don't have the devolved powers to make this happen. And as the committee was hearing evidence, and was going through the Seven Steps, they weren't entirely clear, as to what wasn't within the control. And they did push the cabinet secretary on that quite a bit. Yeah, there were cabinet secretaries at the time, they changed their names [Short laughing] But, it wasn't really clear what they thought was the sticking point, and we got the feeling that the Welsh government had made a decision to not prioritise the grey areas in-between devolution settlements. So, the Immigration Act and all the right-to-rent stuff was a really good example of them not considering the devolved impact of a thing that would have a huge impact. And again, I did a little update for our committee chair a few weeks ago, and it doesn't seem like this assessment is taken place. And, so, we still don't know when this right to rent checks might be forced upon ... You know, housing is a devolved area, I mean, it's a clear sort of conflict. But I think that's the difficult thing with, particularly with refugees and asylum seekers, the issue sits completely in-between the two devolved powers. So, I guess it's easy for things to drop between the gasps, in that respect. So, the Seven Steps were something that was brought up from the beginning by stakeholders, and they brought it up in evidence, I think, and then there were events. So, I think they have the Sanctuary in the Senedd event, while we were talking evidence. So, all of our members heard about this, and it was something that they kept brining up, as a way to sort of gathering everything together. But it wasn't, they didn't just accept that this was always going to be in the report. They had discussions about 
whether they thought it was a good idea to commit to have this in the report. But they had disagreements about whether it should be in there or not. And the end of it they did decide to commit to it. You know, whether it has an impact or not is ...

Researcher: [...] That's interesting, because it says, and I am quoting: However, stakeholders believe, and the Committee agrees, that Wales can become a Nation of Sanctuary simply by taking actions which do fall within the Welsh Government's responsibilities. So, if I understand it right phrased to focus on devolved response to asylum policy, rather than on asylum policy itself?

\section{C: Exactly.}

Researcher: So, maybe we can elaborate a bit more. You started mentioning, but how was it discussed what Wales can and cannot do? Was that a big discussion of ... because, arguably, the Seven Steps are slightly ... [...] ...How was the discussion around what can we do, what can we not do?

C: So, that's something that gets dealt with very early dawn. So, when I do the scoping of an enquiry, it goes to our legal team, to make sure it is all within the devolved settlement. We wouldn't put, for instance, something in the terms of reference about giving asylum seekers the right to work or something like that, it wouldn't fit within what the institution is supposed to do. But, the devolution question ... So, that was the parameters I tried to outline from the start, but obviously, a lot of the discussion was about non-devolved issues. I think, trying to think when they might have discussed ...

Researcher: If they didn't do it so much that is interesting as well ...

C: Because, I suppose, they are quite well trained into just focusing on things that they can change. So, within an enquiry I am dealing with in the moment, the obvious focus of it is on employment law, but they can't do that. So, they have to come at it from an abstract angle. And I think that's kind of what happened with this enquiry. That was another issue, actually, that was brought up in the discussion whether they should do it or not, was: Well, you know, is this worth it? Can we have any influence over ...? But, I mean, as you can see in the final report, you know, there is a bit of stuff about making, you know, advocating for Wales at the UK government level, and we put these things in reports every now and again. I mean, it just means that a Welsh minster might write to an equivalent of the UK government minister, doesn't usually have that 
much influence, but I think, our committee in particular, need to be a bit more ambitious, in how they ask for things. Because if we just focus on ...

Researcher: A bit more pushy?

C: Exactly. We've done things like ... We are doing an enquiry into human rights and Brexit. You know, human rights isn't devolved, but it doesn't mean that it is not having an impact. And it's the same with refugees and asylum seekers.

Researcher: Same logic, isn't it? Housing and ...

C: And if you look at refugees and asylum seekers as just people that live in Wales, and, you know, lots of the things that they ... their interactions with the state: education, housing, transport, healthcare. That's all devolved. So, when we were designing this enquiry, that was forefront in my mind. So, yeah, the devolution aspect of it is kind of natural to them. Like, they kind of know what's pointless to [...] otherwise they wouldn't go all over. They didn't spend ages on asylum support, or something like that, but they did talk a lot about changing the discretionary assistance fund. Which is within Welsh government's control to be accessible. So, it doesn't really answer your question, but they didn't have one discussion about it.

Interview transcript: Daniella* Development Worker Swansea City of Sanctuary, Head of the Nation of Sanctuary Steering Group

Researcher: This is sort of the first question, I am not even sure if you can help me with it, but: Do you know how the idea first emerged?

D: Not really...

R: Not so much?

D: The City of Sanctuary idea, obviously, you know the history of that, originated in Sheffield. Swansea was the second ever in the UK. And when the project was first designed, there was only Swansea and Cardiff City of Sanctuary groups in Wales.

R: Yeah

D: In September 2015, the world was rocked by the photo of Ailan Kurdi. And lots of City of Sanctuary groups, or affiliated groups, have sprung up as a result of that kind 
of 'revolution of generosity'. So, there is now at least ten groups in Wales. So, what I really don't know is how Wales had this idea of being a Nation of Sanctuary before there were even other groups in Wales, apart from Cardiff and Swansea. So, I don't know. Aled Edwards might know.

R: I already knew a little bit of things there, but thought you might have a bit of an inside, but it's totally fine. That there was only Swansea and Cardiff, and now ten groups, is really interesting, but I think we can hopefully get back to that, I don't know, a bit. Maybe correct me if I am wrong here, but I had a bit of the feeling that the sort of the way the project developed, the Nation of sanctuary project, a lot of motivation and sort of drive behind that came out of the Swansea group. Is that true, or where there sort of other groups kind of behind it that really pushed for the idea?

D: I think, out of the City of Sanctuary groups, Swansea was the most driven around the idea. Mainly because A.T, our co-chair here in Swansea, is also a UK City of Sanctuary trustee. So, he has got this kind of national, strategic vision that you potentially don't see in other local groups, because they are much more focused on what they want to do locally.

\section{R: Yeah}

D: However, I think to say that it is solely driven by Swansea City of Sanctuary is a bit of an overstatement, because there is lots of other, non-City of Sanctuary groups and organisations in Wales. Displaced People in Action being one of them, Oxfam Cymru have been really supportive, who have equally been behind it the whole way.

D: Yeah. So, the last of the background questions I guess slightly refers to the first one, but... Have you a bit of an insight in the organisation, of where the initial motivation came from to kind of continue with that 'Nation of Sanctuary' concept. Did that really come out of that summer of 2015, or where there sort of other factors to say: Okay, we have a City of Sanctuary group, now we really push that to the Welsh level. What was the kind of motivation behind that?

D: ... [Thinking a couple of second] ... That's a good question. I think the current drive, [thinking]...the current enthusiasm really came out of that conference in April. So, we had 140 people come to that, representing 55 plus organisations. And A.T was instrumental in getting some of the most enthusiastic people to then commit to being 
part of the steering group, that would continue to drive that forward [Thinking] But in terms of where the concept itself came from, I couldn't say what drove that.

R: Okay. Have to try to keep digging there a bit.

R: Alright, so thanks very much for the kind of starting insight. Sort of the second section now, and again, you know, we might go in a slightly different way there, but what I found quite interesting is the kind of geography of the 'nation of sanctuary'. And how you said, at the beginning there where this sort of Swansea and Cardiff, these kinds of two cities, and now there is ten groups in all of Wales. So, I would like to go into that a little bit. As I said before, or you said: Yeah, there was Swansea driving it, but was there sort of from the beginning, with the Nation of Sanctuary idea, was that something that came mainly really from Swansea and Cardiff, or where their sort of other groups, kind of, added on? How did that kind of coordination develop? I am still trying to get a contact with someone, but for example Abergavenny Town of Sanctuary. Or, there is now a Valleys of Sanctuary. How did that coordination came about?

D: So, the local groups, I would say, sprung up in response to local need. I don't think there is any group that has been formed in order to contribute to 'Nation of Sanctuary'. I think it is much more: We're here in Abergavenny, as an example, there are new Syrian refugees here, and we want to do something to make sure they feel really welcome here. So, in terms of the coordination, it's taken mainly me and people with Welsh wide policy roles. So, people like H.R at Oxfam Cymru, T.C at the Welsh Refugee Council, to pull in different people that represent different parts of Wales. Ask them to contribute to the work towards all making Wales a 'Nation of Sanctuary'. So, I still think [Thinking] it is a Cardiff driven concept, but I don't think that it is Cardiff centric, which is an important distinction. Because, the Nation of Sanctuary, it's now called the Nation of Sanctuary sub-group of the Welsh Refugee Coalition, has representatives from all parts of Wales. And they all contribute equally, more or less [Short laugh]. So, it really does feel like that we are all pulling together in the same direction. But the coordination is still, you know, it's me and my Cardiff colleagues. 


\section{Examples of ethnographic fieldnotes}

\section{Fieldnotes 'Wales as a Nation of Sanctuary' conference (27/04/2017)}

The introduction speech by R. is mentioning the phrase "a warm welsh welcome", and she is talking about how people from all over Wales are here today, followed by asking where people are from, hands are going up, most people seem to be from Cardiff, but a lot are also from North and West Wales. There is an option at this conference for online mapping the participants with postcodes. During the introduction, one of the issues that is mentioned is to 'celebrate contribution', but also that the attempts of this conference should go "further than the local", that it is about being the "first nation" to attempt to become such a Nation of Sanctuary, as well as that it should therefore entail the "entire country". She is saying that this even more appropriate 'now' to talk about it, with Brexit and a new general election looming, as she says 'now' in Wales "the picture is a little brighter". With the material from the evidence committee, she continues, we know need to "put words into action". Moreover, she explains, she thinks that it cannot be top-down alone, that it would need to involve local authorities, the private and the third sector, and that the focus should be on Wales and in Wales, and that there is a "lot we can do in our own borders". "Now is the time for action", she is finishing the first speech.

They start the second presentation with the emphasis that Wales could be the "world's very first Nation of Sanctuary". A sense of pride and achievement? Part of the conference programme today is to hear testimonies and stories from refugees and asylum seekers who came to Wales, and the first person to start this part of the programme with, an older man from Pakistan, residing in Swansea, describes how he had a 'paradise lost'. The next speech that follows this testimony, is from the Welsh Assembly member, B.J, who was invited to speak here. She talks first about how she is amazed at the grassroots support in front of her, and how she thinks that this kind of support is central for "defying the attitudes". She then mentions how the last recommendation in the committee report she worked on was to endorse the Nation of Sanctuary, and that she endorses it as well. She continues to explain how shocked she was, learning through her work with regards to the committee report, that so many refugees and asylum seekers used the phrase 'I used to be somebody', to hear what she called "heart-breaking stories". She thus replies in her speech to the audience and the 
committee: "You are still somebody here". [What are the implications of this phrasing? Here?]

Then, housing is mentioned as being devolved, and that there should be a move towards developing what one calls here the "confidence to complain", however, it is still mentioned how people active often "face the wrath of the Home Office". One of the participants announces that Newport wants to become the next City of Sanctuary, followed by applause. After this, it is mentioned that we should also include and consider the view "of other Celtic nations". The next speech is by M., who has travelled down here from Glasgow and is originally from Somalia, he is talking about bridges between what he calls the 'general public and new migrants', and emphasis that it is important to inform: "What does it mean when they come?", and that "You would be surprised how migration has affected your nations". [Interesting implication? Part of the national pride narrative?] He is then talking a little bit more about his personal stories. He came in 2001 to Scotland, and he had lived in both Glasgow and Croyton. He then emphasis how the "Scottish government is supportive in terms of language", that they use the language of welcome. He mentions here the 'New Scots Strategy', which he describes as a way of seeing refugees as part of their communities.

\section{Fieldnotes Sanctuary in the Senedd Event, $24^{\text {th }}$ January 2018}

Soon after the workshop ends, the event continues with discussing the theme of destitution, which had been chosen to be the overarching theme for today, at 12.15 with R.C from EYST in Swansea and chair of the Welsh Refugee Coalition, doing a short speech. She describes Wales as a 'welcoming and cohesive' country, and the positive working with the Welsh government. Their new deliver plan has the working title of 'Nation of Sanctuary'. But, R.C says, it would not be such a nation when in it are people who live in destitution. (Is that why this is the theme, as there would be no nation of sanctuary without the end to destitution?) The first-person speaking is T.S from the Welsh Refugee Council, welcoming people to the third Sanctuary in the Senedd event. She begins by emphasising how we have seen a lot of things going well. Local communities hosting people from Syrian, 'financial investment and community sponsorship' [Wording interesting?], but also that we should 'welcome people who are travelling individually'. "By design, they are dependent on the state", she says. She 
continues that it is now almost 20 years since the dispersal system, and that we have seen dramatic changes since then. Destitution, she says, is not only inhuman and 'shameful', but also economically and in the sense of well-being detrimental "for our nation" .... [...]

The last section of the event now deals with 'ShareDydd', a hosting scheme from Cardiff, with Mr H.H and Mr A.K as the speakers. On a power point page, the scheme is described as "a network of individuals offering hospitality, in the form of accommodation, meals, welcome and solidarity, to destitute asylum seekers in and around Cardiff'. C.M from the British Red Cross then introduces everyone, H.H being from Sudan, and A.K being the host. A.K starts by describing how they got introduced to each other, and that originally, Andy had moved into a new house and felt guilty about the spare bedroom he had, that was how the original idea came about. Moreover, he describes how he works in construction, and how the activity has helped him in "not maybe changing opinions, but perspectives', and how the 'converge is a lot better', as he was apparently facing through work a lot of anti-migrant sentiment. Moreover, he talked about the 'satisfaction of helping' and that he wanted to show his 'daughters how lucky they are' and ensure that they grow up with different ethnicities and cultures. He thinks, he is adding, that this can also help "challenging the backlash". A.K says, moreover, that the experience was 'awkward at first, as you invite someone you don't know into your house', but it passes fast. H.H described it as 'good, overall', staying for three month with the family. T.S ends this section then with the remark of how these schemes could be understood as part of a broader homelessness agenda. The event then finishes with a short speech by B.J, who says that these testimonies where a "message if nothing else to the Home Office", and that while ultimate control lies with the UK government, we can 'urge' the WG to 'lobby' the UK government. Moreover, she talks about the Swansea event, she talked to me about as well, as says that "housing came up loud and clear" ... 


\section{E. Example of research inquiry briefings}

Y Pwyllgor Cydraddoldeb, Llywodraeth Leol a Chymunedau | 15 Rhagfyr 2016

Equality, Local Government and Communities Committee | 15 December 2016

\section{Inquiry into refugees and asylum}

Research briefing and suggested questions

This paper provides a summary of the evidence received last week, and suggested areas for questioning for witnesses.

\section{Key findings from last week's session}

Last week the Committee took evidence from Siân Summers-Rees, Oxfam Cymru, the Red Cross, Welsh Refugee Council and a refugee. The key issues raised by witnesses were:

\section{- Welsh Government policy}

- There was a feeling that the Welsh Government and the media are continuing the 'two tier' system into devolved areas - for example, by having a Syrian Taskforce, rather than a refugee and asylum seeker taskforce. This means that people relocated under the Syrian Vulnerable Persons Relocation Scheme (SVPRS) receive better support than other refugees;

- Problems related to the 28-day 'move on' period: after someone is granted refugee status and the requirement to find their own accommodation, income etc. Witnesses thought that housing options should be offered early on; employment, benefits and education advice needs to be strengthened to prevent people from falling into destitution, trafficking or crime;

- Oxfam raised concerns that the Welsh Government's Syrian refugee Operations Board have not met since June;

- There was a lot of work around recognised prior learning (qualifications) in Wales a few years ago but it never progressed beyond pilot schemes. There were calls for a new specialist education and employment service;

- There was a perception that support for asylum seekers and refugees in Wales has declined due to cuts from both UK and Welsh Government- the Welsh 
Refugee Council's previous 'one stop shop' being cited as an example (previously funded by Home Office);

- Siân Summers-Rees considered that transport is a major barrier to integration, especially with more refugees being dispersed to rural areas;

- Many witnesses claimed that English for speakers of other languages (ESOL) provision is not sufficient to meet demand in Wales - the Committee heard that classes are frequently over-subscribed with large waiting lists;

- There are some problems accessing healthcare for refugees and asylum seekers, especially around the use of LanguageLine;

- The Red Cross called for the Welsh Government's Discretionary Assistance Fund (DAF) criteria to be expanded to include people with no recourse to public funds. Northern Ireland have a crisis fund that provides emergency payment to people with NRPF - the pilot scheme cost $£ 20,000$ in NI and most payments were under $£ 50$;

- People with no recourse to public funds - there are many periods where people are at risk of NRPF. NRPF leaves people at risk of destitution and exploitation.

\section{- UK Government policy}

- The Immigration Act 2016 is likely to have a big impact on devolved areas including housing and looked after children. The Red Cross said that the Act was 'likely' to increase destitution. The 'right to rent' checks in the Act makes it an offence to rent to a person 'who is disqualified as a result of their immigration status'; while this is currently only applicable in England, the UK Secretary of State "may by regulations make such provision as the Secretary of State considers appropriate for enabling any of the residential tenancies provisions to apply in relation to Wales, Scotland and Northern Ireland" (section 42);

- There is 'two tier' asylum process - Syrians arriving through SVPRS are receiving the 'gold standard' of support, whereas all other asylum seekers and refugees have to go through standard process and do not receive as much support. Welsh Refugee Council provided a specific example that resourcing is heavily focused on Syrians - "we have four caseworkers [..] supporting 700 
people over the last quarter. By contrast, our Syrian Resettlement Scheme supported 46 people, so ten families, over the last year with two caseworkers";

- The quality and oversight of asylum accommodation in Wales. Witnesses highlighted the conflict of interest - the Home Office processes asylum applications and provides their housing, meaning that people are afraid to complain. Some organisations considered that asylum housing should be within the control of the Welsh Government - the contracts will soon be up for renewal meaning that the Welsh housing sector could be supported to win the contract. Local authorities previously provided asylum accommodation, now it's run by private companies;

- The lack of legal advice and independent advocacy available to asylum seekers in Wales. The fact that AMs are not allowed to advocate on behalf of asylum seekers(only MPs are allowed to do this) was cited as an example of the lack of advocacy;

- There was a perception that the devolved administrations should co-ordinate and vocalise the similar concerns being experienced in different countries to the UK Government.

- Unaccompanied asylum-seeking children (UASC)

- Witnesses noted that there are no reliable statistics on the number of UASC in Wales, but earlier in 2016 it was around 37. There was a perception that these low numbers make it even more important to ensure that this vulnerable group are supported and protected;

- Some suggested that the funding available to support UASC is inadequate compared to what the Welsh Government requires;

- There was strong support for the establishment of a Welsh Guardianship Service to fill the gap of independent advocacy for children;

- $\quad$ Recent research from ECPAT (End Child Prostitution, Child Pornography and Trafficking of Children for Sexual Purposes) found that Welsh local authorities reported that none of their 14 trafficked children and 2 of their 57 unaccompanied children went missing ( 1 permanently);

- There was a perception that there is insufficient training available to social workers in Wales on conducting age assessments for unaccompanied children. 
Sian Summers-Rees called for a designated person in each local authority to conduct assessments. Conducting accurate assessments would reduce judicial review costs for local authorities when decisions are overturned.

\section{- Community cohesion}

- The Welsh Refugee Council and Oxfam suggested that local authorities require contracted organisations supporting Syrian refugees through the SVPRS "not to attract media attention", because of community cohesion fears $^{1}$. Some considered this a missed opportunity to promote positive stories of refugees, but there were concerns about stigma and targeting. However, the opposite was true in Ceredigion, which made a concerted effort to involve media in resettlement;

- Difference in media coverage in Wales and Scotland - Oxfam considered that promoting Wales as a 'nation of sanctuary' would encourage positive media interest;

- Witnesses thought that the Welsh Government should be leading and coordinating integration activities in Wales at a strategic level;

- Community cohesion work in Wales in relation to refugees and asylum seekers is relatively new, and many local authorities do not have experience in this area.

\section{Panel 1: Local government}

The Wales Strategic Migration Partnership (WSMP) is one of twelve Regional Strategic Migration Partnerships funded by the Home Office, and is based at the Welsh Local Government Association (WLGA). The WSMP, along with all the UK Strategic Migration Partnerships, has been tasked by the Home Office to take a lead role in co-ordinating the Syrian Vulnerable People Resettlement Scheme.

${ }^{1}$ Issue clarified with Welsh Refugee Council - requirements are verbal, not written into contracts 
The Welsh Local Government Association (WLGA) represents the interests of local government and promotes local democracy in Wales. It represents the 22 local authorities in Wales.

1. Welsh Government policy

The WLGA states that all 22 local authorities have committed to receiving refugees through the SVPRS, and 300 people are estimated to have been resettled in in the first year of the programme. Its evidence notes that "the majority of local authorities had limited, if any, previous experience of working with refugees". 


\section{Appendix F. Archival material}

Document 1: Swansea Council document (2000)

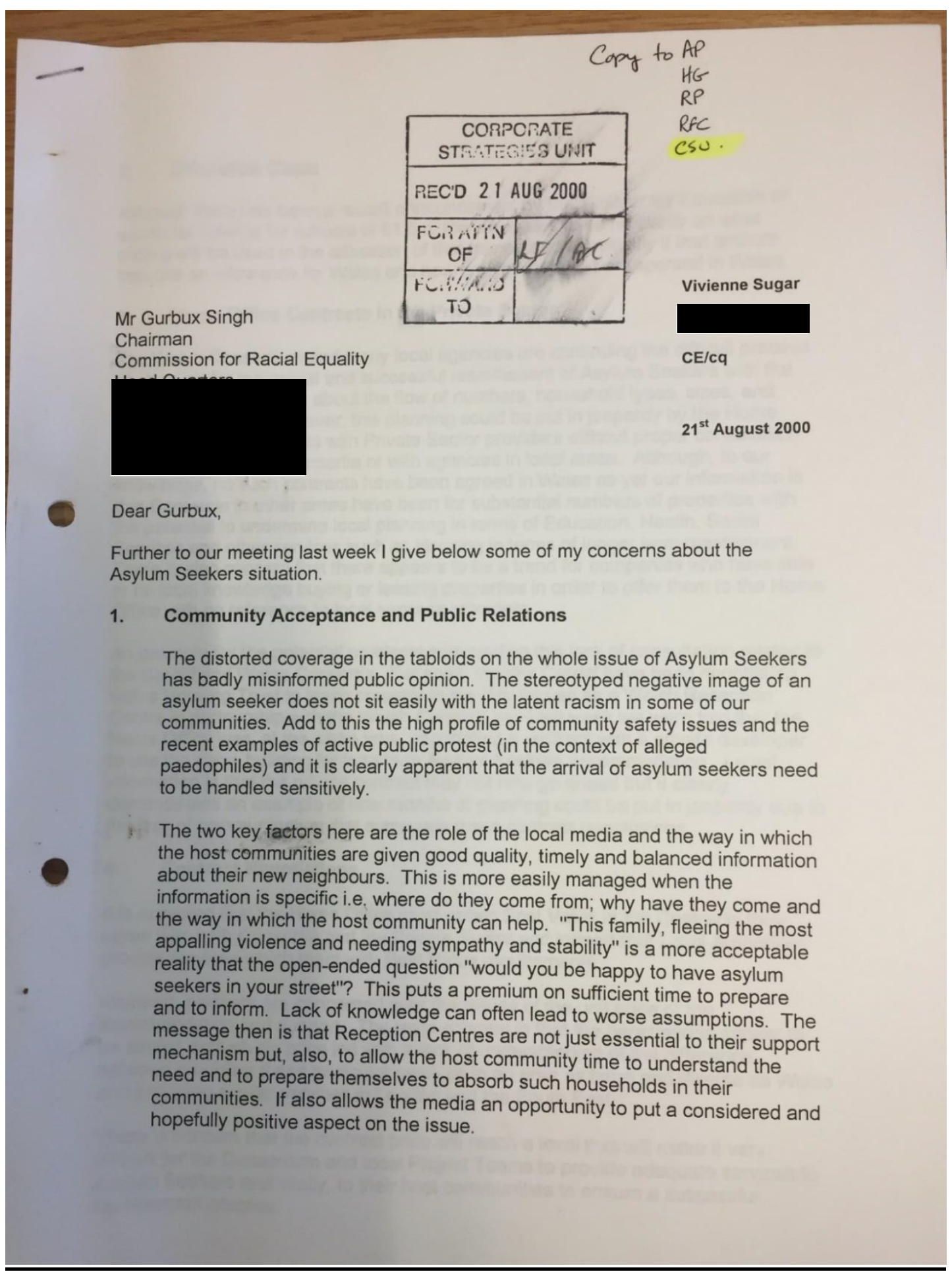

Sugar, V., 2000. Corporate Strategies Unit. From City \& County of Swansea to Commission for Racial Equality. Received 21 August [Letter] D 251/5/18. Swansea: West Glamorgan Archive [Photograph] 
Document 2: South Wales Evening Post article (2000)
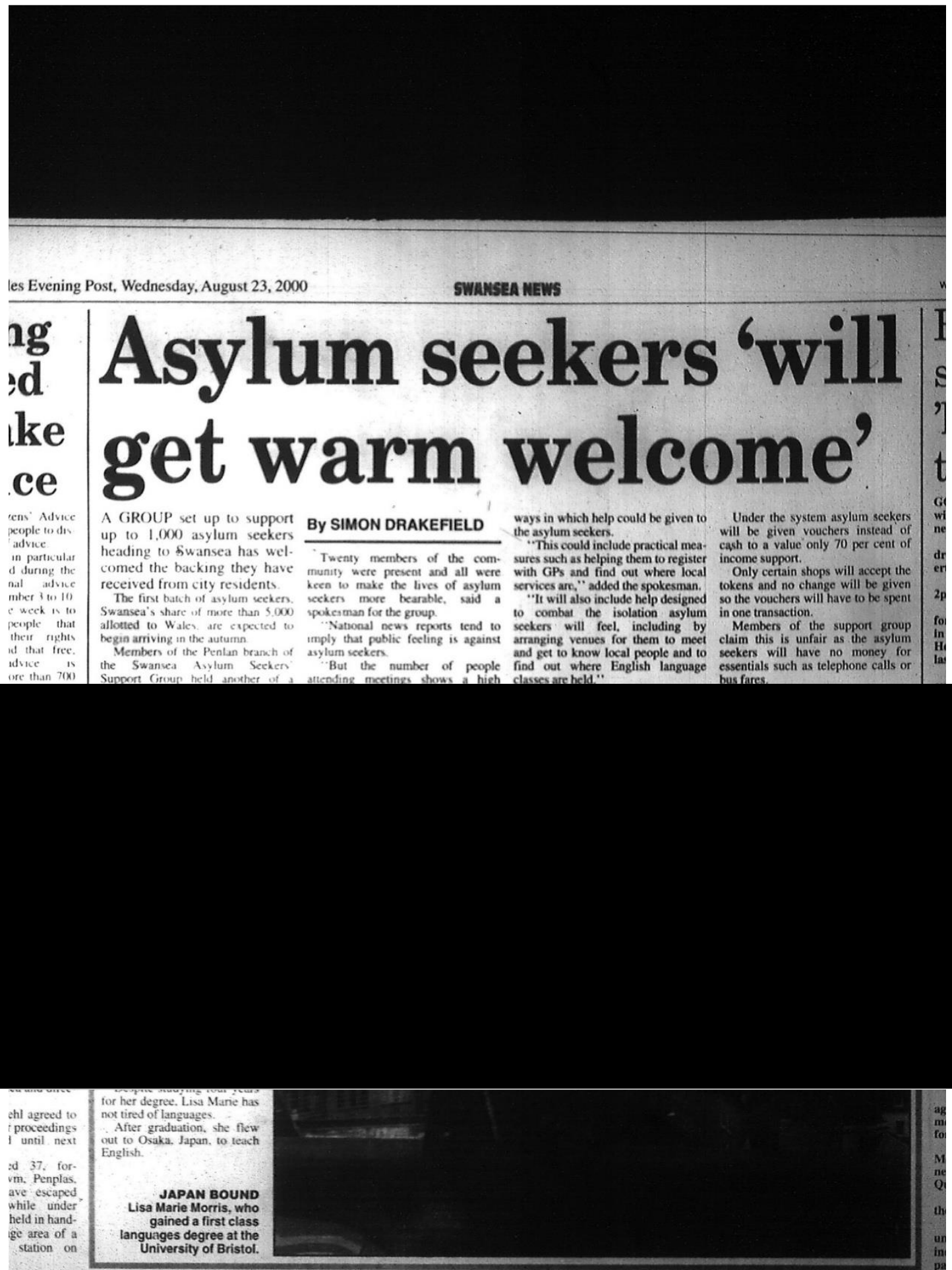

ON THE GRAPEVINE

Drakefield, S., 2000. Asylum seekers 'will get a warm welcome'. South Wales Evening

Post. 23 August. [Microfilm-Scan] Swansea: West Glamorgan Archive 
Document 3: South Wales Evening Post article (2001)

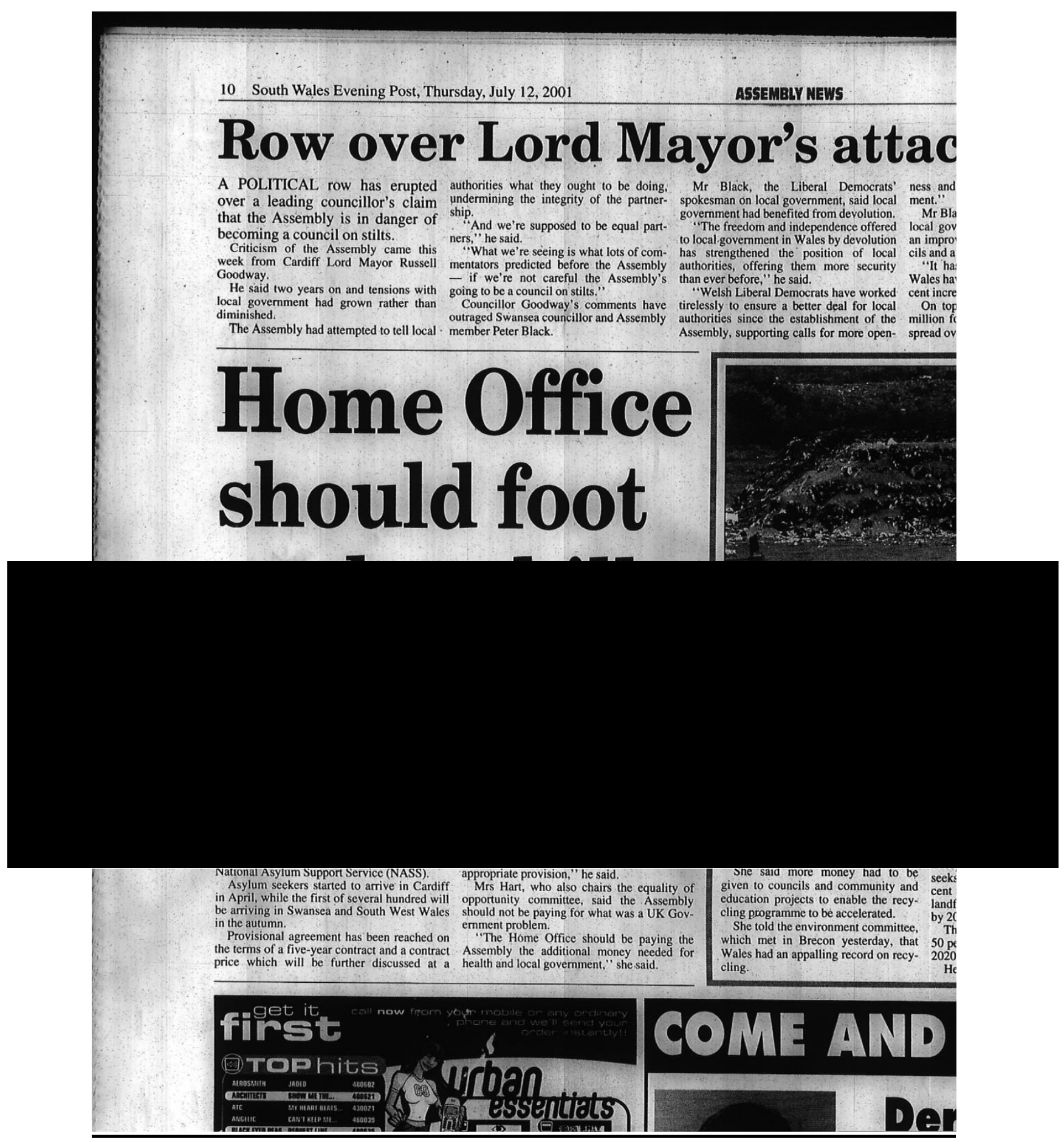

Walters, B., 2001. Home Office should foot asylum bill. South Wales Evening Post. 12 July. [Microfilm-Scan] Swansea: West Glamorgan Archive. 
Document 4: Western Mail article (2001)

\section{NEWS The Westem Mail 繁}

CARDIFF: No cause for concern, say officials, as protest against I

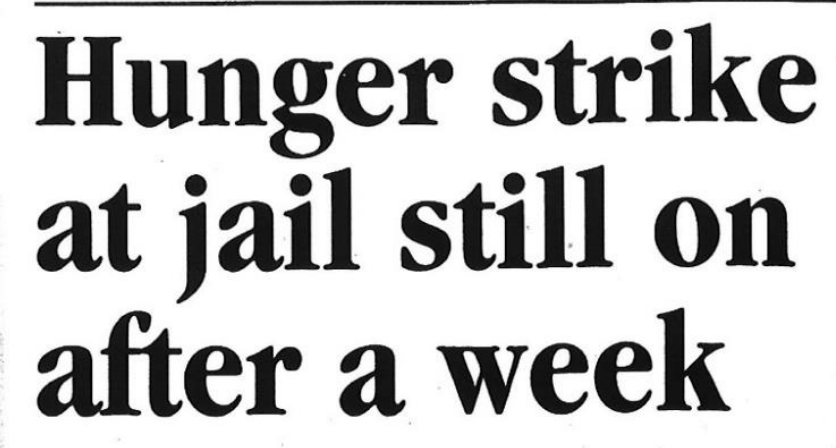

PAUl Carey

Education Reporter

Attack on Arabs

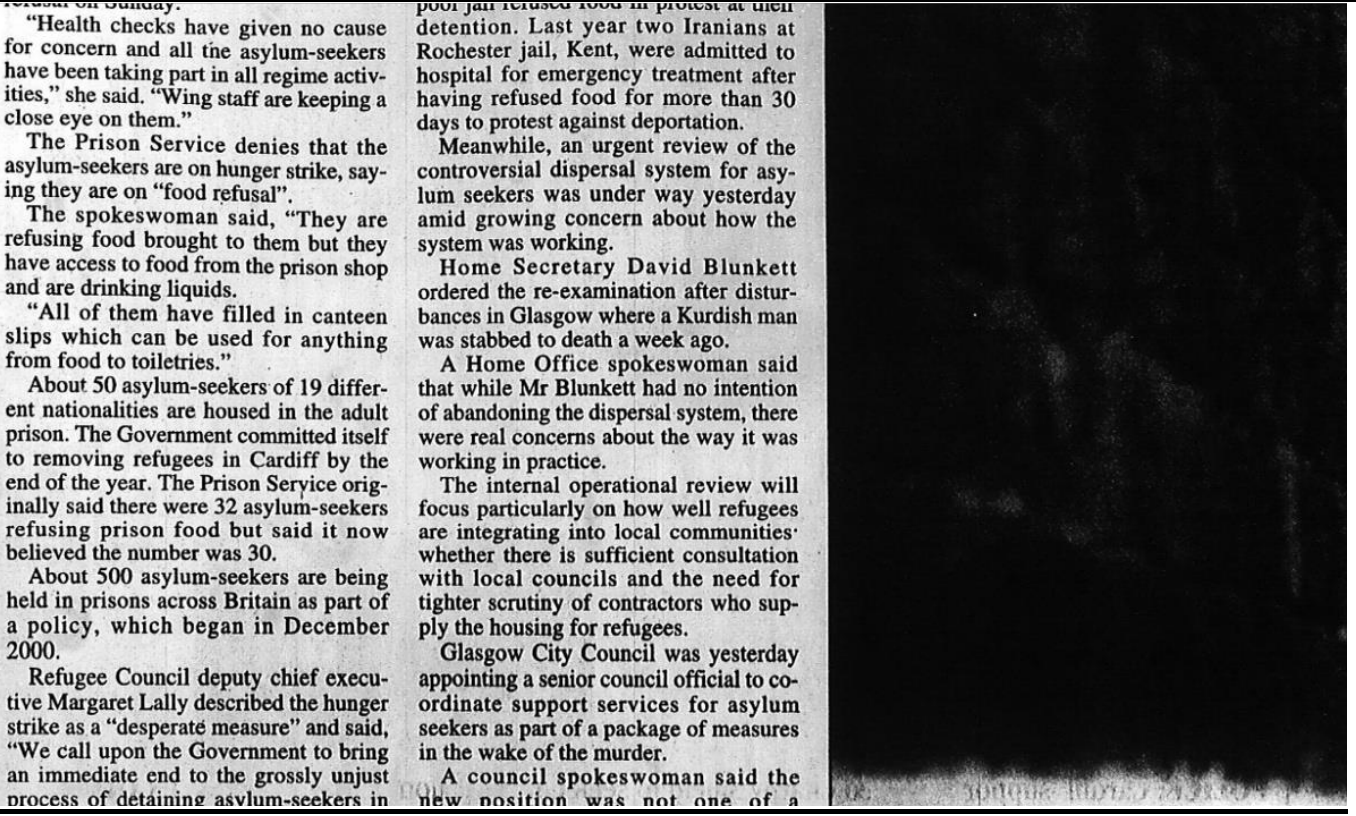

Carey, P., 2001. Hunger strike at jail still on after a week. Western Mail. 14 August.

[Microfilm-Scan] Swansea: West Glamorgan Archive 


\section{G. NVivo coding scheme (Preliminary)}

\section{Data organisation and management}

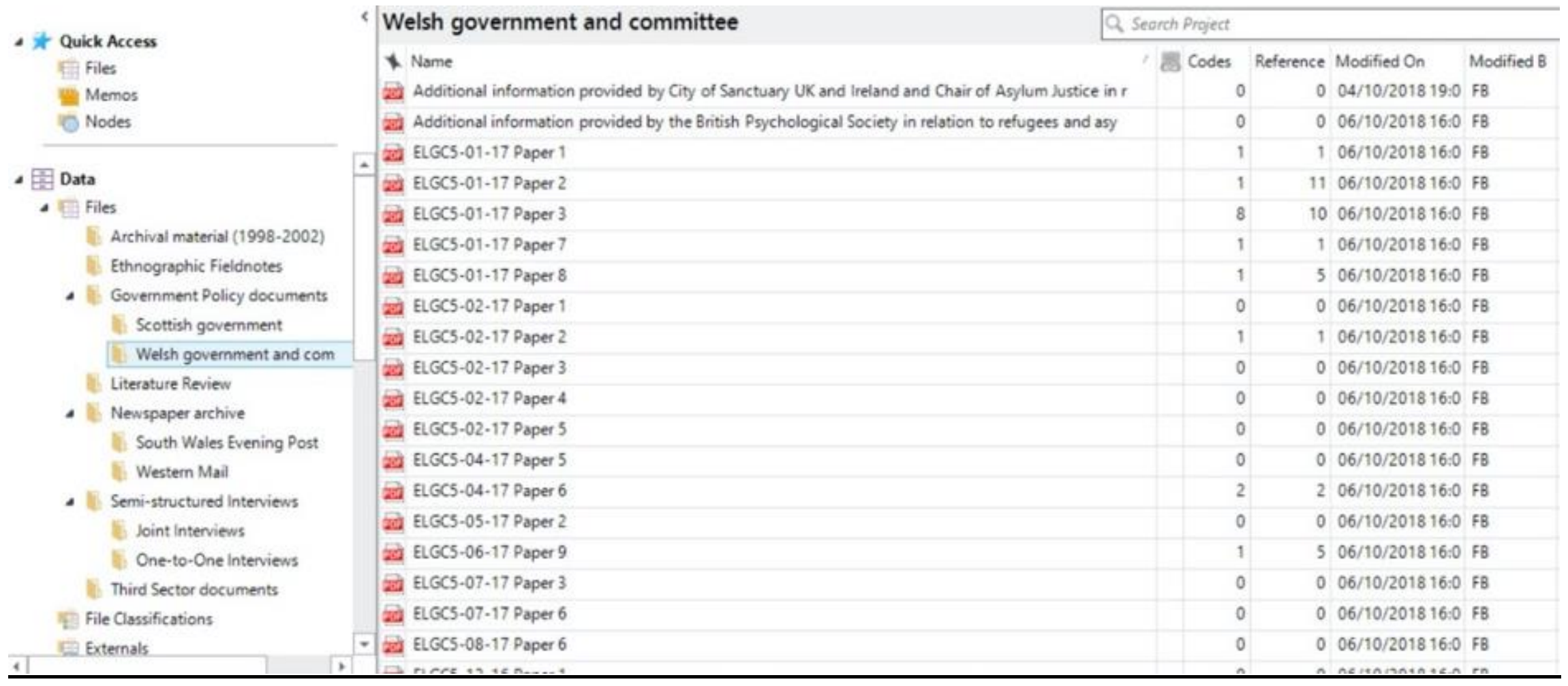

This screenshot shows the organisation of the data into six larger folders, with another six sub-folders. The large categorisation is the following: Archive Material, Ethnographic Fieldnotes, Government Policy Documents, Literature Review, Newspaper archive, Semi-Structured Interviews and Third Sector Documents. 
Memos and research project structure

$\Delta \neq$ Quick Access

Files
Nodes

$\triangle$ Codes

10 Nodes

(2) Relationships

IC Relationship Types

$\triangle$ Cases
10 Cases

-1) Case Classifications
Pi) Government
A. Third Sector and Civil Society

\begin{tabular}{|l|l|}
\hline Memos \\
\hline Research Questions Chapter I \\
\hline Research Questions Chapter II \\
\hline Research Questions Chapter III \\
\hline Thesis Research aims and objectives \\
\hline
\end{tabular}

This screenshot shows the memos, which were constructed with regards to the main research question and the following sub-question. In addition, case classifications were separated into government on one hand, and third sector and civil society on the other. 
Preliminary NVivo codes

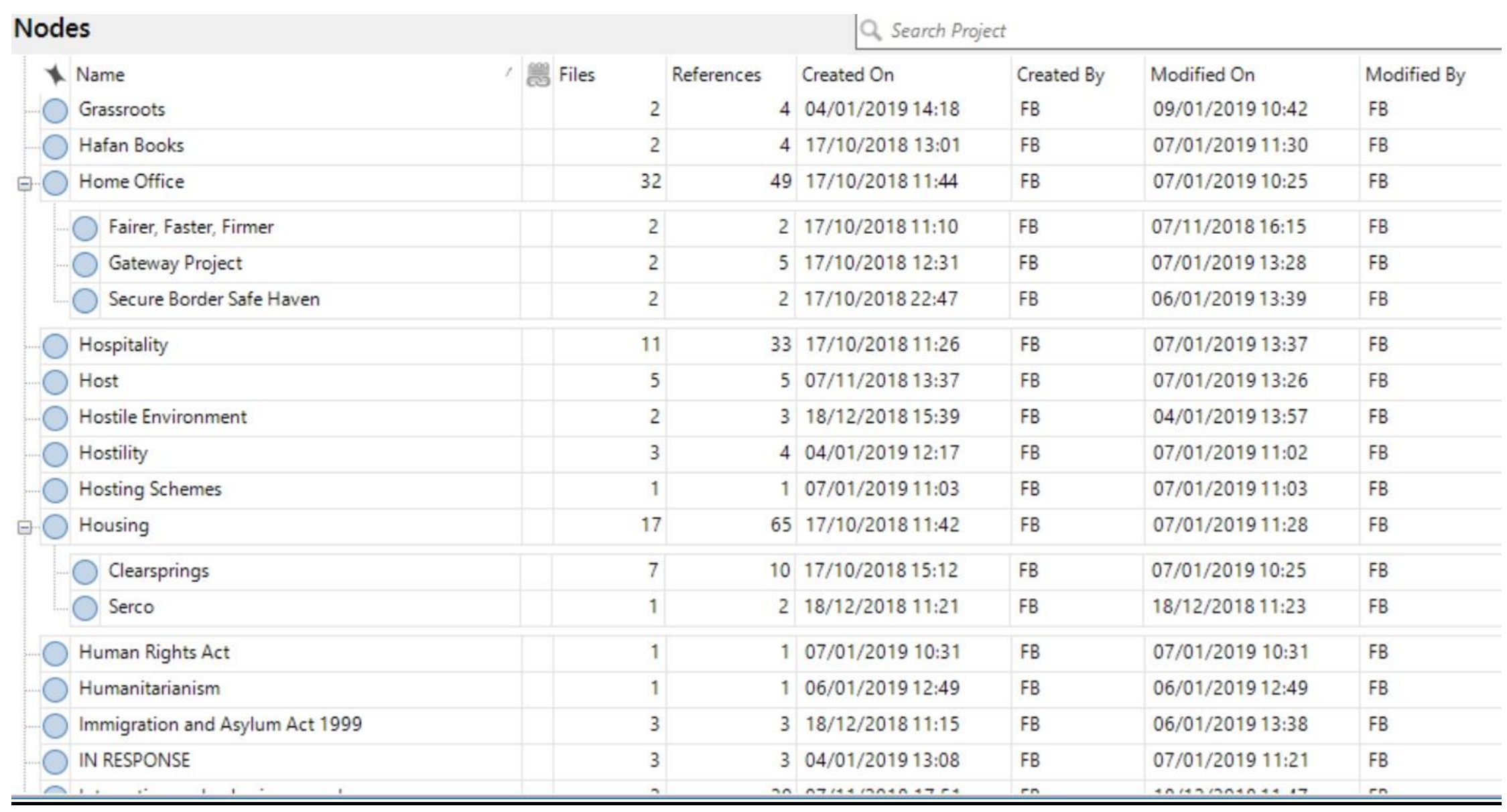

This screenshot is an example of the preliminary codes (nodes in NVivo) that were used to classify the material. It shows how some codes, such as Home Office or Housing, would be separated into more detailed categories referring for example to different white papers. 
Emerging coding categories (example 1)

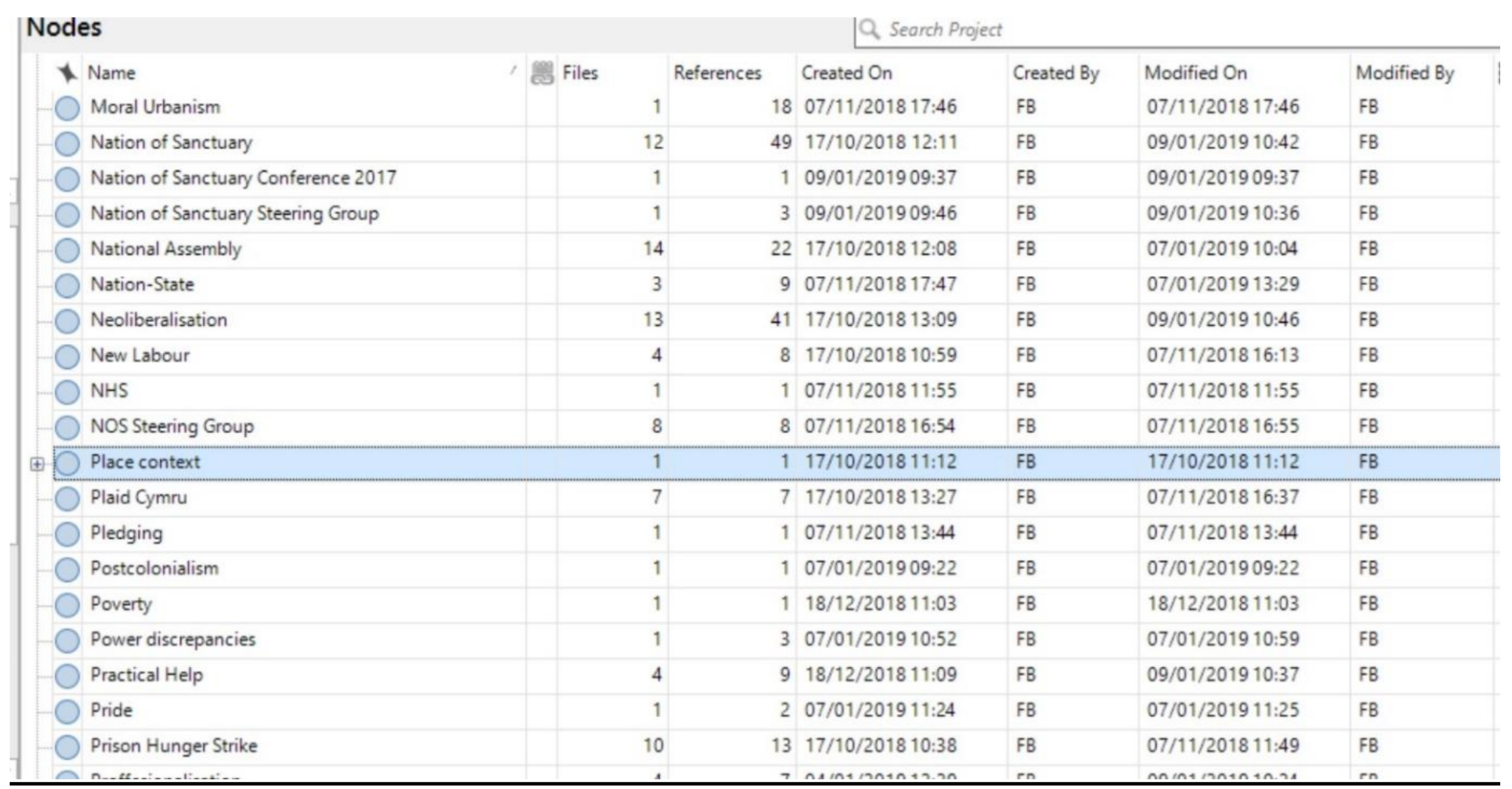

This screenshot gives an indication of how you can see some categories appearing more often than others in terms of marked files and references, which would then give an indication on where to pull codes into broader categories that could structure the chapters, for example, Nation of Sanctuary and Neoliberalisation. 
Emerging coding categories (example 2)

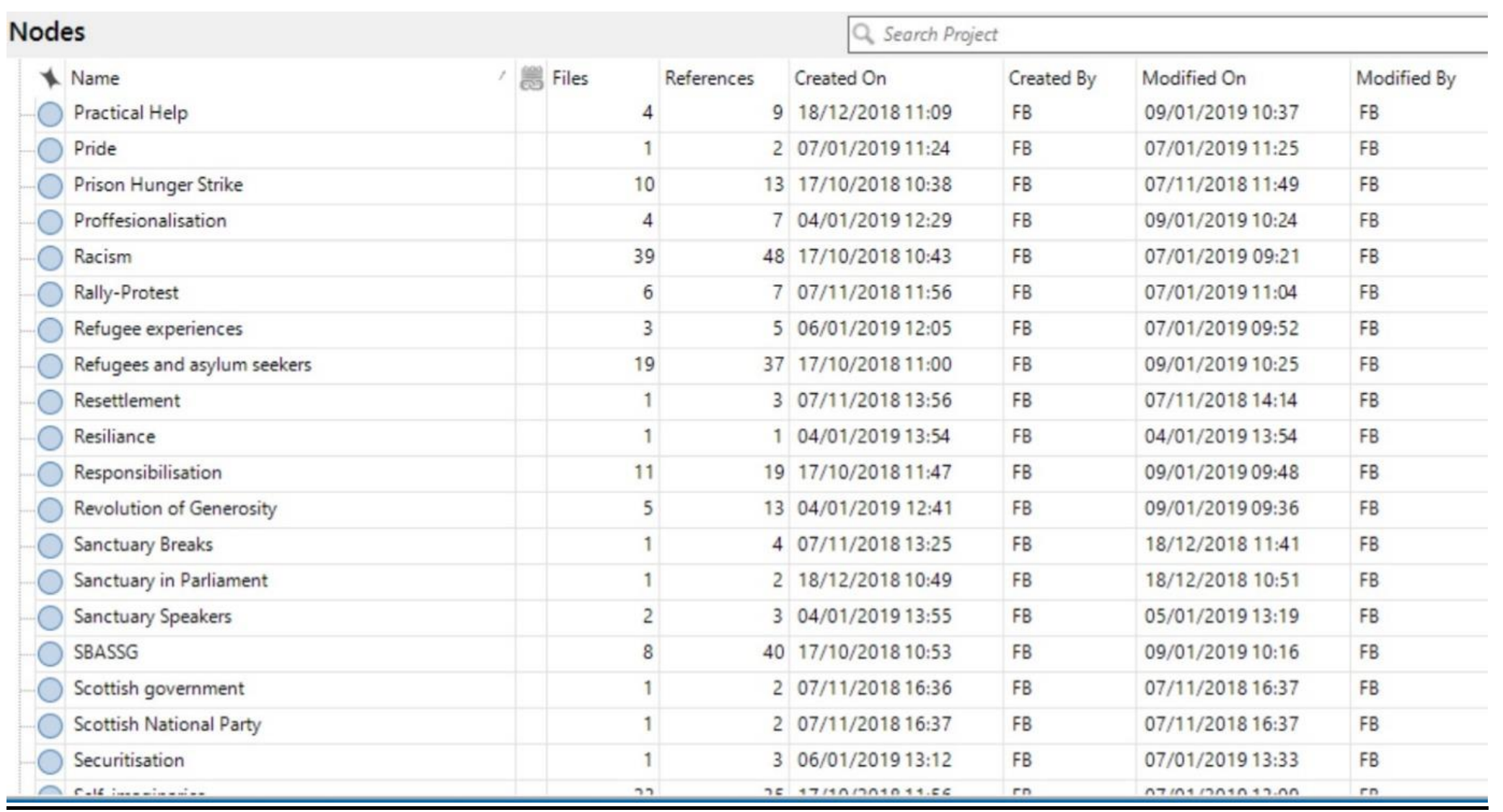

This screenshot gives an indication of how you can see some categories appearing more often than others in terms of marked files and references, which would then give an indication on where to pull codes into broader categories that could structure the chapters, for example: SBASSG, racism and refugees and asylum seekers. 
Coding with sensitivity to time and periodisation

\begin{tabular}{|c|c|c|c|c|c|c|c|c|}
\hline Nodes & & & & Q Search $P_{r}$ & & & & \\
\hline Name & , 器 & Files & References & Created On & Created By & Modified On & Modified By & : \\
\hline Time Context & & 1 & 1 & $17 / 10 / 201810: 31$ & $F B$ & $17 / 10 / 201811: 06$ & FB & \\
\hline 2000 & & 10 & 16 & $17 / 10 / 201810: 32$ & $F B$ & $07 / 01 / 201911: 20$ & $F B$ & \\
\hline 2001 & & 18 & 23 & $17 / 10 / 201810: 32$ & $F B$ & $07 / 11 / 201816: 22$ & $F B$ & \\
\hline 2002 & & 2 & 4 & $17 / 10 / 201810: 32$ & FB & $07 / 11 / 201815: 52$ & $F B$ & \\
\hline 2005 & & 10 & 10 & $17 / 10 / 201810: 32$ & $F B$ & $07 / 11 / 201814: 24$ & $F B$ & \\
\hline 2010 & & 3 & 6 & $17 / 10 / 201810: 32$ & $F B$ & $07 / 01 / 201911: 20$ & FB & \\
\hline 2015 & & 14 & 36 & $17 / 10 / 201810: 33$ & $F B$ & $09 / 01 / 201910: 38$ & $F B$ & \\
\hline 2016 & & 2 & 5 & 07/11/2018 12:56 & $F B$ & $18 / 12 / 201810: 55$ & FB & \\
\hline Tonin campaign & & 2 & 9 & $17 / 10 / 201810: 56$ & $F B$ & $07 / 11 / 201815: 36$ & $F B$ & \\
\hline Town of Sanctuary & & 2 & 2 & $17 / 10 / 201811: 46$ & $F B$ & 17/10/2018 13:14 & $F B$ & \\
\hline Two-Tier system & & 8 & 15 & $17 / 10 / 201812: 40$ & $F B$ & $07 / 01 / 201913: 32$ & $F B$ & \\
\hline UK government & & 9 & 12 & $07 / 11 / 201813: 36$ & $F B$ & 09/01/2019 10:26 & $F B$ & \\
\hline Unity in Diversity & & 2 & 2 & $06 / 01 / 201912: 01$ & $F B$ & 07/01/2019 11:08 & $F B$ & \\
\hline Volunteering & & 6 & 16 & 07/11/2018 13:44 & $F B$ & $07 / 01 / 201910: 47$ & FB & \\
\hline Voucher system & & 1 & 1 & $17 / 10 / 201817: 24$ & $F B$ & $17 / 10 / 201817: 24$ & $F B$ & \\
\hline Vulnerability & & 2 & 2 & $17 / 10 / 201822: 49$ & $F B$ & 07/11/2018 15:38 & FB & \\
\hline Wales-Wide Approach & & 1 & 1 & $18 / 12 / 201811: 06$ & $F B$ & 18/12/2018 11:06 & $F B$ & \\
\hline 'War-torn area' & & 1 & 1 & $07 / 11 / 201813: 57$ & $F B$ & $07 / 11 / 201813: 57$ & $F B$ & \\
\hline Welcome to Swansea & & 1 & 1 & 18/12/2018 11:48 & $F B$ & 18/12/2018 11:48 & $F B$ & \\
\hline
\end{tabular}

This screenshot shows how the material was also coded in terms of 'Time Context', which means the specific year in which something took place.

One can see larger periods emerging: between 2000 and 2002, and between 2010 and 2016. This is translated into the way in which the data was presented in the thesis. The high number of codes in 2005 is related to the murder of Kalan Kawa Karim, in 2015 to the 'European refugee crisis'.

Both events are therefore playing also significant roles in the way the data has been presented. 


\section{Bibliography}

\section{A. Books and academic journal articles}

Adamson, D.L., 1991. Class, Ideology and the Nation: A Theory of Welsh Nationalism. Cardiff: University of Wales Press

Agnew, J., 1994. The Territorial Trap: The Geographical Assumptions of International Relations Theory. Review of International Political Economy 1(1), 53-80

Agnew, J., 2004. Geopolitics: Re-Visioning World Politics. London: Routledge

Ahmed, S., 2004. Collective feelings: Or, the impression left by others. Theory, Culture \& Society, 21 (2), 25-42

Amin, A., 2006. The good city. Urban Studies. 43, 1009-1023

Amin, A., 2012. Land of Strangers. Cambridge: Polity Press

Anderson, B., 1991. Imagined Communities. London: Verso Books

Appadurai, A., 2006. Fear of Small Numbers: An Essay on the Geography of Anger. Duke University Press

Appadurai, A., 2016. Aspirational Maps- On migrant narratives and imagined future citizenship. Blaetter fuer Deutsche und International Politik. (1) [Online] Available at: https://www.eurozine.com/aspirational-maps/ [Accessed 11 July 2020]

Arendt, H., 1951. The Origins of Totalitarianism. New York: Harcourt Brace

Armbruster, H., 2018. "It was the photograph of the little boy": reflections on the Syrian Vulnerable Persons Resettlement Programme in the UK. Ethnic and Racial Studies, 1-20

Askins, K., 2015. Being Together: Everyday Geographies and the Quit Politics of Belonging. ACME: An International E-Journal for Critical Geographies, 14(2), 470478

Atkinson, P.A., and Coffey, A., 2004. Analysing documentary realities. In: Silvermann, D., Eds., 2004. Qualitative research: Theory, method and practice. London: Sage, 56-75 
Bagelman, J., 2013. Sanctuary: a politics of ease? Alternatives: Global, Local, Political. 38(1), 49-62

Bagelman, J., 2016. Sanctuary City: A Suspended State. New York: Palgrave Macmillan

Bagelman, J. 2019. Sanctuary artivism: expanding geopolitical imaginations. In: Darling, J. and Bauder, H., Ed., 2019. Sanctuary cities and urban struggles- Rescaling migration, citizenship and rights. Manchester: Manchester University Press, 131-162 Balibar, E., and Wallerstein, I., 1991. Race, Nation, Class: Ambiguous Identities. London: Verso Books

Barbero, I., 2012. Expanding Acts of Citizenship: The Struggles of Sinpapeles Migrants. Social \& Legal Studies, 21(4), 529-547

Bauboeck, R., 2003. Reinventing urban citizenship. Citizenship Studies, 7, 139-160

Bauder, H., 2014. Why we should use the term 'illegalized' refugee or immigrant. International Journal of Refugee Law, 26(3): 327-332

Bauder, H., 2016. Sanctuary Cities: Policies and Practice in International Perspective. International Migration. 1-14

Barnett C. and Bhogal I., 2009. Becoming a City of Sanctuary: A Practical Handbook with Inspiring Examples. Sheffield: Plug and Tap

Berlant, L., 2004. Compassion (and Withholding). In: Berlant, L., Eds., 2004. Compassion: the culture and politics of an emotion. New York: Routledge, 1-14

Bidet, J., 2016. Foucault with Marx. Londond: Zed Books

Bigo, D., 2002. Security and Immigration: Toward a Critique of the Governmentality of Unease. Alternatives, 27, 63-92

Billig, M., 1995. Banal Nationalism. London: Sage Publications Ltd

Brown, W., 2016. Sacrificial Citizenship: Neoliberalism, Human Capital, and Austerity Politics. Constellations, 23(1), 3-14

Bulley, D., 2013. Producing and Governing Community (through) Resilience. Politics, 33(4), 265-275 
Bulley, D. and Sokhi-Bulley, B., 2014. Big Society as Big Government: Cameron's Governmentality Agenda. British Journal of Politics and International Relations, 16, $452-470$

Bulley, D., 2015. Ethics, power and space: International hospitality beyond Derrida. Hospitality \& Society, 5(2-3), 185-201

Bulley, D., 2017. Migration, Ethics and Power- Spaces of Hospitality in International Politics. London: Sage

Butler, J. and Spivak, C., 2010. Who Sings the Nation-State? Chicago: Seagull Books Charles, E.N., Cheesman, T., and Hoffmann, S. Eds. 2005. Soft Touch-Refugees Writing in Wales. Swansea: Hafan Books

Closs Stephens, A., 2013. The Persistence of Nationalism: From Imagined Communities to Urban Encounters. London: Routledge

Closs Stephens, A., 2016. The affective atmospheres of nationalism. Cultural Geographies, 23 (2), 181-198

Connolly, W., 2004. The Complexity of Sovereignty. In: Edkins, J., Pin-Fat, V. and Shapiro, M., Eds., 2004. Sovereign Lives- Power in Global Politics. New York: Routledge, 23-41

Cope, M., 2003. Coding transcripts and diaries. In: Clifford, N, Valentine, G., Eds., Key Methods in Geography. Thousand Oaks: Sage, 445-459

Crange, M., and Cook, I., 2007. Doing Ethnographies. London: Sage Publications Darling, J., 2010. A city of sanctuary: the relational re-imagining of Sheffield's asylum politics. Transactions of the Institute of British Geographers. 35, 125-140

Darling, J., 2011. Domopolitics, governmentality and the regulation of asylum accommodation. Political Geography, 30 (5), 263-271

Darling, J., 2013. Moral Urbanism, asylum, and the politics of critique. Environment and Planning, 45, 1785-1801

Darling, J., and Squire, V., 2013. Everyday enactments of sanctuary: The UK City of Sanctuary movement. In: Lippert, R., and Rehaag, S., Ed., 2013. Sanctuary Practices in International Perspectives. Oxon: Routledge, 191-203 
Darling, J., 2016a. Forced Migration and the city: Irregularity, informality, and the politics of presence. Progress in Human Geography, 1-12

Darling, J., 2016b. Asylum in Austere Times: Instability, Privatization and Experimentation within the UK Asylum Dispersal System. Journal of Refugee Studies. 29 (4), 483-505

Darling, J., 2019. Sanctuary, presence, and the politics of urbanism. In: In: Darling, J. and Bauder, H., Ed., 2019. Sanctuary cities and urban struggles- Rescaling migration, citizenship and rights. Manchester: Manchester University Press, 242-264

Davies, C., 2004. Crowds March Against Racism in the City. South Wales Evening Post. 15 September. p.1

Deacon, R., 2014. Devolution. In: Jones, B., and Norton, P., Politics UK. $8^{\text {th }}$ Edition. London: Routledge, 220-244

De Genova, N., 2016. Series Editor’s Forward. In: Bagelman, J., 2016. Sanctuary City: A Suspended State? New York: Palgrave Macmillan. ix-xi

DeGenova, N., and Tazzioli, M., 2016. Europe / Crisis: Introducing New Keywords of "The Crisis" in and of "Europe". In: New Keywords Collective, Europe /Crisis: New Keywords of 'the Crisis' in and of 'Europe', Near Futures [Online] 1 "Europe at a Crossroads". March 2016. Available at: http://nearfuturesonline.org/ europecrisisnew-keywords-of-crisis-in-and-of-europe/ [Accessed at 11 July 2020]

Derrida, J., 2000. Of Hospitality: Anne Dufourmantelle invites Jacques Derrida to Respond. Translated by Bowly, R. Stanford: Stanford University Press

Derrida J, 2002. Negotiations: Interventions and Interviews, 1971-2001. Translated by E Rottenberg. Stanford: Stanford University Press

Disch, L.J, 1994. Hannah Arendt and the Limits of Philosophy. Cornell University Press

Dikec, M, 2002. "Pera, peras, poros: longing for spaces of hospitality. Theory, Culture and Society, 19(1-2) 227-247

Dikec, M., 2005. Space, Politics, and the Political. Environment and Planning D: Society and Space. 23 (1), 171-188 
Edkins, J. and Pin-Fat, V., 2004. Introduction: Life, Power, Resistance. In: Edkins, J., Pin-Fat, V. and Shapiro, M., Eds., 2004. Sovereign Lives- Power in Global Politics. New York: Routledge, 23-41

Fairclough, N., and Wodak, R., 1997. Critical Discourse Analysis. In van Dijk, T., Ed, Discourse Studies: A Multidisciplinary Introduction (Vol. 2). London: Sage, 258-284.

Fassin, D., 2005. Compassion and Repression: The Moral Economy of Immigration Policies in France. Cultural Anthropology, 20(3), 362-387

Fassin, D., 2012. Humanitarian Reason: A Moral History of the Present. Berkeley: University of California Press

Fay, B., 1996. Contemporary Philosophy of Social Science: A Multicultural Approach. London: Wiley-Blackwell

Fiddian-Qasmiyeh, E., 2016. Representations of displacement from the Middle East and North Africa. Public Culture, 28 (3), 457-473

Fortier, A.M., 2005. Pride politics and multiculturalist citizenship. Ethnic and Racial Studies, 28 (3), 559-578

Foucault, M., 2004. Security, Territory, Population. New York: Palgrave Macmillan Gadamer, H.G., 2013. Truth and Method. Bloomsbury Academic. Reprint Gill, N. 2010. New state-theoretic approaches to asylum and refugee geographies. Progress in Human Geography, 34: 626-645

Gill, N., 2018. The suppression of welcome. Fennia, 196(1), 88-98

Giudici, M., 2014. Immigrant narratives and nation building in a stateless nation: The case of Italians in post-devolution Wales. Journal of Ethnic and Racial Studies, 37(8), $1409-1426$

Guma, T., Woods, M., Yarker, S., and Anderson, J. 2019. "It's that kind of Place Here": Solidarity, Place-Making and Civil Society Response to the 2015 refugee crisis in Wales, UK. Social Inclusion, 7(2), 96-105

Hage, G., and Eckersley, R., 2012. Introduction. In: Hage, G., and Eckersley, R., Eds., Responsibility. Melbourne: Melbourne University Press, 1-11 
Halfacree, K. H. and Boyle, P. J., 1993. The challenge facing migration research: the case for a biographical approach. Progress in Human Geography, 17(3): 333-348

Haynes, A., Devereux, E., Carr, J., Power, M.J., and Dillane, A., 2016. Conclusion: Opportunities for Resistance through Discourse. In: Haynes, A., Power, M.J., Devereux, E., Dillane, A., and Carr, J., Ed., Public and Political Discourses of Migration: International Perspectives. London: Rowman \& Littlefield, 225-233

Hess, S., Kasparek, B., Kron, S., Rodatz, M., Schwertl, M., Sontowski, S., Hg. 2016. Der lange Sommer der Migration- Grenzregime III. Assoziation A

Hill, E., 2016. Welcoming Nations? Hospitality as a Proxy for National Identity: A Consideration of British and Scottish Contexts. In: Haynes, A., Power, M.J., Devereux, E., Dillane, A., and Carr, J., Ed., Public and Political Discourses of Migration: International Perspectives. London: Rowman \& Littlefield, 193-206

Hoggart, K., Davies, A., Lees, L. 2002. Researching Human Geography. London: Routledge

Huysmans, J., 2006. The Politics of Insecurity: Fear, Migration and Asylum in the EU. London: Routledge

Isin, E., 2002. Being Political: Genealogies of Citizenship. Minneapolis: University of Minnesota Press

Isin, E., 2007. City. State: Critique of Scalar Thought. Citizenship Studies, 11(2), 211228

Isin, E., 2009. Citizenship in flux: The figure of the activist citizen. Subjectivity, 29, $367-388$

Jackson, M.D., 2009. Where thoughts belong: An anthropological critique of the project of philosophy. Anthropological Theory, 9 (3), 235-251

Jenks, C., and Neves, T., 2000. A walk on the wild side: Urban ethnography meets the Flâneur. Cultural Values, 4 (1), 1-17

Kakoliris, G., 2015. Jacques Derrida on the Ethics of Hospitality. In: Imafidon, E., Eds., 2015. The Ethics of Subjectivity: Perspectives since the Dawn of Modernity. London: Palgrave Macmillan J 
Kvale, S. and Brinkmann, S., 2015. Interviews: Learning the Craft of Qualitative Research Interviewing. 3rd Edition. Thousand Oaks, CA: Sage Publications

Laclau, E. and Mouffe, C., 2014. Hegemony and Socialist Strategy: Towards a Radical Democratic Politics. London: Verso Books. $3^{\text {rd }}$ Edition

Laurier, E., 2003. Participant Observation. In: Clifford, N. and Valentine, G., Eds., 2003. Key Methods in Geography. London: Sage, 116-131

Lewis, H., 2007. Destitution in Leeds: The experiences of people seeking asylum and supporting agencies. York: Joseph Rowntree Charitable Trust [Online] Available at: https://www.jrct.org.uk/userfiles/documents/Destitution\%20in\%20Leeds\%20(researc h\%20report\%20full).pdf [Accessed 13 July 2020]

Lippert, R., 2005. Sanctuary, Sovereignty and Sacrifice: Canadian Sanctuary Incidents, Power and Law. University of British Columbia Press

Lippert, R. and Rehaag, S., Eds., 2013. Sanctuary Practices in International Perspective: Migration, Citizenship and Social Movements. London: Routledge

Malkki, L.H., 1995. Refugees and exile: From 'refugee studies' to the national order of things. Annual Review of Anthropology, 24: 495-523.

Malkki, L.H., 1996. Speechless Emissaries: Refugees, Humanitarianism, and Dehistoricization. Cultural Anthropology, 11 (3), 377-404

Malpass A., Cloke P., Barnett C., Clarke N., 2007. Fairtrade urbanism? The politics of place beyond place in the Bristol Fairtrade City campaign. International Journal of Urban and Regional Research. 31, 633-645

Martin, L.L., and Mitchelson, M.L., 2009. Geographies of detention and imprisonment: Interrogating spatial practices of confinement, discipline, law, and state power. Geography Compass 3(1): 459-477

Massey, D., 1991. A Global Sense of Place. Marxism Today. (38), 24-29

Massey, D., 1994. Space, Place, Gender. Minneapolis: University of Minnesota Press Massey, D., 2005. For Space. London: Sage 
Mavelli, L., 2017. Governing populations through the humanitarian government of refugees: Biopolitical care and racism in the European refugee crisis. Review of International Studies, 43(5), 809-832

McDaniel, P., 2018. Shared humanity, city branding, and municipal immigrant integration initiatives in the south-eastern United States. Southeastern Geographer, $58,250-281$.

McNevin, A., 2006. Political Belonging in a Neoliberal Era: The Struggle of the SansPapiers. Citizenship Studies, 10(2), 135-151

McNevin, A., 2013. Ambivalence and Citizenship: Theorizing the Political Claims of Irregular Migrants. Millennium: Journal of International Studies, 41(2), 182-200

Molz, J.G., and Gibson, S., Eds., 2007. Mobilizing Hospitality: The Ethics of Social Relations in a Mobile World. Aldershot: Ashgate Publishing Limited

Mooney, G. and Williams, C. 2006. Forging new 'ways of life'? Social policy and nation-building in devolved Scotland and Wales', Critical Social Policy, 26(3), 608629

Mountz, A. et al. 2012. Conceptualizing detention: Mobility, containment, bordering, and exclusion', Progress in Human Geography, 37(4), 522-541

Mouffe, C., 2018. For a Left Populism. London: Verso

Mueller, M., 2010. Doing Discourse Analysis in Critical Geopolitics. L'Espace Politique, 12 [Online], Available at: http://journals.openedition.org/espacepolitique/1743; DOI: https://doi.org/10.4000/espacepolitique.1743 [Accessed 10 July 2020]

Mycock, Andrew. 2012. 'SNP, identity and citizenship: Reimagining state and nation', National Identities 14: 53-69.

Netto, G., 2011a. Identity Negotiation, Pathways to Housing and "Place": The Experience of Refugees in Glasgow'. Housing, Theory and Society. 28(2): 123-143.

Netto, G., 2011b. Strangers in the City: Addressing Challenges to the Protection, Housing and Settlement of Refugees. International Journal of Housing Policy. 11(3): 285-303 
Nyers, P., 2010. No One is Illegal Between City and Nation. Studies in Social Justice, 4(2), 127-143

Nyers, P., and Rygiel, K., Ed, 2012. Migration and Citizenship: Activism and the Politics of Movement. London: Routledge

Perl, G. and Strasser, S., 2018. Transnational Moralities: The Politics of Ir/Responsibility of and Against the EU Border Regime. Identities, 25(5), 507-523

Peterie, M., 2018., Personal care as political activism: Refugee and asylum seeker friendship programmes. Aust J Soc Issues, 53, 400-415

Pirouet, L., 2001. Whatever happened to asylum in Britain: A tale of two walls. Oxford: Berghahn Books

Ranciere, J., 1999. Dis-agreement: Politics and Philosophy. Minneapolis: University of Minnesota Press.

Ridgley, J. 2008. Cities of Refuge: immigration enforcement, police, and the insurgent genealogies of citizenship in U.S. Sanctuary Cities. Urban Geography, 29(1): 53-77.

Robinson, G.M., 1998. Methods and Techniques in Human Geography. London: Wiley

Robinson, V., 2003. Croeso I Cymru- Welcome to wales? Refugees and Asylum Seekers in Wales. In: Williams, C., Evans, N. and O'Leary, P., Ed., 2003. A Tolerant Nation? Exploring Ethnic Diversity in Wales. Cardiff: University of Wales Press, 179200

Rose, N., 1999, Inventiveness in politics. Economy and Society. 28, 467-493

Rosello, M., 2001. Postcolonial Hospitality: The Immigrant as Guest. Stanford: Stanford University Press

Sales R., 2002. The deserving and the undeserving? Refugees, asylum seekers and welfare in Britain. Critical Social Policy. 22, 456-478

Sales, R., 2007. Understanding Immigration and Refugee Policy. Bristol: Policy Press Sassen, S., 2006. Territory, Authority, Rights: From Medieval to Global Assemblages. Princeton: Princeton University Press 
Sassen, S. 2008 Territory, Authority, Rights: From Medieval to Global Assemblages. $2^{\text {nd }}$ Edition. Princeton, Princeton University Press.

Shaw, K., 2004. Creating/Negotiating Interstices: Indigenous Sovereignties. In: Edkins, J., Pin-Fat, V. and Shapiro, M., Eds., 2004. Sovereign Lives- Power in Global Politics. New York: Routledge

Sim, D., and Bowes, A., 2007. Asylum seekers in Scotland: the accommodation of diversity. Social \& Policy Administration, 41(7), 729-746

Sirriyeh, A., 2018. The Politics of Compassion-Immigration and Asylum Policy. Bristol: Bristol University Press

Speers, T., 2001. Welcome or Overreaction? Refugees and Asylum Seekers in the Welsh Media. Wales Media Forum. Cardiff: Centre for Journalism Studies Cardiff University

Squire, V., 2009. The Exclusionary Politics of Asylum. Basingstoke: Palgrave Macmillan

Squire, V., 2011. From Community Cohesion to Mobile Solidarities: The City of Sanctuary Network and the Strangers into Citizens Campaign. Political Studies, 59, 290-307

Squire, V. and Bagelman, J., 2012. Taking not waiting: space, temporality and politics in the City of Sanctuary movement. In: Nyers, P., and Rygiel, K., Ed, 2012. Migration and Citizenship: Activism and the Politics of Movement. London: Routledge, 146-165

Squire, V. and Darling, J., 2013. The "Minor" Politics of Rightful Presence: Justice and Relationality in City of Sanctuary. International Political Sociology, 7, 59-74

Staniforth, E., 2015. “The journey's only just begun”: Exploring sub-Saharan African migrations through Europe. $\mathrm{PhD}$. Swansea University

Still, J., 2010. Derrida and Hospitality: Theory and Practice. Edinburgh: Edinburgh University Press

Van Liempt, I., and Bilger, V., 2009. Introduction: Methodological and Ethical Concerns in Research with Vulnerable Migrants. In: Van Liempt, I., and Bilger, V., 
Eds., 2009. The Ethics of Migration Research Methodology: Dealing with Vulnerable Immigrants. Brighton: Sussex Academic Press, 1-22

Ticktin, M., 2016. Thinking Beyond Humanitarian Borders. Social Research, 83(2), $255-271$

Varsanyi, M.W., 2006. Interrogating "Urban Citizenship" vis-à-vis Undocumented Migration. Citizenship Studies, 10(2), 229-249

Vaughan-Williams, N., 2015. Europe's Border Crisis: Biopolitical Security and Beyond. Oxford: Oxford University Press

Verdery, K., 1996. Whither 'Nation' and 'Nationalism'? In: Balakrishnan, G., 1996. Mapping the Nation. London: Verso Books

Waitt, G.R., 2005. Doing Discourse Analysis. In I. Hay (Eds.), Qualitative Research Methods in Human Geography. Oxford: Oxford University Press, 163-191

Walters, W., 2004a. Secure borders, safe haven, domopolitics. Citizenship Studies, $8(3), 237-260$

Walters, W., 2004b. Some Critical Notes on "Governance". Studies in Political Economy, 73(1), 27-46

Walters, W., 2011. Foucault and Frontiers: Notes on the Birth of the Humanitarian Border. In: Bröckling, U., Krassman, S., and Lemke, T. Ed., Governmentality: Current Issues and Future Challenges, London: Routledge, 138-164

Walters, W., 2012. Governmentality: Critical Encounters. Oxon: Routledge

Walters, W., 2013. Foreword: The Ambiguity of Migration. In: Lippert, R. and Rehaag, S., Eds., 2013. Sanctuary Practices in International Perspective: Migration, Citizenship and Social Movements. London: Routledge, xii-xv

Washington, J., 2020. The Dispossessed-A Story of Asylum at the US-Mexican Border and Beyond. London: Verso Books

Wodak, R., Titscher, S., Meyer, M., and Vetter, EW., 2000. Methods of Text and Discourse Analysis. London: Sage Publications 


\section{B. Newspaper articles and online media material}

Akrap, D., 2015. Germany's response to the refugee crisis is admirable. But I fear it cannot last. The Guardian [Online] 6 September. Available at: https://www.theguardian.com/commentisfree/2015/sep/06/germany-refugee-crisissyrian [Accessed 10 July 2020]

Al-Yafai, F., 2003. Race riots rock Welsh estate. The Guardian. 23 June [Online] Available at: https://www.theguardian.com/uk/2003/jun/24/race.world [Accessed 11 July 2020]

Bailey, S., 2001. Wrangle may delay refugees. South Wales Evening Post. 25 May. p.5 Bailey, S., 2002a. 250 refugees not getting vital aid. South Wales Evening Post. 28 February. P.2

Bailey, S., 2002b. Asylum seekers in limbo. South Wales Evening Post. 2 March. BBC News, 2001a. Asylum 'hunger strikers' assessed. 11 August. [Online] Available at: http://news.bbc.co.uk/2/hi/uk_news/wales/1485171.stm [Accessed 11 July 2020]

BBC News, 2001b. Asylum seeker continue food refusal. 14 August. [Online] Available at: http://news.bbc.co.uk/2/hi/uk_news/wales/1490434.stm [Accessed 11 July 2020]

BBC News, 2015a. Migrant Crisis: PM says UK will fulfill moral responsibilities. [Online] 3 September Available at: https://www.bbc.co.uk/news/uk-34135870 [Accessed 21 August 2019]

BBC News, 2015b. Demonstrators take to streets to say 'refugees welcome' in Wales. [Online] 13 September. Available at: https://www.bbc.com/news/uk-wales-34233051 [Accessed 10 July 2020]

BBC News, 2018. Petition to stop deportation of Otis Bolamu to DR Congo. [Online] 23 December. Available at: https://www.bbc.co.uk/news/uk-wales-46667979 [Accessed on 11 July 2020]

$B B C$ News, 2019. Asylum seeker who fled DR Congo returns to Swansea. [Online] 14 January. Available at: https://www.bbc.co.uk/news/uk-wales-46861727 [Accessed on 10 July 2020] 
Butler, R., 2002. "We can’t live on just £36,54 a week”. South Wales Evening Post. 7 February. Front Page

Carey, P., 2001. Hunger strike at jail still on after a week. Western Mail. 14 August.

Dallmore, C., 2000. Cost of language are forced upon us. South Wales Evening Post. 26 April. p.6

Daniel, W., 2000. Voters must decide on Welsh. South Wales Evening Post. 10 April. Davies, R., 2000a. Asylum seeker plan sparks furry. South Wales Evening Post. 24 April

Davies, R., 2000b. Asylum seekers no threat claim. South Wales Evening Post. 27 April. p.4

Dicks, M., 2001a. Race Hate Demo Fury. South Wales Evening Post. 10 April. Front page

Dicks, M., 2001b. No reason for riots over race. South Wales Evening Post. July [Date unidentifiable]

Drakefield, S., 2000. Asylum seekers 'will get a warm welcome'. South Wales Evening Post. 23 August.

Greaney, S., 2000. New homes for asylum seekers. South Wales Evening Post. 10 April. p.5

James, E., 2001a. 30 refugees begin prison hunger strike. Western Mail. 9 August.

Jenkins, E.W., 2000. Be grateful for status of Welsh. South Wales Evening Post. 27 April. p.6 Jones, M.M., 2000. Take pride in national tongue. South Wales Evening Post. 21 April.

Lisle, S., 2004a. Police probe racial link in city murder. South Wales Evening Post. 7 September. p. 2

Lisle, S., 2004b. Speak up to reports of racism. South Wales Evening Post. 8 September. p.5

Malik, N., 2000. We won't tolerate racism of any kind. South Wales Evening Post. 7 August 
Mason, T., 2001. Morgan backs Oxfam's call to end vouchers. Western Mail. 8 August. p.8

Missing Migrants Project. 2020. Fatalities by month. [Online] Available at: https://missingmigrants.iom.int/region/mediterranean [Accessed 26 July 2020]

Murray, K., 2000. Taking the middle course on asylum. Housing Today. 24 August, p.12-13. D 251/5/18. Swansea: West Glamorgan Archive

Mynott, E., 1999. New Labour, new immigration controls. LGIU equalities news. May. p.9. D 251/5/18. Swansea: West Glamorgan Archive

Peregrine, C., 2002. Safe Haven- or poverty in the land of sanctuary? South Wales Evening Post. 8 February. P.8

Plaid Cymru. 2019. \#OtisBolamu and \#MichaelGebredikan are both based in Wales and both at risk of deportation from a hostile UK Government. We have a duty to support people who need out support and ensure Wales is the nation of sanctuary we purport to be, says @ bethanjenkins. [Twitter] Screenshot [Accessed 12 July 2020]

Sherna, N., 2001. Asylum seekers to end hunger strike. Western Mail. 15 August. p.3 Smith, S., 2019. Wales becomes 'nation of sanctuary' for asylum seekers, refugees. NBC News 7 May [Online] Available at: https://www.nbcnews.com/news/world/wales-becomes-nation-sanctuary-refugeesasylum-seekers-n987536 [Accessed at 13 July 2020]

South Wales Evening Post, 2000. Sick of having Welsh rammed down throat. 3 April. p.6.

South Wales Evening Post, 2000. Welsh language vote welcome by majority. 19 April. p.6.

South Wales Evening Post, 2000. Asylum seekers due in Summer. 22 May.

South Wales Evening Post, 2000. Racism grows against the English. 7 August

South Wales Evening Post, 2001. [unidentifiable] ... fascists not welcome. 21 May. p. 15

South Wales Evening Post, 2001. Rhodri slams BNP camp. September [Date unidentifiable] 
Stoakes, D., 2000. Persecution bids over anti-Welsh bias claims. South Wales Evening Post. 14 August.

Taylor, D., 2018a. Home Office loses 75\% of its appeals against immigration rulings. The Guardian [Online] 3 September. Available at: https://www.theguardian.com/uknews/2018/sep/03/inhumane-three-quarters-of-home-office-asylum-appeals-fail [Accessed 11 July 2020]

Taylor, D., 2018b. Congolese asylum seekers faces forced removal from UK on Christmas Day. The Guardian [Online] 23 December. Available at: https://www.theguardian.com/uk-news/2018/dec/23/congolese-asylum-seeker-facesforcible-removal-from-uk-on-christmas-day-torture-drc-government [Accessed on 10 July 2020]

Taylor, D., 2020. Congolese torture survivor gets Home Office reprieve. The Guardian [Online] 15 January. Available at: https://www.theguardian.com/politics/2020/jan/15/congolese-torture-survivor-getshome-office-reprieve [Accessed on 10 July 2020]

Walters, B., 2000. Will Wales benefit from new policy? South Wales Evening Post. 10 April. p.10

Walters, B., 2001. Home Office should foot asylum bill. South Wales Evening Post. 12 July. p. 10

Western Mail, 2001a. AMs speak out as refugees kept in jail. 10 August. Cardiff: WM Western Mail, 2001b. Review of asylum system. 11 August. Cardiff: WM. P.4

Woodman, G., 2000. Time to end this intrusion in our lives. South Wales Evening Post. 15 April.

Wyn, E., 2001. Rural and urban areas face calamity. South Wales Evening Post. 12 September. 


\section{Parliamentary documents and administrative material (Government and Third Sector)}

Equalities, Local Government and Communities Committee, National Assembly for Wales, 2017. "I used to be someone": Refugees and Asylum seekers in Wales. April. Report. Cardiff: National Assembly for Wales. [Online] Available at: https://senedd.wales/laid\%20documents/cr-ld11012/cr-ld11012-e.pdf [Accessed 17 July 2020]

House of Commons Committee of Public Accounts, 2017. The Syrian Vulnerable Persons Resettlement Programme. Report HC768. London: House of Commons. 13 January [Online] Available: https://publications.parliament.uk/pa/cm201617/cmselect/cmpubacc/768/768.pdf Accessed 17 July 2020]

Home Office, 1998. Faster, Fairer, Firmer: A Modern Approach to Immigration and Asylum. The Home Office, London. D 251/5/18. Swansea: West Glamorgan Archive Home Office, 2002 Secure Borders, Safe Haven: Integration with Diversity in Modern Britain. The Home Office, London

Home Office, 2005 Understanding Gateway: The Gateway Protection Programme for Refugees. The Home Office, London

Home Office, 2016. Apply for Community Sponsorship. [Online] Available at: https://www.gov.uk/government/publications/apply-for-full-community-sponsorship [Accessed at 28 July 2020]

Home Office, July 2017. The Syrian Vulnerable Persons Resettlement Scheme (SVPRS) Guidance for Local Authorities and Partners. The Home Office. London

Jones, M. and Johnson, H., 7 December 2016a. Research Briefing: Inquiry into refugees and asylum seekers in Wales. 16/650. Cardiff: National Assembly for Wales Research Service

Jones, M. and Johnson, H., 15 December 2016b. Research briefing and suggested questions. 16/1650. Cardiff: National Assembly for Wales Research Service

Jones, M. and Johnson, H., 11 January 2017a. Research briefing and suggested questions. 16/1653. Cardiff: National Assembly for Wales Research Service 
Jones, M. and Johnson, H., 19 January 2017b. Research briefing and suggested questions. 16/1654. Cardiff: National Assembly for Wales Research Service

Johnson, H., 10 February 2017c. Inquiry into refugees and asylum seekers. Key issues. 17/2163. Cardiff: National Assembly for Wales Research Service

McGuinness, T. 14 June 2017. The UK Response to the Syrian Refugee Crisis. Briefing Paper

Number 06805, London: House of Commons Library. [Online] Available at: https://commonslibrary.parliament.uk/research-briefings/sn06805/ [Accessed 17 July 2020]

Sargeant, M., January 2017a. Welsh Government Evidence Paper: Equalities, Local Government and Communities Committee Inquiry into refugees and asylum seekers in Wales. Cardiff: Equalities, Local Government and Communities Committee (5)-2-17. Paper 1

Sargeant, M., May 2017a. Written response by the Welsh Government to the report of the Equalities, Local Government and Communities Committee entitled "I used to be someone": Refugees and Asylum Seekers in Wales. Cardiff: Equalities, Local Government and Communities Committee. [Online] Available at: https://senedd.wales/laid\%20documents/gen-ld11074/gen-ld11074-e.pdf [Accessed 17 July 2020]

Sugar, V., 2000. Corporate Strategies Unit. From City \& County of Swansea to Commission for Racial Equality. Received 21 August [Letter] D 251/5/18. Swansea: West Glamorgan Archive

Swansea City of Sanctuary (SCOS), 2010. Swansea City of Sanctuary: Application for National Recognition. [Application Document] May 2010.

Swansea City of Sanctuary (SCOS). 2014. Swansea City of Sanctuary Annual Report 2013-2014. [Online] Available at: http://www.cityofsanctuary.org/files/final_draft_annual_report.pdf [Accessed 12 July 2020]

Swansea City of Sanctuary (SCOS), 2015. Mentor Handbook. [Leaflet] Swansea: SCOS. 
Swansea City of Sanctuary (SCOS), 2017. SiP 2017: Dignity not Destitution. 29 November.

[Online]

Available

at:

https://swansea.cityofsanctuary.org/2017/11/29/sip2017-dignity-not-destitution [Accessed 14 July 2020]

Swansea City of Sanctuary (SCOS), 2020. Share Tawe. [Online] Available at: https://swansea.cityofsanctuary.org/share-tawe [Accessed 14 July 2020]

Welsh Government, 2020. Imagining the potential of Wales as a true Nation of Sanctuary during Refugee Week 2020. 18 June. Press release [Online] Available at: https://gov.wales/imagining-the-potential-of-wales-as-a-true-nation-of-sanctuaryduring-refugees-week-2020 [Accessed 14 July 2020] 